EKATERINA GEORGIEVA

\title{
Non-finite adverbial clauses in Udmurt
}

\author{
PhD dissertation
}

2018 


\title{
Non-finite adverbial clauses in Udmurt
}

\author{
PhD dissertation
}

Supervisors:

DR. GÉCSEG ZSUZSANNA

DR. KOZMÁCS ISTVÁN

University of Szeged

Graduate School in Linguistics

Uralic Studies PhD Programme

Szeged, 2018. 


\section{Contents}

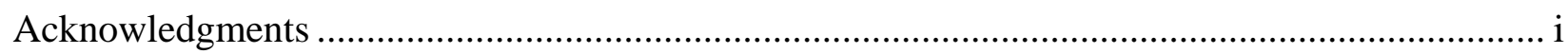

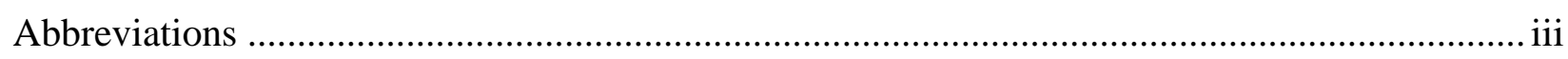

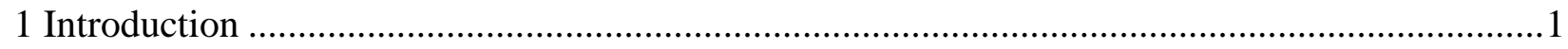

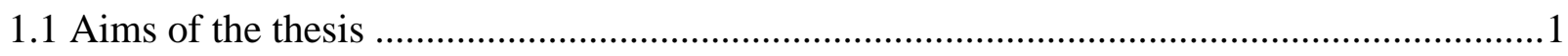

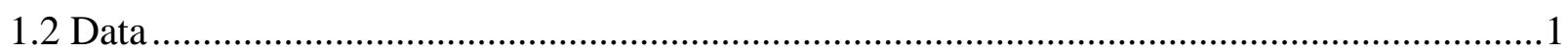

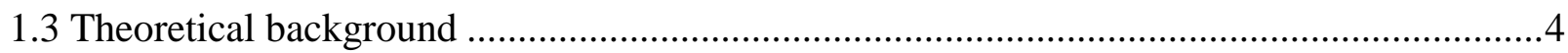

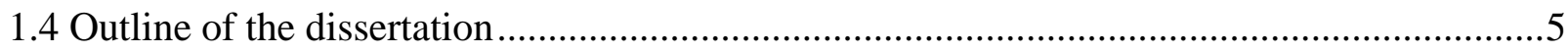

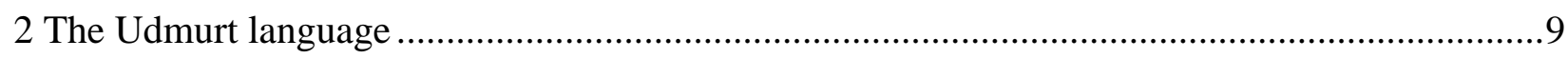

2.1 Genetic affiliation and sociolinguistic background .............................................................

2.2 Writing system, literacy and resources ..............................................................................17

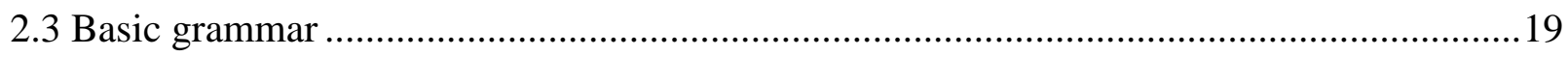

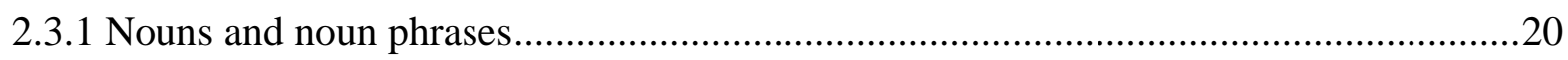

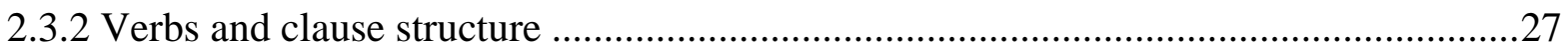

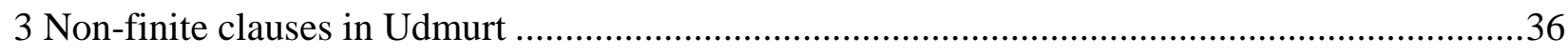

3.1 Finiteness in the typological and generative literature .......................................................36

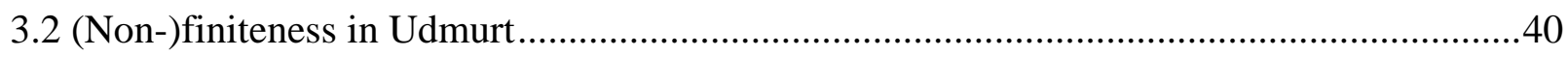

3.3 Non-finite verbs in Udmurt: a first approximation .............................................................46

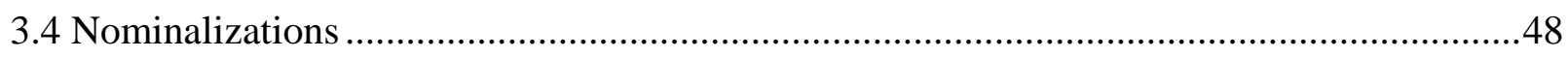

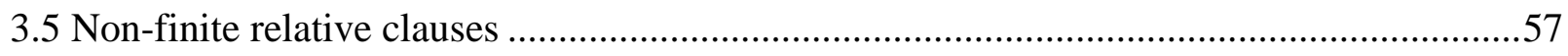

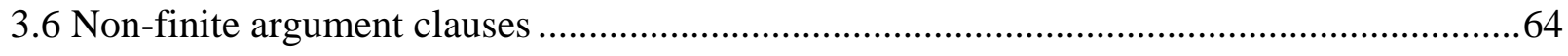

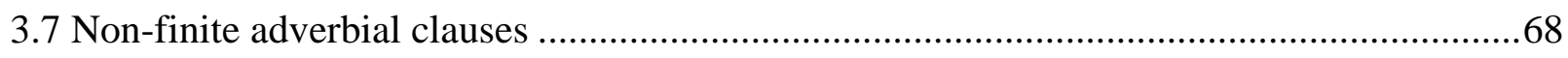

3.7.1 Typological overview of adverbial clauses ................................................................68

3.7.2 Non-finite adverbial clauses in Udmurt .........................................................................75

3.7.2.1 Postposition + nominalization ...........................................................................

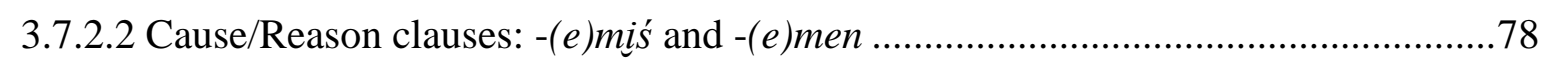

3.7.2.3 Adverbial clauses with the adverbial case (?) ........................................................80

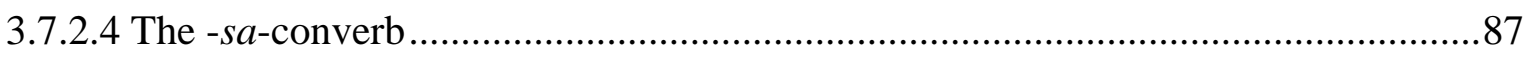

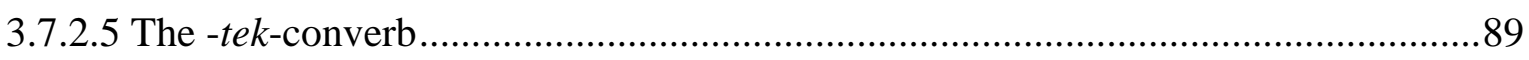

3.7.2.6 The $-k u$-converb.............................................................................................90

3.7.2.7 The -toź-converb............................................................................................91 
3.7.2.8 The participle/converb -mon ..................................................................................94

3.8 Interim summary: non-finite clauses in Udmurt................................................................97

4 The structure of non-finite adverbial clauses in Udmurt...........................................................98

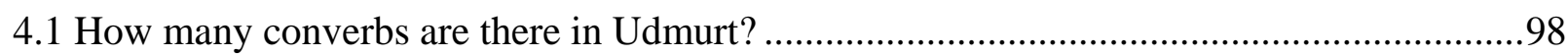

4.1.1 Revisiting the existing approaches to converbs in Udmurt.............................................98

4.1.2 The morphological make-up of converb suffixes ........................................................100

4.2 The internal syntax of Udmurt adverbial clauses .............................................................. 110

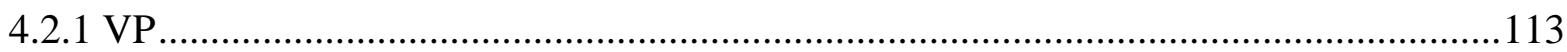

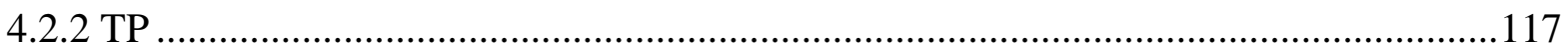

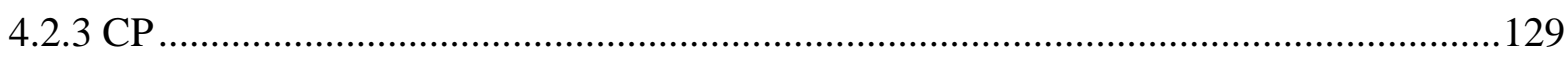

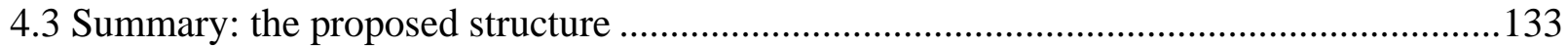

5 Subjects, agreement and adjunct control ...............................................................................136

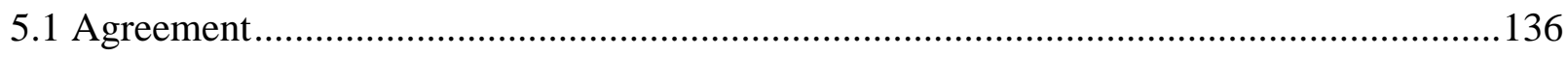

5.2 Null and overt subjects in Udmurt non-finite adverbial clauses..........................................151

5.3 Control: theoretical preliminaries ……………………..................................................159

5.4 Adjunct control in Udmurt.............................................................................................165

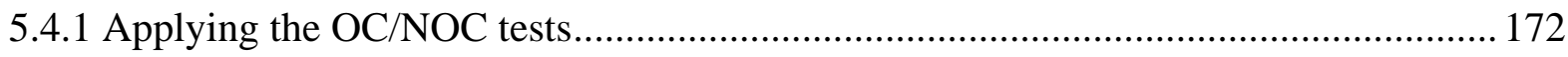

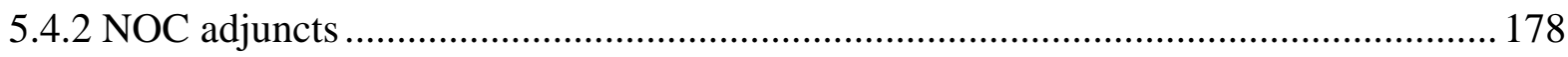

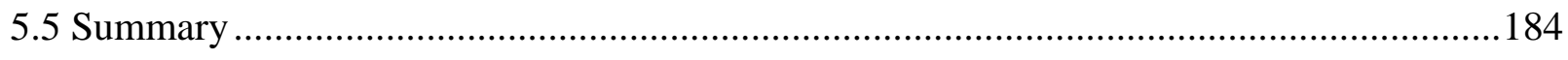

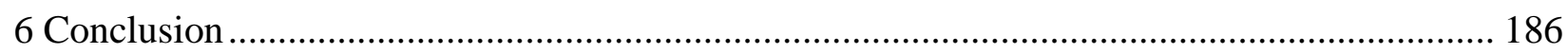

Appendix 1 Transliteration used in this dissertation ................................................................ 190

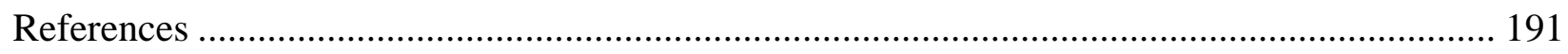




\section{Acknowledgments}

My Udmurt journey started in September 2009 when I attended a class and had to translate Udmurt folktales without any previous knowledge of the language and its grammar. This journey went through fieldwork (meaning: long trains, small villages, piles of questionnaires, picking berries/mushrooms, interviewing speakers, etc.), academic work and the struggle of writing a dissertation, but now it has finally come to an end. Now it's the time to thank the people who helped me along the way.

First of all, I am immensely indebted to all Udmurt speakers I have met and worked with during my fieldworks for their patience and helpfulness. There are a couple of Udmurt consultants (and more importantly, friends!) who played a special role: Ekaterina Suncova, Ekaterina Ermakova, Anna Semenova, Irina “Zangarik” Krestyaninova, Yulia Speshilova and Nelli Lopatina, тау бадӟым! During my fieldworks I received great support from the teachers and students of the Udmurt Department at the Udmurt State University, and especially from Natalia Kondratyeva, Olga Strelkova, Dmitry Efremov, Galina Lesnikova and Svetlana Shirobokova.

This dissertation would not have been possible without István Kozmács, my supervisor, who made me translate those folktales back then, and Zsuzsanna Gécseg, my second supervisior, who gave valuable input on my manuscripts.

My referees, Krisztina Szécsényi and Orsolya Tánczos, put an enormous amount of work into reviewing the manuscript of this dissertation. I am very grateful to them for their valuable comments and suggestions.

I also thank all my colleagues from the University of Szeged and the Research Institute for Linguistics at the Hungarian Academy of Sciences who supported me while I was working on this thesis. I would like to mention a couple of them who contributed to this dissertation in various ways. I will list their names (in alphabetical order): Dékány Éva (for her suggestions on manuscripts and conference talks), Keresztes Júlia (for sending me that dissertation and proof-reading this dissertation), Marcel den Dikken (for our discussion on ellipsis), Mus Nikolett (for the pilóta-keksz-bet and everything else), Ótott-Kovács Eszter (for being my first co-author), Sipőcz Katalin (for being always helpful with the paperwork for my grant applications), Sipos Mária (for the support during the last couple of months). I am very grateful to Marianne Bakró-Nagy for inspiring me to study Finno-Ugristics in the first place 
and to István Kenesei for making me realize that I am more interested in syntax than I originally thought. They both supported my academic career over the years.

Additionally, there are some international colleagues whom I would like to thank: the Surrey Morphology Group crew (Oliver Bond, Greville Corbett, Matthew Baerman, Timothy Feist and Marina Chumakina) where I had the chance to spend 5 months during my $\mathrm{PhD}$ studies; the linguists from the Institute for Linguistics at the University of Leipzig (and especially, Barbara Stiebels, Philipp Weisser and Sandhya Sundaresan) where I spent 3 weeks in Spring 2018; Timofey Arkhangelsky (for being such an enthusiastic collaborator); and Nikita Muraviev (for the ted'/toź-skype chats).

Finally, I would like to express my deepest gratitude to my family and friends who have supported me for so many years (without even understanding the topic of this dissertation!).

Женялы сптау. 


\section{Abbreviations}

\begin{tabular}{|c|c|c|c|}
\hline $\mathrm{ABL}$ & ablative (case) & PRS & present \\
\hline ACC & accusative (case) & PRT & particle \\
\hline ADD & additive & PST & past \\
\hline $\mathrm{ADV}$ & adverbial (case) & PTCP.POT & potential participle \\
\hline AOR & aorist (Turkish) & PTCP.PRS & present participle \\
\hline ATTR & attributivizing suffix & QUOT & quotative \\
\hline ATTR.NEG & negative attributivizing suffix & SG & singular \\
\hline AUX.PST & past auxiliary & TERM & termnative (case) \\
\hline CAUS & causative & $\mathrm{V}$ & verb \\
\hline CMPR & comparative & $\mathrm{VN}$ & verbal noun \\
\hline CVB & converb & & \\
\hline CVB.LIM & limitative converb & $<\mathrm{P}>$ & unfilled pause \\
\hline CVB.NEG & negative converb & $<\mathrm{H}:>$ & hesitation \\
\hline CVB.SIM & simultaneous converb & & \\
\hline DAT & dative (case) & $\sqrt{ }$ & Root \\
\hline ELA & elative (case) & AgrP & Agreement Phrase \\
\hline ЕMPH & emphatic & AspP & Aspect Phrase \\
\hline EVID & evidential (past) & CauseP & Cause Phrase \\
\hline EXCL & exclusive & $\mathrm{CP}$ & Complementizer Phrase \\
\hline EXIST & existential (auxiliary) & DP & Determiner Phrase \\
\hline FREQ & frequentative & IP & Inflection Phrase \\
\hline FUT & future & KLOCP & Locative Case Phrase \\
\hline GEN & genitive (case) & $\mathrm{KP}$ & Case Phrase \\
\hline ILL & illative (case) & $\mathrm{MP}$ & Mood Phrase \\
\hline IMP & imperative & NegP & Negation Phrase \\
\hline INE & inessive (case) & NPLACEP & Locative Postposition Phrase \\
\hline INS & instrumental (case) & NRELP & Relational Noun Phrase \\
\hline INTR & intransitive (suffix/stem) & NumP & Number Phrase \\
\hline NEG & negative (verb) & $\mathrm{PP}$ & Postposition Phrase \\
\hline NEG.PRS & negative present (auxiliary) & PossP & Possesive Phrase \\
\hline NLOC & locative nominalizer & $\mathrm{TP}$ & Tense Phrase \\
\hline NMLZ & nominalizer & VoiceP & Voice Phrase \\
\hline NMLZ.NEG & negative nominalizer & vP & small VP \\
\hline OPT & optative & VP & Verb Phrase \\
\hline PL & plural & & \\
\hline
\end{tabular}




\section{Introduction}

\subsection{Aims of the thesis}

This dissertation deals with non-finite adverbial subordinate clauses in Udmurt (Uralic; Permic). My goal is two-fold: firstly, to provide a description of the various non-finite adverbial clauses in Udmurt with special reference to their morphosyntax and syntax. Secondly, I aim at analyzing the Udmurt data using the tools of generative grammar.

The detailed description is needed since Udmurt is an endangered and fairly understudied language from a syntactic point of view. Thus, the in-depth description of nonfinite adverbial clauses makes an important step towards the syntactic analysis of the Udmurt language. Non-finite adverbial clauses have received much less attention in comparison to relative and argument clauses in recent studies on Udmurt (cf. Serdobolskaya et al. 2012; Brykina \& Aralova 2012; Klumpp 2016; Dékány \& Tánczos 2015, 2017). So far the only existing monograph dealing exclusively with non-finite adverbial clauses is Perevoshchikov (1959). This dissertation is meant to overcome this void on both a descriptive and a theoretical level. I aim at laying out some foundations based on which more detailed theoretical accounts can be built in the future. Although the topic of this dissertation is nonfinite adverbial clauses, several other issues are touched upon in connection with them: word order, phrase structure (of finite clauses), case-marking and agreement.

In the following chapters, I try to show that non-finite adverbial clauses in Udmurt are highly relevant to several syntactic questions in the literature on (non-)finiteness: what counts as a non-finite clause and how non-finiteness is represented syntactically; the morphosyntactic and syntactic variation in adverbial clauses; the syntax of converbs and nominalizations, as well as adjunct control. These issues are far from settled in the generative literature, hence, providing data from a previously undescribed language like Udmurt may be beneficial to our general understanding of these syntactic phenomena.

\subsection{Data}

One of the main virtues of this dissertation is the language material presented in it. Although there are a couple of recent grammars and descriptive studies on the Udmurt language (see $\S 2.3)$, the language data in them rely strongly on the traditional grammars of Udmurt, namely, GSUJa I, II, III (1962, 1970, 1974). This means that the examples presented in them were 
collected in the 1950s or even earlier. In my view, these data should be handled carefully since one cannot exclude that possibility of language change affecting the acceptability of the presented syntactic structures in today's Udmurt.

In this dissertation I use a large amount of data collected during four fieldwork trips in Udmurtia between 2013 and 2016. Hence, the data clearly exemplify today’s Udmurt. This is also important since Udmurt is an endangered language, thus, presenting new material contributes to its documentation.

I worked with Udmurt-dominant native speakers living in the territory of Udmurtia or Tatarstan whose age ranges from 20 to 65 . The consultants speak different dialects of Udmurt (on the dialectal division of Udmurt see §2.1). The collection points were Alnash, Grakh and Kijasa districts (Southern Udmurtia), Igra and Balezino districts (Northern Udmurtia), Izhevsk (capital of Udmurtia), as well as Kukmor district (Tatarstan). Based on this, I also hint at the possible syntactic variation between the different dialects of Udmurt in this thesis. Needless to say, Udmurt dialectal syntax is an unexplored territory: the dialectological works on Udmurt usually focus on dialectal variation in the domains of phonology, morphology and the lexicon.

The fieldwork methodology used in this dissertation relies on a mix of techniques. Firstly, I conducted semi-structured interviews from which I present numerous examples. These are cited as follows:

(1) fieldwork recording, date of recording, (filename), speaker's initials, collection point

Additionally, I provide spontaneous examples from my fieldwork notes. Thirdly, I use elicited examples. During my fieldwork trips I collected data from a couple of questionnaires in order to obtain grammaticality judgements. The elicited examples are particularly important since they provide information about ungrammatical patterns. Based on this, we can draw conclusions about the syntactic structure involved. Since attested examples provide information only about certain possible patterns, we need negative evidence in order to prove that the unattested patterns are indeed impossible. Although this approach is widely accepted in the literature, the traditional grammars of Udmurt do not make use of it, and only a couple of recent studies present grammaticality judgment data.

Furthermore, I also use corpus data based on the Udmurt Corpus, Udmurt Social Media Corpus and Turku-Izhevsk Corpus (see §2.2) in order to provide information about frequency 
of certain non-finite clauses and/or (morpho)syntactic patterns. Finally, I present examples from other descriptive studies and grammars. In this case, the majority of the examples were double-checked by at least one native speaker, and if there is a difference in the judgements, I indicate this in the text.

All examples are fully glossed in accordance with the Leipzig Glossing Rules. The transcription used in this dissertation is summarized in Appendix 1.

It is important to explain why it is necessary to provide data from different dialects of Udmurt instead of using examples only from standard Udmurt. The problem is that using data from different sources and dialects might make the data set heterogeneous. My main arguments are the following. The spontaneous data collected during my fieldwork trips indeed show certain dialectal features on the level of phonology, morphology and syntax. In my opinion, the question of making the data homogenous, thus comparable, is definitely important, but since the differences between the Udmurt dialects are not severe, using examples from different varieties does not pose serious problems. There are certain syntactic differences, such as subject-doubling (§5.1) and -(o)nja-clauses (§3.7.2.3) that seem to correlate with the speakers' dialect, but demonstrating these differences contributes to the value of the thesis. Secondly, in accordance with recent studies dealing with the varieties of the Udmurt language (e.g. Edygarova 2014), I assume that the material I have collected cannot be considered dialectal per se since the boundaries between dialectal and spoken varieties in today's Udmurt are less clear-cut. It is also important to keep in mind that standard Udmurt has shorter history and different sociolinguistic situation than standard Hungarian, Finnish and Estonian, for example. The strongest argument against basing the analysis on standard Udmurt comes from the sociolinguistic observations made by Edygarova (2014), Shirobokova (2011) and Salánki (2007) that the knowledge of standard Udmurt varies among the native speakers, and many of them consider themselves more fluent in their own dialect than in standard Udmurt dialect (for a discussion see §2.1). This is crucial with respect to the elicited data which is meant to show the native speakers' grammaticality judgments. The consultants were asked explicitly to rely on their own intuitions, and not on their knowledge of standard Udmurt (which might have been acquired in school or show signs of prescriptivism, etc.). Thus, since the methodology adopted in this work relies on native speakers' judgments, the results presented do not provide a description of a normative grammar. 


\subsection{Theoretical background}

This dissertation has two parts: a descriptive and a theoretic one. Chapter 3 provides a description of non-finite clauses, with special reference to adverbial clauses. This chapter is written in a (fairly) theory-neutral framework. I take into account the main advances of the typological literature, specifically, I make use of the typological classification of adverbial clausal relations proposed by Kortmann (1996) (§3.7). In Chapter 4 and 5, I take a closer look at several syntactic phenomena related to non-finite adverbial clauses. The tools used in these two chapters come from the Chomskyan generative grammar.

This dissertation also deals with converbs, i.e. non-finite verb forms whose main function is to express adverbial subordination (Haspelmath 1995: 3). Although converb is used mostly as a typological term, there are several works dealing with the syntax of converb clauses in the framework of generative grammar (Kornfilt 2003; Weisser 2015; Ótott-Kovács 2016; Grashchenkov 2017).

The syntax of non-finite clauses has been in the center of interest in generative studies over the past decades. According to Adger (2007: 23), finiteness "names a possibly openended set of phenomena and may very well have no satisfactory definition”, thus, the syntactic account of the phenomena traditionally associated with finiteness might not require this notion. Moreover, there are many ways in which non-finiteness might be indicated in the clause.

One way to account for the differences between finite and non-finite clauses is to say that non-finite clauses lack certain syntactic structure otherwise found in finite clauses. In other words, they are truncated. The truncation analysis has been put forward for various nonfinite clauses (Adger 2003; Kornfilt \& Whitman 2011; Pires 2006; Wurmbrand 2001, a.o.). In order to understand the idea of the truncation analysis, one must review the clause structure in the generative literature. It is standardly assumed that clauses have three domains: VP, TP and $\mathrm{CP}$. The VP is the thematic domain in which the arguments of the verb are introduced. The TP is the inflectional domain, which is responsible for tense, agreement and case-licensing. The CP is the discourse domain that is related to topic, focus, force, wh-movement, and finiteness. (In $\S 4.2$, the internal structure and main properties of these three domains will be summarized.) Non-finite clauses might project up to CP, similarly to finite clauses, but might have a reduced structure. Thus, we can potentially find TP-sized or VP-sized non-finite clauses. Additionally, some non-finite clauses are 'mixed-extended projections' (Borsley \& Kornfilt 2000; Alexiadou 2001 et seq., a.o.). In this case, we find one or more nominal 
functional categories in addition to an extended verbal projection. There is a considerable cross-linguistic variation in in the amount of both verbal and nominal structure in these nonfinite clauses.

Non-finite clauses have also attracted a lot of attention because of control. In the generative literature, control is understood as the referential dependency between the null subject of a non-finite clause (PRO) and its antecedent. Two types of control structures are assumed: obligatory and non-obligatory control, which differ in a number of properties (Williams 1980). Put simply, in obligatory control constructions, PRO is bound locally, while non-obligatory control involves cases in which PRO does not find its antecedent locally. Instead, its referent is determined based on the context.

Adjunct control has been largely understudied in comparison to complement control. It is often assumed that adjunct control involves strict obligatory control, however, nonobligatory control is also found (Hornstein 2001; Pires 2006; Sundaresan 2014; Williams 1992; Kawasaki 1993; Landau 2013, 2017; Green 2018, a.o.). Below I illustrate obligatory and non-obligatory control into adjunct clauses.

(2) Landau (2013: 221, ex. (432a))

Billi called us [before/after/while/without $P R O_{i}$ visiting his aunt].

(3) Kawasaki (1993: 173, ex. (24))

[After PRO pitching the tents], darkness fell quickly.

The choice between obligatory and non-obligatory control is determined by several factors. Some of them are structural, others are semantic/pragmatic. Generally, it has been observed that the relevance of pragmatic factors plays a bigger role in adjunct control than in complement control. (The main properties of adjunct control will be further reviewed in §5.3.)

\subsection{Outline of the dissertation}

This dissertation is organised as follows. In Chapter 2, I not only summarize the Udmurt grammar with special reference to morphosyntax and syntax, but also give an overview of the demographic and sociolinguistic data, the dialectal variation as well as the available resources for the Udmurt language. This introduction is needed not only to facilitate the analysis of nonfinite adverbial clauses, but also to provide the reader with a general background to Udmurt. 
Chapter 3 gives an overall description of non-finite clauses in Udmurt. The existing grammars of Udmurt deal with non-finite verb forms rather that non-finite clauses. Firstly, I discuss the notion of finiteness: the traditional understanding of it is that non-finite verbs do not show tense morphology. Recent studies have argued that finiteness is a property of a clause. Thus, a question arises whether finiteness can be accounted for in terms of syntactic properties. I will point out several syntactic parameters in which finite and non-finite clauses differ in Udmurt. The existing grammars of Udmurt distinguish three types of non-finite verbs: 'participles', 'converbs' and 'infinitives'. Additionally, there are two non-finite forms that deserve special attention: the -(e)m-non-finites and -(o)n-non-finites. In terms of syntactic distribution, they can be used in relative, argument and adverbial clauses, as shown in (4)-(6).

(4) Relative clause

[Pet'a-len tue mertt-em] pispu-ez umoj bude. Petya-GEN this.year plant-NMLZ tree-3sG well grow[PRs.3sG] 'The tree planted by Petya is growing well.'

(5) Argument clause

[Dǐšetiś-leś urok-ez pir-poć valekt-em-ze] todi-śko.

teacher-ABL lesson-ACC in.detail explain-NMLZ-3SG.ACC know-PRS[1sG] 'I know that teacher explained the lesson in detail.'

(6) Adverbial clause

Tolon [kuaź zor-em-en] busi-je ez vetle $=$ no [...] yesterday weather rain-NMLZ-INS field-ILL NEG.PST.3 go[PL]=ADD 'Yesterday they did not go to the field because it was raining (lit. with the weather raining).' ${ }^{1}$

The traditional grammars of Udmurt, as well as some recent studies propose that the -(e)m-form in (4) is a participle, the one in (5) is a deverbal noun/nominalization, and the one in (6) is a converb. In this dissertation I argue against this analysis, and deal with clause types instead: non-finite relative, adverbial and argument clauses in which the very same non-finite form is used. I discuss the morphosyntactic properties of the three clause types, such as the case-marking of the subject and agreement markers on it. Special attention is paid to adverbial

\footnotetext{
${ }^{1}$ The example comes from the Turku-Izhevsk Corpus (Kenesh/D/5:783).
} 
clauses. They can be formed with converbs and nominalizations selected by postpositions/semantic cases. The functions of the various types of non-finite adverbial clauses are described within the typological framework proposed by Kortmann (1996).

In Chapter 4, I take a closer look at the internal structure of non-finite adverbial clauses. Firstly, I discuss the notion of 'converb' and raise the question of whether this category can be dispensed with. The second question I address concerns the clause size of non-finite adverbial clauses. I apply several tests in order to determine whether the three clausal domains (VP, TP, and $\mathrm{CP}$ ) are present. As noted above, non-finite clauses often have truncated structure, thus, the question arises of whether we find evidence for a full clausal structure, and if not, at which clausal level truncation takes place. For instance, consider example (7).

(7) Udmurt Corpus (Удмурт дунне 2008.05.06)

[eke-mi kematek skripka-ze kuti-le-mte-isiti-z]
son-1PL long.time violin-3sG.ACC touch-FREQ-NMLZ.NEG-ELA-3sG
'because our son hasn't/doesn't touch his violin for a long time'

The question is what the presence of an object and subject tells us about the underlying structure of (4). More specifically, how they are assigned case. This is particularly relevant in the case of the subject since nominative case is said to be licensed by a finite $\mathrm{T}$ in Government and Binding Theory (Chomsky 1981). This view is also maintained in Minimalism (Chomsky 1995). However, empirical data from various typologically unrelated languages have shown that nominative subjects are possible in non-finite clauses. This has sparked a serious debate around the 'nominative as a structural case' analysis. Furthermore, in (7), we also find a frequentative suffix and agreement on the negated non-finite predicate. Thirdly, the non-finite clause also contains a temporal adverbial. Finally, it must be explained what the temporal interpretation of this clause is, given that the non-finite predicate does not show tense morphology.

Chapter 5 deals with several questions related to subjects of non-finite adverbial clauses. Specifically, I discuss subject agreement: the morphosyntactic patterns attested and the optionality of agreement. Additionally, I investigate the interpretive properties of null and overt subjects. The contrast between them is illustrated in (8) and (9). 
(8)

$\begin{array}{llllll}\text { [Gurt-e } & \text { berti-sa] } & \text { Kol'a } & \text { Liza-li } & \text { kńiga-ze } & \text { śot-i-z. } \\ \text { home-ILL } & \text { go.home-CVB } & \text { Kolya } & \text { Liza-DAT } & \text { book-3sG.ACC } & \text { give-PST-3SG }\end{array}$

'_ ${ }^{\mathrm{i} /{ }^{*} \mathrm{j}}$ having gone home, Kolyai gave his book to Lizaj.'

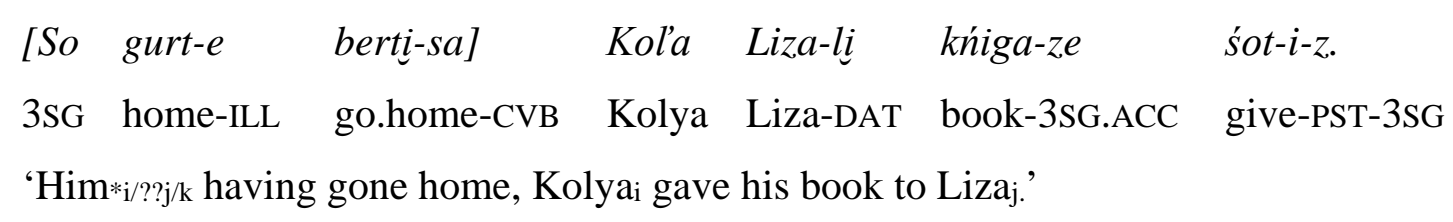

I will discuss the alternation between null and overt subjects and its theoretical implications. Firstly, it must be shown whether it is always the case that overt subjects are disjoint in reference from the matrix subject. Secondly, it must be clarified whether null subjects are always interpreted as referring to the matrix subject. This has implications on our assumptions regarding the nature of null subjects. I raise the question of whether we are dealing with control, and if yes, what kind of control: obligatory or non-obligatory.

Chapter 6 summarizes the main research questions and results of this dissertation. Additionally, I point out topics for further research connected to the issues discussed in this thesis. 


\section{The Udmurt language}

This chapter provides general background about the Udmurt language. It is organized as follows: in $\$ 2.1$, I discuss the genetic affiliation of Udmurt as well as basic sociolinguistic information about the language (including geographical distribution, speaker populations, dialects, language contact and standard language). Then, in $\$ 2.2$, I discuss the Udmurt writing system, the transliteration systems and the most important resources for Udmurt, such as grammars, dictionaries, text collections, corpora and NLP tools. In $\S 2.3$, I provide a grammatical sketch of the Udmurt language with special reference to morphology and syntax.

\subsection{Genetic affiliation and sociolinguistic background}

Udmurt (exonym: Votyak/Votiak) is a Uralic language. Together with the Komi-Zyryan and Komi-Permyak languages, it belongs to the Permic branch of the Uralic language family. It should be mentioned that the Udmurt language and the Komi languages are not mutually intelligible.

Udmurt is spoken mainly in the Udmurt Republic. The Udmurt Republic (or Udmurtia) is a federal subject of the Russian Federation within the Volga Federal District. Its capital is Izhevsk. Geographically the Udmurt Republic is located in the European part of the Russian Federation to the west of the Ural Mountains and 1,000 km northeast of Moscow. It borders the Republic of Tatarstan, the Republic of Bashkortostan, Perm Krai and Kirov Oblast, where Udmurt diasporas are also found (as well as in the Sverdlovsk Oblast). The following map shows the location of Udmurtia within the Russian Federation (overleaf).

Udmurts can be divided into two main groups, namely, Northern and Southern Udmurts, which is motivated both historically and ethnographically. ${ }^{1}$ The Northern-Southern division is also relevant with respect to the dialects of Udmurt. As Kelmakov (1998: 37) observes, this division has been proposed even in the first descriptions and vocabulary list collections from the $18^{\text {th }}$ century. ${ }^{2}$ The dialectal variation of modern Udmurt, however, is more differentiated. Kelmakov (1998: 41-44) divides the Udmurt dialects into four main groups: Northern, Central, Southern and Beserman dialect groups. ${ }^{3}$ The Besermans constitute

\footnotetext{
${ }^{1}$ On the history and ethnography of the Udmurts see Vladykin \& Khristolyubova (1997).

${ }^{2}$ For an overview of the dialectological studies concerning the Udmurt language the interested reader may wish to consult Kelmakov (1998: 37-41) and Kelmakov (2003: 45-49).

${ }^{3}$ For other possible dialectal divisions see Kelmakov (2003: 36-38).
} 
a separate ethnic group (see the demographic data below). ${ }^{4}$ As far as their language is concerned, the Beserman dialect can be grouped together with the Northern Udmurt dialect based on the area where they can be found. However, the Beserman dialect differs from them, and in fact, it shows some similarities to the Southern dialects (Kelmakov 2003: 99-135; Tepliashina 1970).

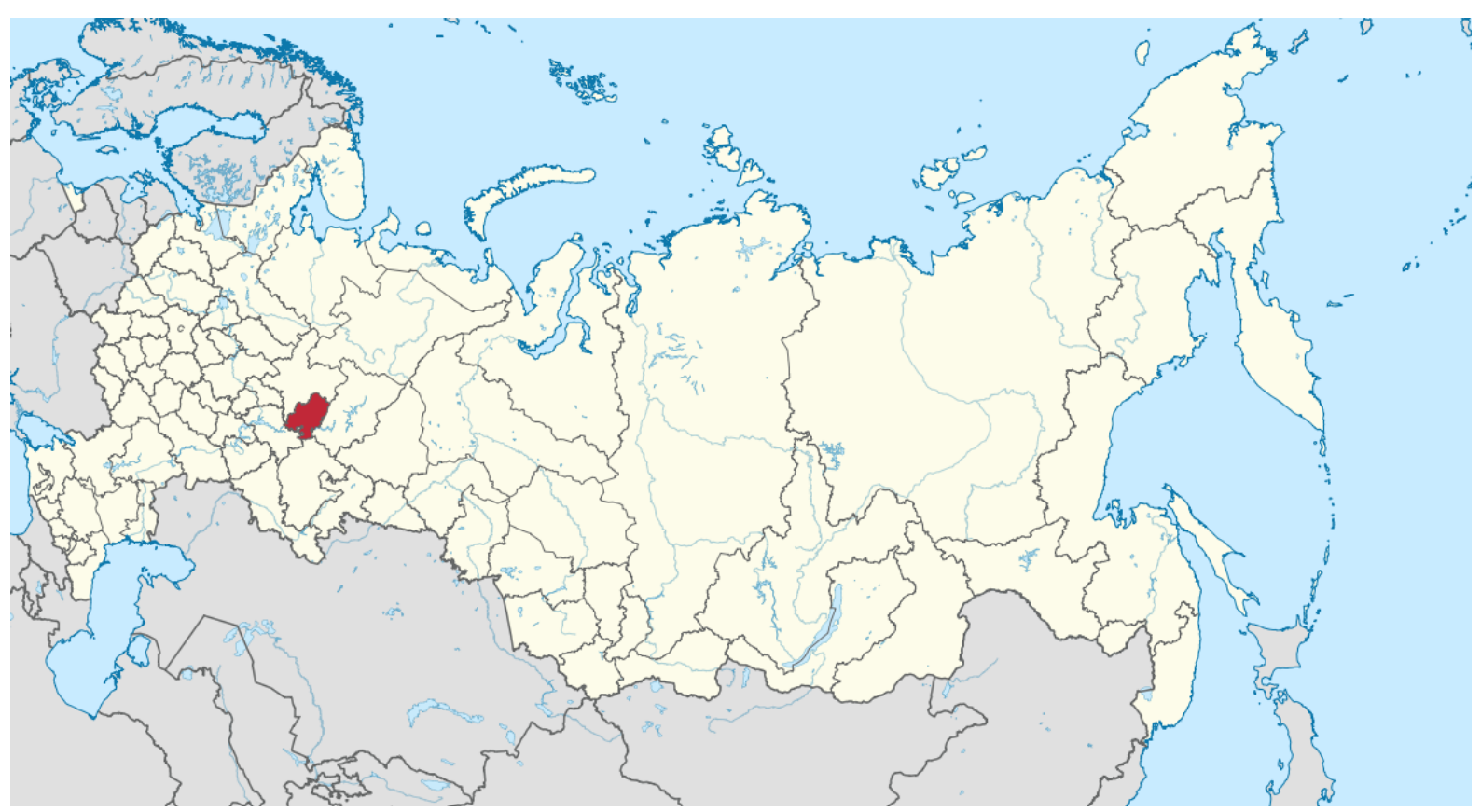

Figure 1 Location of the Udmurt Republic ${ }^{5}$

The Northern dialects are spoken along the Cheptsa river basin in the Northern part of Udmurtia and partly in the Kirov Oblast, and include the Upper Cheptsa (верхнечепецкий), Middle Cheptsa (среднечепецкий) and Lower Cheptsa (нижнечепецкий) dialects. The Southern dialects are spoken in the Southern part of Udmurtia, as well as by the Udmurt diasporas in Tatarstan, Bashkortostan, Perm Krai, Kirov Oblast and Sverdlovsk Oblast. The latter has been referred to as Southern Peripheral. The Southern Peripheral dialects are further divided into several subdialects, such as Shoshma (шошминский), Kukmor (кукморский), Bavli (бавлинский), Tashkin (ташкинский), Tatyshli (татышлинский), etc. The dialectal division of the Southern dialect spoken in Udmurtia and the one of the Central dialect group is less clear (Kelmakov 1998: 42, 2003: 59).

\footnotetext{
${ }^{4}$ Their ethnogenesis is disputable. For instance, it has been suggested that the Besermans are udmurtised Turkic peoples (Teplyashina 1970: 6-12).

${ }^{5}$ https://en.wikipedia.org/wiki/Udmurtia\#/media/File:Udmurt in Russia.svg 
Generally, the Udmurt dialects are mutually intelligible and the main differences between them are with respect to phonology, morphology and lexicon. Winkler (2001: 6) claims that "morphology and syntax are nearly identical" in the Udmurt dialects. As for morphology, the dialectological works discuss several morphological differences between the Udmurt dialects (Kelmakov 1998: 111-160). For example, the accusative marker used on plural nouns is $-t i$ in the Northern dialects, but $-i z$ in the Southern dialects. However, the Udmurt dialectal syntax has been an unexplored topic.

As far as language contact is concerned, Udmurt has had language contacts with Russian. From the beginning of the 20th century, the Russian language has been strongly influencing Udmurt. Udmurt also belongs to the so-called Volga-Kama Sprachbund (Bereczki 1983; Wintschalek 1993). The languages of the Volga-Kama Sprachbund (Mari, Komi, Udmurt, Mordvin, Tatar, Bashkir, Chuvash, Russian) have developed common grammatical features due to long-lasting language contacts. Among the languages of this area, Udmurt, and especially its Southern dialects, has had the closest contact with Tatar.

According to the Expanded Graded Intergenerational Disruption Scale (EGIDS), the status of Udmurt is 5, i.e. it is a developing language (Simons \& Fennig 2017). ${ }^{6}$ This means that: "[t]he language is in vigorous use, with literature in a standardized form being used by some though this is not yet widespread or sustainable". ${ }^{7}$ These conclusions regarding the level of endangerment of the Udmurt language seem fairly optimistic. Yet, in my view, the sociolinguistic situation of Udmurt is rather worrying.

Let us first discuss the Udmurt speaker population based on the USSR Census of 1989, the Russian Census of 2002 and the Russian Census of 2010. ${ }^{8}$ These three censuses provide information about the ethnicity of the respondents (in Russian: национальность 'nationality'). Based on this, we can determine the number of ethnic Udmurts. Additionally, the respondents are asked about their knowledge of the Russian language as well as about their competence in other languages. The three censuses, however, differ with respect to the questions regarding the mother tongue of the respondents. The Census of 1989 and the Census of 2010 provided statistics about the number of ethnic Udmurts whose mother tongue is Udmurt and of those ethnic Udmurts whose mother tongue is Russian (Census 1989;

\footnotetext{
${ }^{6}$ The Ethnologue report on Udmurt. Available at: https://www.ethnologue.com/language/udm. (Retrieved: 05.10.2017)

${ }^{7}$ The Ethnologue Language Status Scale. Available at: https://www.ethnologue.com/cloud/udm. (Retrieved: $05.10 .2017)$

${ }^{8}$ For an analysis of earlier censuses see Salánki (2007: 19-27).
} 
Census 2010). On the other hand, the Census of 2002 did not include a question about the mother tongue of the respondents (Census 2002).

The statistics of these three censuses are summarized in Table 1. It should be emphasized that in the table below, the language skill data (both mother tongue and language competence data) are based only on the ethnic Udmurts. Thus, column 3 shows the number of people who identify themselves as Udmurts (in the 'nationality' box of the questionnaire) as well as report that their mother tongue is Udmurt, column 4 shows the number of ethnic Udmurts who state that their mother tongue is Russian, etc.

Table 1 The Udmurt population

\begin{tabular}{|l|r|r|r|r|r|}
\hline Census & Ethnic Udmurt & \multicolumn{2}{|c|}{ Mother tongue } & \multicolumn{2}{c|}{ Knowledge of } \\
\hline & & Udmurt & Russian & Udmurt & Russian \\
\hline $\mathbf{1 9 8 9}$ & 746,793 & 520,101 & 224,351 & 40,647 & 458,004 \\
\hline $\mathbf{2 0 0 2}$ & 636,906 & NA & NA & 429,411 & 625,298 \\
\hline $\mathbf{2 0 1 0}$ & 552,299 & 342,963 & 207,936 & 298,628 & 546,044 \\
\hline
\end{tabular}

Table 1 allows us to draw the following conclusions. Firstly, it can be observed that the number of ethnic Udmurts has decreased over the last three decades. Secondly, it is also obvious that the number of Udmurt speakers has decreased, too. Thirdly, it can be seen that (almost) all Udmurts are bilingual.

However, there are some problems with the census data. Firstly, the division of "Udmurt mother tongue" and "Knowledge of Udmurt" cannot be equated with the sociolinguistic division of L1 and L2 speakers. According to the Census of 2010, the number of ethnic Udmurts whose mother tongue is Udmurt $(342,963)$ and the number of ethnic Udmurts who have competence in Udmurt $(298,628)$ together is bigger than the number of ethnic Udmurts $(552,299)$. This is partly due to the structure of the questionnaire used in this census: the respondents were asked first to list the languages they have competence in, and only then, to fill out their mother tongue. ${ }^{9}$ Hence, it was possible to list Udmurt in both boxes.

It is also striking that the number of the "mother tongue Udmurt speakers" is bigger than the number of people who state to have competence in Udmurt. As noted by Salánki (2007: 26, fn. 29), it might be the case that not all respondents who identified their mother

\footnotetext{
${ }^{9}$ The blank form of the Russian Census of 2010 is available online at: http://www.gks.ru/free_doc/new_site/perepis2010/croc/Documents/Vol1/11.pdf . (Retrieved: 05.10.2017) 
tongue as Udmurt speak the language. During my fieldworks, I have discussed the notion of "mother tongue" with my consultants, and it seems that the definition of this term might be blurred with "ethnicity” for some Udmurts (Jääts 2015: 115 reaches similar conclusions with respect to the census data about the number of Komi-Permyak speakers).

Furthermore, the term “родной язык” ('mother tongue') is used in the Russian educational system to denote a specific type of classes. The (ethnic) Udmurt children may be enrolled in classes, where they study the Udmurt language and Udmurt literature (on the educational system in Udmurtia see below). Needless to say, the enrollment in such classes does not necessarily correlate with actual competence in Udmurt. However, some respondents might have identified themselves as native speakers of Udmurt since they have attended "Udmurt mother tongue" classes at school.

Table 2 summarizes the data about the Udmurt populations according to the administrative regions of the Russian Federation based on the Russian Census of 2010. As mentioned in the previous subsection, Udmurts live primarily in the Udmurt Republic, but Udmurt diasporas are also found in the Republic of Tatarstan, Republic of Bashkortostan, Perm Krai, Sverdlovsk Oblast and Kirov Oblast. Table 2 also shows the statistics regarding the language skills of the ethnic Udmurts living in these regions. It needs to be emphasized that Udmurts are a minority even in Udmurtia: according to the Census of 2010, the population of Udmurtia is approximately 1,520,000 inhabitants, and the ethnic Udmurts are about 410,000 .

Table 2 The Udmurt populations according to the administrative regions of the Russian Federation (Russian Census of 2010)

\begin{tabular}{|l|r|r|r|}
\hline & Ethnic Udmurt & Udmurt mother tongue & Knowledge of Udmurt \\
\hline Udmurtia & 410,584 & 266,907 & 229,203 \\
\hline Tatarstan & 23,454 & 20,113 & 19,474 \\
\hline Bashkortostan & 21,477 & 19,233 & 17,473 \\
\hline Perm Krai & 20,819 & 10,256 & 9,690 \\
\hline Sverdlovsk Oblast & 13,789 & 4,847 & 3,948 \\
\hline Kirov Oblast & 13,639 & 7,070 & 6,171 \\
\hline
\end{tabular}

I would also like to discuss one group of Udmurt speakers, namely, the Besermans. Although Beserman is considered one of the dialects of Udmurt, Besermans form a distinct 
ethnic group. Teplyashina (1970: 23-27) provides information about early censuses from the $17^{\text {th }}$ century in which Besermans were listed separately. Salánki (2007: 26, fn. 30) mentions that 10,035 people identified themselves as Besermans in the Census of 1926. The Besermans were not listed separately from the Udmurts in the subsequent censuses (Pimenov 1993: 31), but they are a distinct ethnic group in the Census of 2002 and Census of 2010. However, neither of these two censuses reports of Beserman speakers. As shown in Table 3, though the Beserman are listed as a separate ethnic group, the self-reported mother tongue of about $75 \%$ of them is Udmurt.

Table 3 The Beserman population

\begin{tabular}{|l|r|r|r|r|r|r|}
\hline Census & \multirow{2}{*}{$\begin{array}{c}\text { Ethnic } \\
\text { Beserman }\end{array}$} & \multirow{2}{*}{$\begin{array}{c}\text { Beserman } \\
\text { Speaker }\end{array}$} & \multicolumn{2}{|c|}{ Mother tongue } & \multicolumn{2}{|c|}{ Knowledge of } \\
\cline { 4 - 7 } & & Udmurt & Russian & Udmurt & Russian \\
\hline 2002 & 3,122 & - & NA & NA & 2,573 & 3,038 \\
\hline 2010 & 2,201 & - & 1,673 & 521 & 1,621 & 2,184 \\
\hline
\end{tabular}

Below I will give the overview of the sociolinguistic situation of the Udmurt language in Udmurtia, leaving aside the Udmurt diasporas in the neighboring republics.

Zamyatin (2015: 293) discusses the issue of the titular state language status given to several languages in the Russian Federation. The official language status applies to the regional executive authorities, whereas federal ones are unilingual. Moreover, he argues that the titular languages are not used in many domains of language use, and as a result, the sociolinguistic situation resembles diglossia (Zamyatin 2015: 290, 296). Zamyatin (2015: 298-299) specifically discusses the case of the Udmurt language in the Udmurt Republic where Udmurt has a co-official status with Russian. He points out that Udmurt is listed after Russian in the Declaration of State Sovereignty of Udmurtia (September 20, 1990), in the constitution (December 7, 1994) and in the language law. Zamyatin (2015: 298) also argues that in the language policy documents of other republics within the Russian Federation, the titular language is listed before Russian, hence, listing Russian first has a symbolic meaning. Furthermore, the Concept of the State Nationalities Policy in the Udmurt Republic does not mention equality of languages. 
Turning to bilingualism, we have already seen that practically all Udmurts acquire knowledge of Russian, i.e. are bilingual. ${ }^{10}$ Salánki (2007: 59) claims that the older generation of Udmurt speakers is balanced or Udmurt-dominant bilingual, while the younger generation is balanced or Russian-dominant. Shirobokova (2011:134-135) argues that in the Muvyr municipality of Sharkan district (Udmurtia), the old generation is Udmurt-dominant, the middle-aged generation is balanced or Udmurt-dominant, and the younger generation is either balanced or dominant bilingual, but the question of whether the young generation is Russianor Udmurt-dominant is left unanswered. Moreover, both Salánki (2007) and Shirobokova (2011) suggest that we are dealing with subtractive bilingualism in all age groups.

As for the domains of language use, both Shirobokova (2011: 127-129) and Salánki (2007: 110) argue that Udmurt is used mostly in the informal domains. On the other hand, the use of Udmurt is very restricted in the public domains, and especially, in the administrative domain, where, in practice, all official documents are written only in Russian (Salánki 2007: 114-115; Shirobokova 2011: 129). Additionally, Salánki (2007: 136-137) shows that the Udmurts living in villages (especially, in Central and Southern Udmurtia) tend to be Udmurt-dominant, whereas the Udmurts living in Izhevsk are more often Russian-dominant. It should be also noted that Udmurts, especially those belonging to the younger generation, read mostly in Russian (Shirobokova 2011: 102-105; Salánki 2007: 117-118).

A few remarks are also in order regarding the educational system in the Udmurt Republic. Salánki (2007: 36-37) reports that Udmurt was used as language of instruction in schools until the 1930s when Russian became the official medium of instruction. This led to the conversion to Russian-medium education since the 1970s. Nowadays, Udmurt is taught only as a subject in schools (Udmurt language and Udmurt literature classes), while the medium of instruction is Russian. It is important to emphasize that not all schools in Udmurtia provide Udmurt classes, and the number of these schools is decreasing: 408 in the school year 2000/2001, 320 in the school year 2006/2007, and 214 in the school year 2015/2016. ${ }^{11}$

Nevertheless, there are some positive developments signaling the revitalization of the language. One of them is the fact that Udmurt is used in printed and digital mass media (for example, newspapers: Удмурт дунне, Инвожо, Дарт and Вордскем кыл; TV channels and

\footnotetext{
${ }^{10}$ Additionally, the Udmurts living in Tatarstan, as well as those living in Southern Udmurtia close to the border with Tatarstan acquire knowledge of not only Udmurt and Russian, but also of Tatar (Salánki 2007: 26-27). According to the Census of 2010, 20,825 ethnic Udmurts have reported to speak Tatar: 2,003 of them live in Udmurtia, 8,215 in Tatarstan and 7,678 in Bashkortostan.

11 The statistics come from Salánki (2007: 37) and the official reports available on the homepage of the Ministry of Education and Science of the Udmurt Republic: https://udmedu.ru/regulatory/stats/ (Retrieved: 05.06.2018). 
radio: Мынам Удмуртие and Удмуртия). Another positive sign is the use of Udmurt in the online domain: there are several blogs, written in $\mathrm{Udmurt}^{12}$, and native speakers, especially from the young generation, use Udmurt in social media.

Now let us turn to the development of the literary language, i.e. standard Udmurt. The first extensive Udmurt text collections appeared in the $19^{\text {th }}$ century (see $\$ 2.2$ ). The Udmurt literary language was developed mainly in the twenties and thirties of the $20^{\text {th }}$ century. The development of the literary language involved the unification of certain grammatical forms used in the Northern or Southern dialects (Salánki 2007: 56). As Salánki (2007: 56) points out, the development of the standard language is not completed even nowadays since Udmurt has restricted use in the public domains, and this requires for the lexicon to be enhanced with several lexemes.

Edygarova (2014: 388) claims that the knowledge of standard Udmurt differs among the native speakers. Shirobokova (2011: 142-143) also reports that $67 \%$ of the participants from the old generation and $72 \%$ of the participants from the middle-aged generation have difficulties understanding the standard language. In the case of the young generation, $42 \%$ of them report that they do not understand the standard language very well, but $29 \%$ state that they do. As reported in this study, the speakers have difficulties with the lexicon of the standard language, which Shirobokova attributes to the fact that those speakers have limited access to books and mass media written in standard Udmurt. Similarly, Salánki (2007: 82-83) also reports that generally Udmurt speakers consider themselves less fluent in standard Udmurt than in their own dialect (this tendency is less observable in the case of the young generation, but still present). Furthermore, Salánki (2007: 90-91) claims that the majority of Udmurts who participated in her study speak only or predominately in dialect, but she also observes the following tendencies: the use of both dialectal and standard Udmurt is more frequent in the case of the mid-aged generation, as is the use of only standard Udmurt in the case of the young generation. It must be emphasized, though, that this study is based on selfreported data, and as Salánki (2007: 90, fn. 139) herself mentions, it is not clear whether the language variety called "standard" by the respondents is equal to standard Udmurt. Edygarova (2014) distinguishes between standard Udmurt and its vernacular varieties. Moreover, she proposes that there are local and cross-local vernacular varieties. The former show features of a particular dialect, while in the latter, both features of mixed dialect and standard forms occur (Edygarova 2014: 379). Hence, it seems plausible that nowadays, we

\footnotetext{
${ }^{12}$ For more information on Udmurt blogs see http://vk.com/udmblog. 
cannot speak of "pure" dialects. Rather, we can distinguish (spoken) local varieties of Udmurt that show dialectal features (to a varying degree). To conclude, we can observe differences in today's Udmurt according to several parameters: standard-dialectal/spoken, city-village, oldyoung generation, etc.

\subsection{Writing system, literacy and resources}

The Udmurt alphabet is based on the Cyrillic script with five additional letters: “ӜЖ/Ӝ”, “Ӟ/3”,

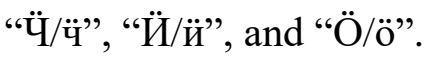

Scientific papers dealing with Udmurt use different transcriptions. Some of them are Latin-based, others are Cyrillic-based. The Cyrillic-based transcription has been used in the dialectological text collections published in Udmurtia, this transcription system is presented by Kelmakov (1998: 44-50). The differences between the Latin-based transcriptions concern mostly the affricates, as well as the close central/back and mid central/back vowels. The Latin transcriptions are usually based on the Finno-Ugric transcription (FUT), also called Uralic Phonetic Alphabet (UPA). ${ }^{13}$ This phonetic transcription system was first published by Setälä (1901). Posti \& Itkonen (1973) specifically discuss the transcription of the individual Uralic languages, including Udmurt, and summarize the Latin-based transcriptions used in the text collections from the $19^{\text {th }}$ century in comparison to the standard Cyrillic-based Udmurt orthography. Additionally, in some scientific publications, Udmurt is transcribed (partly) with ISO 9 characters instead of the UPA characters. Recently, Udmurt has been transcribed with IPA alongside the UPA in the UraLUID database (see below).

The transcription used in this dissertation is based on the FUT system, as summarized in Appendix 1. Examples from other sources used in this dissertation were also transliterated accordingly.

The first written sources collected in the $18^{\text {th }}$ century were word lists. ${ }^{14}$ Starting from the late $19^{\text {th }}$ century, several text collections also appeared (Munkácsi 1887, 1952; Wichmann 1901). In the $20^{\text {th }}$ century, several dialect text collections were also published (Kelmakov 1981, 1990, 2015; Nasibullin 1982). Moreover, case studies of individual subdialects have also been published (cf. Karpova 2005 on the Middle Cheptsa dialect and Teplyashina 1970

\footnotetext{
${ }^{13}$ The Uralic Phonetic Alphabet characters for the Universal Coded Character Set can be found online at: http://std.dkuug.dk/jtc1/sc2/wg2/docs/n2419a.pdf. (Retrieved: 05.12.2017)

${ }^{14}$ The interested reader is referred to Teplyashina (1965) for an extensive discussion of all Udmurt texts collections.
} 
on the Beserman dialect). These works present not only text materials, but also grammatical sketches of the relevant (sub)dialects.

Furthermore, there are several corpora. The Turku-Izhevsk Corpus ${ }^{15}$ contains c. 11,000 texts form newspapers published between 1997 and 2002. The Udmurt Corpus ${ }^{16}$ contains about 9.5 million tokens of mostly newspaper texts representing the standard Udmurt published between 2007 and 2018. Additionally, the Udmurt Social Media Corpus ${ }^{17}$ contains about 2.6 million tokens coming from open posts and comments by Udmurt-speaking vkontakte users (up to February 2018). In both corpora, the automatically annotated texts have not been disambiguated. ${ }^{18}$ The Beserman Udmurt Corpus ${ }^{19}$ contains transcribed texts of various genres in the Beserman dialect of Udmurt (the size of the corpus is c. 65,000 tokens). The texts were recorded during fieldwork trips conducted between 2003 and 2015, and have been morphologically annotated, glossed and translated into Russian. The UraLUID database $^{20}$ also contains Udmurt texts: analyzed samples from old text collections (Munkácsi 1887 and Wichmann 1901) and new blogs. In this dissertation, I present examples form the Turku-Izhevsk Corpus, Udmurt Corpus and Udmurt Social Media Corpus.

Let us briefly discuss the NLP tools available for Udmurt. There are three morphological analyzers developed for standard Udmurt. ${ }^{21} 22{ }^{23}$ Additionally, there are some online dictionaries, for instance, the online version of Kirillova's (2008) Udmurt-Russian dictionary. ${ }^{24}$ Furthermore, there are several end-user support tools, such as online spellcheckers $^{25}$, transcription/transliteration tools ${ }^{26}$ and diacritic helpers ${ }^{27}$, etc. Last but not least, one should mention Grigoriy Grigoriev, an Udmurt native speaker and activist, who has been developing end-user support tools, such as spell-checkers, fonts, keyboards and smartphone apps. $^{28} 29$

\footnotetext{
${ }^{15} \mathrm{http}: / /$ volga.utu.fi/portal/cgi-bin/login.cgi

${ }^{16} \mathrm{http}: / /$ udmurt.web-corpora.net/udmurt corpus/search

17 http://udmurt.web-corpora.net/udmurt_social_networks/search

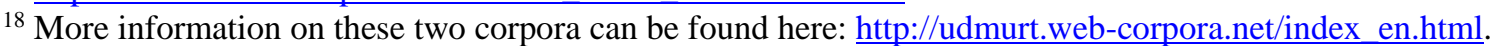

19 http://beserman.ru/corpus/search

20 http://www.nytud.hu/depts/tlp/uralic/dbases_udmurt.html

21 http://www.morphologic.hu/component/option,com_wrapper/Itemid,632/lang,hu/.

22 http://giellatekno.uit.no/cgi/index.udm.eng.html.

23 https://github.com/timarkh/uniparser-grammar-udm/

24 http://dict.fu-lab.ru/index.php/index/6.xhtml

25 http://webspell.fu-lab.ru/

${ }^{26} \mathrm{http}: / / \mathrm{www}$. univie.ac.at/maridict/site-2014/transcription-general.php?int $=0$

${ }^{27} \mathrm{http} / / / \mathrm{www} . u n i v i e . a c . a t / m a r i d i c t /$ site-2014/transcription-universal.php

28 http://udmspell.ru/blog/

${ }^{29}$ https://play.google.com/store/apps/developer?id=vorgoron
} 


\subsection{Basic grammar}

Udmurt is a moderately well-described language. The most important handbooks on the Finno-Ugric languages include chapters on the Permic languages and on Udmurt (Sinor 1988; Abondolo 1998). Besides, there are a couple of descriptive grammars and grammatical sketches, such as Kel'makov \& Hännikäinen (1999), Suihkonen (1995), Bartens (2000), Kozmács (2001), Winkler (2001, 2011), written in Finnish, Hungarian, German or English. Despite this, there is scarcity of publications on Udmurt in English, most of the literature is written in Russian. Among the descriptive studies published in Russian, one should mention the three volumes of the Udmurt descriptive grammar (GSUJa 1962, 1970, 1974) since they are the most detailed descriptions of the Udmurt language. Based on these grammars, as well as taking into account a couple of recent studies, I will summarize the main morphological and syntactic properties of Udmurt.

Typologically, Udmurt is an agglutinative language. It is a head-final language, its neutral word order is considered to be SOV although recent studies argue that there is an ongoing change to SVO (see \$2.3.2 for discussion). Moreover, Udmurt is a pro-drop language with nominative-accusative alignment and Differential Object Marking.

The main word classes in Udmurt are nouns, verbs, adjectives, numerals, pronouns, and postpositions. It is a typologically interesting feature of Udmurt that it has inclusive and exclusive 1PL pronouns (Kozmács 1998). As Cysouw (2013) observes, the inclusive/exclusive distinction is uncommon in Eurasia, moreover, he argues that "[t]here is no distinction in any language in Europe and its wider surroundings", with the nearest cases being attested in the Caucasus. The Udmurt inclusive pronoun is the 1PL reflexive pronoun aśmeos 'ourselves', whereas the 1PL personal pronoun $m i$ 'we' is used as an exclusive pronoun.

Below, I present some of the key features of the Udmurt grammar with special references to morphosyntax and syntax. With respect to morphology, I will focus mainly on two word classes, namely, nouns and verbs. The understanding of the basic features of Udmurt morphology will provide basis for comparison between finite and non-finite verbs on the one hand, and non-finite verbs and nouns, on the other. Additionally, the main syntactic properties of the Udmurt language will be presented. I will review the structure of noun phrases and (finite) verb phrases/clauses. I will specifically discuss subordinate clauses. It must be emphasized, however, that Udmurt syntax is an unexplored field, hence, this subsection cannot provide a detailed discussion of many aspects of the syntax of Udmurt. 


\subsubsection{Nouns and noun phrases}

In Udmurt, nouns are marked for number, case, possession and, according to Winkler (2001), for definiteness. Udmurt distinguishes two numbers: singular (zero marked) and plural (its marker is $-(j) o s)$ : pukon 'chair' and pukon-jos 'chair-PL'.

Udmurt nouns decline for 15 cases: nominative, accusative, dative, genitive, ablative, caritive/abessive ${ }^{30}$, instrumental, inessive, illative, elative, prolative ${ }^{31}$, terminative, egressive, adverbial and approximative. Some additional case suffixes are used in Beserman Udmurt as well as in the Northern dialects (Karpova 2005; Teplyashina 1970; Usacheva \& Arkhangelskiy 2017).

Additionally, possessive suffixes are used to indicate the person/number features of the possessor (singular/plural, $1^{\text {st }} / 2^{\text {nd }} / 3^{\text {rd }}$ person). Different possessive suffixes are used to signal alienable/inalienable possession (for a detailed discussion of possession see Edygarova 2010). The possessive suffixes expressing alienable possession contain the vowel $-e$ - in the singular, while the ones expressing inalienable possession contain the vowel $-i-$. However, the alienable and inalienable possessive suffixes are completely identical in the plural. Below, I exemplify the alienable and inalienable possessive paradigms. The nouns are in the nominative (which is zero marked).

Table 4 Alienable and inalienable possessive suffixes (pukon 'chair',jïr 'head')

\begin{tabular}{|c|c|c|c|c|c|}
\hline & Alienable & Inalienable & & Alienable & Inalienable \\
\hline 1SG & pukon-e & $j \underline{j} \mathbf{i} r-\underline{i}$ & 1PL & pukon-mi & jir-mi \\
\hline 2SG & pukon-ed & jịr-idd & 2PL & pukon-di & jirr-di \\
\hline 3SG & pukon-ez & jigr-iz & 3PL & pukon-zi & $j \underline{j} r-z i$ \\
\hline
\end{tabular}

The difference between inalienable and alienable possession is observed only when the possessive suffixes attach to the bare stem of the noun. If the noun is in the plural, the possessive suffixes contain the vowel $-i$ - irrespective of semantic class of the noun they attach to, cf. pukon-jos-iz 'chair-PL-3SG his/her chairs'.

Similarly to other Uralic languages, possessive suffixes in Udmurt are used not only to express possessive relations, but also in non-possessive contexts (Nikolaeva 2003; Fraurud

\footnotetext{
30 The term 'caritive' is used by Winkler (2001) and Bartens (2000), while Hamari (2011) and Edygarova (2010) prefer the term 'abessive'. In this dissertation I use the latter term.

${ }^{31}$ This case is generally termed 'prolative' in most of the grammars, with the exception of Winkler (2001) who uses the term 'transitive'.
} 
2001; Gerland 2014). Winkler (2001) argues that the 3SG possessive suffix can be used to express definiteness. Typically, the $2 \mathrm{SG}$ and $3 \mathrm{SG}$ possessive suffixes can have such nonpossessive usages. In these cases, the possessive suffixes do not denote a possessive relation between the possessee and the possessor, but rather express deixis and associative relationship in Nikolaeva's (2003) terms, as shown in (1). Additionally, the 3SG possessive suffix $-(j) e z$ can be used to express "a kind of contrastive emphasis whose background need not be expressed explicitly in the context" (Winkler 2001: 32). (On this use of the 3sG possessive suffix see also Riessler 2016 and É. Kiss \& Tánczos forthcoming).

(1) fieldwork, spontaneous

(Context: talking about the weather)

Tell-iz keźit.

wind-3SG cold

'The wind is cold.' (lit. Its wind is cold.)

In Udmurt, some case markers follow the possessive suffixes, while others precede them. ${ }^{32}$ Additionally, some case suffixes can show either orders. The three groups are often referred to "Px-Cx", "Cx-Px", and " $\mathrm{Cx}-\mathrm{Px} / \mathrm{Px}-\mathrm{Cx}$ " in the Finno-Ugric literature, respectively ("Px" stands for possessive suffix, " $\mathrm{Cx}$ ” for case suffix). Table 5 summarizes the order of possessive suffixes and case markers in Udmurt.

Table 5 The order of possessive suffixes and case suffixes

\begin{tabular}{|l|l|l|l|l|l|l|l|l|l|l|l|l|l|l|}
\hline & ACC & DAT & GEN & ABL & ABE & APPROX & INE & ILL & INS & ELA & EGR & PROL & TERM & ADV \\
\hline CX-Px & & & & & & & $\checkmark$ & $\checkmark$ & $\checkmark$ & $\checkmark$ & $\checkmark$ & $\checkmark$ & $\checkmark$ & $(\checkmark)$ \\
\hline Px-Cx & $\checkmark$ & $\checkmark$ & $\checkmark$ & $\checkmark$ & $\checkmark$ & $\checkmark$ & & & & & & $(\checkmark)$ & $(\checkmark)$ & $\checkmark$ \\
\hline
\end{tabular}

As shown in Table 5, three case suffixes, namely, the adverbial, prolative and terminative cases are said to show both orders. However, the existing grammars differ with this respect to this question. Firstly, Emelyanov (1927: 135) claims that both orders are attested with the terminative and adverbial, while Jakovlev (1931: 23-24) points out this for

32 Historically, the Udmurt case suffixes are divided into primary and secondary, and the later grammaticalization of the latter group is offered as an explanation for the variation in the order of the suffixes (Bartens 2000: 117-118). On the order of the possessive suffixes and case markers in the Uralic languages from a diachronic point of view see Honti (2004). 
the prolative. The terminative is said to be attested with both orders in more recent grammars, too (Winkler 2001: 29; Bartens 2000: 110; Kozmács 2001: 31 mentions that Px-Cx order is rare). Most grammars claim that the adverbial can only follow the possessive suffixes, but Kelmakov \& Hännikäinen (1999: 187) state that the Cx-Px order is also possible. According to Edygarova (2010: 109-111), it is only the adverbial marker that shows variation in today's Udmurt. The adverbial is particularly relevant since it is used with non-finite verbs (see the discussion in Chapter 3 and 4).

The accusative, dative, genitive, ablative, abessive, and approximative case suffixes follow the possessive suffixes presented in Table 4 above, cf. pukon-e-len 'chair-1SG-GEN of my chair' and jir-i-len 'head-1SG-GEN of my head' (preserving the distinction between alienable and inalienable possession). ${ }^{33}$

The inessive, illative, instrumental, elative, and egressive case suffixes, on the other hand, precede the possessive suffixes. In this case, the declension is not as straightforward. Firstly, some of these case suffixes show allomorphy and syncretism in the possessive paradigm. For instance, the inessive marker on non-possessed nouns is -in and the illative marker is $-(j) e /-i$. In the possessive paradigm, however, these two cases are syncretic; their marker is $-(j) a$-. From synchronic point of view, the $-a$ - might be analyzed as the actual exponent of the inessive/illative case (cf. Winkler 2001: 25). Note also that the terminative case forms also contain the vowel $-a-.^{34}$ Below, I illustrate the declension in the inessive/illative and terminative cases since they are relevant with respect to the non-finite clauses discussed in this dissertation.

Table 6 The $\mathrm{Cx}-\mathrm{Px}$ order

\begin{tabular}{|c|c|c|c|c|c|}
\hline & INE/ILL & TERM & & INE/ILL & TERM \\
\hline 1SG & jïr-am & jïr-oź-am & 1PL & $j i r-a-m i$ & jïr-oź-ami \\
\hline 2SG & jir-ad & jür-oź-ad & 2PL & $j \underline{j} r-a-d \underline{i}$ & jïr-oź-adi \\
\hline 3SG & jïr-az. & jịr-oź-az & 3PL & $j i r-a-z i$ & jïr-oź-azi \\
\hline
\end{tabular}

The second peculiarity of these case suffixes is that they are followed by different possessive suffixes than the ones presented in Table 4 above. The possessive suffixes differ

\footnotetext{
${ }^{33}$ The accusative forms are in fact more problematic. For the sake of simplicity, I analyse these noun forms as containing a portmanteau suffix, thus, I gloss forms like jir-me or jir-mes as 'head-1SG.ACC' and 'head-1PL.ACC', respectively.

${ }^{34}$ For the sake of simplicity, I segment the terminative forms in the following way: jir-oź-am 'head-TERM-1SG'.
} 
most crucially in $1 \mathrm{SG}$. We saw that the $1 \mathrm{SG}$ possessive suffix $-(j) e$ for alienable possession and - $i$ for inalienable possession (cf. Table 4). However, if the noun bears the inessive/illative, elative, egressive, terminative or adverbial cases, the $1 \mathrm{SG}$ possessive suffix that follows the case suffix is not $-(j) e /-i$, but $-m$. The suffix $-m$ has been reconstructed as the Proto-Permic 1SG possessive suffix. Later, this ending has been lost in the possessive paradigm, see Bartens (2000) among others (however, the disappearance of this suffix has been the subject of debate). Contrary to the above, others have argued that there has never been an $-m$ in most of the oblique cases of the possessive paradigm (Lytkin 1952: 106-107; Edygarova 2010: 159160). In Edygarova's (2010: 159-160) view, the 1SG suffix - $m$ expresses grammatical agreement rather than possession. According to her, the set of possessive suffixes presented in Table 6 must be distinguished from the possessive suffixes presented in Table 4 since the former are used not only on nouns, but also on postpositions, numerals, pronouns and some non-finite verb forms (Edygarova 2010: 86-89).

Let us now review the syntax of noun phrases in Udmurt. In the noun phrases of Udmurt, demonstratives are usually the first elements, followed by numerals, adjectives and the head noun. Attributive adjectives, as a rule, do not agree in case with the head noun. ${ }^{35}$ Numerals usually do not trigger concord in plural with the head noun. This is illustrated in (2).

\author{
(2) elicited \\ ta kik ćeber pispu \\ this two beautiful tree \\ 'these two beautiful trees'
}

To my knowledge, Simonenko \& Leontjev's (2012) paper is the only existing analysis of Udmurt noun phrases that aims at providing a general description of noun phrases (and not of a particular phenomenon in the nominal domain) based on the Beserman dialect of Udmurt. Their analysis is within a minimalist/Distributed Morphology framework. Simonenko \& Leontjev (2012) propose the following syntactic structure of the Beserman Udmurt noun phrases. $^{36}$

\footnotetext{
${ }^{35}$ Adjectives marked with contrastive suffix -(j)ez agree with the noun (see É. Kiss \& Tánczos forthcoming).

${ }^{36}$ Note that there is no DP layer. Simonenko \& Leontjev (2012) assume a DP only in the presence of a demonstrative pronoun.
} 
We have already seen that number and possession are realized as suffixes on the possessee. In order to account for this, Simonenko \& Leontjev (2012) propose that the inflected noun forms can be derived via head movement: the $\mathrm{N}$ first moves to Num, then to Poss, and finally, to $\mathrm{K}$.

The structure of noun phrases depicted in (3) represents the cases where the possessive suffixes precede the case suffixes. Recall that the reverse order, i.e. $\mathrm{Cx}-\mathrm{Px}$ is also attested with certain case suffixes, cf. Table 6. In order to explain this order, Simonenko \& Leontjev (2012) propose that these case suffixes are similar to relational nouns and postpositions. Several relational nouns are used in Udmurt, such as ber 'back (part)', aź 'front (part)', $u l$ 'low (part)', vil 'top (part)', pal 'side', urdes 'flank', etc. (Usacheva 2012). The latter two are illustrated in (4). Additionally, there are also inflecting postpositions, for example dor'around, at', cf. (5).

(4) Usacheva (2012: ex. (1))

[Beserman Udmurt]

So-len urdesk-a-z, bur pal-a-z sâle petuk.

3SG-GEN flank-INE/ILL-3SG right side-INE/ILL-3SG stand[PRS.3SG] rooster

'There is a rooster at its side, at its right side.'

(5) Usacheva (2012: ex. (40))

[Beserman Udmurt]

Gid' dor-ân sâle pař́ tuš'.

stall at-INE stand[PRS.3SG] pig tub

'There is a tub for the pigs next to the stall.'

As Usacheva (2012) argues, both relational nouns and inflecting postpositions take possessive suffixes and locative cases, but only the former can be marked in the plural, take core cases and be modified with adjectives. To capture these differences, Simonenko \& Leontjev (2012) propose the structure shown in (6a, b). The differences between relational nouns and postpositions concern the number of projections below PossP as well as the type of complement (DP or PossP) selected. Moreover, they suggest that locative cases (i.e. the ones that show Cx-Px order) are similar to relational nouns and inflecting postpositions, but even smaller in size, as shown in (6c). They consist only of a $\mathrm{K}_{\mathrm{LOC}} \mathrm{P}$, and select for a NumP. In all 
three cases, a PossP caps off the structure. In Chapter 3 and 4, it will be shown that several non-finite adverbial clauses are case-marked or postpositional forms of nominalizations, thus, this analysis of postpositional phrases is important for the discussion of non-finite clauses.

(6)

a. Relational nouns:

[PossP Poss [KP K [NumP Num [N $\mathrm{N}_{\mathrm{ReL}} \mathrm{P} \mathrm{N}_{\mathrm{ReL}}$ [DP D [PossP Poss [NumP Num [NP]]]]]]]

b. Postpositions:

[PossP Poss [K $\mathrm{K}_{\text {loc }} \mathrm{P} \mathrm{K}_{\text {loc }}$ [N $\mathrm{Nlace}_{\mathrm{P}} \mathrm{N}_{\mathrm{place}}$ [PossP Poss [NumP Num [NP]]]]]

c. $\mathrm{Cx}-\mathrm{Px}$ cases:

[PossP Poss [K $\mathrm{K}_{\mathrm{LOC}} \mathrm{P} \mathrm{K}_{\mathrm{LOC}}[\mathrm{NumP}$ Num [N]]]]

In Udmurt, the possessee bears possessive suffixes and the possessor is in the genitive case, as shown in (7). Pronominal possessors do not have to be overt unless they are emphatic; their person/number features are indicated via the agreement suffix on the possessee.

(7) elicited

Peta-len puni-jez ute.

Peter-GEN dog-3SG bark[PRS.3SG]

'Peter's dog is barking.'

According to Simonenko \& Leontjev (2012), the possessive suffixes are obligatory. The possessor - which they argue to be a genitive-marked modifier - is never obligatorily present, and if overt, can be moved out of the noun phrase (i.e. external possessors, not illustrated here). They claim that the genitive-marked modifier sits in Spec,KP, cf. (8). Furthermore, the possessor is in parenthesis presumably because it need not be present overtly. Based on this, Simonenko \& Leontjev (2012) argue that the possessor is not licensed by the possessive morpheme on the possessee, but it is coreferential with the pro in Spec,PossP. 
Possessive constructions in Udmurt have one peculiarity: if the possessive phrase is assigned the accusative, the possessor does not bear the genitive, but the ablative case, cf. (9).

(9) elicited
Pet'a-leś puni-ze śud-i.
Peter-ABL dog-3SG.ACC feed-PST[1SG]
'I fed Peter's dog.'

Simonenko \& Leontjev (2012) tentatively propose that the genitive-ablative alternation is a case agreement/concord between the head and the possessor. Assmann et al. (2014), on the other hand, analyze this as an instance of case-stacking (genitive and accusative) which is however disallowed in Udmurt. Consequently, the default semantic case, the ablative is realized on the possessor.

Additionally, a remark is in order regarding the so-called "juxtaposed possessive construction" in Udmurt. Traditionally, it has been assumed that possession in Udmurt can be expressed by simply juxtaposing two nouns, without using any morphological marking on either of them, for instance, tir nid 'ax lever' (Edygarova 2010: 187). Edygarova (2010: 186202) argues that this is juxtaposed possessive constructions that express part-whole relationship. Edygarova divides the juxtaposed constructions into several subgroups, but claims that only two of them are (semantically) possessive, namely, the tir nid 'ax lever' and the uči ćirdem 'nightingale-singing' types of juxtaposed construction. The latter type will be discussed in §3.6. The former type has been investigated by Fejes (2005). Fejes (2005: 153156) demonstrates that these are actually $\mathrm{N}+\mathrm{N}$ compounds: the "possessor" cannot be modified morphologically, it has generic meaning, it cannot be referred to anaphorically, no modifier can intervene between the "possessor" and the "possessee", etc. Simonenko \& Leontjev (2012) also discuss these constructions briefly, but do not put forward a clear analysis. They nevertheless mention that these constructions cannot be modified morphologically, nor can modifiers intervene between the juxtaposed elements, but they do not explicitly state that these are compounds. Fejes (2005: 156) also points out that this question is particularly relevant from a historical perspective since the $\mathrm{N}+\mathrm{N}$ compounds are said to originate from the juxtaposed possessive construction. The "juxtaposed possessive construction" is considered the most archaic type of possessive construction in the FinnoUgric languages (Serebrennikov 1964 among many others). 


\subsubsection{Verbs and clause structure}

In Udmurt, verbs show rich inflectional and derivational morphology. As for their conjugation, verbs are usually divided into two conjugation classes, namely, the $-i$ and $-a$ classes, depending on the last vowel of the stem (in most grammars, these are referred to as Conjugation I and Conjugation II). The morpheme order is the following: stem - (derivational suffixes) - tense - agreement.

It must be said that the traditional grammars (at least implicitly) make a distinction between inflectional and derivational morphology, but no criteria have been proposed of how to distinguish them in Udmurt. Generally, the sections on derivational morphology discuss not only denominal verb suffixes, but also certain voice and aspect suffixes (Bartens 2000; Winkler 2001). These suffixes derive transitive, intransitive, causative and reflexive verbs or express various aspectual meanings, such as perfective/imperfective aspect and different aktionsarts. As for their inflection, verbs in Udmurt inflect for tense, mood, person and number, indicating the person/number features of the subject. Unlike other Uralic languages, no object agreement is used in Udmurt. Below, I will briefly present the inflectional morphology used on finite verbs.

Udmurt has a rich tense system, including four synthetic tenses and several analytical ones. The four synthetic tenses are the present, future, past and the so-called second past tense (see below). Table 7 shows the conjugation of the $-i$-verb vitini 'to wait'. ${ }^{37}$ As shown in Table 7, the exponent of the past tense is $-i$, the marker of the future tense is $-o$, while the present tense suffix is -śko (in the first and second person).

Table 7 The present, future and past tense (vit'ini 'to wait')

\begin{tabular}{|l|l|l|l|}
\hline & PRESENT & FUTURE & PAST \\
\hline 1SG & vit'i-śko & vit'-o & vit'-i \\
\hline 2SG & vit'i-śko-d & vit'-o-d & vit'-i-d \\
\hline 3SG & vit'-e & vit'-o-z & vit'-i-z \\
\hline 1PL & vit'i-śko-m(i) & vit'-o-m(i) & vit'-i-m(i) \\
\hline 2PL & vit'i-śko-di & vit'-o-di & vit'-i-di \\
\hline 3PL & vit'-o & vit'-o-zi & vit'-i-zi \\
\hline
\end{tabular}

${ }^{37}$ There are some slight differences in the conjugation of the - $a$-verbs, but these are irrelevant for the present overview. 
From a typological point of view, one of the peculiarities of the Udmurt tense system is that the present is morphologically more marked than the future and the past (Haspelmath 1998). Diachronically, the present tense marker $-s k$ is a derivational suffix. This suffix is still used in modern Udmurt as a derivational suffix and it can be used as intransitivizing, passivizing, reflexive, anticausative and antipassive marker (Kozmács 2008; Tánczos 2016; F. Gulyás 2017). Synchronically, verbs can contain both the derivational and the present tense -śk-suffix, as shown in (10) (the derivational one is glossed as reflexive according to its function in the sentence).

\section{(10) elicited}

(Mon) sina-śki-śko.

(I) comb-REFL-PRS[1SG]

'I am combing myself.'

There is one more synthetic tense, namely, the so-called second past tense (Siegl 2004). It should be noted that Winkler (2001: 49) considers it a mood. Its paradigm is quite complex, but its main exponent is the non-finite $-(e) m$ (discussed in Chapter 3). Additionally, two derivational suffixes are also used: the intransitivizing suffix $-s ́ k$ and the frequentative suffix -l'l'a. (The paradigm of this tense differs considerably in the Udmurt dialects as well as in the descriptive grammars, see Siegl 2004: 56-60). Functionally, this past tense expresses hearsay, mirativity, inferentiality or non-volitional action (when used in the $1^{\text {st }}$ person). It is also used in traditional narrative texts. However, Siegl (2004: 162) argues that the Permic languages do not have a grammaticalized evidential system, but rather the second past tense can be used as an evidential strategy. ${ }^{38}$ The following example illustrates the use of the evidential.

(11) fieldwork recording, 2014_07_26_000, EK, Kukmor

$$
\text { mânam anaj=no kaban ul-e peğ̌-em. }
$$

1SG.GEN mother=ADD hayrick under-ILL hide-EVID[3SG]

'My mother hid under the hayrick, too.'

\footnotetext{
${ }^{38}$ In this dissertation I nevertheless use the gloss EVID instead of PST2.
} 
Additionally, there are several analytic tenses. The analytical tenses are formed by combining a synthetic verb form with the morphologically invariant past copula val or its evidential counterpart vilem. This gives rise to the following combinations: present tense $\mathrm{val} / \mathrm{vilem}$, future tense $+\mathrm{val} / v i \mathrm{lem}$, past tense $+\mathrm{val} / \mathrm{vilem}$ and evidential + val/vilem. ${ }^{39} \mathrm{In}(12)$, the analytic past tense consisting of a future verb form and the copula val is used. According to the descriptive grammars, it expresses a habitual action in the past.

(12) Udmurt Corpus (Иднакар, 2012.03.08)

Aźlo vuž jurt-in kinmí-sa bir-o-d val.

before old building-INE freeze-CVB die-FUT-2SG AUX.PST

'You'd freeze to death in the old building before.'

There are three moods in Udmurt: indicative (zero marked), conditional (its marker is -sal) and imperative. The imperative is used only in the second person. In $2 \mathrm{sG}$, a bare verb stem is used, while in the 2PL, the verb stem contains the plural suffix - $e$, cf. (13).

(13) Edygarova (2015: 272, ex. (8c, f))
a. baśti!!
b. baśt-e!
take[IMP.2SG]
take-IMP.2PL
'Take!'
'Take (pl)!'

Winkler (2011: 103) assumes a fourth mood, namely, the optative, formed with the particle med and a verb form in the future tense, but Klumpp (2016: 548) and Serdobolskaya et al. (2012) argue that this particle is an optative complementizer.

Udmurt utilizes only subject agreement; no object agreement is used. Subject agreement is obligatory on tensed verb forms, cf. Table 7 above (note that the 1 sG agreement suffix is zero marked). In the evidential and conditional, however, agreement is not obligatory (in certain person/number combinations), and there is dialectal variation in this respect.

Turning to the syntax of finite clauses, Udmurt is a pro-drop language with nominativeaccusative alignment and Differential Object Marking. Direct objects are either unmarked or

\footnotetext{
${ }^{39}$ Winkler (2001: 47-48) considers some additional constructions to be past tense forms, for instance the one formed with the non-finite $-(e) m$ and the verb vań 'exist'.
} 
marked with the suffix $-(j) e z$. The accusative marker is (historically) a 3SG possessive suffix (cf. Table 4). Example (14) illustrates both pro-drop and the Differential Object Marking. ${ }^{40}$

(14) elicited

a. (Mon) ulmo sí-i.

(I) apple[ACC] eat-PST[1SG]

'I ate an apple/apples.'

b. (Mon) ulmo-jez śi-i.

(I) apple-ACC eat-PST[1SG]

'I ate the apple.'

Regarding the constraints on DOM in Udmurt, it has been argued that the case-marking of objects depends on definiteness/specificity, animacy and the semantics of the verb (Kondratyeva 2000, 2011; Tánczos 2016: 42-48; Serdobolskaya \& Toldova 2012; Winkler 2001: 20-21). Definite objects (such as proper names, pronouns and nouns with possessive suffixes) are always case-marked. Indefinites, and especially indefinite non-specific objects are unmarked.

Udmurt has three types of causatives: lexical, factive and periphrastic causatives (Tánczos 2016). Factive causatives are derived with the suffix - $t$, as shown in (15), while periphrastic causatives feature the verb kosini 'to order' or the verb leźini 'to let' that select for either a finite CP (in the optative) or an infinitive. Causative constructions in Udmurt are typologically interesting since the causee is accusative-marked, and hence, there are two accusative marked DPs in the same clause. It has been observed that cross-linguistically, the causee is encoded with an oblique case (Comrie 1981). However, Tánczos (2016: 116) argues that the use of $-(j) e z$ is an intermediate stage between the associative use of the $3 \mathrm{SG}$ possessive suffix and its core accusative use.

(15) Tánczos (2016: 108, ex. (19a))

Saša Maša-jez pinal-ez babitî-t-i-z.

Sasha Masha-ACC baby-ACC rock.to.sleep-CAUS-PST-3SG

'Sasha had Masha rock the baby to sleep.'

${ }^{40}$ In this dissertation, I gloss the unmarked objects with [ACC] and the -(j)ez-marked ones with ACC. 
Tánczos (2016) analyzes the Udmurt factive causatives as monoclausal, but bi-eventive. The monoclausality is supported by negation and binding facts: negation (i.e. the negative verb, see below) cannot scope over embedded verb of the causative construction, and a personal pronoun cannot be bound by the causer. Arguments for the bi-eventivity of Udmurt factive causatives come from the following facts: both the core event and the causing event can be modified by low adverbials. Furthermore, non-finite clauses give rise to ambiguity: either the causer or the causee can serve as controllers of the subject of non-finite clauses (this test will be discussed in Chapter 5). Tánczos (2016) assumes the following structure: VoiceP $>$ CauseP $>$ VoiceP $>$ Cause P $>$ vP $>\sqrt{ } \mathrm{P}$.

In Udmurt, negation is expressed with the help of a negative verb that carries tense and agreement morphology ${ }^{41}$, while the main verb is marked for number. ${ }^{42}$ Below I illustrate negation in the past tense: the negative verb $e^{-}$takes agreement markers (the $1 \mathrm{SG}$ form is unmarked). The main verb is in a bare stem form in the singular, while in the plural, it takes the suffix $-e$.

Table 8 Negation in the past tense (mini- 'go')

\begin{tabular}{|l|l|l|l|l|l|}
\hline 1SG & $e j$ & mini & 1PL & $e-m$ & mine \\
\hline 2SG & $e-d$ & mini & 2PL & $e-d$ & mine \\
\hline 3SG & $e-z$ & mini & 3PL & $e-z$ & mine \\
\hline
\end{tabular}

It should be noted that non-verbal predicates and imperatives are negated in a different way (for a detailed description see Edygarova 2015). It is important to mention that the negative verb expresses sentential negation. Constituent negation is achieved by focusing the constituent that immediately precedes the negative verb, cf. (16) (Edygarova 2015: 282, 284 285).

(16) Edygarova (2015: 282, ex. (33b))

$\begin{array}{lllll}\text { Dišetskiś-jos } & \text { tros } & \text { (kuźa) } & \text { ezz } & \text { vue. } \\ \text { student-PL } & \text { many } & \text { (people) } & \text { NEG.PST.3 } & \text { arrive[PL] }\end{array}$

'Not many students arrived.'

\footnotetext{
${ }^{41}$ This holds for the future and the past tense. In the present tense, the negative forms consist of the future negative verb, and the main verb carries the present tense marker $-s^{\prime} k$-.

42 The form of the main verb is often called 'co-negative' (however, Edygarova 2015 calls it 'semifinite form').
} 
Mitchell (2006) discusses the negative verbs used in several Uralic languages and proposes that $\mathrm{NegP}$ is generated above $\mathrm{TP}$ in some of the languages of the Finno-Ugric family, and below TP in others. If NegP is below TP, the negative verb carries tense marking as well. This is the case in Udmurt. If, however, NegP is above TP, tense is marked on the lexical verb (this is the case in Finnish, for instance). If this analysis is on the right track, it can be argued that finite clauses involve the following projections: (extended) $\mathrm{CP}>\mathrm{TP}>$ NegP $>$ AspP* $>$ VoiceP $>$ vP. ${ }^{43}$ It must be emphasized that the syntax of Udmurt is largely undescribed, and no general proposal exists of the syntactic structure of finite clauses.

Generally, Udmurt is considered to be an SOV language (see Vilkuna 1998 and Winkler 2001, a.o). The word order of the language is not strict, however. It has been argued that there is an ongoing change from OV to VO in modern Udmurt. The change can be observed in the basic word order (Asztalos \& Tánczos 2014; Asztalos et al. 2017), complementizers (Tánczos 2013) and relative clauses (Dékány \& Tánczos 2015). It has been argued that SVO can be the neutral word order in today’s Udmurt (Asztalos \& Tánczos 2014).

Tánczos (2010) demonstrates that word order can be influenced by the information structure of the sentence. She provides examples of different word orders, such as SOV, SVO, OSV and OVS, which, according to her analysis, are to be explained with the Topic/Focus features of the constituents. For instance, according to Tánczos (2010), the O-Adv-S-V word order in (17) is driven by the focalization of the subject (which sits in a preverbal focus position) and the topicalization of the object to a sentence initial position. ${ }^{44}$

(17) Tánczos (2010: 224, ex. (4a))

[тор Terminator-ez] kinoteatr-in [FосSaša] ućk-i-z.

Terminator-ACC cinema-INE Sasha watch-PST-3SG

'It was Sasha who watched the Terminator in the cinema.'

Asztalos \& É. Kiss (2016) assume three different focus positions in the Udmurt clause: an immediately preverbal focus position (illustrated above in (17)), a sentence final focus position and a sentence initial focus position, as shown in (18a, b) below, respectively.

\footnotetext{
${ }^{43}$ In contrast to Mitchell (2006), I do not assume a separate AgrP. I also leave aside mood/modality.

${ }^{44}$ A question arises whether the adverbial is also a topic, and more generally, what the position of adverbials in Udmurt is. Tánczos (2010: 226, fn. 8) does not discuss the exact position of the adverbial, and as far as I know, adverbials in Udmurt have not been investigated so far.
} 
Asztalos \& É. Kiss (2016) argue that the sentence initial and the sentence final focus positions have developed under the influence of Russian.

Asztalos \& É. Kiss (2016)
a. Tužges $=$ no ćeber kartina-jez most=ADD beautiful picture-ACC
$d a s^{\prime} a-z$ [FOC Kat'a].
b. [FocKat’a] tužges=no ćeber kartina-jez Katya Katya most $=$ ADD beautiful picture-ACC daśa-z.

'It was Katya who made the most beautiful picture.'

Finally, let us turn to complex clauses. Coordinate clauses in Udmurt are finite, they are marked with the additive clitic no 'also, even' (see Arkhangelskiy 2014 on clitics in Udmurt). ${ }^{45}$ This is shown in (19).

(19) fieldwork 2014, elicited
Kol’a kišnojaśk-i-z=no
korka
pukt-i-z.
Kolya marry-PST-3SG=ADD house[ACC] build-PST-3SG
'Kolya got married and built a house.'

As far as subordination is concerned, Udmurt uses both finite and non-finite subordinate clauses. Winkler (2001: 73) classifies the subordinate clauses into three types: "a) those with a finite verb and a subordinative conjunction resp. relative pronoun, b) those with a finite verb and without a subordinative conjunction resp. relative pronoun, c) those with an infinite verbal form and without a conjunction”. With respect to finite subordination, Tánczos (2016: 22) claims that it is a new development in the language, and it seems to be connected to the OV-VO parametric change.

Leaving aside type (b), i.e. parataxis (but see Klumpp 2016: 555-556), the three major subordinate clause types, namely, relative, adverbial and argument clauses can be finite or non-finite. Finite relative clauses are postnominal and contain a relative pronoun, kudiz 'which-3SG', cf. (20).

\footnotetext{
${ }^{45}$ This clitic should not be confused with the Russian complementizer no 'but' which is also used in Udmurt. It is noteworthy, however, that the clitic is written separately according to the Udmurt orthography. 
(20) Udmurt Corpus (Мынам Удмуртие, 2010.10.12)

$\begin{array}{lllll}\text { šećkila-śko } & \text { kalik-ez, } & \text { kudiz } & \text { ule } & \text { gurt-in. } \\ \text { congratulate-PRS[1SG] } & \text { people-ACC } & \text { which } & \text { live[PRS.3SG] } & \text { village-INE }\end{array}$

'I congratulate (admire/respect) the people who live in villages.'

There are finite adverbial clauses as well. Conditional and concessive clauses are formed with the clitic(s) $=k e$ 'if' and $=k e=n o$ 'although (lit. if even)', respectively, and contain a finite verb. Conditional clauses are illustrated in (21).

(21) Udmurt Corpus (Удмурт дунне, 2008.12.26)

Et $t^{\prime}-i=k e, \quad \quad$ likt $-o-d=a$ ?

invite-PST[1SG]=if come-FUT-2SG=Q

'If I invite(d) [you], will/would you come?'

Finally, finite argument clauses contain the complementizer šuisa. This complementizer is the converb form of the verb šui- 'say'. Analogical complementizers are found in Mari, Tatar, Chuvash and Mongolic languages; it has been argued that the development of the complementizer from the converb form šuisa in Udmurt is a Tatar influence (Bartens 2000: 311). The complementizer šuisa appears at the end of the clause, as shown in (22).

(22) elicited

Mon malpa-śko [ton bert-o-d šuisa].

I think-PRS[1SG] you come.home-FUT-2SG that

'I think you will come home.'

It has been observed that the Udmurt complementizers may be doubled by their Russian counterpart, resulting in structures like (23) (Tánczos 2013). In this example, the sentencefinal complementizer is doubled by the Russian complementizer čto.

(23) Tánczos (2013: 99, ex. (5))

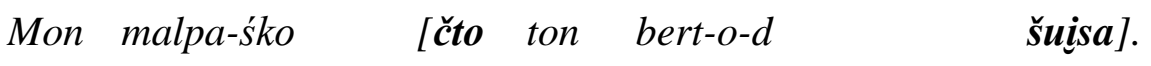

I think-PRS[1SG] that you come.home-FUT-2SG that

'I think you will come home.' 
This is not the only complementizer pair in Udmurt, further examples are jesli $\ldots=k e$ 'if', hot'a ... =ke=no 'although' and raz ... bere 'after (causal)' (Salánki 2007; Shutov 1999; Winkler 2011). Tánczos (2013) examines the syntactic change from sentence-final to sentence-initial complementizers in Udmurt, and, more generally, from OV to VO. She considers the complementizer-doubling a transitional stage in this change.

Having reviewed the main morphological and syntactic properties of Udmurt, I will turn to the description of non-finite clauses in Udmurt. In Chapter 3, I will discuss at length the various types of non-finite clauses: relative, argument and adverbial. Chapter 4 and 5 will be devoted to adverbial clauses entirely. 


\section{Non-finite clauses in Udmurt}

In this chapter I deal with the different non-finite clause types in Udmurt. I illustrate their functions and discuss their morphosyntactic properties. The discussion is based on the existing grammars and descriptive studies, but at the same time, it departs from several assumptions made in the traditional grammars of Udmurt, thus, presenting a novel description. I provide new data, based on which several generalizations made in the literature will be modified. Special attention is given to adverbial subordination, and more specifically, to converb clauses and to various adverbial clauses formed with nominalizations.

As a preamble, a few remarks are in order with respect to what non-finite verb forms and non-finite clauses are. I summarize the most common types of non-finite verbs and the main morphosyntactic properties of non-finite clauses cross-linguistically from typological and theoretical perspectives, as well as the main ideas about finiteness found in recent literature (§3.1). Based on this, I will also propose morphosyntactic and syntactic criteria for distinguishing non-finite clause from finite ones in Udmurt (\$3.2). Then I turn to non-finite verbs in Udmurt and their classification according to the existing descriptions (§3.3). I take a closer look at nominalizations (\$3.4). In §3.5-3.7, I discuss non-finite relative, argument and adverbial clauses.

\subsection{Finiteness in the typological and generative literature}

The traditional approach to finiteness implies that finiteness is a property of the verb (Nikolaeva 2007). Non-finite verbs differ with respect to morphosyntactic and syntactic properties, such as argument structure (including the morphosyntactic encoding of the arguments), expression of TAM and agreement markers, negation, valence and voice distinctions. Accordingly, non-finite clauses are those clauses whose main predicate is a nonfinite verb.

It is cross-linguistically common that non-finite clauses do not form a unified class even in one and the same language. This has been shown for various unrelated languages, for instance Gaelic (Adger 2007), and Kazakh (Ótott-Kovács 2016). It is also possible that one and the same non-finite form is used in several syntactic structures, associated with different syntactic properties (see Bartos 2009 on Hungarian -vA participle; Kazenin \& Testelets 2004 
on Tsakhur converb clauses; Grashchenkov 2017 on -Ip-clauses in several Turkic languages; Abney 1987 and Pires 2006 on English -ing gerunds, a.o.).

In the typological literature, the considerable cross-linguistic variation between nonfinite clauses is not problematic since finiteness is viewed as a scalar concept, determined by a cluster of parameters. These include the loss of verbal properties (such as TAM and agreement morphology) and presence of nominal properties (case-marking, use of determiners, reduced argument structure, etc.). This is often referred to as (morphosyntactic) deranking (the term comes from Stassen 1985, see also Cristofaro 2003, Hetterle 2015, a.o.). The morphosyntactic deranking is motivated by the semantic integration of the events. According to Givón (2001: 328), "the stronger is the semantic or pragmatic connectivity between two events/states, the stronger are the syntactic dependencies between the two clauses that code them", i.e. the degree of semantic integration of the dependent event into the main event correlates with its syntactic dependence.

In generative syntax, the notion of finiteness has been viewed as crucial for the licensing of nominative case on the subject (Chomsky 1981: 50). In recent publications, finiteness is viewed as a sentential property rather than a verbal one (Bianchi 2003; Adger 2007). Moreover, it has been proposed that finiteness is associated with the CP domain (and not the IP/TP domain). Following Rizzi's (1997) influential proposal, it has been assumed the $\mathrm{CP}$ contains several projections, the lowest of which is FinP.

(1) Split CP Hypothesis (Rizzi 1997: 297)

ForceP $>$ TopP* $>$ FocP $>$ TopP* $>$ FinP $(>$ IP)

Bianchi (2003) argues that the Fin head encodes information about the speech event, including both the temporal reference of the event and the participants in the event (the latter being relevant to person agreement). She claims that if Fin $^{\circ}$ is specified for [+finite], it is anchored to the speech event time and it selects for a TP (or AgrP/IP) on which person agreement is realized. Non-finite verbs, on the other hand, are not anchored to the speech event time. Bianchi (2003) proposes the notion of logophoric centre which is understood as a speech or mental event which comprises information about the speaker and the subject of the clause (and the relationship between them, i.e. whether the subject is identical to the speaker, etc.). She argues finite clauses encode the so-called external logophoric centre in the [+finite] Fin head. A [-finite] F head, on the other hand, encodes an internal logophoric centre, 
namely, the matrix clause constitutes the internal logophoric centre for the non-finite clause. This means that the logophoric centre of non-finite clauses is determined anaphorically, i.e. via the logophoric centre of another clause (according to Bianchi, this holds for nonobligatory and obligatory partial control).

Adger (2007: 23) raises the question of whether finiteness can be dispensed with in the grammar altogether. This means that the phenomena traditionally associated with finiteness should be explained in a different way. He adopts Bianchi's (2003) proposal that finiteness is encoded in Fin ${ }^{\circ}$ in the syntactic structure, but in the same time, proposes that "although there is just one way to be finite (which is to be specified as [finite:+]), there is more than one way to be non-finite" (Adger 2007: 26). He argues that the Fin head might be specified as [-finite] or the FinP can be missing altogether. In the latter case, the non-finite clause is truncated, i.e. structurally reduced. Moreover, truncation can take place at different levels, resulting into non-finite TP and non-finite VP clauses, for example. The truncation analysis has also been advocated by Kornfilt \& Whitman (2011), who propose that there are vP, TP and CP nominalizations. Similar ideas have been proposed in Wurmbrand (2001, et seq.) regarding infinitives.

It should be emphasized that some finite subordinate clauses are also said to be truncated. It has been long observed that several adverbial clauses do not show Main Clause Phenomena, such as argument fronting (Haegeman 2003, 2010 and the references therein). One of the possible analysis is that the left periphery of these clauses is reduced (Haegeman 2003). An alternative analysis suggests that there is operator movement, and argument fronting is impossible because it gives rise to an intervention effect (Haegeman 2010).

In the literature, one finds several non-finite verb forms, such as participle, converb, infinitive and nominalization. Comrie \& Thompson's (2007: 334) definition of nominalizations is "turning something into a noun". Under this broad label they assume two main types of nominalizations: activity/state nominalizations and argument (agent, instrument, locative, etc.) nominalizations. The nominalizations denoting activities or states are sometimes called action nominals, masdars, deverbal nouns, complex event nouns, and process nominals (Comrie \& Thompson 2007; Noonan 2007; Koptjevskaja-Tamm 1993; Grimshaw 1990; Haspelmath 1996; Alexiadou 2001 et seq.). The terminology, however, is not fully consistent, and sometimes it is based on the theoretical framework used and/or the language family under investigation. 
Putting the terminological issues aside, what is common in both the typological and the generative literature is that nominalizations are considered to display both verbal and nominal properties. This insight is reflected in Koptjevskaja-Tamm's (1993) typological classification. She proposes that there are different types of nominalizations: Sentential, Possessive-Accusative, Ergative-Possessive and Nominal. The labels of these nominalization types reflect the various degrees of similarity of the nominalization to finite verbs or to nouns. A similar idea is found in the generative literature, too. It has been proposed that nominalizations are mixed-extended projections (Borsley \& Kornfilt 2000; Alexiadou 2001 et seq., a.o.). This means that they contain an extended verbal projection with a nominal layer on top of it.

Non-finite clauses can be classified as relative, adverbial and argument clauses. Ideally, each type of non-finite verb form (participle, converb, nominalization) would be used in only one non-finite clause type. Haspelmath (1996) argues that non-finite verb forms are inflectional forms, moreover, they are formed with word-class-changing affixes. His main idea is that non-finite verb forms preserve the internal syntax of the verb (phrase) while its external syntax changes. Participles, for instance, have an adjective-like external syntax, i.e. modify noun phrases. Converbs, on the other hand, behave like adverbial phrases since they modify verbs. Nominalizations have a noun-like distribution, hence, they can be used as arguments in the main clause. As Ylikoski (2003) observes, the main problem with this approach is that infinitives are missing. Infinitives are very often (diachronically) related to nominalizations, but in many languages the two types of non-finite forms are difficult to tell apart synchronically (Koptjevskaja-Tamm 1993: 33-42). Additionally, converbs are also closely related to nominalizations. As will be shown in this chapter, Udmurt nominalizations are not an exception, they are closely related to other non-finite verb forms, such as converbs and participles.

This short overview of the notion of finiteness is meant to emphasize the following facts. Firstly, non-finite clauses differ from each other in various respects: function (relative, adverbial, argument clauses), morphosyntactic and syntactic properties, such as argument structure, case-marking, expression of TAM categories, clausal structure involved, etc. Based on this, it would not be a surprise to find that non-finite clauses in Udmurt do not constitute a unified group either. As will be shown in this chapter, non-finite clauses in Udmurt indeed represent various types. Moreover, I take the syntactic approach to finiteness: I argue that the differences between the various non-finite clause types are to be explained with differences in 
terms of syntactic structure. In what follows, I point out several morphosyntactic and syntactic properties in which finite and non-finite clauses in Udmurt differ.

\section{2 (Non-)finiteness in Udmurt}

There are several differences between finite and non-finite clauses. The traditional grammars (e.g. GSUJa I 1962) usually mention the following: lack of tense and mood inflection, lack of agreement (or in the case of certain non-finite clauses, its optionality), the impossibility to be used as predicates of main clauses, and the impossibility to be used with the negative verb. Below I illustrate these differences between finite and non-finite clauses, as well as discuss some additional parameters.

In Chapter 2, we saw that verbs in Udmurt are marked for tense. None of the Udmurt non-finite verbs, however, takes tense morphology. Furthermore, finite verbs in Udmurt can be followed by a copula in the analytic past tenses (see \$2.3.2). This is not an option in the case of the non-finite predicates. In Chapter 4, I will be discussing the implications of the lack of tense marking in non-finite clauses, and more specifically, whether this suggests the lack of a TP. The presence of $\mathrm{T}$ is also relevant with respect to the case-marking of subjects.

Finite and non-finite clauses also differ with respect to agreement. As mentioned in Chapter 2, finite clauses, and more specifically, tensed clauses always show subject agreement. The omission of the subject agreement markers leads to ungrammaticality, as shown in (2). In non-finite clauses, however, agreement is either not obligatory or not possible at all. Consider (3) in which the negative converb bears no agreement. (Agreement in non-finite clauses will be discussed later in this chapter, as well as in Chapter 5.)

(2) elicited

$\begin{array}{llll}\text { Pijaš-jos } & \text { čukaźe } & \text { bakća-in } & \text { užal-o-*(zi). } \\ \text { boy-PL } & \text { tomorrow } & \text { garden-INE } & \text { work-FUT-3PL }\end{array}$

'The boys will work in the garden tomorrow.'

(3) fieldwork, spontaneous

Šid-ez [odig pol=no sura-tek] peźt-i.

soup-ACC one times=ADD stir-CVB.NEG cook-PST[1SG]

'I cooked the soup without stirring (it) even once.' 
Furthermore, finite and non-finite clauses differ with respect to the subject's casemarking. In finite clauses, subjects are in the nominative (2). In non-finite clauses, however, there are three options: nominative, genitive or instrumental. Instrumental subjects are illustrated in (4) (nominative and genitive subjects are also exemplified, cf. (6) and (13) below). In sections $§ 3.5-\S 3.7$, I will demonstrate that the case-marking of subjects depends on the non-finite clause type (relative, argument or adverbial).

(4) elicited

[Pet'a-jen tue mertt-em] pispu umoj bude.

Petya-INS this.year plant-NMLZ tree well grow[PRS.3SG]

'The tree planted by Petya is growing well.'

Additionally, the differences between finite and non-finite clause concern negation. In finite clauses, negation is expressed with a special negative verb marked for tense and agreement (§2.3.2). Some non-finite clauses do exhibit negation, but crucially, the negative verb used in finite clauses never appears in non-finite clauses (see $\S 3.3$ and $\$ 3.7 .2 .5$ ).

There are several syntactic properties in which finite and non-finite clauses in Udmurt differ. The first and most important one is that non-finite verbs cannot function as main predicates. ${ }^{1}$

As discussed in Chapter 2, finite clauses in Udmurt can show different word orders: SOV, SVO, VSO, etc. The OSV order results when the subject is in focus and the object is topicalized (Tánczos 2010).

(5) Tánczos (2010: 224, ex. (4a))

$\begin{array}{llll}\text { [тор Terminator-ez] } & \text { kinoteatr-in } & \text { [FoС Saša] } & \text { ućk-i-z. } \\ \text { Terminator-ACC } & \text { cinema-INE } & \text { Sasha } & \text { watch-PST-3SG }\end{array}$

'It was Sasha who watched the Terminator in the cinema.'

Non-finite clauses, on the other hand, are generally head-final with SOV word order. This is supported by the following minimal pair: the SOV order is judged grammatical (6), while the OSV order is degraded (7).

\footnotetext{
${ }^{1}$ There are certain non-finite verbs (e.g. - $(e)$ min and $\left.-(o) n o\right)$ that can be used in predicative position with a (covert) copula (Asztalos 2010; F. Gulyás \& Speshilova 2014; GSUJa I 1962: 266, 268-269; Kelmakov \& Hännikäinen 1999: 96; Winkler 2001: 58).
} 
(6) fieldwork 2014, elicited

[Kol’a kirž́an-ze kiř̆́a-ku] mon so šori ućk-i.

Kolya song-3SG.ACC sing-CVB.SIM $1 \mathrm{SG} \quad 3 \mathrm{SG}$ at look-PST[1SG]

'When Kolya was singing his song, I looked at him.'

(7) fieldwork 2014, elicited

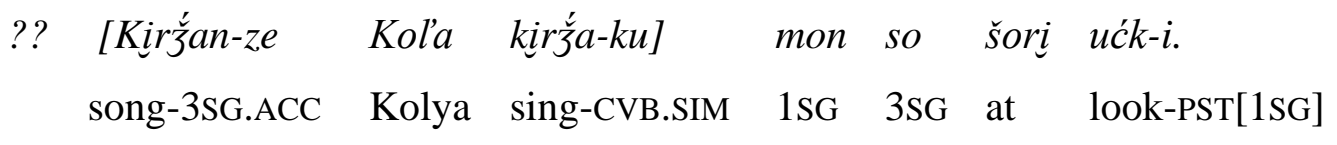

Intended: 'When Kolya was singing his song, I looked at him.'

However, some remarks are in order. Firstly, the head-final nature of non-finite clauses in Udmurt seems to be a very strong tendency, nevertheless, one might occasionally find possible counterexamples, especially from spoken data. In example (8), the locative adverbial korka 'into the house' follows the converb.

(8) fieldwork recording, 2014_07_21, VE, Alnash, Udmurtia
[...] tińi soźi murjo bord-i jêtiśko [pirị-sa korka]
well this.way chimney on-ILL touch[PRS.3PL] go.in-CVB house[ILL]
'Well, (one/they) touch the chimney like this after entering the house.'

It should be noted that native speakers often reject non-head-final non-finite clauses in elicitation tasks or consider them very colloquial. Thus, it seems that non-finite clauses are strictly head-final, as opposed to finite ones where for instance, SVO order is much more acceptable (and frequently attested in corpora, too). Consider also example (9) in which the converb clause shows SVO order, and consequently, the sentence is degraded.

(9) fieldwork 2014, elicited

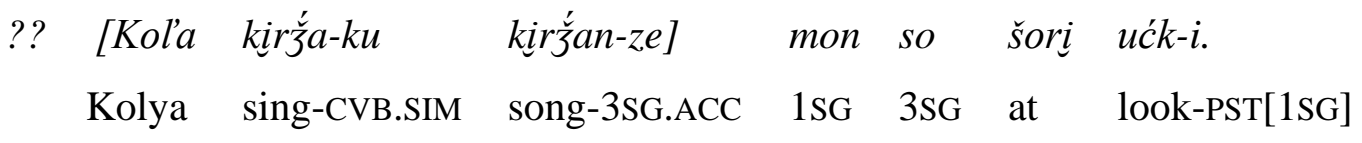

Intended: 'When Kolya was singing his song, I looked at him.'

We have already seen that OSV order is also degraded (7). However, it is possible to 
encounter examples in which a temporal or a place adverbial precedes the subject of the nonfinite clause, cf. (10) and (11). These examples were judged grammatical by my consultants.

(10) Turku-Izhevsk Corpus (Invozho/A/12:66-67)

$\begin{array}{llllll}\text { Šitaźe } & \text { ińi, } & \text { [vaće } & \text { pumit vuilem } & \text { inti-iś } & m i \\ \text { in.the.evening } & \text { already } & \text { two.together } & \text { against battle } & \text { place-ELA 1PL.EXCL } \\ \text { košk-em] } & \text { bere, } & \text { omir-ez } & \text { direkjat-i-zi } & \text { granatomet-jos=no } \\ \text { leave-NMLZ } & \text { after } & \text { air-ACC } & \text { rend-PST-3PL } & \text { grenade.launcher-PL=ADD } \\ \text { tank-jos-iś } & \text { orudi-os. } & & & \\ \text { tank-PL-ELA } & \text { gun-PL } & & & \end{array}$

'In the evening, after we left the place of the battle, the grenade launchers and the guns of the tanks rent the air.'

(11) elicited

\begin{tabular}{|c|c|c|c|c|c|c|c|}
\hline [Gurt-in & ferma & $u \check{a} a-k u]$ & ad'ami-os & gorod-e & $u g$ & koško & val. \\
\hline village-INE & farm & work-CVB.SIM & person-PL & city-ILL & NEG & leave[PRS.3PL] & AUX.PST \\
\hline
\end{tabular}

Perevoshchikov (1959: 216) does not discuss word order in non-finite adverbial clauses, but makes the following observation regarding their overt subjects: they tend to be placed immediately preceding the non-finite predicate. He provides examples in which the subject is preceded by an adverbial. As we have seen, this is fully grammatical according to my data as well, cf. (10) and (11). However, he also provides an example of OSV, for which I argue that it is degraded in non-finite clauses, cf. (7). According to Perevoshchikov (1959), the immediately preverbal position of overt subjects is a tendency, but not a strict rule. Moreover, there are numerous examples in his study that show SOV order. In my view, this undermines his claims. Based on the data presented above, I conclude that there is a significant difference between finite and non-finite clauses with respect to word order.

As mentioned in Chapter 2, recent studies argue that there is an ongoing changed from OV to VO in Udmurt finite clauses. Non-finite clauses, on the other hand, favor SOV (with the proviso that adjuncts can freely precede the subject, as shown in (10) and (11)). It is wellknown that subordinate clauses show more conservative word order (Hooper \& Thompson 1973, a.o.). Hence, it is not surprising that non-finite clauses in Udmurt tend to show SOV 
order. Hetterle (2015: 127-131) discusses word order in adverbial clauses from crosslinguistic perspective. She observes that the most typical case "involves mere enhancement of the rigidity in positioning of $(\mathrm{S},) \mathrm{V}$ and $\mathrm{O}$ rather than true word order change" (Hetterle 2015: 127). This is attested in OV languages like Lezgian and Turkish: their adverbial clauses are more rigidly verb-final. In addition, there are languages that have word order restrictions in individual adverbial constructions, and the general pattern is that main clauses may display different word order, while word order in (certain) adverbial clauses is more rigid (Hetterle 2015: 129).

Additionally, question formation in some non-finite clauses is more restricted. As noted in Georgieva (2017a), questioning a constituent in converb clauses resembles an echo question, cf. (12).

(12) fieldwork 2014, elicited

Context: Pijaš korkaze puktîkuz buskeljosiz soli veme leśto.

'When a/the boy is building his house, his neighbors help him.'

Kin korka-ze pukti-ku- $(z)$ ?

who house-3SG.ACC build-CVB.SIM-3SG

'Building his house who?'

On the other hand, non-finite argument clauses can contain wh-elements (see Serdobolskaya et al. 2012). Sentence (13) exemplifies object clauses with the wh-elements mali 'why' and kitči 'where[ILL]'.

(13) Shutov (1999: 25)

$\begin{array}{llllll}\text { Oźi } & \text { [pop-leś } & \text { mali, kitći } & \text { košk-em-ze] } & \text { nokin } \\ \text { this.way } & \text { priest-ABL } & \text { why } & \text { where[ILL] } & \text { leave-NMLZ-3SG.ACC } & \text { nobody } \\ e z & \text { tod. } & & & & \end{array}$

NEG.PST.3 know[SG]

'In this way nobody found out why and where the priest had left (lit. the priest's why and where leaving).'

Furthermore, I would like to discuss certain particles/clitics. These include kad' 'it seems/as if', vilem (expresses mirativity) and $u k$ 'after all/emphatic'. Based on their 
semantics, I assume that they are in the C domain. They typically follow the main predicate. Arkhangelskiy (2014) demonstrates that the emphatic/focus clitics $i k$ and $u k$ are in complementary distribution: $u k$ cliticizes to the (finite) predicate, whereas $i k$ attaches to (any) other constituent. Based on the Udmurt Corpus, the clitic $u k$ does not occur after adverbial clauses formed with converbs and nominalizations ${ }^{2}$, whereas the clitic $i k$ is often attested, as exemplified in (14), where $i k$ attaches to a -toź-converb.

(14) Udmurt Corpus (Удмурт дунне, 2008.07.16)

Oźi uža-z, [vojna biriti-toź=ik].

this.way work-PST.3SG war end-CVB.LIM=EMPH

'[The girl] worked like this until the war ended.'

Table 1 summarizes the parameters in which finite and non-finite clauses differ in Udmurt. It seems that non-finite clauses differ from finite clauses with respect to the inflectional domain (tense, agreement features, case-marking of arguments) as well as of the C domain (topic/focus, word order, wh-movement, speaker-oriented clitics). Based on this, one might argue that generally non-finiteness in Udmurt can be deduced to the lack of certain properties.

Table 1 Morphosyntactic and syntactic differences between finite and non-finite clauses in Udmurt

\begin{tabular}{|l|l|l|}
\hline & Finite clauses & Non-finite clauses \\
\hline $\begin{array}{l}\text { Tense morphology } \\
\text { (incl. analytic tenses) }\end{array}$ & $\checkmark$ & $\boldsymbol{X}$ \\
\hline Obligatory agreement & $\checkmark$ & $\boldsymbol{X}$ \\
\hline $\begin{array}{l}\text { Negation (with } \\
\text { negative verb) }\end{array}$ & $\checkmark$ & $\boldsymbol{X}$ \\
\hline $\begin{array}{l}\text { Case-marking of the } \\
\text { subject }\end{array}$ & Nom & $\begin{array}{l}\text { Nom/Gen/Ins } \\
\text { (depending on clause type) }\end{array}$ \\
\hline Word order & non-rigid SOV (SVO?) & rigid SOV \\
\hline Question formation & $\checkmark$ & $\checkmark / X$ (depending on clause type) \\
\hline Modal particles/clitics & $\checkmark$ & $X$ \\
\hline
\end{tabular}

2 There are two examples with -sa-converbs used as manner adverbials (\$3.7.2.4), but they come from poems/song lyrics, in which the word order might have been influenced by stylistic reasons. 
Having made these preliminary remarks on finiteness in Udmurt, now let us turn to the detailed presentation of the individual non-finite verb forms and non-finite clause types.

\subsection{Non-finite verbs in Udmurt: a first approximation}

Traditionally, non-finite verb forms in Udmurt have been divided into three main types: participles, converbs and the infinitive (GSUJa I 1962; Winkler 2001; Bartens 2000; Kelmakov \& Hännikäinen 1999). ${ }^{3}$ Table 2 lists all non-finite verb forms discussed in the descriptive grammars. ${ }^{4}$

It is also noteworthy that some non-finite verbs have negative forms, too. Most of the participles are negated with the attributivizing suffix -tem added after the participle suffix. This suffix expresses the absence of a particular quality, and derives adjectives from nouns, for instance šud 'happiness' > šud-tem 'unhappy' (Edygarova 2015: 283-284). The participle $-(e) m$ has a special negative form (-mte). The negative forms are also listed in the table below.

Table 2 The Udmurt non-finite verb forms (according to the traditional grammars)

\begin{tabular}{|c|c|c|c|c|c|c|c|}
\hline Infinitive & $-n i$ & & & & & & \\
\hline $\begin{array}{l}\text { Participles } \\
\text { (negative) }\end{array}$ & 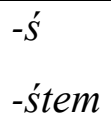 & $\begin{array}{l}-(e) m \\
-m t e\end{array}$ & \multicolumn{2}{|c|}{$\begin{array}{l}\text {-(e)min } \\
\text {-(e)min evell-mte }\end{array}$} & $\begin{array}{l}\text {-mon } \\
\text {-montem }\end{array}$ & $\begin{array}{l}-(o) \text { no } \\
-(o) n t e m\end{array}$ & $\begin{array}{l}-(o) n \\
-(o) n t e m\end{array}$ \\
\hline $\begin{array}{l}\text { Converbs } \\
\text { (negative) }\end{array}$ & $-s a$ & -tek & $-k u$ & -toź & $\begin{array}{l}\text {-mon } \\
\text {-montem }\end{array}$ & $\begin{array}{l}-(e) m i s ́ \\
-m t e i s ́\end{array}$ & $\begin{array}{l}\text {-(e)men } \\
\text {-mtejen }\end{array}$ \\
\hline
\end{tabular}

It should be emphasized that the traditional classification is about non-finite verbal forms rather than non-finite clauses. Moreover, this classification is based on word-classes, which is quite problematic both cross-linguistically and descriptively (Ylikoski 2003). For instance, in Udmurt adjectives do not take any morphological marking in order to be used as adverbs, thus, as Kozmács (2001: 18) points out, it is not surprising that we find homonymous participles and converbs. However, as we will see below, this does not explain all cases of homonymy.

\footnotetext{
${ }^{3}$ The descriptive grammars of Udmurt written in Russian (GSUJa I 1962) use the term deenpuчacmue (adverbial participle), while the non-Russian grammars use the term gerund (Winkler 2001; Kelmakov \& Hännikäinen 1999). Here I use the typological term converb to avoid any potential confusion with English gerunds.

${ }^{4}$ Some of the non-finite suffixes have a slightly different form when used in the two verb conjugations, i.e. in the $-a$-verbs and $-i$-verbs. For instance, the $-i$-verbs take the suffix $-e m$, while the $-a$-verbs are used with the suffix $-m$. In the next subsections, I disregard this morphophonological issue, and mark the allomorph in brackets: $-(e) m$ and $-(o) n$.
} 
In this dissertation, I depart from this traditional classification at several points. Firstly, I propose is that the $-m$-non-finites and the $-n$-non-finites should be included in order to complete the classification of Udmurt non-finite verb forms. These two suffixes are usually discussed in the chapters on derivational morphology, together with other deverbal nominalizers (GSUJa I 1962: 111-114, 117-118). It will be shown that these are nominalizations that express events and have clausal properties (§3.4). Table 3 puts the discussion of Udmurt non-finite verbs into different perspective. As can be seen from the table, the $-m$-non-finites and the $-n$-non-finites can be used as participles (i.e. in non-finite relative clauses), nominalizations (i.e. in argument clauses) and converbs (i.e. in adverbial clauses). ${ }^{5}$

Table 3 The Udmurt non-finite verb forms (revised version)

\begin{tabular}{|c|c|c|c|c|c|c|c|}
\hline Infinitive & $-n \underline{i}$ & & & & & & \\
\hline Participles & $-\dot{S}$ & $-(e) m$ & $-(e) \min$ & -mon & $\begin{array}{l}-(o) n o \\
-(o) n\end{array}$ & & \\
\hline Converbs & $-k u$ & $\begin{array}{l}-(e) m i s ́ \\
-(e) m e n \\
-(e) m j a\end{array}$ & -toź & $-m o n$ & $\begin{array}{l}\text {-(o)nja } \\
\text { (-ońńiga) }\end{array}$ & $-s a$ & -tek \\
\hline Nominalizations & & $-(e) m$ & & & $-(o) n$ & & \\
\hline
\end{tabular}

One way to account for this would be to propose that there are (homonymous) suffixes: -(e) $m_{1},-(e) m_{2},-(e) m_{3}$, for instance. This more or less coincides with the approach advocated in the traditional grammars and in some recent descriptive studies (cf. GSUJa I 1962; Kalinina 2001; Brykina \& Aralova 2012; Serdobolskaya et al. 2012). On the other hand, other studies deal with all -(e)m-non-finites as a group (see Georgieva \& Ótott-Kovács 2016, In Prep. on the morphosyntax of -(e)m-non-finites; Dékány \& Tánczos 2017 on their syntax). In this dissertation, I propose that the distinction between relative, argument and adverbial clauses is more important than the distinction between participles, nominalizations and converbs. Thus, I assume that the very same non-finite forms $-(e) m$ and $-(o) n$ are used in relative, argument

\footnotetext{
5 The distribution of the two nominalizations is not unusual cross-linguistically, and it is also attested in other Uralic languages. For instance, the Ob-Ugric languages pose similar problems: one and the same non-finite form is used in the three different clause types (Nikolaeva 1999; Csepregi 2012; Bíró 2014).
} 
and adverbial clauses. Additionally, some Udmurt converbs originate from nominalizations, and in some cases, it is hard to draw the line between converbs and (case-marked) nominalizations even on the synchronic level (see the discussion in \$3.7.2 and §4.1).

In the next section, I will take a closer look at the two nominalizations (§3.4). Then, I discuss relative, argument and adverbial clauses with special reference to their functions and highlight some of their morphosyntactic properties (\$3.5-\$3.7). Additionally, it should be noted that the existing descriptions do not usually discuss the productivity of the individual non-finite verb forms. I will argue that some non-finite clause types are not productive in today's Udmurt. Moreover, I will propose that some non-finite verb forms should be considered lexicalized forms. I will also make some remarks about dialectal variation.

\subsection{Nominalizations}

In this section, I discuss the two nominalizations, $-(o) n$ and $-(e) m$. First, I summarize the claims made in the literature about them. The $-(e) m$-nominalizations have attracted more attention in the literature that the $-(o) n$-nominalizations.

In GSUJa I (1962: 111-114, 117-118), it is observed that the deverbal nouns formed with the suffixes $-(o) n$ and $-(e) m$ express events/states, and in some cases, result/instrument/agent nouns. An example of this is žećiran that can mean '(event/state of) swinging' or 'swing (object)'. The suffixes $-(o) n$ and $-(e) m$ are discussed together with other deverbal nominalizers denoting the agent or theme. However, they crucially differ from all other deverbal nominalizers since they have clausal properties, which we will discuss next.

Serdobolskaya et al. (2012) demonstrate that $-(e) m$-nominalizations allow for adverbial modifiers like finite clauses and have (full) argument structure. At the same time, these clauses look like possessive constructions: their subject bears genitive/ablative case and the nominalization takes possessive suffixes (the ones used to express alienable possession, see §2.3.1) and case suffixes. The distribution of these nominalizations is also "nouny": they can be used in argument clauses (e.g. subject clauses, object clauses) or as complements of postpositions. However, -(e)m-nominalizations cannot be pluralized, as opposed to nonderived nouns. An illustrative example is given below. 
(15) elicited

Diššetiś-leś dišetskiś-jos-li urok-jos-iz (tros pol) valekt-em-ze

teacher-ABL student-PL-DAT lesson-PL-ACC many times explain-NMLZ-3SG.ACC

/*valekt-em-jos-se vań-zi todo.

/*explain-NMLZ-PL-3SG.ACC all-3PL know[PRS.3PL]

'Everybody knows that the teacher explains/explained the lessons (many times) to the students.'

These properties of -(e)m-nominalizations have been discussed by Dékány \& Tánczos (2017) as well. They propose a formal account according to which these clauses are mixedextended projections. Since these nominalizations show very little nominal structure, Dékány \& Tánczos (2017) argue that there is no nominalizer, but only a DP layer. The subject of the nominalization moves to Spec,DP where it gets genitive case. In their account, $-(e) m$ spells out a verbal projection, possibly a non-finite $\mathrm{T}$.

Serdobolskaya et al. (2012) distinguish between $-(e) m$-nominalizations and $-(e) m$ participles. This approach is supported by the differences with respect to their temporal orientation and the case-marking of their subject. They argue that $-(e) m$-participles always express an event completed before the time of the matrix predicate, while - $(e) m$ nominalizations can express not only an anterior event, but also a simultaneous one when selected by perception verbs. Furthermore, instrumental-marked subjects are licit only with -(e)m-participles. Thirdly, in Beserman Udmurt, only the -(e)m-participles can be negated (in this case, the suffix -mte is used instead of $-(e) m) .{ }^{6}$ Dékány \& Tánczos (2017) do not discuss these differences, but their account of $-(e) m$-participles is the following: these clauses are TP-s without a nominal layer on top of them, and the instrumental subject is an adjunct, similar to by-phrases.

The nominalizations formed with $-(o) n$ - also can express an event/state. ${ }^{7}$ As with $-(e) m$ nominalizations, the $-(o) n$-nominalizations take case suffixes and possessive suffixes. However, the differences between the two types of nominalizations are rather poorly understood. Serdobolskaya et al. (2012) argue that -(o)n-nominalizations show more nominal properties than -(e)m-nominalizations. For instance, they lexicalize into nouns whose meaning is not a process/state/event, for instance vâjâton 'fishing sinker' from the verb vâjâtânô 'sink

\footnotetext{
${ }^{6}$ This is not the case in the dialects I have worked on. Examples of negated nominalizations will be given in $\S 3.6$.

${ }^{7}$ Based on this, I gloss - $(o) n$-nominalizations as vN 'verbal noun'.
} 
(transitive)'. They also mention that $-(o) n$-nominalizations can take plural marking, e.g. č'aklaš'k-on-jos 'problem/worry-VN-PL'. Moreover, they argue that these nominalizations can be used productively as complements of postpositions (i.e. forming adverbial clauses, see below), but have very limited use in argument position: in Beserman Udmurt, they occur only with phasal predicates, as shown in (16).

(16) Serdobolskaya et al. (2012 ex. (96))

[Beserman Udmurt]

\author{
[Dâš-ečkk-on-e] bâr-i-z. \\ study-INTR-VN-1SG end-PST-3SG \\ 'I graduated (lit. My studying ended).'
}

Additionally, Serdobolskaya et al. (2012) discuss the temporal orientation of the two nominalizations. They argue that $-(o) n$-nominalizations are neutral with respect to time reference, while $-(e) m$-nominalizations typically express an action completed before the action described by the matrix clause. Similarly, Klumpp (2016: 562-566) claims that $-(o) n$ is a present participle, while $-(e) m$ is a perfect participle.

Teiermayer (2002) argues that bere 'after' selects for -(e)m-nominalizations, while ponna 'for/in order' combines with $-(o) n$-nominalizations. Similarly, Brykina \& Aralova (2012) propose that the $-(e) m$-nominalizations can be used only with postpositions that express a situation anterior to the matrix event (such as bere 'after' and dirisen '(temporal) since'), but not with postpositions that express a simultaneous or posterior event (such as diroź 'until/before' and dirja 'during'). It also seems that -ABL aźlo 'before' ${ }^{8}$ selects for $-(e) m$ nominalizations. On the other hand, postpositions like aźin 'before' and dirja 'during' are used with -(o)n-nominalizations.

In my view, the generalizations drawn in the literature correctly capture the empirical facts, but nevertheless, some refinements can be made.

Firstly, both -(e)m and $-(o) n$-nominalizations can denote not only events, but also other types of nominalizations, which I list under the label 'non-events'. A couple of examples are given in (17) (based on GSUJa I 1962: 112-114, 117-118).

\footnotetext{
${ }^{8}$ I doubt whether aźlo is indeed a postposition. First of all, its morphological make-up consists of the relational noun $a z$ ' 'front part' (found in $a z ́$-in 'front.part-INE, in front/before') and the attributivizing suffix -lo (see GSUJa I 1962: 144). In fact, aźlo is also used as an adjective/adverbial, meaning 'previous(ly), earlier:ADJ/ADV' (this is also noted in GSUJa I 1962: 311). This "postposition" assigns the ablative to its complement, but this can be explained with the fact that standard NP-s in Udmurt comparative constructions bear ablative, i.e. -ABL aźlo is not an ablative-assigning postposition, but a garden variety comparative construction.
} 
(17)

\begin{tabular}{|l|l|l|}
\hline & Events & Non-events \\
\hline puk- 'sit' & pukon 'sitting' & pukon 'chair' \\
\hline ร̌ećirra- 'swing' & క̌ećiran 'swinging' & ร́ećiran 'swing' \\
\hline ekt- 'dance' & ekton 'dancing' & ekton 'dance' \\
\hline pumiśk- 'meet' & pumiśkon 'meeting' & pumiśkon 'meeting, appointment, date' \\
\hline
\end{tabular}

\begin{tabular}{|l|l|l|}
\hline & Events & Non-events \\
\hline ńula- 'sweat' & ńulam 'sweating' & ńulam 'sweat:N' \\
\hline vera- 'say' & veram 'saying' & veram 'speech, utterance' \\
\hline kill'- 'remain' & kil'em 'remaining' & kil'em 'leftovers' (usually PL) \\
\hline $\begin{array}{l}\text { mertć- 'pierce, } \\
\text { sink' }\end{array}$ & mertćem 'sinking' & mertćem 'splinter' \\
\hline
\end{tabular}

In GSUJa I (1962: 112-114), it is noted that the $-(o) n$-nominalizations occur more often with their 'non-event' meaning. Additionally, their 'non-event' meaning is often instrumental nominalization (in the sense of Comrie \& Thomson 1985), cf. pukon 'chair', while the 'nonevent' $-(e) m$-nominalizations typically encode the result of the action/process. However, the $-(o) n$-nominalizations can also encode events. This is demonstrated by the fact that they can be used as subjects of event-selecting predicates like happen or take place (see Grimshaw 1990), as shown in (18).

(18) elicited

[Pet'a-len vil' korka-ze pukt-on-ez] kema mine $=$ ńi. Petya-GEN new house-3SG.ACC build-VN-3SG for.a.long.time go[PRS.3SG]=already 'Petya has been building his new house for a while now (lit. Petya's building of his new house has been going (on) for a while).'

Also, -(o)n-nominalizations can have a case-marked object, as in the example above, and can be used with aspectual modifiers like kema 'for a long time', as illustrated below (this is also noted by Kelmakov \& Hännikäinen 1999: 184). 
(19) Kelmakov \& Hännikäinen (1999: 184)

Kema puk-on žad’it-i-z.

for.a.long.time sit-VN exhaust-PST-3SG

'Sitting for a long time exhausted (me).'

The presence of a case-marked object is indicative of the presence of argument structure. ${ }^{9}$ Furthermore, vP-adverbs like bidesak 'completely' are also licit (20).

(20) elicited

[Vuž radio-jez bidesak sertt-on] umoj malpan ej val.

old radio-ACC completely disassemble-VN good idea NEG.PST AUX.PST

'It wasn't a good idea to disassemble the old radio completely.

(lit. The disassembling of the old radio completely wasn't a good idea.)'

Moreover, $-(o) n$-nominalizations appear with their internal argument, but without an external one, as in (20) (and numerous examples of this can be found in corpora). As for -(e)m-nominalizations, Serdobolskaya et al. (2012) do not claim that the presence of the external argument is obligatory, but based on the data I have seen, it seems that they tend to occur with both their internal and external argument.

Turning to pluralization, I claim that only 'non-event' nominalizations can be pluralized. To illustrate this, I provide the following minimal pair. Firstly, observe that in the singular, the $-(o) n$-nominalization in (21) has three different readings: alongside the instrument reading, it can denote an event, but it can also denote a manner nominalization (in the sense of Comrie \& Thompson 2007). The -(e)m-nominalization in (22) allows only for the latter two readings.

\section{(21) elicited}

$\begin{array}{llll}\text { Ivan-len } & \text { క̌ećira-n-ez } & \text { anaj-ataj-os-se } & \text { pajmitt-i-z. } \\ \text { Ivan-GEN } & \text { swing-VN-3SG } & \text { mother-father-PL-3SG.ACC } & \text { amaze-PST-3SG }\end{array}$

\footnotetext{
${ }^{9}$ Here I disregard the cases where the object is unmarked (and the nominalization does not have any other adverbs) because they might be cases of synthetic compounding (e.g. truck-driving). Fejes (2005: 158-160) discusses forms like gondir ull'an 'bear-hunting', and claims that this is indeed a compound. He also observes that Udmurt utilizes a syntactic construction in which the object is case-marked, gondir-ez ull'an 'bear-ACC hunting'.
} 
'Ivan's swing amazed his parents.' ('instrument')

'The way in which Ivan was swinging amazed his parents.' ('manner')

'Ivan's swinging amazed his parents.' ('event')

(22) elicited

Ivan-len žećira-m-ez anaj-ataj-os-se pajmit-i-z.

Ivan-GEN swing-NMLZ-3SG mother-father-PL-3SG.ACC amaze-PST-3SG

'The way in which Ivan was swinging amazed his parents.' ('manner')

'Ivan's swinging amazed his parents.' ('event')

In the plural, the event reading is ruled out with both nominalizations, cf. (23) and (24).

(23) elicited

Ivan-len žećíra-n-jos-izz anaj-ataj-os-se pajmit-i-z.

Ivan-GEN swing-VN-PL-3SG mother-father-PL-3SG.ACC amaze-PST-3SG

'Ivan's swings amazed his parents.' ('instrument')

?'The ways in which Ivan was swinging amazed his parents.' ('manner')

*'Ivan's swingings amazed his parents.' ('event')

(24) elicited

Ivan-len žećira-m-jos-izz anaj-ataj-os-se pajmit-i-z.

Ivan-GEN swing-NMLZ-PL-3SG mother-father-PL-3SG.ACC amaze-PST-3SG

'The ways in which Ivan was swinging amazed his parents.' ('manner')

*'Ivan's swingings amazed his parents.' ('event')

Recall that it has been suggested that the two nominalizations differ with respect to their temporal orientation. I believe this generalization to be correct, but there is room for a slight modification. I argue that that the two nominalizations express relative rather than absolute time. According to Klein (1994) and Demirdache \& Uribe-Etxebarria (2004), both tense and aspect relate two times. Tense relates the time of utterance to the time which the utterance is about ('topic time'/'assertion time'). Aspect, on the other hand, relates the topic time/assertion time to the time at which the event takes place ('situation time'/'event time'). 
In light of this, I argue that the temporal differences between $-(o) n$-nominalizations and -(e)m-nominalizations are aspectual since the event expressed with them is ordered with respect to the topic time/assertion time, and not to the utterance time. The contrast between the two can be seen easily in the following examples. In (25) and (26), topic time/assertion time is yesterday. The difference between them is that according to (25), Petya and Masha talked about their intention to buy a puppy. Example (26), on the other hand, implies that at the time of talking, they had already bought a puppy.

(25) elicited

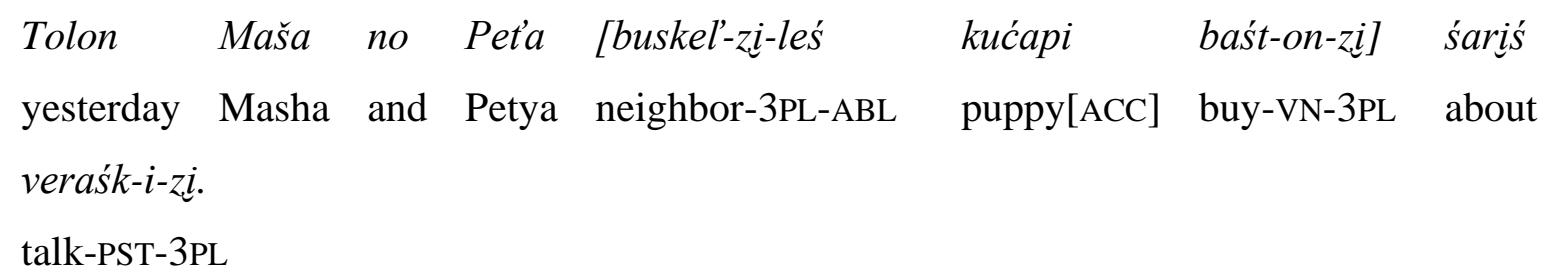

'Yesterday, Masha and Petya talked about buying a puppy from their neighbor.'

(26) elicited

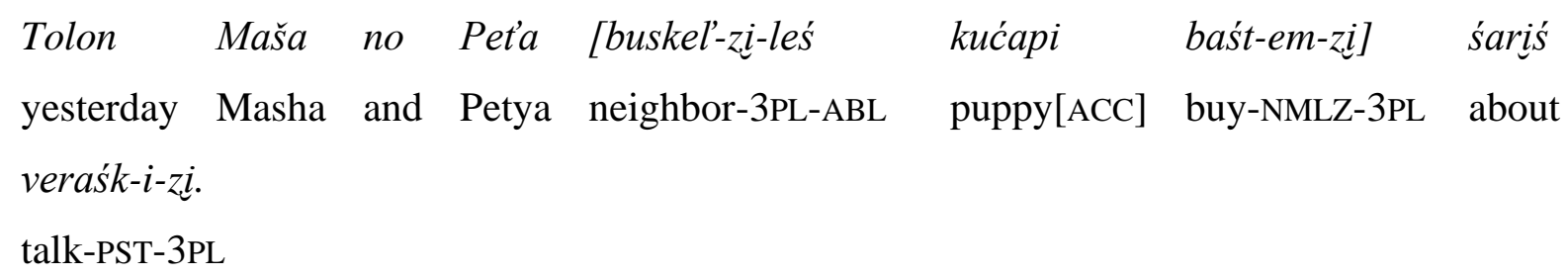

'Yesterday, Masha and Petya talked about how they had bought a puppy from their neighbor.'

Recall also that Serdobolskaya et al. (2012) observe that the -(e)m-nominalization in (27) can have a simultaneous reading since it is selected by a verb of perception. A further piece of evidence that $-(e) m$-nominalizations are not always anterior to matrix event comes from example (28).

(27) Serdobolskaya et al. (2012, ex. (98))

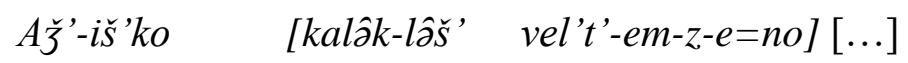

see-PRS[1SG] people-ABL walk-NMLZ-3SG.ACC=ADD [...]

'I see people walk and [...]' 
(28) Georgieva \& Ótott-Kovács (2016: 63, ex. (26))

Soos [mineśtím likkt-em-me] vit'-i-zi.

3PL 1SG.ABL come-NMLZ-1SG.ACC wait-PST-3PL

'They waited/were waiting for me to arrive/my arrival.'

In (28), the arrival has not taken place at the time of the event expressed in the matrix clause. I propose that the meaning is actually 'They were waiting for the moment when my arrival will have taken place', which is compatible with the anterior. In this case, the arrival is ordered before a reference time in the future. In the case of (27), it seems plausible to assume that the simultaneous reading is determined by the perception verb. It has been observed that the complements of perception verbs select for complements that do not have independent temporal reference (cf. Noonan 2007). (As a side note, it should be mentioned the event of walking in (27) might not be completed before the event of seeing, but it has most probably started before it, thus the anteriority is still present.)

As for the distribution of $-(o) n$-nominalizations, they seem to be quite frequent as subject clauses (see the examples presented in this section), but object clauses are also attested (see §3.6). Additionally, postpositions like śariśs 'about' also select for either - $(o) n$ nominalizations or $-(e) m$-nominalizations. Recall that Brykina \& Aralova (2012) and Teiermayer (2002) have argued that the two nominalizations are selected by different postpositions. Brykina \& Aralova's (2012) explanation for this is also fully compatible with the proposal that the two nominalizations express relative time, i.e. aspect.

Based on corpus data from the Udmurt Corpus and Turku-Izhevsk Corpus, however, one can find counterexamples. As mentioned in Georgieva (2017b: 33), the postposition intije 'instead', for example, is attested with both types of nominalizations. Even the temporal postpositions, such as ażin 'before' may be used not only with -(o)n-nominalizations, but also with -(e)m-nominalizations, cf. (29) and (30) below.

(29) Udmurt Corpus (Удмурт дунне, 2013.06.14)

[Vil' už bordị kutsk-on] aźin nịriśs vań-ze radjale,

new work to start-VN before first everything-3SG.ACC organize[IMP.2PL]

ćotale, $\quad$ mertale.

count[IMP.2PL] measure[IMP.2PL]

'Before starting a new project, first consider (lit. organize, count and measure) every detail.' 
(30) Udmurt Corpus (Удмурт дунне, 2010.01.22)

[Sereg baśt-em-di] aźin odno=ik kure aźvil

corner[ACC] buy-NMLZ-2PL before by.all.means ask[IMP.2SG] previous

kuźo-jez-leś dokument-jos-se.

owner-3SG-ABL document-PL-3SG.ACC

'Before you buy a property (lit. a corner), you should by all means get its documents from the previous owner.'

Examples (29) and (30) are similar to each other since they both describe hypothetical situations, and not factual ones. ${ }^{10}$ But even with factual situations, one might find examples of aźin 'before' with -(e)m-nominalizations (31).

(31) Udmurt Corpus (Иднакар, 2015.04.10)

$\begin{array}{llllll}\text { Noš } & \text { [diplom } & \text { baśt-em-ez] } & \text { aźin, } & 4-t i k u r s-i s ́ e n & \text { eššo, kišnojaśk-i-z. } \\ \text { but } & \text { degree[ACC] } & \text { receive-NMLZ-3SG } & \text { before } 4^{\text {th }} \text { year-EGR } & \text { only marry-PST-3SG }\end{array}$

'But before he graduated, only as a fourth-year student, he got married.'

Based on this evidence, it seems that the two nominalizations are not in complementary distribution when used with postpositions and relational nouns. Rather, it seems that this is a strong tendency, but not a strict rule.

To conclude, it seems that the differences between the nominalizations formed with $-(e) m$ and $-(o) n$ are related to their argument structure, temporal reference and syntactic distribution. The two nominalizations can be used in several constructions, see Table 4.

Table 4 The syntactic distribution of $-(e) m$ - and $-(o) n$-nominalizations

\begin{tabular}{|l|l|l|}
\hline & $-(e) m$-nominalization & $-(o) n$-nominalization \\
\hline relative clauses & $\checkmark$ & $\checkmark$ \\
\hline argument clauses & $\checkmark$ & $\checkmark$ \\
\hline adverbial clauses & $\checkmark$ & $\checkmark$ \\
\hline modal constructions & $\checkmark$ & $\checkmark$ \\
\hline passive construction & $\checkmark$ & \\
\hline evidential & $\checkmark$ & \\
\hline
\end{tabular}

${ }^{10}$ Thanks to Krisztina Szécsényi for pointing out this fact. 
In the next section, I will focus on relative, argument and adverbial clauses. It should be emphasized that the description of non-finite relative and argument clauses is not mean to be detailed since this dissertation is primarily concerned with non-finite adverbial clauses. Nevertheless, it is important to discuss relative and argument clauses in order to highlight certain differences between these three different clause types. Among non-finite relative and argument clauses, I focus only on the ones headed by $-(e) m$ and $-(o) n$. I focus on the functions and morphosyntactic properties of the three clause types. These include the subject's casemarking and agreement. A clarification is in order: as mentioned above, the two nominalizations take possessive suffixes that refer to the subject. Thus, I use the term 'agreement' to cover the possessive suffixes used on nominalizations.

The discussion of modal constructions (formed with the verbs van' 'exist', pote 'go out/appear/seem/want' and lue 'be (possible)') goes beyond the scope of the present dissertation (but see Winkler 2001: 47-48, 53, 68; Kelmakov \& Hännikäinen 1999: 208-209, 211-213; GSUJa II 1970: 115-116). I also leave aside the evidential (cf. §2.3.2) and the socalled 'resultative participle' -(e)min. The descriptive works (e.g. GSUJa I 1962: 268-269) mention that this participle can be used only in a predicative position (sometimes accompanied by a copula), but not in an attributive position, i.e. as a prenominal relative clause. Based on this, it is dubious whether this is indeed a participle. Furthermore, Asztalos (2010) and F. Gulyás \& Speshilova (2014) convincingly show that this non-finite verb form should be considered a passive construction.

\subsection{Non-finite relative clauses}

As mentioned in Chapter 2, both finite and non-finite relative clauses are used in Udmurt. Non-finite relative clauses are prenominal and do not contain a relative pronoun, while finite relative clauses are postnominal with a relative pronoun. According to the descriptive grammars, non-finite relative clauses are headed by participles. The participles were listed in Table 2 (§3.3). The traditional classification of Udmurt participles is based on their active/passive meaning and/or their temporal orientation (present, past, future) (GSUJa I 1962; Kalinina 2001). Typologically, relative clauses might differ with respect to the positions they can relativize on the Accessibility Hierarchy (Keenan \& Comrie 1977). The Accessibility Hierarchy shows the accessibility of NP positions in main clauses to relativization cross-linguistically, and the positions are ranked in the following order from 
most accessible to least accessible, cf. (32). Hence, there might be participles that can relativize only subject NPs or participles that can relativize subject and object NPs, etc.

(32) The Accessibility Hierarchy (Keenan \& Comrie 1977)

$\mathrm{SU}>\mathrm{DO}>\mathrm{IO}>\mathrm{OBL}>\mathrm{GEN}>\mathrm{OCOMP}^{11}$

Turning to -(e)m-participles, Kalinina (2001: 86-88, 90-103) claims that they are either passive or active and it has past time reference. She distinguishes three types of $-(e) m$ participles: passive participles formed from transitive verbs (33a), active participles formed from transitive verbs (33b) and active participles formed from intransitive verbs (33c).

(33) Kalinina (2001: 90, 95, 98)

a. [puni ku-leś vur-em] iźi

dog fur-ABL sew-NMLZ hat

'(a/the) hat sewn from/of dog fur'

b. [kalik ponna ulem-zes śot-em] ad'ami-os

people for life-3PL.ACC give-NMLZ person-PL

'(the) people who have sacrificed their lives for the others'

c. [šuš kuara-leś kǐškaśk-em] val

scary voice-ABL be.scared-NMLZ horse

'(a/the) horse that got scared by a/the scary voice'

Based on (33a, b, c), it seems that the relativization can target either subjects or objects (Brykina \& Aralova 2012; Georgieva \& Ótott-Kovács 2016). However, in Georgieva \& ÓtottKovács (In Prep.), we point out that all intransitive verbs in Kalinina's (2001) study are unaccusatives. Relative clauses with unergative verbs are strongly degraded, as shown in (34).

(34) Georgieva \& Ótott-Kovács (In Prep., elicited)

?? [diskoteka-in ekt-em] nil

disco-INE dance-NMLZ girl

Intended: '(a/the) girl who danced in the disco'

${ }^{11} \mathrm{SU}=$ subject, $\mathrm{DO}=$ direct object, $\mathrm{IO}=$ indirect object, $\mathrm{OBL}=$ oblique case arguments, $\mathrm{GEN}=$ (genitive) possessor, OCOMP = object of comparison. 
Dékány \& Tánczos (2017) also propose that the relativization can target only internal arguments, and in certain exceptional cases, it might target subjects that measure out the event, as in a learned man. Furthermore, Kalinina (2001) mentions that type (33b) is less frequent. In Georgieva \& Ótott-Kovács (In Prep.), we argue that the examples of type (33b) presented in Kalinina (2001) have a rather idiomatic meaning, and do not denote an event with an episodic reading. Based on this evidence, we conclude that $-(e) m$-participles can relativize only internal arguments.

Additionally, Brykina \& Aralova (2012) claim that in Beserman Udmurt, it is also possible to relativize indirect objects, instrument and locative adverbials. The relativization of locative adverbials is illustrated in (35).

Brykina \& Aralova (2012, ex. (145))

[Beserman Udmurt]

$\begin{array}{lllll}\text { [Mânam } & \text { ul-em] } & \text { korka-je sâle } & \text { šur dor-ân. } \\ \text { 1SG.GEN live-NMLZ house-1SG stand[PRS.3SG] } & \text { river next-INE } \\ \text { 'The house where I lived is next to the river.' } & \end{array}$

Different claims have been made in the literature regarding the morphosyntax of the non-subject relative clauses formed with $-(e) m$. Firstly, the presence of an overt subject and/or agreement in them is by no means obligatory: very often the subject is covert. In this case, it has an arbitrary interpretation, as in (33a). If the subject is overt, there are several possibilities. Table 5 summarizes the patterns discussed in the literature. Illustrative examples are given below.

Table 5 Morphosyntactic patterns in non-subject relative clauses headed by $-(e) m$

\begin{tabular}{|c|c|c|}
\hline Subject's case & Agreement & Example \\
\hline Gen & $\begin{array}{c}\text { yes } \\
\text { (on the head noun) }\end{array}$ & $(35),(36)$ \\
\hline Gen & no & $(37)$ \\
\hline Ins & no & $(38)$ \\
\hline Nom & no & $(39)$ \\
\hline
\end{tabular}


(36) elicited

[Pet'a-len tue mertt-em] pispu-ez umoj bude.

Petya-GEN this.year plant-NMLZ tree-3SG well grow[PRS.3SG]

'The tree planted by Petya is growing well.'

(37) Dékány \& Tánczos (2017)

[Kill'em ar-in peśataj-len pukt-em] korka tunne క̌ua-z.

last year-INE grandfather-GEN build-NMLZ house today burn-PST.3SG

'The house built by grandfather last year burned down today.'

(38) elicited

[Pet'a-jen tue mertt-em] pispu umoj bude.

Petya-INS this.year plant-NMLZ tree well grow[PRS.3SG]

'The tree planted by Petya is growing well.'

(39) Kalinina (2001: 88)

Šići sil' utća-ni mini-sa [kion kut-em] iž

fox meat[ACC] look.for-INF go-CVB [wolf[NOM] catch-NMLZ] sheep[ACC]

šed't-em.

find-EVID[3SG]

'The fox went hunting and found a/the sheep caught by the wolf.'

In Georgieva \& Ótott-Kovács (2016), we argue that the most common pattern is the one illustrated in (35)-(36). This pattern is problematic in terms of locality since the possessive suffix does not appear on the non-finite predicate, but on the head noun. Similar relative clauses are found in several Eurasian languages, for instance in Northern Khanty, Mansi, Kazakh, Kirghiz, Uyghur, Uzbek, Buryat and Daghur (Nikolaeva 1999; Kornfilt 2005, 2015). As for the Udmurt data, it is unclear whether the genitive-marked noun in (36) is indeed a subject, and not simply a possessor. As mentioned in Georgieva \& Ótott-Kovács (2016: 56), examples like (36) are ambiguous: Pet'a-len 'Petya-GEN' can be interpreted either as a subject or as a possessor. In the latter case, the sentence means 'Petya's tree planted this year'. 
Moreover, agreement cannot be marked on the non-finite predicate, cf. (40) (Georgieva \& Ótott-Kovács 2016). (As will be shown in \$3.6, non-finite argument clauses headed by $-(e) m$ differ from relative clauses with respect to the placement of agreement.)

(40) Georgieva \& Ótott-Kovács (2016: 55, ex. (6))

*[tue mertt-em-mi] pispu-os

[this.year plant-NMLZ-1PL] tree-PL

Intended: 'the trees planted by us this year'

Example (40) was unanimously rejected by our consultants who represent the Northern, Central, Southern and Southern Peripheral dialects. However, Brykina \& Aralova (2012) present one piece of data from the Beserman dialect in which agreement is marked on the non-finite predicate. Example (41) contrasts sharply with (40).

(41) Brykina \& Aralova (2012: ex. (173))

[Beserman Udmurt]

[Kwaštt-em-ed] jablok-ed jun českât.

dry-NMLZ-2SG apple-2SG very tasty

'The apples that you dried are very tasty.'

Brykina \& Aralova (2012) argue that agreement can be marked on the non-finite predicate only if the subject of the relative clause is covert. They provide a minimal pair of (41) with the personal pronoun you in the instrumental, which is judged ungrammatical by their informants. However, they do not provide examples with a genitive-marked subject and agreement on the non-finite predicate. It is unclear to me whether the ungrammaticality is to be explained with the overtness of the subject, as claimed by Brykina \& Aralova (2012), or with its case-marking (since instrumental-marked subjects in relative clauses do not trigger agreement). Additionally, Brykina \& Aralova (2012) do not discuss the fact that the head noun in (41) also bears a $2 \mathrm{SG}$ possessive suffix. Hence, it is hard to draw conclusions about this pattern, and more generally, about possible dialectal variation with respect to agreement in non-finite relative clauses. As far as I can see, Brykina \& Aralova's (2012) data suggest that the pattern with genitive-subject and agreement on the head noun is attested in Beserman Udmurt, cf. (35), as well as the pattern with instrumental-marked subject and no agreement. 
Regarding instrumental-marked subjects, it can be speculated whether this pattern has emerged due to Russian influence: in Russian passive constructions, the agent is assigned the instrumental case (Georgieva \& Ótott-Kovács 2016). ${ }^{12}$ Brykina \& Aralova (2012) also suggest that this pattern is probably influenced by Russian (and according to them, it is less frequent in Beserman Udmurt). While most studies (Brykina \& Aralova 2012; Dékány \& Tánczos 2017; Georgieva \& Ótott-Kovács 2016; Kalinina 2001) present examples with animate agentive subjects (for which both genitive and instrumental are acceptable), to my knowledge, [-agentive] subjects have not been discussed. According to my data, they can bear instrumental case, as witnessed in (42a), but are degraded with the genitive case (42b).

(42) elicited
a. [zor-en miśk-em] śures
rain-INS wash-NMLZ road
b. ??[zor-len miśk-em] śures-ez
rain-GEN wash-NMLZ road-3SG
'the road washed by the rain'

As for the pattern illustrated in (39), it has been claimed that the subject of Udmurt nonfinite relative clauses can bear nominative case (see Kalinina 2001: 88 and Timerxanova 2011: 264-265 for Standard Udmurt; Brykina \& Aralova 2012 and Serdobolskaya et al. 2012 for Beserman Udmurt). According to Brykina \& Aralova (2012), this pattern is marginal in Beserman Udmurt (and they do not illustrate it). It is noteworthy that the above-mentioned studies provide only a handful of examples of this pattern. Moreover, they seem to come from older texts: Kalinina (2001) cites Udmurt vižikiljos [Udmurt fairytales], published in 1920 as the source of example (39). ${ }^{13}$ More importantly, this pattern has been marked as ungrammatical in today's Udmurt (Georgieva \& Ótott-Kovács 2016: 56). One can speculate whether we are dealing with a diachronic change, however, this question goes beyond the aims of the current dissertation.

Let us now turn to the participles $-(o) n$ and $-(o)$ no. The participle $-(o) n$ is said to have future/present temporal orientation or can express habitual action (Brykina \& Aralova 2012).

\footnotetext{
12 The passive construction with -(e)min can also optionally have an instrumental-marked agent, and this is also said to be influenced by Russian (Asztalos 2010; F. Gulyás \& Speshilova 2014).

13 A very similar example, in which the main clause differs minimally, but more importantly, the non-finite relative clause is the same, is also found in Munkácsi (1881: 254).
} 
Additionally, the future/deontic participle in $-(o)$ no is also used. ${ }^{14}$ In this case, the attributivizing suffix $-o$ is added to the non-finite verb. This attributivizing suffix is used to derive adjectives from nouns: šud 'happyness' > šud-o 'happy' or gon 'fur' > gon-o 'with fur'. Brykina \& Aralova (2012) argue that in Beserman Udmurt, the attributivizing suffix is optional. According to them, this participle can relativize several syntactic functions except for subject, i.e. direct object, indirect object (43), as well as adverbials (44).

Brykina \& Aralova (2012, ex. (156))

[Beserman Udmurt]

[Mânam jurt-on-o] abi-e pereš'.

1SG.GEN help-VN-ATTR grandmother-1SG old

'The grandmother whom I help is old.'

$$
\text { Brykina \& Aralova (2012, ex. (157)) [Beserman Udmurt] }
$$

[Val-ez š'užja-n] sânan-ze Vaš’a âst-i-z.

horse-ACC clean-VN comb-3SG.ACC Vasya loose-PST-3SG

'Vasya lost his comb with which he brushes the [mane of the] horse.'

Dékány et al. (2017) argue that this participle can relativize subjects, as long as the subject is an internal argument, compare the following two examples:

(45) Dékány et al. (2017)

\section{a. ?(?)[čukaźe kirř́-an-o] pijaš tomorrow sing-VN-ATTR boy}

'the boy who has to sing tomorrow'

b. [sojaz arńa-in vu-on-o] kuno next week arrive-VN-ATTR guest 'the guest to arrive next week'

Brykina \& Aralova (2012) claim that the participles in -(o)no do not necessarily express deontic modality. Dékány et al. (2017), on the other hand, argue that the term 'future

\footnotetext{
14 According to GSUJa I (1962: 266) the -(o)no-participle should be distinguished from the impersonal verbs expressing obligation (“безличные глаголы должествования”). Winkler (2001: 58) and Kelmakov \& Hännikäinen (1999: 96) suggest that this participle can be used either in adnominal position or as a predicate.
} 
participle' is probably a misnomer since these relative clauses have a deontic meaning. Brykina \& Aralova's (2012) arguments are based on the fact that certain -(o)no do not have a deontic meaning: jaratono 'beloved/favorite' (and not 'the one that must be loved') and gažano 'respected/honoured' (and not 'the one that must be respected'). These are, however, lexicalized forms.

According to Dékány et al. (2017), the subject in non-subject relative clauses headed by $-(o)$ no bears the genitive case, and there is no agreement, as shown in (46). As can be seen from the Beserman example in (43), agreement can be marked on the head noun.

(46) Dékány et al. (2017)

$\begin{array}{lllll}\text { [čukaźe povar-len kall'en pǐz-on-o] } & \text { sil' } \\ \text { tomorrow chef-GEN slowly cook-VN-ATTR meat }\end{array}$

'the meat to be cooked slowly by the chef tomorrow'

\subsection{Non-finite argument clauses}

Non-finite argument clauses in Udmurt are headed by infinitives or nominalizations.

The infinitive -ni is used with motion verbs, as well as with modal, emotive and aspectual (/phasal) predicates, such as kutskini 'to start', bigatini 'can, be able', kule 'must', jara 'be allowed', turttini 'to try, strive, have a goal, endeavor', tîršinin 'to try, make efforts, do one's best', jaratini 'to love', etc. (cf. Serdobolskaya et al. 2012). Infinitives are also used in the periphrastic causative construction formed with the verb kosini 'to order' (Tánczos 2016), as shown in (47). ${ }^{15}$

(47) fieldwork recording, 2014_08_11, TS, Balezino district, Udmurtia gužem todi-śko=na $\langle\mathrm{P}\rangle$ [t’ut’u voźma-n] kosi-ll-o val. summer know-PRS[1SG]=still chick[ACC] take.care-INF order-FREQ-PRS.3PL AUX.PST 'I still remember that in summer they used to make me take care of the chicks.'

\footnotetext{
${ }^{15}$ In many dialects of Udmurt, the suffix of the infinitive is $-n$ instead of $-n i$, as in (47). Thus, the dialectal infinitive is homonymous with the - $(o) n$-nominalization. This homonymy can be observed only in the case of the $a$-verbs; in the case of the $i$-verbs, the dialectal infinitive is also $-n$, but the nominalization if formed with the suffix -on. Moreover, - $(o) n$-nominalizations and infinitives clearly have a different distribution, for instance, only infinitives can be used in causative constructions. However, it is worth mentioning that historically, the infinitive is reconstructed as a deverbal nominalizer $*_{-} n V$ bearing lative case (Bartens 2000: 228).
} 
The infinitive does not take possessive suffixes and case suffixes. It cannot be negated, it cannot have an independent subject and it shows subject or (direct) object control (Serdobolskaya et al. 2012; Klumpp 2016: 560-562).

The two nominalizations are used with todini 'to know sth/about sth; to find out sth', šumpotini 'to be happy about something', adš́ini 'to see', vit’ini 'to wait (for something to happen)', etc. Nominalizations used in argument positions look like possessive constructions: their subject bears the genitive and there is agreement on the non-finite predicate (Dékány \& Tánczos 2017; Georgieva \& Ótott-Kovács 2016; Serdobolskaya et al. 2012). This is shown in example (48), where the negated counterpart of $-(e) m$, -mte heads a subject clause. Consider also example (49) which differs from (48) in two respects: it doesn't have a genitive subject but a nominative one, and there is no agreement on the non-finite predicate. However, this leads to ungrammaticality.

(48) Shutov (1999: 27), elicited

$\begin{array}{lllll}\text { [Dangir-len } & \text { śurlo-ze } & \text { śoti-mte-jez] } & \text { nilaš-li } & \text { jara-z. } \\ \text { Dangyr-GEN } & \text { sickle-3SG.ACC } & \text { give-NMLZ.NEG-3SG } & \text { girl-DAT } & \text { appeal-PST.3SG }\end{array}$

'The girl liked (the fact) that Dangyr did not give his sickle.'

(49) elicited, based on Shutov (1999: 27)

\begin{tabular}{|c|c|c|c|}
\hline *[Dangir & śurlo-ze & śoti-mte] & $n i l a \check{s}-l i$ \\
\hline Dangyr & sickle-3SG.ACC & give-NMLZ.NEG & appeal-PST.3sG \\
\hline
\end{tabular}

Object clauses also look like possessive constructions. Recall that if the possessive phrase is assigned accusative case, the possessor bears the ablative case instead of the genitive case (§2.3.1). This also happens in non-finite clauses used as object complements, cf. (50).

(50) Georgieva \& Ótott-Kovács (in Prep., elicited)

\begin{tabular}{|c|c|c|c|}
\hline [Diššetiś-leś & pirr-poć & valekt-em-ze] & todi-śko. \\
\hline teacher-ABL & lesson-ACC in.detail & explain-NMLZ-3SG.ACC & know-PRS[1SG] \\
\hline
\end{tabular}


Based on this evidence, it seems that non-finite argument clauses are like possessive constructions, and it can be argued that they are nominalized (Dékány \& Tánczos 2017; Georgieva \& Ótott-Kovács 2016; Serdobolskaya et al. 2012). More specifically, Dékány \& Tánczos (2017) propose an analysis according to which -(e)m-non-finite used in argument position are mixed-extended projections (along the lines of Borsley \& Kornfilt 2000, a.o.). The genitive case is licensed by the $\mathrm{D}$ head that caps off the extended verbal projection (which is a TP according to Dékány \& Tánczos 2017). The fact that non-finite argument clauses display the 'genitive-ablative alternation', i.e. the possessor is marked for ablative, and not for genitive, if the possessum bears accusative case, just like in regular possessive constructions, also supports the mixed-extended projection analysis. This case alternation is problematic for any theory of case (for a possible account see Assmann et al. 2014), but in principle, the analysis proposed for possessed DPs can be extended to cover non-finite argument clauses since they pattern with possessive constructions. (As will be shown in $\$ 3.7$, non-finite adverbial clauses show a morphosyntactic pattern that does not pattern with regular possessive constructions.)

The $-(o) n$-nominalizations used in argument position behave in a similar way: the subject (if overt) must be in the genitive/ablative case. Two representative examples of subject and object clauses headed by $-(o) n$-nominalizations are given below.

(51) Vasilyev, N. V. 1969, “Kin ton, ataj?”, p. $35^{16}$

Gožtet-in vera-min [Šapovalov-len $k u$ vu-on-ez].

letter-INE say-PASS Shapovalov-GEN when arrive-VN-3SG

'In the letter it is written when Shapovalov is due to arrive (lit. Shapovalov's when arrival).'

(52) Udmurt Corpus (Удмурт дунне, 2008.11.19)

[Kuaź-leśs kiče lu-on-ze] vaź čukna=ik šẹde=ńi. weather-ABL what.kind be-VN-3SG.ACC early morning=EMPH feel[PRS.3SG]=already 'Early in the morning, [s/he] already feels/knows what the weather will be.'

There are certain non-finite argument clauses that seem to deviate from the abovedescribed strategy. The first exception is found in object complement clauses (53).

\footnotetext{
16 This novel is available online at: http://elibrary.unatlib.ru/handle/123456789/7319 (Retrieved: 2018-02-01.) 
(53) Georgieva \& Ótott-Kovács (2016: 63, ex. (28))

$\begin{array}{lll}\text { [Proverka } & \text { ortć-em]-ez } & \text { vit'-on-o. } \\ \text { examination } & \text { be.over-NMLZ-ACC } & \text { wait-VN-ATTR }\end{array}$

'One has to wait for the examination to be over.'

In (53), the agreement is not present and the subject is in the nominative. I argue that the "subject" of the nominalization is in fact the non-head of a deverbal compound (Georgieva 2016a). This is supported by the following evidence: the "subject" cannot be a pronoun or proper noun; it cannot be pluralized; it does not pass the anaphora test (i.e. a finite relative clause cannot refer to it); it cannot be modified or questioned; and no modifiers can intervene between the "subject" and the non-finite predicate. The latter test is illustrated in (54).

(54) Georgieva (2016a: 85, ex. (16))

*[Proverka kall'en ortć-em]-ez vit'-on-o.

examination slow(ly) be.over-NMLZ-ACC wait-VN-ATTR

Intended: 'One has to wait for the examination to be over slowly.'

Thus, object clauses like (53) are not an exception, and the generalization that object clauses must be nominalized can be maintained. We have already seen that subject clauses must be nominalized, too. Based on this, it is tempting to extend this generalization to all argument clauses. The problem is that one can find examples of non-nominalized argument clauses, especially in the case of dative argument clauses or non-finite clauses selected by subcategorized postpositions (pace Dékány \& Tánczos 2017 and Serdobolskaya et al. 2012 who present only examples of nominalized argument clauses). In (55), the subject niliz 'his daughter' is in the nominative case, and not in the genitive case.

(55) Turku-Izhevsk Corpus (Kenesh/G/9:583)

[Nil-iz vordsk-em-li] $\quad$ šumpot-em intije [...]

daughter-3SG be.born-NMLZ-DAT be.happy-NMLZ instead

'Instead of being happy about the fact that his daughter was born [...]' 
It should be noted that the acceptability of (55) varies among speakers (as reported in Georgieva 2016a). According to my data, the nominalized version of (55), (56) is grammatical for all speakers.

(56) elicited

[Nil-iz-len vordsk-em-ez-li] $\quad$ sumpot-em intije [...]

daughter-3SG-GEN be.born-NMLZ-3SG-DAT be.happy-NMLZ instead

'Instead of being happy about the fact that his daughter was born...'

In sum, it can be concluded that the general pattern in argument clauses is the nominalized one. This is summarized in Table 6.

Table 6 Morphosyntactic patterns in non-finite argument clauses

\begin{tabular}{|c|c|c|c|}
\hline & Subject's case & Agreement & Example \\
\hline Subject clauses: & Gen & yes & $(48),(51)$ \\
\hline Object clauses: & Abl & yes & $(50),(52)$ \\
\hline Other arguments: & Gen & yes & $(56)$ \\
\hline & ?Nom & no & $(55)$ \\
\hline
\end{tabular}

\subsection{Non-finite adverbial clauses}

Before turning to adverbial clauses in Udmurt, I provide an overview of adverbial clauses from cross-linguistic perspective, based on Kortmann (1996), Givón (2001), Hetterle (2015) and Thompson et al. (2007). Additionally, the main properties of converbs will be discussed.

\subsubsection{Typological overview of adverbial clauses}

Subordinate clauses encompass complement clauses which are used as arguments of a main clause predicate, relative clauses, which modify a noun and adverbial clauses, which modify a verb phrase or main clause (Thompson et al. 2007: 238). Adverbial clauses, however, pose some difficulties with respect to the criteria for subordination (for an overview see Hetterle 2015: 23-46). These problems are related to the fact that adverbial clauses are not arguments of the main predicate, as opposed to complement clauses which are embedded into the main clause. Additionally, the cross-linguistic diversity of adverbial clauses is significant: both their morphosyntactic properties and functions vary considerably across languages. 
Adverbial clause can have several functions with respect to the main clause. Kortmann (1996) groups them into four main types: 'Time', 'Causal-Conditional-Concessive', 'Modal' and 'Other' which are further divided into various adverbial relations. ${ }^{17}$

Table 7 Adverbial relations (Kortmann 1996: 80-81)

\begin{tabular}{|c|c|}
\hline \multicolumn{2}{|l|}{ A. Time } \\
\hline SIMULTANEITY OVERLAP & 'when' \\
\hline SIMULTANEITY DURATION & 'while' \\
\hline SIMULTANEITY CO-EXTENSIVENESS & 'as long as' \\
\hline ANTERIORITY & 'after' \\
\hline IMMEDIATE ANTERIORITY & 'as soon as' \\
\hline TERMINUS A QUO & 'since' \\
\hline POSTERIORITY & 'before' \\
\hline TERMINUS AD QUEM & 'until' \\
\hline CONTINGENCY & 'whenever' \\
\hline \multicolumn{2}{|c|}{ B. CCC (causal, conditional, concessive and related interclausal relations) } \\
\hline CAUSE/REASON & 'because' \\
\hline CONDITION & 'if' \\
\hline NEGATIVE CONDITION & 'unless' \\
\hline CONCESSIVE CONDITION & 'even if' \\
\hline CONCESSION & 'although' \\
\hline CONTRAST & 'whereas' \\
\hline RESULT & 'so that' \\
\hline PURPOSE & 'in order that' \\
\hline NEGATIVE PURPOSE & 'lest' \\
\hline DEGREE/EXTENT & 'insofar as' \\
\hline EXCEPTION/RESTRICTION & 'except/only that' \\
\hline \multicolumn{2}{|l|}{ C. Modal } \\
\hline MANNER & 'as, how' \\
\hline SIMILARITY & 'as, like' \\
\hline COMMENT/ACCORD & 'as' \\
\hline COMPARISON & 'as if' \\
\hline INSTRUMENT/MEANS & 'by' \\
\hline PROPORTION & 'the ... the' \\
\hline \multicolumn{2}{|l|}{ D. Other } \\
\hline PLACE & 'where' \\
\hline SUBSTITUTION & 'instead of' \\
\hline PREFERENCE & 'rather than' \\
\hline CONCOMITANCE & 'wobei' (German) \\
\hline NeGative CONCOMITANCE & 'without' \\
\hline ADDITION & 'in addition to' \\
\hline
\end{tabular}

17 Following the conventions of the aforementioned typological studies, the labels of adverbial clauses are capitalized. 
As can be seen from Table 7, Kortmann (1996) proposes a very fine-grained classification of adverbial clauses (similar, but less differentiated classifications are found in Givón 2001; Hetterle 2015; Thompson et al. 2007). Below, I briefly discuss only those adverbial clauses that will play a role in the discussion of Udmurt non-finite adverbial clauses.

Let us start with temporal clauses. Their function is to locate the event expressed in the main clause in time, and can encode various temporal relations, such as precedence, subsequence, simultaneity, terminal/initial boundary, etc. Among the temporal relations listed above, 'when'-clauses are the most general ones (Givón 2001: 330; Hetterle 2015: 47; Kortmann 1996: 182). They can denote an event occurring prior, posterior, or simultaneously to the event expressed in the main clause, as shown in (57).

(57) Givón (2001: 330, ex. (7))
a. When she came, he had already left.
(precedence)
b. When he got up, she did too.
(subsequence)
c. When she lived there, everybody was real friendly.
(simultaneity)

The adverbial clauses of Simultaneity DuRATion ('while') and Simultaneity CoEXTENSIVENESS ('as long as') also denote simultaneous events to the one expressed in the main clause. Kortmann (1996: 84) defines them as follows: Simultaneity DuRATiON ' $p$ opens up a time interval for the whole or part(s) of which $q$ is true', whereas SimULTANEITY Co-EXTENSIVENESS ' $p$ opens up a time interval for the whole of which $q$ is true'. Thus, these adverbial clauses always express a time interval (as opposed to 'when'-clauses which can be punctual, cf. (57a, b)). The difference between the two types concerns the overlap between the two events: according to Kortmann's (1996) definition, SiMULTANEITY Co-EXTENSIVENESS must encode full overlap, while SIMULTANEITY DURATION might encode either partial or full overlap. Example (58) illustrates the latter type.

(58) Kortmann (1996: 84)

I learnt all about flowers while we lived in the country.

Clauses of ANTERIORITY ('after') express events that precede the situation encoded in the main clause, while clauses of POSTERIORITY ('before') refer to situations that follow it (Kortmann 1996: 84-85), cf. (59). Nevertheless, 'before'-clauses cannot be viewed as simply 
the reverse of 'after'-clauses for the following reasons: certain 'before'-clauses express that the event did not take place (antiveridical in Giannakidou's 1998 terms), cf. Ruth died before she saw her grandchildren. These 'before'-clause contrast with the factual/veridical 'before'clauses, illustrated in (59b). Additionally, it has been observed that cross-linguistically, 'before'-clauses show negative polarity (or irrealis markers) (Hetterle 2015: 136-141; Kortmann 1996: 184).

(59) Kortmann (1996: 84-85)

a. After we had breakfast we went to the river.

b. We had breakfast before we went to the river.

There is one more adverbial clause type that also often displays negation crosslinguistically, namely, TERMINUS AD QUEM ('until'). These clauses refer to a situation that marks the endpoint of the event expressed in the main clause (Kortmann 1996: 85), cf. (60). It has been observed that 'until'-clauses might contain "expletive" negation (see Abels 2005 on Russian and Ürögdi 2012 on Hungarian) or are licensed in negated matrix clauses (the socalled 'NPI-until', cf. Karttunen 1974).

(60) Kortmann (1996: 85)

We had a wonderful summer until my mother arrived.

Furthermore, Kortmann (1996: 183) argues that SiMULTANEITY Co-EXTENSIVENESS ('as long as') and TERMINUS AD QUEM ('until') are to be considered complements of each other: 'as long as'-clauses open up a time interval for the whole of which the matrix proposition is true, whereas 'until'-clauses mark the endpoint of this time interval. Thus, the meaning of 'until'-clauses is ' $q$, until $p$ ', which is (roughly) equivalent to ' $q$, as long as not- $p$ ', cf. (61).

(61) Kortmann (1996: 183, ex. (19))

We'll keep you here

a. until you tell us where the money is.

b. as long as you haven't told us where the money is. 
Additionally, it should be mentioned that diachronically, temporal clauses may change into non-temporal ones. For instance, 'while'-clauses often develop an adversative/concessive meaning, 'after'- and 'since'-clauses turn into causal clauses, and 'before'-clauses into 'rather than'-clauses (cf. Traugott \& König 1991; Kortmann 1996: 189-193). Furthermore, it is crosslinguistically common for conditional clauses and 'when'-clauses to be expressed in the same way (Givón 2001: 332).

Turning to the next major adverbial clause type, the Causal-Conditional-Concessive adverbial relations, I will leave aside conditional and concessive clauses since they are finite in Udmurt (§2.3.2). CAUSE/REASON clauses express a cause, reason or motivation that brings about the event of the main clause (Kortmann 1996: 85). Most typological studies do not tell apart reason and causal clauses, but it can be observed that the former type involves internal motivation, while the latter involves external motivation (Givón 2001: 335-336; Hetterle 2015: 51), as illustrated in (62).

(62) Hetterle (2015: 51, ex. (45))

a. Our sand castle got damaged because Jim ran over it.

b. Since Mandy wanted to be home early that day, she hailed a taxi cab.

Additionally, it is cross-linguistically common for reason and purpose clauses to be expressed in the same way (Hetterle 2015: 51; Thompson et al. 2007: 250-251). However, purpose clauses express a motivating event which must be unrealized at the time of the main event, thus they are hypothetical rather than factual, as opposed to reason clauses, compare (63) and (62b). It has been also observed that purpose clauses tend to show subjectcoreference (Cristofaro 2003: 157). Furthermore, result clauses are also closely related to purpose clauses and causal clauses (Hetterle 2015: 52).

(63) Kortmann (1996: 86)

I drove into London in order to buy a piano.

Manner clauses specify how an event is performed. Kortmann relations (1996: 87-88) distinguishes six distinct subtypes of modal, but Hetterle (2015: 53-54) regroups them into two main types: MANNER PER SE/INSTRUMENT clauses and SIMILARITY/COMPARISON. MANNER PER SE/INSTRUMENT clauses express how an event is performed and by which means this is 
achieved, respectively. Kortmann (1996: 87) argues that instrument clauses can be converted into a purpose relation, while manner clauses cannot. Illustrative examples are given in (64).

(64) Kortmann (1996: 87-88)

a. My father stiffened, straightening his shoulders.

b. By twisting her body sideways, she freed herself.

The fourth major class of adverbial relations in Kortmann (1996) includes the SUBSTITUTION, PREFERENCE and NEGATIVE CONCOMITANCE clauses. The NEGATIVE CONCOMITANCE clauses ('without') express that the event of the main clauses is not accompanied by another event (and often this runs counter to expectation or is simply regarded as remarkable). SUBSTITUTION clauses are defined as follows: "of two alternatively possible events/activities $p$ and $q, q$ happens or is performed although $p$ was rather to be expected" (Kortmann 1996: 88) (65a). The definition of PREFERENCE clauses, on the other hand, is: "of two alternatively possible events/activities $p$ and $q, q$ is preferred (by the generally volitional subject referents) and renders $p$ unnecessary or improbable" (Kortmann 1996: 89) (65b).

(65) Kortmann (1996: 89)

a. We stayed at home instead of going for a walk in the snow.

b. Rather than go there by plane, I would take the slowest train.

SUBSTITUTION and PREFERENCE clauses are discussed together in Givón (2001: 336) and Thompson et al. (2007: 263-264) since the appropriate reading depends primarily on the presence of a volitional subject referent. However, Kortmann (1996: 205) observes that the two adverbial clause types are marked by different subordinators in the languages of his sample, thus, should be kept apart.

Additionally, most studies distinguish between pre-posed and post-posed adverbial clauses (Givón 2001: 343-348; Thompson et al. 2007: 295-298). It has been suggested that post-posed adverbial-clauses in English have a narrow, local, semantic connectivity to the main clause, while pre-posed adverbial clauses have a wider scope and are often linked not only to the main clause, but to the preceding paragraph. Thompson et al. (2007: 297) suggest that in OV languages, centre-embedded adverbial clauses, i.e. when the adverbial clause is 
placed between the subject and the rest of the main clause, are functionally equivalent to postposed adverbial clauses in English. Thompson et al. (2007: 292-295) argue that (pre-posed) adverbial clauses can function as topical or backgrounded clauses. This is supported by the fact that some languages mark adverbial clauses with the same topicalizing marker used to mark topicalized NPs. However, Givón (2001: 344-345) states that adverbial clauses are not true topics: similarly to topics, they are given and backgrounded, but unlike topics, pre-posed adverbial clauses rarely bear cataphorical or anaphorical importance.

Let us now discuss the typological definitions of converb. According to Haspelmath (1995: 3), converbs are non-finite verb forms whose main function is to express adverbial subordination. Haspelmath (1995: 4) points out that this definition implies that converbs must be verb forms that belong to the inflectional paradigm of verbs, and not verbs combined with a complementizer/subordinator. Moreover, he argues that converbs are non-finite, i.e. they lack TAM and agreement morphology. However, Haspelmath (1995: 5-7) observes that the picture is complicated by the fact that some converbs may take possessive suffixes agreeing with the subject, especially in cases where possessive suffixes and (verbal) agreement suffixes do not differ. Additionally, converb clauses are defined as adverbial, as opposed to deverbal nouns/nominalizations and participles that are used in argument and relative clauses, respectively. This definition also excludes clause-chaining constructions formed with converbs (according to Haspelmath 1995: 8, this is not a typical use of converbs), but it is attested in the case of Turkic -Ip-converbs. Furthermore, he distinguishes three types of converbs: Same-Subject, Different-Subject, and Varying-Subject (depending on whether the converb can have an independent subject from the matrix one).

Finally, Haspelmath (1995: 12-17) argues that converb clauses are subordinate, and not coordinate clauses. This is supported by the following tests: discontinuous word order (i.e. centre embedding); position of the converb clause with respect to the main clause; backward pronominalization; restrictiveness and their ability to act as the focus of the sentence; and extraction possibilities. Haspelmath (1995: 17) notes that diachronically, converbs often originate from adpositional or case-marked forms of nominalizations.

Having summarized the main properties of adverbial clauses and converbs from a typological point of view, let us turn to non-finite adverbial clauses in Udmurt. 


\subsubsection{Non-finite adverbial clauses in Udmurt}

Non-finite adverbial clauses in Udmurt are formed with the two nominalizations when they are selected by semantic cases and postpositions, as well as with converbs. In the table below, I summarize all (potential) converb morphemes, discussed in the literature. (Note that this table will be revised partly in this subsection, as well as in $§ 4.1$, where I discuss at length what should count as a converb in Udmurt.)

Table 8 Converbs in Udmurt

\begin{tabular}{|l|l|}
\hline Converb & Rough meaning in English \\
\hline$-s a$ & $\begin{array}{l}\text { 'when' } \\
\text { 'after' } \\
\text {-ing gerund (temporal and manner) } \\
\text { 'since' (causal) }\end{array}$ \\
\hline$-t e k$ & $\begin{array}{l}\text { 'without doing something' } \\
\text { 'not having done something' }\end{array}$ \\
\hline$-k u$ & $\begin{array}{l}\text { 'when' } \\
\text { 'while' }\end{array}$ \\
\hline$-t o z ́$ & 'until' \\
'before' \\
'while' \\
resultative/degree \\
'rather than'
\end{tabular}

In the next subsections, I will discuss the various types of adverbial clauses. With respect to their morphosyntax, adverbial clauses in Udmurt can have nominative subjects (with or without agreement markers, depending on the non-finite verb), but there are some additional patterns. 


\subsubsection{Postposition + nominalization}

There are several postpositions/relational nouns that select for a nominalization, forming a non-finite adverbial clause. These are bere 'back-ILL after (temporal, causal)', aźin 'front-INE before', vilisis 'top-ELA because', dirja 'time-ADV at, during', ponna 'for, in order', intije 'place-ILL instead', etc.

In (66), the non-finite clause is the complement of the postposition bere 'after'. The subject of the non-finite clause is nominative and there is no agreement on the non-finite predicate. This is the most common pattern in Different-Subject non-finite adverbial clauses (Georgieva \& Ótott-Kovács 2016).

(66) Georgieva \& Ótott-Kovács (2016: 58, ex. (15))

\begin{tabular}{|c|c|c|c|c|c|c|}
\hline [Tolkien & kul-em] & bere & so-len & pi-jez & Christopher & ataj-ez-leś \\
\hline [Tolkien & die-NMLZ] & after & 3SG-GEN & son-3SG & Christopher & father-3SG-ABL \\
\hline pottimte & kniga-o & & pott- & & & \\
\hline anpublish & book-P & 3 SG.A & publ & -PST-3SG & & \\
\hline
\end{tabular}

'After Tolkien's death (/ after Tolkien (had) died) his son Christopher published his father's unpublished books.'

This is not the only possible morphosyntactic pattern, however. Agreement can be marked in these clauses. We saw in $\$ 3.6$ that nominalizations look like possessive constructions when used in argument position. Hence, we might expect nominalizations heading adverbial clauses to behave similarly. In other words, we would expect that in the presence of agreement on the non-finite predicate the subject, if overt, should be genitive and not nominative. This is also what the Udmurt descriptive grammars consider to be grammatical (cf. Shutov 1999: 24-25). This prediction is generally borne out, cf. (67).

(67) Georgieva \& Ótott-Kovács (2016: 60, ex. (18), (19))

\begin{tabular}{|c|c|c|c|c|c|}
\hline [Tolkien-*(len) & kul-em-ez] & bere & so-len & $p i$-jez & Christopher \\
\hline [Tolkien-GEN & die-NMLZ-3SG & after & 3SG-GEN & son-3sG & Christopher \\
\hline ataj-ez-leś & pottimte & kniga-os & & pott-i-z. & \\
\hline father-3sG-ABL & unpublished & book-PL- & SG.ACC & publish-PST & $-3 \mathrm{SG}$ \\
\hline
\end{tabular}


However, nominative subjects are not ruled out completely. For certain speakers, examples like (68) are grammatical (Georgieva \& Ótott-Kovács 2016). Similar sentences are attested in corpora as well. These examples are particularly problematic since the subject is nominative in the presence of possessive suffixes on the non-finite predicate. This casemarking pattern, however, is unattested with non-derived nouns used as possessors (cf. $\S 2.3 .1)$.

(68) Georgieva \& Ótott-Kovács (2016: 61, ex. (22))

$\%$ [Kol’a škola-je min-em-ez] bere mon kniga lidšíni kutsk-i.

[Kolya school-ILL go-NMLZ-3SG] after 1SG book[ACC] read-INF start-PST[1SG] 'After Kolya (had) left for school, I started reading a book.'

There is one more patter to discuss. Certain postpositions, namely the ones that go back to relational nouns, e.g. ber- 'after (temporal, causal)', aź- 'before' can take inessive/illative case and agreement markers. Thus, agreement is marked on the relational noun/postposition, and not on the nominalization (69).

(69) Udmurt Corpus (Удмурт дунне, 2008.01.16)

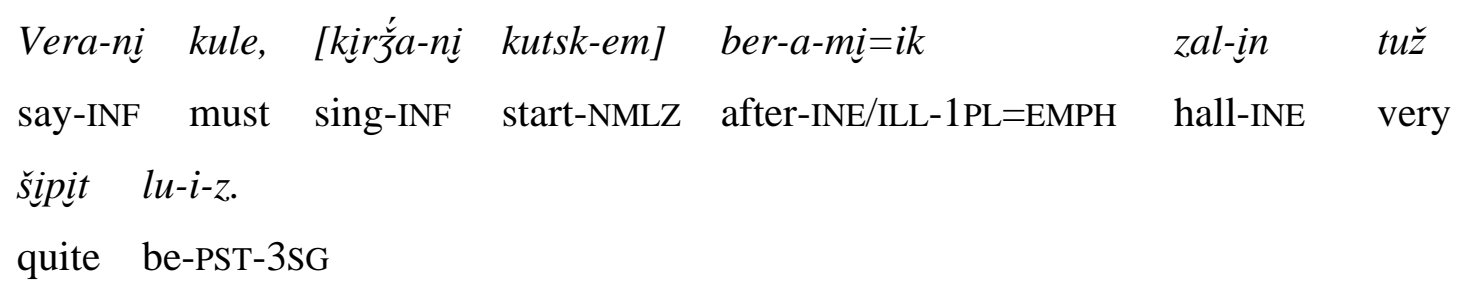

'It has to be said, after we started singing, the hall became silent.'

This pattern is less surprising in the light of the morphosyntactic patterns found in nonfinite relative clauses: agreement is marked on the head noun. However, this pattern seems less frequent in the Udmurt Corpus: there are only 631 hits of $-(e) m$-nominalizations followed by the inflected postposition ber-, while the number of inflected $-(e) m$-nominalizations followed by bere is $5,128 .{ }^{18}$

\footnotetext{
${ }^{18}$ Since the examples in the corpus have been annotated automatically, there might be some false positive hits. 
In Georgieva \& Ótott-Kovács (2016, in Prep.), we argue that the 'unmarked' pattern is the most common in Different-Subject clauses with overt subjects. We also claim that the 'Gen+Agr' and 'Nom+Agr' patterns are more restricted. Table 9 summarizes the patterns.

Table 9 Morphosyntactic patterns in 'after'-clauses (-(e)m bere)

\begin{tabular}{|c|c|c|}
\hline Subject's case & Agreement & Example \\
\hline Nom & no & $(66)$ \\
\hline Nom & yes & $(68)$ \\
\hline Gen & yes & $(67)$ \\
\hline
\end{tabular}

\subsubsection{Cause/Reason clauses: -(e)miś and -(e)men}

The non-finites $-(e) m i s ́$ and $-(e) m e n$ are considered converbs in some traditional grammars (Kelmakov \& Hännikäinen 1999: 232-233; Winkler 2001: 61). In fact, they can transparently be segmented into a nominalization and a case suffix. Moreover, their meaning is compositional. Hence, I argue that it is unnecessary to treat them as converbs.

The non-finite -(e)miś contains an elative case suffix (its negative form is also fully

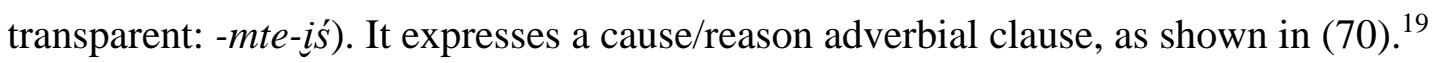

(70) fieldwork recording, 2014_07_15, OS, Izhevsk, Udmurtia

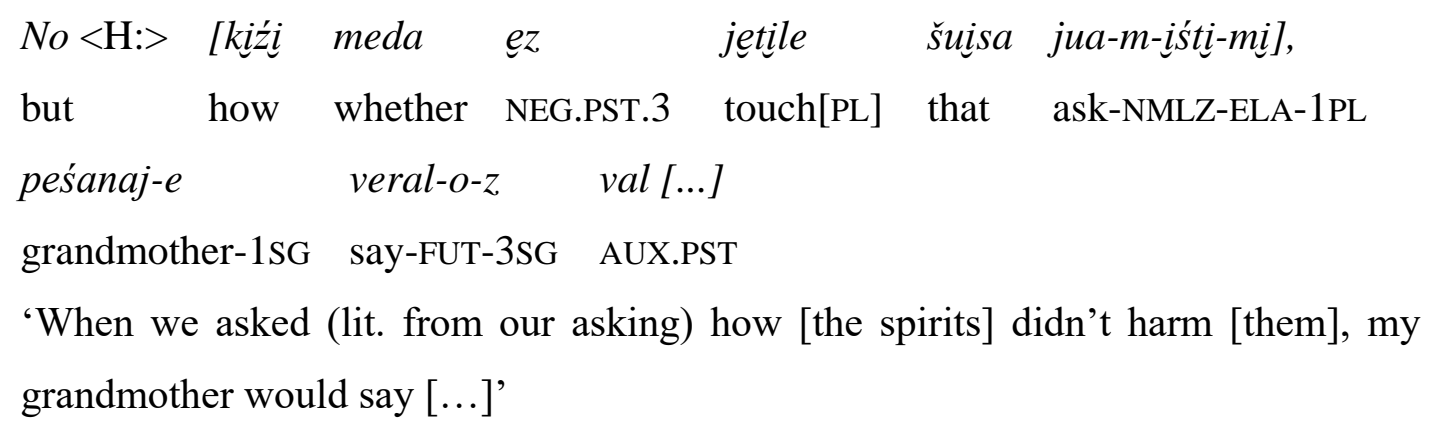

The non-finite -(e)men contains an instrumental case suffix (its negative form is -mte-jen). It expresses a 'by doing something' or 'with doing something', as shown in (71). In (72), the non-finite clause has a reason adverbial flavor.

\footnotetext{
${ }^{19}$ Additionally, it can be used as a (subcategorized) adverbial with the verb dugdini 'to stop' with the meaning ‘to stop doing sth' (lit. ‘to stop from doing sth') (Kelmakov \& Hännikäinen 1999: 232). 
(71) Udmurt Corpus (Удмурт дунне, 2010.11.02)

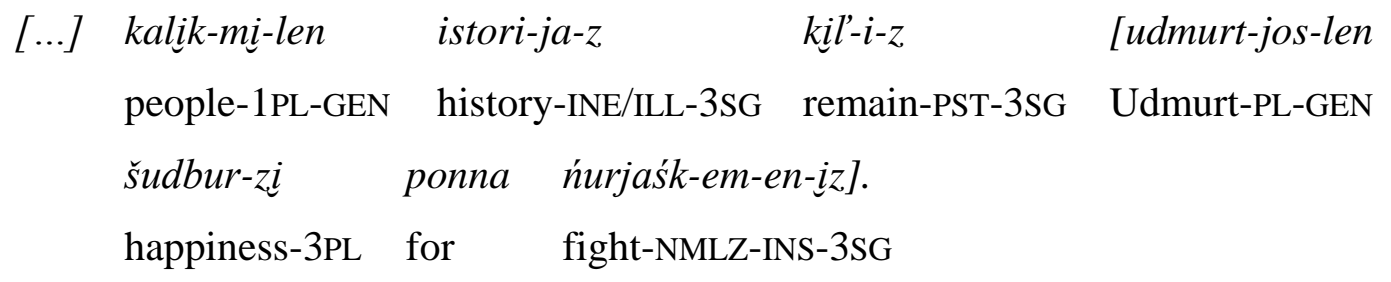

'[the teacher] remained in our history with his fight for the well-being of the Udmurts.'

(72) Turku-Izhevsk Corpus (Kenesh/D/5:783)

Tolon [kuaź zor-em-en] busi-je ezz vetle=no [...]

yesterday weather rain-NMLZ-INS field-ILL NEG.PST.3 go[PL]=ADD

'Yesterday they did not go to the field because it was raining (lit. with the weather raining),'

These adverbial clauses present a similar case to 'after'-clauses discussed above. Firstly, they can have an overt subject in nominative case without agreement, cf. (72). Again, the expectation would be that the overt subject would bear genitive case in the presence of agreement (example (71) does not provide evidence since the subject is covert). However, nominative subjects are grammatical, as proven by (73). Similar examples with -(e)men are presented in the traditional grammars as well (GSUJa II 1970: 117-118). Note that the agreement marker follows the case suffix (as with underived possessors in the elative and instrumental, cf. §2.3.1).

(73) Udmurt Corpus (Удмурт дунне 2008.05.06) $)^{20}$

$\begin{array}{lllll}\text { Kišno-je, } & \text { [eke-mi kematek } & \text { skripka-ze } & \text { kuti-le-mte-iśti-z], } \\ \text { wife-1SG } & \text { son-1PL long.time } & \text { violin-3SG.ACC } & \text { touch-FREQ-NMLZ.NEG-ELA-3SG } \\ \text { kuddir } & \text { 亏̌urgete }[. . .] & & \\ \text { sometimes } & \text { grumble[PRS.3SG] } & \end{array}$

'Because our son hasn't/doesn't touch his violin for a long time, my wife sometimes grumbles (at him) [...]'

As for genitive subjects, they are possible, but it seems that they are used in different contexts. These non-finite clauses might be used with the matrix verb gerž́aśkini 'to connect (intransitive)', and in this case, the sentence means 'something is connected with/related to

\footnotetext{
${ }^{20}$ The example probably contains a typographic error: kutilemteiśtiz instead of kutilimteiśtiz.
} 
something', cf. (74). There are numerous examples of this construction in the Udmurt Corpus, and they clearly prefer the nominalized pattern.

(74) Udmurt Corpus (Удмурт дунне, 2009.01.16)

So gerక̆aśk-emin [kivaltiś-jos-mi-len ogkiliśs uža-ni

3SG connect:INTR-PASS authority-PL-1PL-GEN together work-INF

bigati-mte-jeni-zi].

be.able-NMLZ.NEG-INS-3PL

'This is related to the inability of our authorities to work together.'

Genitive subjects are also possible in $-(e) m i s ́$-clauses, but again, this pattern is used predominantly with subcategorized -(e)miśs-clauses, e.g. 'something stems/arises/comes from something' or 'to be afraid of something', as in (75).

(75) Udmurt Corpus (Удмурт дунне 2007.03.13)

[Nilpi-os-si-len udmurt lu-em-iśtí-zi] čem-ges kiš̌kalo, leśa,

child-PL-3PL-GEN Udmurt be-NMLZ-ELA-3PL often-CMPR be.afraid[PRS.3PL] probably anaj-ataj-os-si.

mother-father-PL-3PL

'It is probably more often [the case that] the parents are afraid of their children becoming Udmurts.'

Table 10 Morphosyntactic patterns in -(e)miśs/-(e)men-clauses

\begin{tabular}{|c|c|c|}
\hline Subject's case & Agreement & Example \\
\hline Nom & no & $(72)$ \\
\hline Nom & yes & $(73)$ \\
\hline Gen & yes & $(74),(75)$ \\
\hline
\end{tabular}

\subsubsection{Adverbial clauses with the adverbial case (?)}

In this subsection, I discuss the adverbial clauses, headed by -(e)mja and -(o)nja. In this case, the nominalization is in the so-called 'adverbial' case. The adverbial case in Udmurt has three different functions: (i) derives adnominal modifiers (76); (iii) 'according to/based on' (77a, 
b); (iii) on nominalizations, it can express a temporal clause, meaning 'when, as' (78). Additionally, the adverbial case is found on the postposition dir-ja 'time-ADV, at/during'.

(76) Winkler (2001: 24, ex. (46))
udmurt kil-ja
dišsetiś
Udmurt language-ADV teacher
'teacher of Udmurt'

(77) elicited

a. Plan-ja uža-j.

plan-ADV work-PST[1SG]

'I worked according to the plan.'

b. Diśkut-ez-ja todma-j.

clothes-3SG-ADV recognize-PST[1SG]

'I recognized [him/her] based on his/her clothes.'

(78) Udmurt Corpus (Удмурт дунне 2009.05.26)

$$
\begin{array}{lllll}
\text { No } & \text { [dir } & \text { ortć-em-ja] } & \text { šedi-ni } & k u t s k-i[\ldots] \\
\text { but time } & \text { pass-NMLZ-ADV feel-INF } & \text { start-PST[1SG] }
\end{array}
$$

'But as the time passed by, I started to feel [...]'

In my view, the status of the adverbial case suffix is problematic for at least two reasons. Firstly, the term 'adverbial case' is confusing because this suffix is not used to derive adverbs from adjectives. In other languages that utilize an adverbial case (e.g. Georgian and Adyghe), the adverbial is used to derive adverbs (Hewitt 1995: 534-535; Serdobolskaya 2016). ${ }^{21}$ Additionally, this case is used to mark secondary predicates and it can be used in certain non-finite clauses. As can be seen from (76)-(78), the Udmurt adverbial has different functions, crucially, it is not used to derive adverbs from adjectives. ${ }^{22}$ The most frequent use of the adverbial in today's Udmurt is the adnominal modifier function, especially in the

\footnotetext{
${ }^{21}$ I thank Orsolya Tánczos for raising this question in her review. I am also grateful to Ludger Paschen for the references on Adyghe.

${ }^{22}$ Although it is interesting that the adverbial can be used in non-finite clauses in Georgian and Adyghe, but a detailed comparison goes beyond the scope of this dissertation.
} 
standard language. This seems to be related to the need of translating various terms/concepts from Russian that require adnominal modifiers, e.g. Ministry of Education.

In my opinion, the adverbial case is problematic not only because of its seemingly unrelated functions, but also because of its similarity to the inessive/illative allomorph used before possessive case suffixes. The inesssive/illative marker is $-a /-j a$ with the latter used when the noun stems ends in a vowel, cf. gurt-a-m 'village-INE/ILL-1SG in/to my village' and munćo-ja-m 'sauna-INE/ILL-1SG in/to my sauna', while the adverbial case suffix is -ja. Recall also that the inessive/illative case precedes the possessive suffixes, while the adverbial case either precedes or follows the possessive suffixes (cf. \$2.3.1). The varying order of the possessive suffixes and the adverbial is also problematic (recall that this is the only case suffix that allows both orders in today's Udmurt).

Edygarova (2010: 109-111) makes the following observations regarding the Cx-Px and Px-Cx order with respect to the adverbial case used with $-(e) m$ - and $-(o) n$-nominalizations. She claims that the Cx-Px order occurs when the nominalization is used as an adverbial clause and, in this case, the possessive suffixes indicate agreement with the subject, as shown in (79). The Px-Cx order, on the other hand, is preferred when the nominalization is used as (manner/circumstantial) adverbial, see (80).

(79) Edygarova (2010: 110, ex. (129))

$\begin{array}{llllll}\text { [uža-nô } & \text { bâgat-em-ja-s] } & \text { śud-em, } & \text { pe, } & \text { soostâ } & \text { so. } \\ \text { work-INF } & \text { be.able-NMLZ-ADV-3SG } & \text { feed-EVID[3SG] } & \text { QUOT } & \text { 3PL.ACC } & \text { 3SG }\end{array}$

'While he could work, he was feeding them, they say.'

(80) Edygarova (2010: 111, ex. (133))
[Bigat-em-e-ja=no
valam-e-ja]
$u \check{a} a-s ́ k o$.
be.able-NMLZ-1SG-ADV=ADD understand-NMLZ-1SG-ADV work-PRS[1SG]
'I work according to my (own) abilities and intuition (lit. understanding).'

Although this generalization seems to be correct, it can be further specified. What I would like to point out is that in (79), the meaning of the non-finite clause is not 'according to his ability to work', but rather 'during/while/in the time when he could work'. ${ }^{23}$ This holds for

\footnotetext{
${ }^{23}$ The English translations of (79) and (80) Edygarova's translations in which she uses the Russian complementizer poka 'while'.
} 
all examples with the Cx-Px order presented by Edygarova (2010). The same pattern is found in the examples presented by Fokos-Fuchs (1958), as well as in the data from the Udmurt Corpus.

Essentially, the meaning of (79) resembles the inessive/illative case. Recall also that the adverbial and the inessive/illative are formally very similar, and the inessive/illative shows the Cx-Px order. I argue it might be the case that in examples like (79) we find the inessive/illative case, and not the adverbial. This is supported by the semantics of the adverbial clause (it is 'in', and not 'according to'), as well as by the Cx-Px order (characteristic of the inessive/illative). In this way, we also account for the varying order of the adverbial and the possessive suffixes by saying that there is actually no variation since the Cx-Px order involves the inessive/illative, and not the adverbial.

There are two complications with this proposal. Firstly, it must be explained why the inessive/illative suffix appears with an epenthetic $-j$-, even though the stem does not end in a vowel. A possible explanation for this might be the fact that in several dialects, suffixes that normally do not require an epenthetic $-j$-, are used with one, cf. škola-jos 'school-PL' (dialectal) vs. škola-os 'school-PL' (standard). The more serious problem is that the inessive/illative allomorph $-(j) a$ is used only with possessive suffixes, whereas the adverbial suffix -ja can be used without possessive suffixes, cf. (77a) and (78). Example (78) is particularly interesting since it clearly has a temporal meaning (and not 'according to/based on'). A tentative proposal would be to say that the inessive/illative can be used without possessive markers. The link between the adverbial and the inessive/illative can be shown based on diachronic evidence as well. According to Rédei (1988: 383), the adverbial suffix goes back to a lative/prolative $-j$ and lative $-a$ (the latter goes back to $*_{-} k$ ). Moreover, there are examples that are ambiguous between the 'in' and 'according to/based on' reading or the 'according to/based on' reading can be derived from the temporal one. Consider the semantic change of in (the time of) my thinking > in my opinion, (-(e)mja-non-finites are very frequent with the verb 'think') or of I recognized him while he was walking > I recognized him based on the way he was walking. Hence, it might be the case that the adverbial, i.e. 'according to/based on', is a special function of the inessive/illative that developed (or that has been developing) from the temporal meaning.

We find the same correlation between the meaning of the adverbial clause and the order of adverbial case and the possessive suffixes with $-(o) n$-nominalizations as well. When the possessive suffixes precede the adverbial, the non-finite clause means 'according to/based on' 
(81). Note that the nominalization does not encode an event, it means 'religion, belief'. Based on the Udmurt Corpus, it seems that most $-(o) n$-nominalizations used followed by the adverbial case are also non-events: ivorton 'notification', kuron 'request', kiržan 'song', ulon 'life', koson 'order', etc.

(81) Udmurt Corpus (Удмурт дунне 2008.05.28)

Mi um l'uki-śke ad'ami-jez vǐži-jez-ja, osk-on-ez-ja [...]

1PL.EXCL NEG.1PL separate-PRS[PL] person-ACC root-3SG-ADV believe-VN-3SG-ADV

'We don't separate people based on their origin and/or religion.'

Furthermore, the reverse order, i.e. Cx-Px, is also attested. In this case, the adverbial clause expresses a simultaneous event with the situation described by the matrix clause (82).

(82) fieldwork recording, 2014_08_11, TS, Balezino district, Udmurtia muš-jos-mi peğ̌́i-ll'am=ńi=no [baba-jeni-mi vir-oń-ńa-mi]]. bee-PL-1PL escape-EVID.3PL=already=ADD grandmother-INS-1PL be.busy-VN-ADV-1PL 'Our bees had (long) flown away while we/me and my grandmother were busy [taking care of the chicks].'

Above, I raised the question of whether the $-(e) m j a$-clauses contain the adverbial case marker (especially, when they have a temporal meaning). Here, we are facing the same problem: the meaning of the adverbial clause in (82) is much closer to temporal 'in', i.e. inessive/illative, than to 'based on/according to'. Most grammars do not discuss this use of -(o)n-nominalizations separately, but Fokos-Fuchs (1958) asks whether we are dealing with a converb. He concludes that this is not the case (see also the discussion in §4.1).

A couple of remarks are in order regarding -(o)nja-clauses. Firstly, observe that the nominalization has the form virońnami instead of the (standard) vironjami. The explanation for this is is that the glide of the adverbial palatalizes the preceding consonant and assimilates to it, resulting in -ńn- (similar assimilation is found with other suffixes, as well). However, it seems that -(o)nja-clauses are attested with (at least) three different suffixes: alongside the standard -(o)nja, we find -(o)ńńa- and -(o)nna-. These data come mainly from the Udmurt Social Media Corpus (which contains spoken/dialectal texts), but are also found in the Udmurt Corpus. The examples presented in Fokos-Fuchs (1958) also contain different forms. 
Although forms like -(o)ńńa- can be explained morphophologically, I suggest that the variety of forms of these adverbial clauses indicates that these were originally unrelated forms, which later collapsed in the form -(o)nja. The different origin of the non-finite forms might also explain the differences in function, which I will discuss next.

Generally, -(o)nja-clauses seem to be used as 'when'- or 'while'-clauses, but the situation is more intriguing. Based on the Udmurt Corpus, these adverbial clauses are far less frequent than the 'when'-clauses headed by the converb - $k u$ (which is the most general way of expressing 'when'-clauses in Udmurt, see §3.7.2.6). There are 8,596 'when’-clauses headed by the converb $-k u$, but only $548-(o) n j a$-clauses. ${ }^{24}$

I attribute this striking difference in frequency to two factors. Firstly, it might be the case that the 'when'-clauses formed with -(o)nja are not used in all dialects. This question requires further research since the corpus contains texts written mainly in standard Udmurt. Secondly, I argue that -(o)nja-clauses actually differ from regular 'when'-clauses. One difference is that -(o)nja-clauses always express a time span and cannot encode punctual events (as opposed to 'when'-clauses). Below I discuss the -(o)ńńa-clauses used in the Middle Cheptsa dialect on which I have worked myself, and draw a parallel with the Beserman Udmurt -(o)ńniga-clauses based on Usacheva \& Serdobolskaya (2015).

Based on my data from the Middle Cheptsa dialect, the -(o)ńna-clauses express not only temporal coincidence between two events, but also imply that the two events happened in the same place. Hence, spatial mismatch is excluded. Consider the following example which is a modified version of (82). The sentence becomes grammatical only if one of the locative adverbials is dropped.

(83) elicited

*Muš-jos-mi bakč́a-ỉn sill-iś

bee-PL-1PL garden-INE stand-PTCP.PRS beehive-ELA escape-EVID.3PL=already=ADD

[baba-jeni-mi azbar-in vir-oń-ńa-mi].

grandmother-INS-1PL yard-INE be.busy-VN-ADV-1PL

'Our bees had (long) flown away from the beehive in the garden while we/me and my grandmother were busy [taking care of the chicks] in the yard.'

\footnotetext{
${ }^{24}$ Here, I include only the adverbial clauses showing agreement. Since the examples in the corpus have been annotated automatically, there might be some false positive hits.
} 
The unavailability of spatial mismatch is noted in Usacheva \& Serdobolskaya (2015: 386) in the case of Beserman Udmurt -(o)ńniga-converbs. According to them, the Beserman dialect does not utilize the most general non-finite form, expressing 'when'clauses, i.e. converb -ku. Instead, other non-finite clauses are used, headed by -idč'ož' (standard Udmurt: -toź, see §3.7.2.7), -(o)ńńa and -(o)ńńiga-converbs. The latter is not used in standard Udmurt (or any other dialect, as far as I know). Usacheva \& Serdobolskaya (2015) focus mainly on the converb -(o)ńniga and its ongoing grammaticalization. The non-finite forms -(o)nja, and -(o)ńniga- are undoubtedly related, both containing the suffix -(o)n. Usacheva \& Serdobolskaya (2015) present one interesting example, shown below in (84), which they mark as ungrammatical. The ungrammaticality is in my opinion a (semantic/pragmatic) oddity: their consultants rejected the sentence because it implies that the teacher delivered her three babies at her workplace.

(84) Usacheva \& Serdobolskaya (2015: 386, ex. (42)) [Beserman Udmurt] *[Vorč'a-jân=no Šamardan-ân učit'el'-ân uža-n'n'iga-m]

Vortsa-INE=ADD Shamardan-INE teacher-INE work-n'n'ig-INE/ILL-1SG mon kwin' pin'al vaj-i.

$1 \mathrm{SG}$ three child[ACC] bring-PST[1SG]

Intended: 'While I was working as a teacher in Vortsa and Shamardan, I gave birth to three children.'

Usacheva \& Serdobolskaya (2015) argue that the spatial mismatch should be explained by the fact that the non-finite forms -(o)ńniga- are also used as locative nominalizations (in the sense of Comrie \& Thompson 2007: 340). This use is illustrated in (85).

(85) Usacheva \& Serdobolskaya (2015: 371, ex. (10)) [Beserman Udmurt]

Skal vožma-n'-n'ig-a-m lâkt-em kijon.

cow herd:V-VN-NLOC-INE/ILL-1SG come-EVID[3SG] wolf

'A wolf came to the place where I herd (the) cows/to my cow pasture.'

Usacheva \& Serdobolskaya (2015: 390) only briefly mention the clauses formed with -(o)nja: according to them, they express an event simultaneous with the matrix clause, but do not mention a ban on spatial mismatch in Beserman Udmurt. I tested an example similar to 
(85): my consultant found (86) odd for the same reason as with example (84) above (delivering the babies at work), but did not reject it completely in contrast to (83). Note that (86) does not contain two different locative adverbials, and this explains why it is more acceptable, albeit still semantically/pragmatically incongruent.

(86) elicited

\#[Isak-inn dišetiś lui-sa uža-ńń-a-m]

Isak-INE teacher be-CVB work-VN-INE/ILL-1SG three child[ACC] bring-PST[1SG]

'While I was working as a teacher in Isak, I gave birth to three children.'

To conclude, it seems that the -(o)ńńa-clauses used in the Middle Cheptsa dialect do not simply encode an event simultaneous with the matrix event (as 'when'-clauses do), they also imply that the two events happened at the same place. Hence, spatial mismatch is excluded. Similar mismatch has been observed in the case of the -(o)ńniga-clauses used in Beserman Udmurt, a dialect that is geographically close to the Middle Cheptsa dialect. According to my preliminary data, the spatial mismatch in -(o)nja-clauses is probably allowed for speakers of other dialects. In Chapter 4, I will propose an account for these adverbial clauses.

\subsubsection{The -sa-converb}

At least three different uses of the -sa-converb head should be distinguished: the temporal converb clauses, manner adverbials and aspectual converb constructions.

The temporal clauses headed by the -sa-converb have vague temporal meaning which can be roughly translated with English -ing gerunds or with 'when' or 'after'-clauses. These clauses express either simultaneous or posterior/anterior action to the main clause. In (87), the converb clause is anterior to the event described by the matrix clause. Additionally, it has been argued that these temporal clauses can have a causal flavor (Perevoshchikov 1959).

(87) fieldwork recording, 2014_07_21, VE, Alnash district, Udmurtia [Azamat-e mini-sa] mi ul-i-mi internat-in.

Azamat-ILL go-CVB 1PL.EXCL live-PST-1PL boarding.school-INE 'Having moved to (the village of) Azamat, we lived in a boarding school.' 
Additionally, the -sa converb can also encode manner adverbials. In the next example, the manner adverbial keśaśki-sa=ik 'shouting' modifies the $-(e) m$-nominalization berdem 'crying'.

(88) fieldwork recording, 2014_08_11, TS, Balezino district, Udmurtia [[keśaśki-sa=ik] berd-em-me] tod-sko=na. shout-CVB=EMPH cry-NMLZ-1SG.ACC know-PRS[1sG]=still 'I still remember that I was crying shouting.'

The third usage of the -sa-converb is in the so-called paired verbs (Russian: cnapeнные глаголь). In this dissertation, I use the term aspectual converb constructions. Similar constructions are found in the Turkic languages (Ótott-Kovács 2016; Grashchenkov 2017), as well as in the Finno-Ugric languages belonging to the Volga-Kama Sprachbund (see Wintschalek 1993: 124-129). The Udmurt aspectual converb constructions are discussed in Kelmakov (1975) and Horváth (2011).

In the aspectual converb construction, the lexical verb is in a converb form and it is accompanied by an (auxiliary) verb which bears the TAM and agreement morphology. These converb constructions express different aspectual relations. In Udmurt, there are two main groups: perfective and imperfective converb constructions (Horváth 2011). The former typically express not only perfective aspect, but also some kind of aktionsart. In the example below, the converb veraśkisa 'talking' forms an aspectual construction with the verb leźini which normally means 'to let, to release'. However, in the aspectual converb construction it denotes an inchoative aktionsart (Horváth 2011: 71).

(89) fieldwork recording, 2014_07_26_000, KK, Kukmor district, Tatarstan

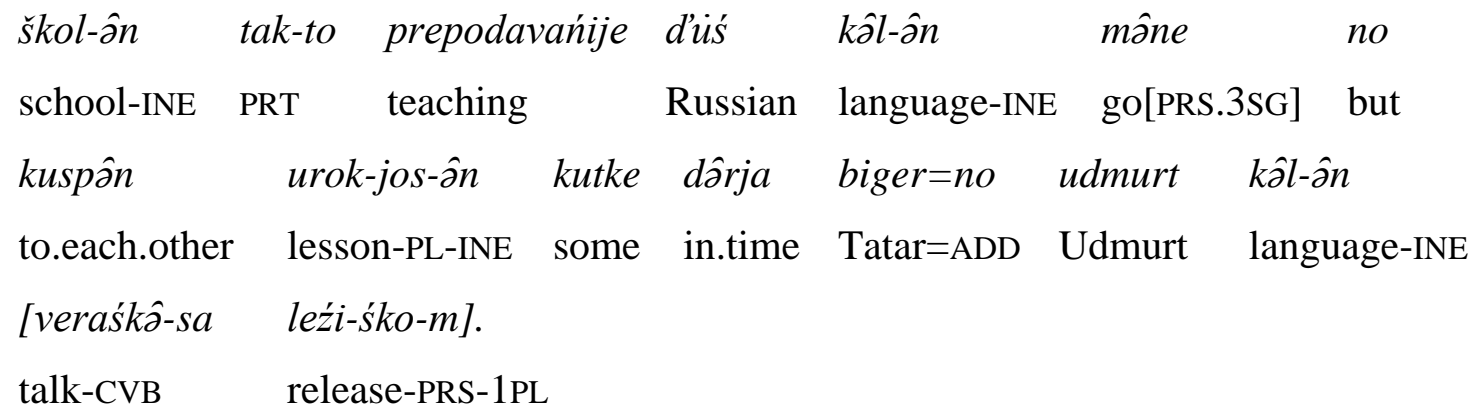

'Well, in school, the language of instruction is Russian but sometimes during the classes we start speaking in Tatar and in Udmurt to each other.' 
Additionally, there are some grammaticalized -sa-converbs. One of them is šuisa 'saying'. It functions as a sentence-final 'that' complementizer (Tánczos 2013) (cf. §2.3.2). Others are ortćisa '(temporal) in' (cf. Hungarian múlva), luissa 'as/being' (secondary predicate, cf. (86)) and probably dirtisa 'in a hurry'.

As for the morphosyntax of the -sa-converbs, it can be seen in the above-given examples that the subject is covert. Overt subjects are possible as well, as shown in (90). Note that the overt subject bears nominative case marking, and there is no agreement on the converb.

(90) elicited

[Amerika ńeft-se vuza-sa] Rossija tros ukśo išste.

America petroleum-3SG.ACC sell-CVB Russia a.lot.of money lose[PRS.3SG]

'Since America is selling petroleum, Russia is losing a lot of money.'

\subsubsection{The -tek-converb}

The converb -tek can be roughly translated with 'without doing something' or 'not having done something'. ${ }^{25}$ This is illustrated in example (91). The -tek-clauses never show agreement, but can have overt subjects in the nominative (92).

(91) fieldwork, spontaneous

Šlid-ez [odig pol=no sura-tek] peźt-i.

soup-ACC one times=ADD stir-CVB.NEG cook-PST[1SG]

'I cooked the soup without stirring (it) even once.'

(92) elicited

[Apaj-os-iz gurt-e berti-tek] Kol'a mezme val.

elder.sister-PL-3SG home-ILL come.home-CVB.NEG Kolya be.sad[PRES.3SG] AUX.PST

'Without his elder sisters coming home/His elder sisters not having come home, Kolya was sad.'

\footnotetext{
${ }^{25}$ I use the gloss CVB.NEG (negative converb) for this non-finite form.
} 
This converb is generally considered to be the negative counterpart of -sa since it can also be used in aspectual converb constructions (Perevoshchikov 1959). In the next example, the converb viri-tek 'without moving' is used in an aspectual construction with the verb killini which otherwise means 'to lie' but in (93), it expresses imperfective aspect.

(93) fieldwork, spontaneous
Kočišs pinal-jos-leś peğ́-i-z=no
cat child-PL-ABL run.away-PST-3SG=ADD move-CVB.NEG lie[PRS.3s]

'The cat ran away from the children and is not moving (lit. is lying without moving).'

\subsubsection{The $-k u$-converb}

The - $k u$-headed converb clauses have temporal meaning, namely, they encode 'when' or 'while'-clauses. ${ }^{26}$ The converb - $k u$ (in some dialects $-k i$ or $-k \hat{\text { ) }}$ expresses actions simultaneous with the one expressed by the predicate in the main clause. The overlap between the two events may be partial or full. Typically, these clauses do not have conditional semantics. However, they can denote generic events, as in example (94), in which the non-finite clause 'talking to each other' does not express one particular event of talking, but rather 'every time when we talk to each other'. In contrast, the - $k u$-clause has an episodic reading in (95).

(94) fieldwork recording, 2013_07_30_001, 6:47, VK, Izhevsk, Udmurtia

亏̌́ć kil-ez um pirt-a-śk-e [kuspa-mi veraśki-ku].

Russian language-ACC NEG.1PL take.in-FREQ-PRS-PL between-1PL talk-CVB.SIM 'We don't use (lit. take in) Russian words when we talk to each other.'

(95) fieldwork 2014, spontaneous

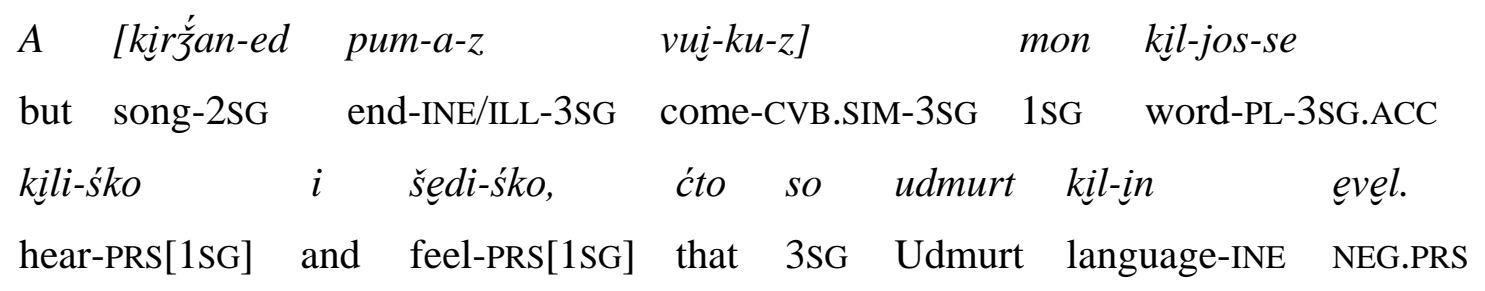

'But when your song comes to an end, I hear its words (lyrics) and realize that it is not in Udmurt.'

\footnotetext{
${ }^{26}$ I use the gloss CVB.SIM (simultanenous converb) for this non-finite form.
} 
This converb can have an overt nominative subject and agreement (95). The agreement suffixes used on this converb are the ones used after the case suffixes $(\$ 2.3 .1)$. Note that Edygarova (2010: 87) claims that the overt subject and person agreement are in complementary distribution in the case of $-k u$-clauses, but according to my data, this is a grammatical pattern for many speakers (see Georgieva 2017a). It has been argued that agreement is not obligatory in these clauses, cf. (94) (Perevoshchikov 1959; Winkler 2001; Bartens 2000). (Agreement in these clauses will be discussed in §5.1.) Additionally, it is possible to have an overt nominative subject without agreement (example (6) in §3.3). The patterns are summarized in Table 11 below.

Table 11 Morphosyntactic patterns in - $k u$-clauses

\begin{tabular}{|c|c|c|}
\hline Subject's case & Agreement & Example \\
\hline Nom & no & $(6)$ \\
\hline Nom & yes & $(95)$ \\
\hline
\end{tabular}

\subsubsection{The -toź-converb}

The converb -toź has several functions (Perevoshchikov 1959). Three of them are temporal, namely, 'until'-, 'before'- and 'while'-clauses. ${ }^{27}$ Closely connected to the temporal uses is the resultative/degree function. Additionally, it can be used in 'rather than' or PREFERENCE clauses. $^{28}$ (This converb has different forms in the Udmurt dialects, -to亏̆, -toś, -ččož, -ććoź or -(ć) ćoź, see Kelmakov 1998: 157-158.)

First, it can head an 'until'-clause, as shown in (96). In this case, the converb clauses set the temporal interval up to which the event described in the matrix clause lasts. Additionally, the converb -toź can also be used in 'before'-clauses, cf. (97).

(96) fieldwork 2014, elicited

Tunne mon [šundi pukśì-toź] uža-j.

today $1 \mathrm{SG}$ sun set-CVB.LIM work-PST[1SG]

'Today I worked until the sun set.'

\footnotetext{
${ }^{27}$ I use the gloss CVB.LIM (limitative converb) for this non-finite form.

${ }^{28}$ I am thankful to Nikita Muraviev for our discussions of 'until'-clauses. 
(97) Udmurt (Matthew 26:75) 29

[Atas ćorti-toź], kuiń pol ton mon bordiśs kuštiśk-o-d. rooster crow-CVB.LIM three times $2 \mathrm{SG}$ 1SG from deny-FUT-2SG

'Before the rooster crows, you will deny me three times.'

In both cases, the event described by the converb clause is posterior to the event of the matrix clause. The difference between 'until'- and 'before'-clause can (at least partly) be reduced to the aspectual properties of the matrix clause: 'until'-clause set the temporal boundary of a durative event, hence, they are possible with stative verbs and activities (as in (96)), while the 'before'-reading arises when the matrix clause is [-durative]), cf. (97)).

The converb -toź can also denote SiMUlTANEITY Co-EXTENSIVENESS. In (98), the adverbial clause marks a time interval for the whole of which the matrix proposition is true. Recall that this type is considered to be the complements of 'until'-clauses: ' $q$, until $p$ ' (roughly) means ' $q$, as long as not-p' (cf. §3.7.1). Example (98) can be also translated with: 'I will look after it until the time when you are not busy anymore'. The similarity of these clause types is also noted in Perevoshchikov (1959: 78).

(98) Turku Izhevsk Corpus (Kizili/A/20:30)

[Ton vetli-toź] mon so-de voźmal-o.

2SG go-CVB.LIM 1SG that-2SG.ACC protect-FUT[1SG]

'While you go [get tableware], I will look after that [hedgehog] of yours.'

Additionally, the overlap between the two events might be partial, as shown in (99). In this example, the event of growing 20 centimeters has taken place within the temporal interval expressed in the adverbial clause.

(99) Turku-Izhevsk Corpus (Invozho/I/4:50)

[Otin ukmis toleź uli-toź-am] bỉdes 20 santimetr-li budi-śkem.

there nine month live-CVB.LIM-1SG as.many.as 20 centimeter-DAT grow-EVID[1SG] 'While I was living there for nine months, I've grown as many as 20 centimetres.'

\footnotetext{
${ }^{29}$ http://finugorbib.com/bible/udmurt/40_Mat26_na.html (Retrieved: 2018-06-20.) 
During my fieldworks, I have observed that this type is not used by all speakers (those who reject examples like (99), correct it with a 'when'-clause, formed with the converb -ku). More generally, I have noticed that the temporal uses of this converb are not very frequent in spoken Udmurt, as opposed to the preferences clause use (see below).

Closely connected to 'until'-clauses are 'resultative/degree' clauses. In (100), the converb clause resembles a resultative secondary predicate. Resultatives are also possible with intransitive verbs (101). In the latter case, there is no fake object as opposed to their English counterparts. In GSUJa I (1962), it has been argued that these are lexicalized forms (degree adverbials) rather than full-fledged non-finite clauses. For instance, no collapsing is implied in (101), similarly to the English translation which does not imply the event of dying. Timerkhanova (2011: 288) observes that this use of -toź-converbs resembles the meaning of -mon-non-finites (§3.7.2.8).

(100) Georgieva (2017c, elicited)
Duriśkiś kort-ez [gordekti-toź]
širirdat-i-z.
smith iron-ACC become.red-CVB.LIM heat-PST-3SG
'The smith heated the iron red.'

(101) Georgieva (2017c, elicited)

Pet'a [pogra-toź] ju-i-z.

Petya collapse-CVB.LIM drink-PST-3SG

'Petya drank himself to death.'

The third use of this converb is not temporal, but modal. It encodes a 'rather than'clause, which expresses bouletic modality (Georgieva 2017b) (102). I argue that these adverbial clauses can encode PREFERENCE but not SUBSTITUTION. ${ }^{30}$

(102) GSUJa I (1962: 288)
[...] [otin uli-toź]
śed tel'-in ul-o.
there live-CVB.LIM dark forest-INE live-FUT[1SG]

'[...] I would rather live in a dark forest than live there.'

${ }^{30}$ SUBSTITUTION clauses are expressed with the postposition intije 'instead' and a nominalization, cf. (55). 
This converb can have an overt nominative subject, cf. (96)-(98). Agreement can be also marked, as shown in (99). The agreement markers are the ones used after case suffixes (§2.3.1). It has been argued that agreement is not obligatory in these clauses (Perevoshchikov 1959; Winkler 2001; Bartens 2000). Additionally, it is possible to have an overt nominative subject and agreement (103).

(103) GSUJa II (1970: 115)

[Ti šutetski-toź-adi] mi turna-n-mes bidest-i-m.

2PL rest-CVB.LIM-2PL 1PL.EXCL scythe-VN-1PL.ACC finish-PST-1PL

'While you were resting, we finished scything.'

Table 12 Morphosyntactic patterns in -toź-clauses

\begin{tabular}{|c|c|c|}
\hline Subject's case & Agreement & Example \\
\hline Nom & no & $(96)-(98)$ \\
\hline Nom & yes & $(103)$ \\
\hline
\end{tabular}

\subsubsection{The participle/converb -mon}

The participle -mon has a modal meaning: it expresses a potentially possible or sometimes a necessary action (Kalinina 2001: 154). Hence, this non-finite form is similar to English deverbal adjectives formed with -able. According to the grammars, this participle can be formed from both transitive and intransitive verbs, cf. (104) and (105).

(104) Kalinina (2001: 158)

$\begin{array}{llll}\text { [mirdem } & \text { kili-mon] } & \text { kuara-jen } & \check{s} u-i-z \\ \text { barely } & \text { hear-PTCP.POT } & \text { voice-INS } & \text { said-PST-3SG }\end{array}$

'(s/he) said (it) with a voice that can be barely heard'

(105) Perevoshchikov (1959: 88)

[armij-e mini-mon] pi

army-ILL go-PTCP.POT son

'(a) son who is (at the age when) he could/should go to the army' 
Kalinina (2001: 152-154) argues that the -mon-participles derived from transitive verbs can be passive (104) or active (106). Notice that in (106), the participle has a direct object.

(106) Kalinina (2001: 152)

[pel'-ez keśi-mon] kịržangur

ear-ACC tear-PTCP.POT music.melody

'deafening (lit. ear-tearing) music'

The traditional grammars acknowledge the fact that this participle often has a lexicalized meaning (Perevoshchikov 1959: 297). Let us mention a couple of very frequent, but most probably lexicalized forms: valamon 'understand-PTCP.POT' means 'understandable, clear' (and not 'a person/thing who is able to understand'); šumpotimon 'be.happy-PTCP.POT' means 'enjoyable' (and not 'a person/thing who is able to be happy'); śinmaśkimon 'fall.in.love-PTCP.POT' means 'adorable, lovely, fantastic' (and not 'a person/thing who is able to fall in love'). It is common that the -mon-participles are very often used without any modifiers (even in the examples presented in Kalinina 2001 and Perevoshchikov 1959). Based on the existing examples, it seems that this participle can have argument structure since at least the internal argument can be present, cf. (106). However, observe that in this example, the participial clause has an idiomatic meaning, it resembles a degree modifier. Kalinina (2001) presents examples in which the participle does not modify a noun, consider (107) in which it is a degree modifier of the adjective ted'i 'white'.

(107) Kalinina (2001: 149)

[śin mal'di-mon] tẹdì derem

eye dazzle-PTCP.POT white shirt

'a gleaming white shirt (lit. a shirt so white that it dazzles the eyes)'

According to the traditional descriptions, there is a converb homonymous with this participle. However, descriptive grammars present very few examples with the "monconverb". There are some very frequent constructions: valamon vera 'say in an understandable way' śinmaśkimon uža 'do a great job (lit. work adorably)', etc. Leaving aside these cases, in the other examples presented in the descriptive grammars, the "mon-converb" expresses the degree of the action (Hamari 2011: 65), as illustrated in the examples below. It 
should be emphasized that these degree modifiers do not necessarily imply an event: (108) does not mean that our backs broke, (109) does not say that the beaten person became a cripple, and (110) does not imply that the buildings quaked.

(108) Udmurt Corpus (burdjos.ru, 22/08/2013)

Ben, žad'-i-mi, $\quad k u s-m i=n o \quad$ [ćigi-mon] viś-i-z...

yes be.tired-PST-1PL waist-1PL=ADD break-PTCP.POT hurt-PST-3SG

'Yes, we got tired, our waists/backs hurt very badly (lit. as if they could break), too...'

(109) Perevoshchikov (1959: 90)

[sessirtí-mon] žug-i-z

cripple-PTCP.POT beat-PST-3SG

'( $\mathrm{s} / \mathrm{he})$ beat (someone) to death'

(110) Perevoshchikov (1959: 302)

[Vań jurtjer-jos zurka-mon], puška-os ogvad'es ỉbill-i-zi.

all building-PL quake-PTCP.POT gun-PL at.one.point shoot-PST-3PL

'At one point, the guns were firing (so blazingly that) all buildings quaked/would quake.'

Even if we disregard the idiomatic meaning and the productivity issues concerning this converb, the problem is that in Udmurt, adjectives do not take any morphological marking in order to be used as adverbs. ${ }^{31}$ Participles, similarly to adjectives, modify nouns, while adverbs and converbs modify verb phrases/finite clauses. If we assume that -mon-participles lexicalize into -able-adjectives, and adjectives do not take suffixes like -ly in order to be used as adverbs, it is not a surprise that these (lexicalized) participles can modify noun phrases, too. Note also that the other Udmurt participles cannot be used to modify verb phrases, neither can converbs in Udmurt be used to modify noun phrases. Thus, it is surprising that the -monparticiples can be used as converbs. Based on this, I conclude that the suffix -mon derives deverbal adjectives that may have some verbal structure, but they differ sharply from other converbs based on their idiomatic meaning and external syntax. The discussion of these

\footnotetext{
${ }^{31}$ Nevertheless, it is assumed that adverbs and adjectives are separate word classes in Udmurt since adverbs like mirdem 'barely' in example (104) cannot be used as adjectives. 
adjectives is certainly an interesting topic, especially in the light of -able-adjectives crosslinguistically (see Oltra-Massuet 2013), which I will leave for future research.

\subsection{Interim summary: non-finite clauses in Udmurt}

In this chapter, I provided a general description of non-finite clauses in Udmurt. First, I discussed the notion of finiteness, and argued that finiteness should be considered a property of the clause. I listed several parameters in which finite and non-finite clauses differ.

Contrary to the traditional description of Udmurt, I proposed that the division between clause types, i.e. relative, argument and adverbial clauses, proves to be more accurate/important than the division between participles, converbs and infinitives. This is supported by the multifunctionality of the $-(e) m$ - and $-(o) n$-nominalizations: they can be used in all three clause types. Instead of postulating homonymous suffixes, I suggested that the very same suffix can be used in several syntactic environments. I discussed the two nominalizations, and refined the claims made in the literature regarding their 'event'/"nonevent' readings, the possibility of pluralization, their temporal orientation and syntactic distribution.

Then, I turned to the three major clause types: relative, argument and adverbial clauses. Although the discussion of relative and argument clauses was rather brief, it provided background for comparison between relative and argument clauses, on the one hand, and adverbial clauses, on the other, in terms of their morphosyntactic properties. The detailed description of adverbial clauses revealed several features of theirs, previously unrecognized in the existing literature, both with respect to their functions and morphosyntactic properties (the subject's case-marking and agreement). These properties will be discussed in the next chapters, which are entirely devoted to adverbial clauses. 


\section{The structure of non-finite adverbial clauses in Udmurt}

In this chapter, I focus on two questions regarding adverbial non-finite clauses in Udmurt. Firstly, I discuss converbs, more specifically, I raise the question of how many converbs are to be distinguished in Udmurt (§4.1). In §4.2, the structure of Udmurt adverbial non-finite clauses will come under scrutiny: I will discuss the size of the extended verbal projection in these clauses. After answering these two questions, the proposed structure of non-finite adverbial clauses will be given in $§ 4.3$.

\subsection{How many converbs are there in Udmurt?}

According to the typological definition, converbs are-finite forms that express adverbial subordination (Haspelmath 1995). As a rule, converbs do not take any semantic cases or postpositions in order to form adverbial clauses. In Chapter 3, I presented illustrative examples of several non-finite forms traditionally termed as 'converbs' in the descriptive grammars of Udmurt. It has already been mentioned that some of these non-finite forms are nominalizations bearing a semantic case. These were the adverbial clauses headed by -(e)men, -(e)miś, -(e)mja and -(o)nja. In what follows, I will demonstrate that converbs in Udmurt represent a scale from fully transparent case-marked nominalizations to morphologically opaque non-finite forms. I will also raise the question of whether some converbs should be considered to be non-finite verbs at all, and propose that most converb clauses can be analysed as postpositional phrases in which the postpositional head selects for non-finite clauses of different types.

\subsubsection{Revisiting the existing approaches to converbs in Udmurt}

Traditional grammars do not propose exact criteria of how to distinguish between (casemarked) nominalizations and converbs. To my knowledge, Fokos-Fuchs (1958) is the only specific proposal in this respect. He discusses Permic verbal adverbs (Verbaladverb in his terminology), defined as typically case-marked or sometimes uninflected deverbal nouns used in adverbial position (Fokos-Fuchs 1958: 277). ${ }^{1}$ However, he argues that verbal adverbial suffixes are not simply a combination of a deverbal noun and a case suffix, because the verbal adverb suffix is no longer segmentable and/or it has an opaque meaning. Thus, his main

1 "Das Verbaladverb ist demnach ein Verbalnomen, das im allgemeinen mit einer Kasusendung versehen, doch seltener auch ohne eine solche, ausschliesslich die Rolle einer Umstandsbestimmung versehen kann.” 
criteria concern the morphological segmentability and semantic transparency of non-finite suffixes. He argues that the non-finites -sa, -tek, -ku and -toź should be classified as verbal adverbs, while the non-finite -(e)mja, -mon and -(o)ńńa should not. Fokos-Fuchs (1958: 289290) argues that the -(e)mja-non-finites - which, according to him, contain the adverbial case - are not verbal adverbs. His arguments are based on the order of possessive suffixes and case markers: their varying order indicates that we are not dealing with a single, fully grammaticalized suffix. The non-finites -(e)men are a borderline case: they are segmentable (into a nominalizing suffix and instrumental case), but their meaning is not transparent (Fokos-Fuchs 1958: 287). He argues that these adverbial clauses are translated into German with als '(causal) since' rather than with mit 'with', which he takes to be indicative of the grammaticalization of this suffix into a verbal adverb. In view of the fact that English -ing gerunds or small clauses selected by the preposition with can have a cause/reason flavoured meaning, cf. (1), his arguments seem less convincing.

(1) Aarts (1992: 42, ex. (114a))

With Peter the referee we might as well not play the match.

It should be emphasized that essentially, Fokos-Fuchs (1958) provides a diachronic account: he presents diachronic evidence regarding the origin of the individual non-finite forms, including their reconstructed forms.

In contrast to Fokos-Fuchs (1958), I aim at providing a synchronic account. As we will shortly see, some of the morphemes which are supposed to be converb suffixes contain morphologically reduced postpositions, but I assume that even these morphologically bound suffixes indicate the presence of underlying syntactic structure.

In this dissertation, I advocate the view that there is no need to posit a separate nonfinite suffix if the non-finite form in question can be segmented morphologically. The segmentation approach might seem unnecessary and undesirable from a descriptive point of view (and probably this is the reason why descriptive grammars do not take a clear standpoint on whether certain case-marked nominalizations are indeed converbs), but it has several advantages. Firstly, it shows the transparency between morphological form and syntactic structure. Secondly, it allows us to provide a uniform account of most non-finite adverbial clauses, without postulating a separate category of 'converbs'. For instance, the adjuncts formed with -(e)miś (-(e)m-nominalization + elative) are accounted for in the same way as the 
-(e)m-nominalizations used as complements of non-subcategorized postpositions/relational nouns, such as bere 'after', aźin 'before', etc. In principle, this account would also be compatible with the analysis of English 'preposition + -ing' clauses.

In my opinion, Fokos-Fuchs' (1958) second criterion, i.e. semantic transparency, can be derived from morphological transparency in the vast majority of cases: morphologically unsegmentable suffixes are semantically opaque, and vice versa.

Let us take a look at Udmurt converbs and their morphological segmentability form a synchronic point of view. As shown in Table 1, some of the potential candidates for being labelled as 'converb' are fully segmentable case-marked forms of nominalizations, others are only partly segmentable, and some forms are opaque. The judgments below differ from those of Fokos-Fuchs (1958) in many respects.

Table 1 Converbs in Udmurt: morphological and semantic transparency

\begin{tabular}{|l|c|c|}
\hline Converb & Morphologically transparent & Compositional meaning \\
\hline$-(e) m e n$ & yes & yes \\
\hline$-(e) m i s ́ s$ & yes & yes \\
\hline$-(e) m j a$ & yes & yes \\
\hline$-(o) n j a$ & yes & yes \\
\hline$-o n ́ n ́ i g a$ & yes (?) & $(?)$ \\
\hline$-m o n$ & yes (?) & $(?)$ \\
\hline$-t o z ́$ & partly & yes \\
\hline$-k u$ & partly/no (?) & $(?)$ \\
\hline$-t e k$ & no & - \\
\hline$-s a$ & no & - \\
\hline
\end{tabular}

We have already discussed the case-marked forms of -(e)m-nominalizations. I argue that in these cases we are not dealing with converbs. In §4.1.2, I will discuss the rest of the converbs listed in Table 1.

\subsubsection{The morphological make-up of converb suffixes}

Let us begin with -(o)nja-non-finites. It was assumed in the previous literature that these contain a nominalizing suffix bearing the adverbial case. In §3.7.2.3, I questioned this view, and suggested that these clauses contain an inessive/illative case suffix. I also demonstrated 
that these adverbial clauses do not allow a spatial mismatch between the events in the main clause and the embedded clause (at least in the Middle Cheptsa dialect). In order to account for this, I propose that the -(o)ńńa-forms have the following structure: -(o)n-ń-a 'VN-ńINE/ILL', rather than -(o)n-ja 'VN-ADV' with the assimilation of the glide, as is standardly assumed. It needs to be clarified what the $-n$ element is. The proposal I put forward here is built on an idea found in Usacheva \& Serdobolskaya's (2015) discussion of the Beserman Udmurt -(o)ńníga-converbs.

According to Usacheva \& Serdobolskaya (2015: 370-371), -(o)ńńiga-converbs should be segmented into (at least) three parts: the deverbal nominalizer -(o)n, the suffix -nig and the vowel - $a$ that precedes the possessive suffixes, used obligatorily on this converb. They argue that the suffix -ńig corresponds to the deverbal nominalizer -ńni used in standard Udmurt to form locative nominalizations. ${ }^{2}$ Hence, the Beserman -(o)ńniga-converbs can be used not only to express a simultaneous event (in this function, their meaning is identical to that of -(o)nja-non-finites), but they can also be used as a locative nominalization (cf. §3.7.2.3). Regarding the suffix -ńig, Usacheva \& Serdobolskaya (2015: 371-373) propose that it contains two morphemes: the so-called 'DOMUS suffix' $-\dot{n}$ and the deverbal nominalizer -ig. ${ }^{3}$ The DOMUS suffix is used in the Beserman dialect as well as in some Northern dialects, including the Middle Cheptsa dialect, and combined with locative case markers, it express the meaning ‘to/from/at someone’s place', e.g. eš-ez-ń-e 'friend-3sG-DOMUS-ILL to his friend's place/house' (Karpova 2005: 60-63). The DOMUS suffixes are said to originate from the postposition dine 'around'. 4

Based on this, I propose that the same case marker/reduced postposition $-\dot{n}$, meaning 'AT(PLACE)', is found in -(o)ńńa as well. Thus, the underlying form is -(o)n-ń-a-(Px) 'VNAT(PLACE)-INE/ILL-(Px)'. This naturally explains the impossibility of spatial mismatch in these clauses. The reason why we find this phenomenon in the Beserman Udmurt and Middle Cheptsa dialects follows from the fact that these dialects use the DOMUS suffix.

Turning to the simultaneous converb $-k u$ (in the Southern dialects: $-k i /-k \hat{a}$ ), it is synchronically completely opaque in terms of morphology. Diachronically, its dialectal form

\footnotetext{
${ }^{2}$ This must be qualified, however: the locative nominalizing suffix in standard Udmurt is always -(o)ńníi, as in dugdil-ońní 'stop:V-NLOC (bus) stop'. Of course, this does not mean that the suffix cannot be segmented.

${ }^{3}$ As for the Beserman Udmurt -(o)ńńiga-coverbs, Usacheva \& Serdobolskaya (2015: 373) themselves consider it to be problematic that according to this segmentation, the "deverbal noun + postposition" is followed by another non-finite form, namely, -ig. Here I do not wish to provide an explanation for these non-finite clauses since they are not used in the dialects I have worked on.

${ }^{4}$ Emelyanov (1927: 123) proposes that these suffixes have grammaticalized from the noun iń 'place'. This is, in principle, also compatible with my proposal regarding -(o)ńna-clauses.
} 
$-k i /-k \hat{s}$ is said to originate from a deverbal noun, formed with the reconstructed suffix *-iki (Bartens 2000: 249-251; Fokos-Fuchs 1958: 307-324; Csúcs 2005: 284). The Komi converb in -ig-(en) is also said to originate from this deverbal suffix. The reconstruction of these two non-finites to a common form has been questioned, though. A. Kövesi (1965: 108-114) argues that the Komi non-finite suffix -ig is, in fact, a deverbal nominalizer: it takes case suffixes or postpositions, it might be used to form adjunct clauses as well as complements of perception verbs ${ }^{5}$, etc. Based on this, she claims that the Komi -ig suffix stems from the derivational suffix $-g$ (< Proto-Finno-Ugric/Proto-Uralic *- $\eta k$ ). According to A. Kövesi (1965: 104-118), the suffix $-g$ is used for denominal noun, deverbal noun, deverbal verb and denominal verb formation, although most of these forms are no longer transparent. A. Kövesi (1965: 114, 119) argues that the Komi non-finite form -ig has developed independently and the Udmurt suffix is a distinct form, however - according to my understanding of her work she does not explicitly say what form the Udmurt suffix comes from. Even Fokos-Fuchs (1958: 317) himself mentions an additional problem with the *-iki suffix: he assumes that it contains a lative suffix, hence, when possessive suffixes attach to this converb, the expected forms would be *-k-a-Px, the vowel $-a$ being the illative case marker. However, the possessive suffixes attach directly to the converb, without the $-a$ vowel. Fokos-Fuchs (1958: 317) does not offer an explanation for this fact. Nonetheless, he argues that this converb can be viewed as a (temporal) case suffix or a postposition since the possessive suffixes used on it are also used after certain case suffixes and postpositions. To make matters even more complicated, Bartens (2000: 251) does not exclude the possibility that the Udmurt converb is, in fact, the lative suffix itself (reconstructed as $*_{-} k$ ). Based on the above-mentioned facts, it seems that the diachronic explanations provided in the literature are not entirely convincing.

Synchronically, the problem is that this converb suffix is homonymous with the content interrogative pronoun 'when' (2a). The content interrogative is also used in indirect questions (2b) or as a complementizer, in which case it is sometimes combined with $k e$ 'if' (2c). ${ }^{6}$ Note also that the matrix clause in (2c) contains the temporal adverbial soku 'then' formed with the distal demonstrative pronoun so 'that' and $k u$ 'when'. As mentioned in GSUJa III (1974: 6162), adverbial clauses headed by kuke are often similar to conditional clauses. This complementizer selects for finite clauses. The temporal adverbial clause can either precede or follow the main clause.

\footnotetext{
${ }^{5} \mathrm{~A}$. Kövesi's term is 'attributum praedicativum', but the examples she provides are with perception verbs.

${ }^{6}$ Example (2c) comes from GSUJa III (1974: 61).
} 
(2)

a. $\mathrm{Ku} \mathrm{likt-o-d?}$

when come-FUT-2sG

'When will you come?'

b. Maša jua-z ku likkt-o-d (šuisa)?

Masha ask-PST.3sG when come-FUT-2sG (that)

'Masha asked when you would come?'

c. Vojna-in samoj umojtem-ez lue soku,

war-INE most bad-3sg be[PRS.3sG] then

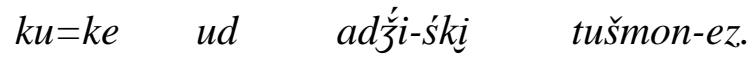

when=if NEG.2 see-PRS[SG] enemy-ACC

'The worst [thing] during war is when you don't see the enemy.'

It is cross-linguistically common for interrogative pronouns to be used as relative pronouns in adverbial clauses, consider the English examples in (3).

(3) Haegeman (2010: 636, ex. (23a, b, c))

a. When did he arrive?

b. I wonder when he arrived.

c. When he arrived, the place was in darkness.

In English, it is also possible to use when with non-finite forms, such as -ing gerunds, see the translation of the next Udmurt example.

(4) Georgieva (2012, 2017a) (adapted from GSUJa I 1962: 286)

[Gožja-ku] predloženi-len pum-a-z toćka pukto.

write-CVB.SIM sentence-GEN end-INE/ILL-3sg full.stop[ACC] put[PRS.3PL]

'When writing, one puts a full stop at the end of the sentence.'

Most scholars nevertheless argue that the Udmurt non-finite $-k u$ is distinct from the content interrogative $k u$ 'when' (Perevoshchikov 1959: 70; Fokos-Fuchs 1958; Csúcs 2005). The original form of this non-finite is assumed to be the dialectal $-k i$, while the form in $-k u$ is 
said to have developed analogically to the content interrogative (Csúcs 2005: 284; FokosFuchs 1958: 316). It is noteworthy that the above-mentioned temporal adverbial soku 'then' also has a dialectal form, i.e. soki, which Csúcs (2005: 247) reconstructs as Proto-Permic *se-ko, noting that the current form soku is an analogous development to the content interrogative. $^{7}$

Given the uncertainties regarding the diachronic origin, two different analyses can be put forward synchronically. According to the first one, the converb suffix is nothing else but the content interrogative (pace the diachronic studies discussed above). Under this analysis, it must be explained why the content interrogative appears attached to the verb as a clitic-like element. ${ }^{8}$ In my view, it is possible that the content interrogative moves out of the clause and attaches to its left (the initial complementizer kuke 'when/if' exemplified in (2c) is presumably a more recent development, as finite subordination is generally assumed to have emerged later in Udmurt). The second option would be to view this suffix as a postposition/case-marker meaning 'at (time)' (in line with Fokos-Fuchs' 1958 insights). This is supported by the temporal adverbial form soku 'that-ku, then' that patterns with sobere 'that-after, after that'. I will take the second approach here. ${ }^{9}$ What remains to be explained (under both analyses) is why $-k u$ attaches to a bare verbal stem without any nominalizing suffix. Observe that in English, when can select for a non-finite form, while in Udmurt, we do not find an overt nominalizing morpheme on the verb. I propose that the reason for this is the temporal reference of $-(e) m$ - and $-(o) n$-nominalizations: as I argued in $\S 3.4$, the former expresses an anterior event, while the latter express a prospective event (with respect to the assertion time/topic time). The function of 'when'-clauses is to express an event simultaneous with the event of the main clause. Thus, the temporal reference of both nominalizations is incompatible with 'when'-clauses. I argue that the bare stem is unspecified for relative time (i.e. aspect).

\footnotetext{
${ }^{7}$ Fokos-Fuchs (1958: 316, fn. 2), however, argues that the dialectal forms of the temporal adverbial have developed under the influence of the converb. This means that the content interrogative must have had the form $k u$, the temporal adverbial must have been soku, while the converb suffix must have been -ki. The emergence of temporal adverbial forms like soki and converb forms with -ku shows the mutual influence of the temporal adverbial and the converb. Given the fact that to my knowledge, the form of the temporal adverbial always corresponds to the form of the converb in the Udmurt dialects, i.e. soki and -ki in the Southern dialects, soku and $-k u$ in all other dialects (and in standard Udmurt), it is more likely that they must have shown the same pattern originally. It is noteworthy that the content interrogative is $k u$ in all varieties of Udmurt.

${ }^{8}$ I thank Krisztina Szécsényi for raising this question.

${ }^{9}$ It must be noted that the content interrogative account is, in principle, compatible with the idea that Udmurt non-finite adverbial clauses are postpositional phrases if we follow Demirdache \& Uribe-Etxebarria's (2004) analysis of 'when'-clauses. They claim that 'when'clauses are postpositional phrases headed by a covert preposition (as opposed to other temporal clauses, in which the preposition is overt).
} 
The negative converb -tek is synchronically a morphologically opaque suffix. Diachronically, it goes back to the caritive suffix $-t$ and the suffix $*_{-} k$ (Fokos-Fuchs 1958: 304-305). The caritive suffix - $t$ is also found in the negative attributivizing suffix -tem (used on adjectives and participles, cf. Chapter 3). The origin of the suffix *-k is disputed: it is reconstructed either as a lative case or as the deverbal nominalizer *-iki discussed above. A. Kövesi (1965: 379) argues that it goes back to the suffix *-nk from which the Komi nonfinite verb -ig originates (see above).

Synchronically, the suffix -tek is the abessive/caritive case marker used on nouns, cf. (5). The converb suffix illustrated in (6) is said to be identical to the case suffix, both synchronically and diachronically (Hamari 2011; Csúcs 2005: 284; Fokos-Fuchs 1958: 302).

(5) elicited

Šid-ez sịlal-tek péźt-i.

soup-ACC salt-ABE cook-PST[1SG]

'I cooked the soup without salt.'

(6) fieldwork, spontaneous

Šid-ez [odig pol=no sura-tek] peźt-i.

soup-ACC one times=ADD stir-CVB.NEG cook-PST[1sG]

'I cooked the soup without stirring (it) even once.'

The problem is that in Udmurt, nouns and verbs take different morphology: we do not find tense markers on nouns, hence, we do not expect to find case markers on verbs either. (Traditional grammars, however, find this issue unproblematic.) Note that in the English translation of (6), we find a gerund, whereas in Udmurt, the suffix -tek attaches directly to the bare verbal stem.

Tamm (2014: 133-134) claims that the abessive case is cross-categorial, since it appears on both nouns and verbs. In my view, this claim is not very explanatory by itself. What is more interesting is the observation that the abessive case does not appear on nominalizations. ${ }^{10}$

There are two problems with Tamm's (2014) claims. Firstly, the nominalizations formed with suffixes -(e)m and -(o)n do not take all case suffixes: Tamm (2014) mentions that

\footnotetext{
${ }^{10}$ This claim is based on data provided by Svetlana Edygarova, a native speaker of Udmurt.
} 
the egressive is also missing, and no data are provided with the prolative and approximative. ${ }^{11}$ Secondly, non-event nominalizations behave like regular nouns, hence, they take all casesuffixes, including the abessive, whereas event nominalizations do not. In Chapter 3, I discussed the word šećiran that can encode an event ('swinging') or an instrument nominalization ('swing'). As shown in (7), the instrument nominalization can be used with the abessive suffix.

(7) elicited

$\begin{array}{lll}\text { Pinal-jos } & \text { క̌ećiran-tek } & \text { kill-i-zi. } \\ \text { child-PL } & \text { swing-ABE } & \text { remain-PST-3PL }\end{array}$

'The children were left without a swing (it was broken/stolen or they didn’t get one).'

Thus, I argue that the abessive can be used with nominalizations, but only in their 'nonevent' reading. Thus, the suffix -tek can select either for nouns (including non-event nominalizations) or verb phrases without any nominalizing suffix. This (more or less) coincides with the original problem: why do we find the same suffix attaching to nouns and verbs.

In order to explain this, I propose the following: when the abessive appears on a noun, it heads a secondary predicate. This follows A. Kövesi (1965: 380), who claims that the abessive-marked nouns in (8) function as 'attributum praedicativum'. According to my understanding of her terminology and the Hungarian translations she provides, it seems that the three abessive-marked nouns function as (absolute) secondary predicates. ${ }^{12}$

\footnotetext{
${ }^{11}$ Furthermore, I doubt that event nominalizations occur with some semantic cases, such as the inessive, illative and probably also terminative.

${ }^{12}$ A. Kövesi’s (1965) translation is: 'ő mint kezetlen, lábatlan nyelvetlen stb. (s mégis) beszél', compare with Munkácsi’s original translation: 'Kezetlen, lábatlan, nyelvetlen, hallástalan, [s mégis] beszél’. Thus, Munkácsi’s and A. Kövesi's translations suggest that kilontäm is coordinated with the three abessive-marked nouns. This is implausible since the word kilontäm contains the negative attributivizing suffix -tem, and not the abessive. Generally, it is assumed that only elements of the same kind can be coordinated. It seems that the confusion is caused by the comma after kiltäk. If, however, this is a secondary predicate in absolute position, it would not be surprising that it is set it off with a pause, in which case the use of comma in the original text is not difficult to explain. Hence, I suggest that kilontäm modifies the predicate. This is also supported by the fact that the meaning of kilontäm is not 'hearingless, i.e. deaf', as in Munkácsi's and A. Kövesi's translations, but 'unhearable/unhearably' (cf. Kirillova 2008).
} 
(8) Munkácsi (1887: 45)

kitäk, pidtäk, kiltäk,

kilontäm

hand:ABE foot:ABE tongue:ABE hear:PTCP.PRS:NEG.ATTR speak[PRS.3sG] writing

'Being handless, footless, tongueless, [it] speaks unhearably - writing.' or

'With no hands, no feet, [and] no tongue, [it] speaks unhearably - writing.' (riddle)

In (8), the meaning of the abessive is not to indicate the manner of how the writing speaks, but to encode a property of writing, in other words we are dealing with a depictive secondary predicate. The secondary predication analysis can be extended to examples (6) and (7). This means that (6) and (7) mean 'I cooked the soup unsalted/being without salt' and 'The children were left swingless/being without a swing', respectively. I assume that the difference between (6) and (7) on the one hand, and (8), on the other, is that the latter is an absolute secondary predicate, i.e. it modifies the whole sentence.

Moreover, it is known that the prepositions with and without in English can select not only for nouns, but also for small clauses (McCawley 1983; Aarts 1992). The term 'Small Clause' "refers to a string of XP YP constituents which enter into a predication relation, but the predicate YP, rather than containing a fully inflected verb, contains an adjective phrase, noun phrase, prepositional phrase or an uninflected verb phrase” (Basilico 2003: 1). We have already seen an example of non-verbal small clauses with the preposition with, cf. (1) above. The predicate of these small clauses might be a non-finite form, such as an -ing-gerund, past participle or an infinitive (9).

(9) McCawley (1983: 275, ex. (14a))

With there (probably) to be a meeting at 1:00, we'd better have a quick lunch.

In light of this, it is not surprising that we find -tek in non-finite clauses. Thus, it is incorrect to say that this suffix is used on both nouns and verbs: the real generalization is that -tek can select for clausal complements. We have already seen in §3.7.2.5 that -tek-clauses can have locative modifiers and overt subjects. One example is repeated below for the reader’s convenience. (The size of these adjunct clauses will be discussed in §4.2.) ${ }^{13}$

\footnotetext{
${ }^{13}$ Here I do not wish to take a stand on the internal structure of the cases in which -tek takes a non-verbal complement.
} 
(10) elicited

[Apaj-os-iz gurt-e berti-tek] Kol'a mezme val.

elder.sister-PL-3SG home-ILL come.home-CVB.NEG Kolya be.sad[PREs.3sG] AUX.PST 'Without his elder sisters coming home/His elder sisters not having come home, Kolya was sad.’

Thus, I assume that synchronically -tek is an opaque postposition/case suffix, meaning 'without'. It is noteworthy that based on data from the $19^{\text {th }}$ century (Munkácsi 1887), it seems that -tek could additionally be marked with the inessive/illative case and possessive suffixes (similarly to other postpositions, cf. §2.3.1), cf. (11). ${ }^{14}$ According to my consultants, these are obsolete examples in today’s Udmurt.

(11) Munkácsi (1887: 108)

[19th century Udmurt]

So-minda zarńi pottitäkadi mon ti-bordiśs ug kučki.

DEM.much gold[ACC] take.out:CVB.NEG:INE/ILL:2PL 1SG 2PL:next:ELA NEG leave[SG] 'I won't leave until/unless you bring that much gold (lit. without you bringing that much gold).'

Note that the meaning of this example is comparable to that of an 'until'-clause in English. In Udmurt, 'until’-clauses are headed by the converb -toź (§3.7.2.7). This converb is segmented into an unproductive deverbal nominalizer $-t$ and a fully productive case suffix, namely the terminative case -oź 'until' (Bartens 2000: 250, 254; Fokos-Fuchs 1958). FokosFuchs (1958: 299) argues that the -toź-forms should be regarded as verbal adverbs because the deverbal nominalizer $-t$ is not productive anymore. Fokos-Fuchs (1958: 287) nevertheless notes that the converb -toź still shows similarities to the terminative, e.g. on both terminative case marked nouns and -toź-converbs, the possessive suffixes are preceded by the vowel - $a$ (which he considers to be an illative case suffix; but see Csúcs 2005: 204 for a different view). Observe also that the main function of this converb, i.e. 'until', reflects the meaning of the temporal use of the terminative case. Thus, the disadvantage of considering -toź to be a single, indivisible suffix, as proposed by Fokos-Fuchs 1958, is that the parallels between the terminative case and -toź-converbs remain a mystery.

\footnotetext{
${ }^{14}$ Since the original notation of the examples contains hyphens, I do not segment the words into morphemes, but use a colon instead.
} 
It has been argued above that the suffix - $t$ in -toź-non-finites is a deverbal nominalizer, which has nothing to do with the caritive suffix - $t$ found in the converb suffix -tek (FokosFuchs 1958: 302). Based on (11), it seems that the adverbial clauses with -toź- and -tek at least functionally overlap. As noted in the typological overview of adverbial clauses (§3.7.1), there is a great amount of cross-linguistic evidence that 'until'- and 'before'-clauses often show negative polarity (or irrealis markers) (Hetterle 2015). Recall that -toź-non-finites can also be used as ‘rather than'-clauses, which also license any in English (I'll take a job rather than go any deeper into debt, cf. Thompson 1972). Based on this evidence, I tentatively propose that the - $t$ element in -toź-non-finites is, in fact, a negation marker. If this is on the right track, then -toź-non-finites contain a negative marker on the bare verb stem and a case suffix. A similar non-finite form is found in Turkish as well: 'before'-clauses can be expressed by a negation marker attaching directly to the verb stem and followed by ablative case marker (Kornfilt 1997: 71). This idea has implications on how we view negation in Udmurt: sentential negation is expressed with a negative verb and it is fully productive, but one might argue that Udmurt also has unproductive (constituent) negation with the suffix $-t$ found in the non-finites clauses with -tek, -toź, and -mte, as well as in the negative attributivizing suffix -tem.

Additionally, this converb has different forms in the Udmurt dialects: -tož, -toś, -ččož, -ććož or -(ć) ćoź (Kelmakov 1998: 157-158). It has been suggested that two of them, -ččož and -ććož, have a different origin: they contain the (reduced) form of the postposition čož(e) ‘along, through, during’ (Perevoshchikov 1959: 76-78). In §3.7.2.7, it was shown that -toźclauses can also express a meaning corresponding to that of English 'while'-clauses. In this case there is a partial overlap between the events expressed by the adjunct and main clause (Simultaneity DuRATiON in Kortmann’s 1996 classification). Recall also this use of -toźclauses seems to be available only in some dialects, which can be easily explained if it goes back to a different postposition (and later possibly collapsed into the common form -toź used in standard Udmurt).

There is one converb left to discuss: -sa. It is morphologically and semantically opaque. Its origin is disputed; with two main theories on the market (see Perevoshchikov 1959: 42-45; Csúcs 2005: 283 and the references therein). According to the first one, this converb must have been a (case-marked) deverbal nominalizer. The other proposal is that it is a Chuvash borrowing. Whichever the right etymology is, in my opinion, this is the only real candidate 
for the category 'converb': it does not take case or possessive suffixes; it cannot be segmented into a nominalization and a case suffix; and it is used only in adverbial clauses.

In the following chapters, I will maintain the gloss CVB for all less convincing cases of converbs for the sake of convenience, but I would like to emphasize that this label does not say much about the structure of these adverbial clauses. What I consider more important is to deal with all the adverbial clauses, irrespectively of whether they are headed by (true) converbs, “pseudo-converbs” or nominalizations used as complements of postpositions. Based on the evidence presented in this subsection, I conclude that most of the adverbial clauses in Udmurt can be reduced to clauses selected by case suffixes/postpositions. In the next subsection, I focus on the internal syntax of adverbial clauses.

\subsection{The internal syntax of Udmurt adverbial clauses}

In order to determine the size of Udmurt non-finite adverbial clauses, I will apply several tests discussed in the generative literature. It is standardly assumed that there are three main clausal domains: VP, TP and CP. These three domains can be further split into several projections. Below the main properties of these three domains are reviewed. ${ }^{15}$

The verb phrase is the thematic domain in which arguments of the lexical verb are introduced. Weather verbs, unaccusative, unergative, transitive, ditransitive and causative verbs differ with respect to the number and type of their arguments. For example, unaccusative and unergative verbs have one argument, but in the case of the former, it is an internal one, i.e. it is introduced in the VP, while the latter take an external argument. There are two main proposals about the position of the external argument. According to Chomsky (1995), it sits in the vP. Kratzer (1996), on the other hand, argues that external arguments are located in VoiceP. According to Kratzer (1996), VoiceP is also responsible for the assignment of accusative case to the object. The analysis of causative constructions put forward by Pylkkänen (2008) also relies on the presence of VoiceP, below which a CauseP is found. This projection houses the causing event. Moreover, the verb phrase encodes information about event structure and aspect. The aspectual information expressed in this layer is directly relevant to the event (Aktionsart or internal aspect), and it is related to the properties of the verb, i.e. the aspectual opposition between imperfective/perfective is often determined by the [ \pm durative] and $[ \pm$ telic] features of the verb. Thus, the VP also contains aspectual information, expressing whether the event is completive, frequentative, etc.

\footnotetext{
15 This summary is based on van Gelderen (2013), unless otherwise specified.
} 
The TP is the inflectional domain which is responsible for tense, mood/modality, viewpoint aspect, agreement and case-licensing. In English, this layer contains at least the following projections: TP > MP > AspP > VP (in current Minimalism, the existence of a separate agreement projection has been abandoned, cf. Chomsky 1995). Demirdache \& UribeEtxebarria (2004) propose a split between AspP and TP. Following Klein (1994), they argue that both tense and aspect relate two times: tense relates the time of utterance to the assertion time. Aspect, on the other hand, relates the assertion time to the time at which the event (or state) happens or holds. The assertion time is the time about which the speaker makes a statement. According to Demirdache \& Uribe-Etxebarria (2004), both Tense and Aspect take a time-denoting phrase as their complement. The external argument of $\mathrm{T}^{\circ}$ is typically the utterance time; its internal argument is the assertion time. Similarly, the external argument of Asp $^{\circ}$ is the assertion time; its internal argument is the event time. Additionally, they are both spatiotemporal ordering predicates with the meaning of AFTER, BEFORE or (WITH)IN. For example, both $\mathrm{T}^{\circ}$ and $\mathrm{Asp}^{\circ}$ convey the meaning (WITH)IN in the case of the present progressive in English. The idea that relative time, i.e. aspect, is located in a separate projection is also found in Haumann (2007) (Rel(ative)t(ense)P).

In Government and Binding Theory, the presence of a finite $\mathrm{T}$ is considered to be crucial for the licensing of nominative case on the subject (Chomsky 1981: 50). Additionally, subjects are said to move to Spec,TP in order to satisfy the Extended Projection Principle (EPP). A more recent motivation for the EPP comes from pragmatic roles or structural requirements, for example, it is argued that Spec,TP is the position in which DPs are interpreted as specific. The role of TP in the structural licensing of nominative case is maintained in recent studies as well. For instance, Pesetsky \& Torrego (2004) propose that nominative case in English involves an uninterpretable Tense feature on the DP which is valued by a finite $\mathrm{T}$. The competing approach proposed within the Dependent Case Theory is that nominative is assigned as an unmarked/default case (Marantz 1991; Baker 2015). As will be discussed in $\S 4.2 .2$, this question is particularly relevant in non-finite clauses.

The CP or the 'discourse' domain is related to topic, focus, force, wh-movement, and finiteness. Rizzi (1997) proposes that the CP layer is split into several projections (12). The lowest of them is FinP, which encodes finiteness. ForceP marks the mood of the sentence (indicative, interrogative, imperative, etc.). Additionally, topicalized and focalized constituents are located in separate projections, TopP and FocP, respectively. 
(12) Split CP Hypothesis (Rizzi 1997: 297)

ForceP $>$ TopP* $>$ FocP $>$ TopP* $>$ FinP $(>$ IP)

Complementizers are also located in the CP. Rizzi argues that the two Italian complementizers che and di occupy different positions: the former is in Force, while the latter is in Fin. The evidence in favour of this comes from topicalization: topics can precede di, but not che. Similar ideas have been put forward in the case of English complementizers (see van Gelderen 2013: 161-163). With regard to adverbial clauses, a remark is in order about the socalled 'prepositional complementizers', such as while, after, before, etc. Some authors (e.g. van Gelderen 2013) analyse them as complementizers, while others (e.g. Haegeman 2003, 2010, 2012; Demirdache \& Uribe-Etxebarria 2004) treat them as prepositions (additionally, neutral labels, e.g. 'connectives' or 'subordinators', are also used in the literature). The two approaches make (fairly) similar predictions about the size of these adverbial clauses. For instance, while can be used both in temporal and in concessive/adversative clauses, and only concessive 'while'-clauses allow for fronted topics. Under the complementizer approach, this suggests that concessive while is in Force, whereas the preposition analysis suggests that it takes a full-blown CP complement. Likewise, temporal while is either located lower or takes a smaller complement. (It must be noted, though, that Haegeman's 2010, 2012 intervention approach does not rely on the assumption that certain adverbial clauses are truncated; it explains the lack of topicalization with operator movement.)

Generally, the possibility of topicalization and focusing in embedded clauses is more limited in comparison to main clauses. This holds not only for adverbial clauses, but also for factive complement clauses and non-finite complement clauses headed by for in English. This indicates that their CP is reduced.

Let us now turn to adverbials associated with the three domains. The position of adverbials is a highly debated topic in the literature. According to Cinque (1999), adverbials sit in specifiers of functional projections. He proposes the following hierarchy of functional projections (13). 
(13) The universal hierarchy of clausal functional projections (Cinque 1999: 106)

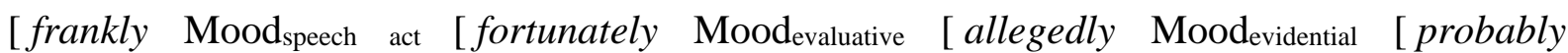

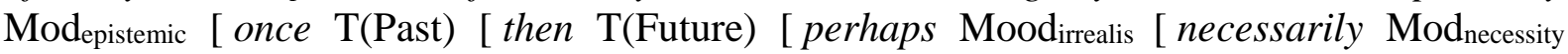

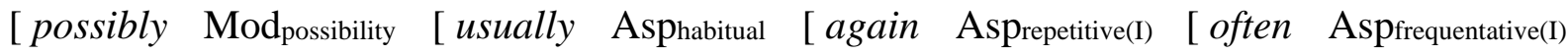

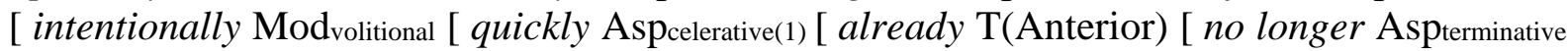

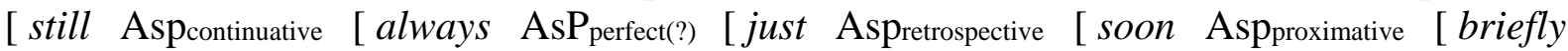
Aspdurative [ characteristically(?) Aspgeneric/progressive [ almost Aspprospective [ completely AspsgCompletive(I) [ tutto Aspp1Completive [well Voice [fast/early Aspcelerative(II) [ again Asprepetitive(II) [ often Aspfrequentative(II) [ completely AspsgCompletive(II)

As can be seen from the hierarchy given in (13), adverbials can be grouped around the three clausal domains, with the TP being the most elaborated one. Although Cinque's (1999) hierarchy has been subject to criticism (see van Gelderen 2013: 123-128; Haumann 2007, a.o.), the idea that certain adverbials might indicate the presence of functional projections is accepted by many researchers. For instance, Haegeman (2003, 2010) shows that high sentence adverbials (e.g. frankly, luckily) are illicit in certain adverbial clauses, which might be taken to suggest that these clauses lack a CP layer. Likewise, the possibility of temporal adverbials in non-finite clauses is said to prove that they have (semantic) tense, and a TP is projected (see Landau 2000, et seq.; Pires 2006, a.o). Thus, the presence/absence of adverbials can be used as a diagnostic for determining the size of the extended verbal projection in non-finite clauses.

In §3.1, it was noted that one way to capture the syntactic differences between finite and non-finite clauses is to assume that non-finite clauses lack certain projections. The truncation analysis has been proposed for nominalizations, gerunds, infinitives and converbs (Kornfilt \& Whitman 2011; Pires 2006; Wurmbrand 2001; Weisser 2015, a.o.). In what follows, I will take a closer look at the internal structure of Udmurt non-finite adverbial clauses with respect to the three clausal domains.

\subsubsection{VP}

To begin with, non-finite adverbial clauses in Udmurt show great similarities to finite clauses with respect to the VP layer.

In Chapter 3, we saw several examples of non-finite adverbial clauses modified by various adverbials: manner adverbials, temporal or locative PPs, etc. In (14), the non-finite clause is modified by the locative adverb otin 'there' and by the temporal adverbial ukmis toleź 'for nine months'. 
Turku-Izhevsk Corpus (Invozho/I/4:50)

[Otin ukmis toleź ulì-toź-am] biddes 20 santimetr-li budi-śkem.

there nine month live-CVB.LIM-1SG as.many.as 20 centimeter-DAT grow-EVID[1sG] 'While I was living there for nine months, I've grown as much as 20 centimetres.'

Now let us discuss manner adverbs. As noted in Chapter 3, compared to adjectives, Udmurt adverbs do not take any extra morphological marking. However, there are a couple of adverbs that cannot be used as adjectives, such as pir-poc' 'in detail/accurately', ros-pros 'thoroughly, in detail', juri ‘deliberately', tokma 'in vain, uselessly', mirdem 'barely', etc. These manner adverbs are licit in non-finite clauses (15) (recall that manner adverbs sit in Spec,VoiceP in Cinque's 1999 hierarchy). Additionally, adverbs like deliberately also indicate the presence of an agent.

(15) elicited

[Juri ros-pros jua-l'l'a-śki-sa] Maša Kol'a-jez isa-z.

deliberately thoroughly ask-FREQ-INTR-CVB Masha Kolya-ACC annoy-PST.3SG

'Deliberately asking him thoroughly, Masha annoyed Kolya.'

Turning to the arguments of the verb, example (16) shows that non-finite adverbial clauses in Udmurt can have objects. Both unmarked and marked objects are possible. Below, I present the minimal pair of (16), (17), in which the object is marked. This means that both finite and non-finite clauses show DOM, possibly with the same constraints on the specificity of the object.

(16) fieldwork recording, 2014_07_21, VE, Alnash, Udmurtia

$\begin{array}{lllll}\text { [každij } & \text { kuno } & \text { pir-ti-ku] } & \text { niriśs =ik } & \text { pukte }<\mathrm{H}:> \\ \text { every } & \text { guest[ACC] } & \text { come.in-CAUS-CVB.SIM } & \text { first=EMPH } & \text { put[PRS.3sG] } \\ \text { క̌ę } & v e ̨-i & \text { pukon-ez } & & \\ \text { table } & \text { next-ILL } & \text { chair-ACC [...] } & & \end{array}$

'When [shei] lets every/a guest come in, [the hosti] first puts a chair next to the table [...]' 
(17) elicited

$\begin{array}{lllll}\text { [každij } & \text { kuno-jez } & \text { pir-ti-ku] } & \text { niriśs=ik } & \text { pukte }<\mathrm{H}:> \\ \text { every } & \text { guest-ACC } & \text { come.in-CAUS-CVB.SIM } & \text { first=EMPH } & \text { put[PRS.3SG] } \\ \text { ร̌ek } & v e ̨ z-i & \text { pukon-ez } & & \\ \text { table } & \text { next-ILL } & \text { chair-ACC [...] } & & \end{array}$

'When [shei $]$ lets every (single) guest come in, [the hosti] first puts a chair next to the table [...]'

Non-finite adverbial clauses can also express various aspectual and voice distinctions. In (18), we find the frequentative suffix $-l$ - and the causative suffix -t-. Observe also that the non-finite clause has an independent subject as well (Petya).

(18) elicited

\begin{tabular}{|c|c|c|c|c|}
\hline [Pet'a & pinal-jos-ịz & kńiga & lidž́i-t & Maša \\
\hline Petya & child-PL-ACC $\quad b$ & book[ACC] & read-c & Masha \\
\hline soos & šumpoti-so & učke & & \\
\hline 3PL & rejoice-CV & $\operatorname{look}[\mathrm{r}$ & S.3SG] & \\
\hline
\end{tabular}

'When Petya made the children read a book (several times), Masha was looking at them, rejoicing.'

In light of the introduction of this subsection, example (18) presents direct evidence for the syntactic structure of the VP in Udmurt non-finite adjunct clauses. Recall that frequentative aspect is one of the 'low' aspectual distinctions. Thus, I argue that AspfreqP is projected in (18), which is supported by the presence of the frequentative suffix.

As for causatives, I adopt Tánczos’ (2016) syntactic analysis (§2.3.2). Tánczos (2016: 117-118) proposes the following account of factive causatives: these constructions are bieventive, hence two Voice layers are projected. The causee sits in the specifier of the lower VoiceP. The higher CauseP is merged on top of the structure in order to account for the factitive causing event; the external argument is introduced in the higher VoiceP.

Thus, I propose that example (18) has the structure depicted in (19). (FP stands for any functional projection above AspFreQP.) 
(19)

[XP -ku- [FP F [AspP -l- [VoiceP Petya [Voice' Voice [CauseP -t- [VoiceP pinaljosiz [Voice' Voice [CauseP Cause [vP v [ $\sqrt{ } \mathrm{P}]]]]]]]]]]$

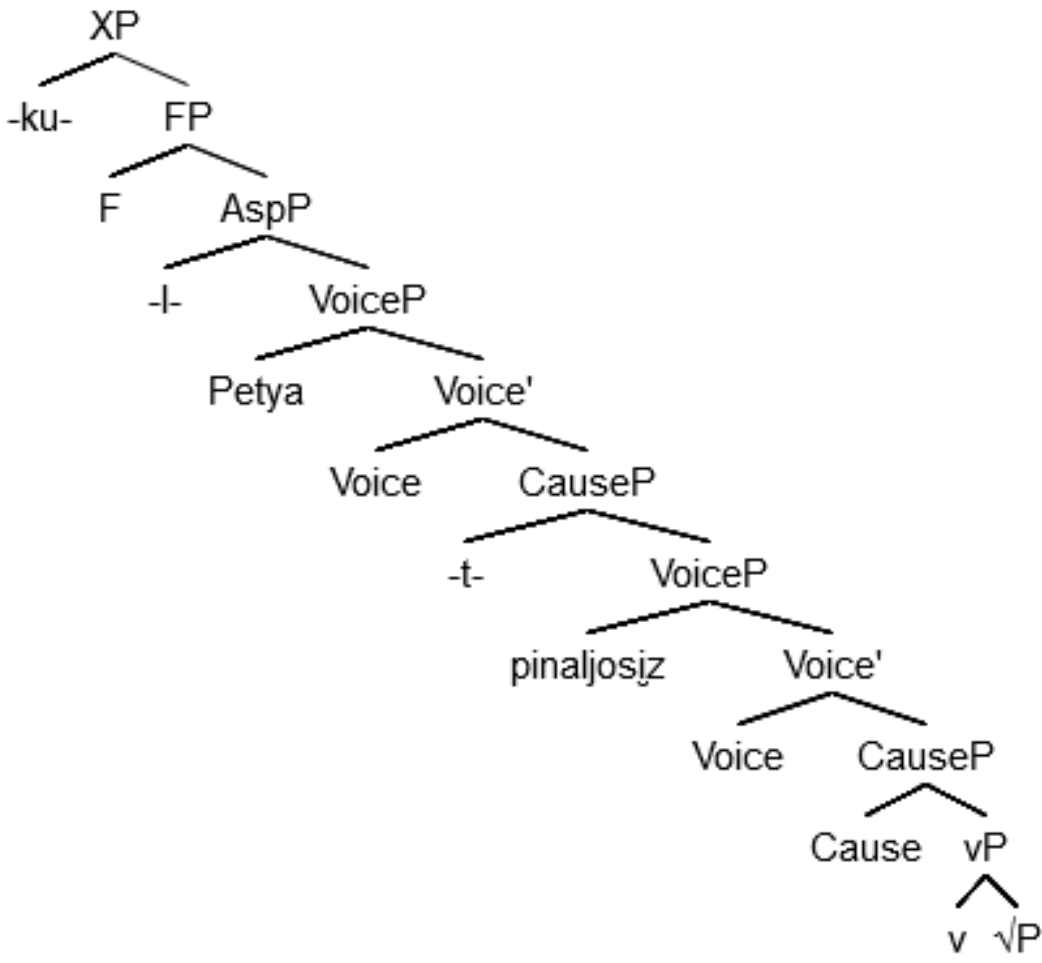

The tree in (19) represents a fairly extended verb phrase. The question that arises now is what structure is assumed in cases when no frequentative and no causative suffix is present. ${ }^{16}$ In this case, I assume that AspP and the (upper) VoiceP/CauseP are not projected. What I try to show with example (18) is how extended the VP can potentially be. Examples similar to (18) can be formed not only with 'while'-clauses (-ku), but also with temporal -sa-converbs, -tek-converbs, -toź-converbs, as well as with nominalizations selected by postpositions/semantic cases.

The fact that aspect and voice morphology is licit in non-finite adverbial clauses has been noted in the traditional grammars of Udmurt (e.g. Perevoshchikov 1959; GSUJa I 1962). These descriptive studies argue that only derivational morphology is found in non-finite clauses, but the distinction between derivational and inflectional morphology is implied rather than explicitly defined. Given that both causative and frequentative aspect morphology can be accounted for in syntactic terms, i.e. as exponents of projections within the VP, this has implications for our understanding of the boundary between the thematic and the inflectional

\footnotetext{
${ }^{16}$ I thank Orsolya Tánczos for raising this question in her review.
} 
domains in Udmurt. In other words, what has traditionally been called 'derivational morphology' in Udmurt corresponds to the lowest clausal domain, the VP. It was shown above that this domain can be undoubtedly split in non-finite adverbial clauses. Next, we will take a look at the inflectional domain.

\subsubsection{TP}

Turning to the structure above AspFreQP, the most important question concerns the presence of $\mathrm{T}$. The presence/absence of $\mathrm{T}$ is relevant for to the possibility of nominative case assignment to the subject. It also plays an important role in the temporal interpretation of the non-finite clause.

As shown in Chapter 3, non-finite adverbial clauses do not show (morphological) tense, but can have either a null or an overt subject. A couple of illustrative examples with overt subjects are given below.

(20) GSUJa I (1962: 288)

[jir viśítoź] pid med viś-o-z [...]
head be.sick-CVB.LIM foot OPT be.sick-FUT-3sG
'May (my) foot hurt rather than (my) head.'

(21) elicited

[Apaj-os-iz gurt-e berti-tek] Kol'a mezme val.

elder.sister-PL-3sG home-ILL come.home-CVB.NEG Kolya be.sad[PREs.3sG] AuX.PST 'Without his elder sisters coming home/His elder sisters not having come home, Kolya was sad.’

(22) elicited

$\begin{array}{llllllll}\text { [Mon } & \text { škola-je } & \text { košk-em] } & \text { bere } & \text { Liza } & \text { kino } & \text { učki-ni } & k u t s k-i-z . \\ \text { [1SG } & \text { school-ILL } & \text { leave-NMLZ] } & \text { after } & \text { Liza } & \text { movie[ACC] } & \text { watch-INF } & \text { start-PST-3sG }\end{array}$

'After I (had) left for school, Liza started watching a movie.'

Note that the subject of the non-finite clause might be a plural DP or a pronoun (in any person/number). It should be emphasized that in all the examples given above, the subjects bear nominative case (and not genitive or any semantic case). The possibility of nominative 
subjects clearly distinguishes non-finite adverbial clauses from non-finite relative and argument clauses (cf. §3.5-3.6).

The question that arises here is how nominative is licensed in non-finite adverbial clauses. As noted in the introduction of this section, there are two main approaches to caselicensing: (i) nominative case is licensed structurally; (ii) nominative is an unmarked/default case. Under the structural licensing approach, the possibility of a nominative subject can be taken as direct evidence for the presence of $\mathrm{TP}$ in the non-finite clauses is question. The biggest problem is the "dual” nature of the non-finite $\mathrm{T}$ in these clauses: on the one hand, no tense marking is found, but on the other hand, nominative is licensed. Alternatively, nominative can be considered to be the unmarked or default case. In this case, however, nominative subjects do not provide evidence for the presence of TP in non-finite clauses. Although the structural approach to nominative case is still dominant in the literature, the cross-linguistic evidence of nominative subjects in non-finite clauses has challenged this view, and several solutions have been proposed in individual languages.

Firstly, it has been argued that the licensing condition for nominative case is not tense but agreement (Raposo 1987; Kornfilt 2003). Thus, untensed clauses can also have nominative subjects as long as they show agreement. Raposo's (1987) account of European Portuguese infinitives goes along the following lines: uninflected infinitives cannot have overt subjects, while inflected infinitives can. Thus, overt subjects are licensed by agreement morphology. (A further proviso in his account is that the agreement in the Infl head must be case-marked itself in order to be able to license nominative case on the subject.) In Chapter 3, we saw examples of non-finite adverbials with nominative subjects and agreement, but crucially, the above-given Udmurt data show that nominative subjects are possible even without agreement. Hence, agreement does not seem to be a requirement for nominative case.

In order to overcome this problem, one might adopt Kornfilt's (2003) analysis of Modern Standard Turkish non-finite clauses. Certain embedded clauses in Turkish show tense morphology without agreement and their subjects cannot bear nominative case; they are accusative-marked in an ECM fashion instead. Hence, she argues that nominative case in Turkish depends on agreement rather than tense. Converb clauses, on the other hand, do not show agreement, but they have nominative subjects. In this case, Kornfilt (2003) proposes that the subject gets a default case, which simply happens to be the nominative in Turkish. Thus, nominative case is licensed via two different mechanisms. The notion of 'default case', however, has been defined in a different way by Schütze (2001). Default case is spelled out 
(postsyntactically) on DPs that are not associated with any case features assigned or otherwise determined by syntactic mechanisms; however, subjects of non-finite clauses do not receive default case (Schütze 2001: 206, 208).

Dependent Case Theory (Marantz 1991; Baker 2015) makes different predictions about case-marking than the standard structural approach to nominative. The core idea is that case is licensed within a domain: if there is one DP within the domain, it bears the unmarked case (nominative/absolutive), and if there are two DPs, one may bear a dependent case (accusative/ergative). Marantz (1991) proposes a disjunctive hierarchy of case realization: lexically governed case $>$ dependent case $>$ unmarked case $>$ default case. Unmarked case is sensitive to the syntactic environment, for instance genitive and nominative case are the unmarked cases within the nominal and verbal domains, respectively. An even more radical proposal has been made by Kornfilt \& Preminger (2015). They argue that nominative case is the absence of case, in other words, nominative is not assigned at all. Sundaresan \& McFadden (2009) also abandon the idea of structural nominative case: In standard Case Theory, case is assigned in order to satisfy the needs of the DP; in their selectional approach to case, on the other hand, the selectional features of verbs/functional heads should be met. Since adjunct clauses are not selected, there is no selectional restriction on the type of subject, thus (obligatorily controlled) PRO subjects and overt nominative subjects are in free alternation (the alternation between null and overt subjects will be discussed in §5.2).

At this point, we should take a closer look at nominative case in Udmurt. The first question is what counts as nominative case. Note that morphologically unmarked nouns appear in several syntactic environments: subjects of finite and non-finite clauses, complements of postpositions, unmarked objects, etc. One might raise the question of whether all unmarked DPs receive the same case and whether it is licensed via the same mechanism. If we compare finite and non-finite adverbial clauses, the first impression we get is that they are very similar: nominative subjects are licit in both cases. However, a difference can also be observed. It was noted above that agreement is not a requirement for nominative case in nonfinite clauses, but in finite (tensed) clauses, agreement is always present (§3.2). This might tilt the balance in favour of the idea that nominative case is licensed via different mechanisms in finite and non-finite clauses. One way to explain the nominative case in examples (20)-(22) is to say that it is licensed by the postpositions heading these clauses, in line with Martin's (2001) Null-P approach to examples like John wants his team to win, in which a silent for is said to license the subject of the infinitive. Postpositions in Udmurt take nominative 
complements, e.g. mon bere 'after me, lit. I after'; similarly, the subject of the 'after'-clause in (22) is also nominative. This approach might seem to be less intuitive in the case of the proper converb -sa, for which the presence of a (covert) postposition seems to be stipulated rather than empirically motivated.

The subjects of converb clauses have been discussed by Ótott-Kovács (2016: 74-75) as well. She proposes that in Kazakh, all converb heads capable of licensing overt subjects sit in $\mathrm{T}$ (Infl in her terminology), and the $\mathrm{T}$ head licenses nominative case on the overt subjects of converb clauses. Nominative subjects in converb clauses thus bear structural rather than default case. However, certain converbs, such as the manner converbs in $-y / a$ and $-I p$, are not capable of licensing an overt subject. In this case, Ótott-Kovács (2016: 76, 81-85) assumes that these converbs head a phrase smaller than a TP. Hence, in her account, the (im)possibility of overt subjects follows directly from the size of the non-finite clause: TP-sized non-finite clauses license overt subjects, whereas smaller non-finite clauses do not. Her proposal is reminiscent of Tóth’s (2000) account of Hungarian - $v A$ adverbial participles, which can also head manner or temporal adjuncts. Tóth (2000) argues that manner -vA-clauses are VoicePs, while temporal-vA-clauses are full CPs. This is supported by the temporal interpretation of the two types of adjuncts. (Their subjects can be only null.) As we will shortly see, these two approaches can be applied to -sa-converbs: the differences between temporal and manner -saconverbs concern temporal interpretation and the possibility of an overt subject.

Above I outlined certain problematic issues connected to nominative case-licensing in non-finite clauses. A final remark is in order: in principle, the unmarked/default case approach does not preclude the possibility of TP being projected. Although I do not wish to fully commit myself to the structural approach to nominative case, and in doing so I leave open the possibility that nominative is licensed as an unmarked case, I argue that an inflectional domain is present in non-finite adjunct clauses. Consider first the following example:

\section{(23) elicited}

\begin{tabular}{|c|c|c|c|c|}
\hline [Pet'a & pinal-jos-iz & kńiga & lidýi-tib-li-ku] & Maša \\
\hline Petya & child-PL-ACC & book[ACC $]$ & read-CAUS-FREQ-CVB.SIM & Masha \\
\hline soos & šumpoti-so & učke & val. & \\
\hline 3PL & rejoice-CV & $\operatorname{look}[\mathrm{P}$ & AUX.PST & \\
\hline
\end{tabular}

'When Petya made the children read a book (several times), Masha was looking at them, rejoicing.' 
Although the non-finite clause in (23) shows no past tense morphology, we somehow interpret it as if it were in the past tense because of the past tense in the main clause. One way to explain this is to draw a parallel with at noon in 'At noon, Masha looked at them', and say that we infer that at noon was prior to the utterance time. Likewise, one might be tempted to account for (23) by saying that the adjunct clause is tenseless, and its past tense reference is simply inferred. However, clausal adjuncts differ from (simple) adverbials since they encode an event. The entailment of an event in non-finite clauses, and more generally, the possibility of an episodic reading, is said to be determined by the presence of temporal features (see van Hout \& Roeper 1998; Martin 2001). Furthermore, temporal dependencies are attested not only with non-finite clauses, but also with various types of finite embedded clauses, for instance in the case of central adverbial clauses that are temporally dependent, albeit finite (Haegeman 2012: 166-168) or in the case of Sequence-of-Tenses (see Kratzer 1998). The accounts proposed for these phenomena do not involve a simple TP-truncation analysis.

Taking into account these considerations, I assume that an inflectional domain is present in Udmurt non-finite clauses. I argue for a split TP, in which the two temporal projections, AspP and TP, should be kept apart (as proposed by Demirdache \& Uribe-Etxebarria 2004, following Klein 1994). It must be emphasized that tense and aspect are often conflated in the literature, and this is especially true in the case of non-finite clauses: the terms 'nonfinite/deficient/weak T', as well as 'relative/semantic tense' are used to cover the temporal features of non-finite clauses, however, it is often not specified whether these features are related to tense or aspect. A further complication is that many authors assume a non-split TP, thus any evidence for temporal features is automatically taken to suggest the presence of TP.

The presence of TP in non-finite clauses is often tested with temporal adverbials, indicating a temporal mismatch between the matrix and the embedded events. Landau (2000, 2013) argues that there are [+tense] and [-tense] infinitives, and they are selected by different predicates (24). ${ }^{17}$ Likewise, there are two types of gerunds: 'clausal gerunds' are [+tense], while ‘TP-defective gerunds' are [-tense] (Pires 2006) (25).

\footnotetext{
${ }^{17}$ A short remark on infinitives in Udmurt: Tánczos (2016: 154) argues that the infinitives used in the Udmurt periphrastic causative construction can have a temporal adverbial, thus, they are TPs. I assume that similarly to English, there are several types of infinitives in Udmurt as well, but their description goes beyond the scope of the present dissertation.
} 
(24) Landau (2013: 66, ex. (136a, b))
a. *Last night, Tom condescended [to help us today].
b. Last night, Tom planned [to help us today].

(25) Pires (2006: 71, ex. (3b), (4))

a. *Philip avoided last night [driving on the freeway this morning].

b. Mary worried (yesterday) [about coming to dinner (tonight)].

Based on this evidence, Pires (2006) states that TP is projected only in clausal gerunds (he assumes a non-split TP). However, Wurmbrand (2014) shows that the temporal features of [+tense] infinitives differ from those of 'finite tense': the latter are absolute (i.e. related to the utterance time), whereas infinitival future is relative (i.e. it can precede the utterance time, as long as it occurs after the time of the matrix event). Thus, the infinitive in (26a) is compatible with yesterday, while the finite verb in future tense is not (26b).

(26) Wurmbrand (2014: 413, ex. (20))

a. Leo decided a week ago [to go to the party yesterday].

b. Leo decided a week ago [that he will go to the party (*yesterday)].

As for the episodic interpretation of the event encoded by the non-finite clause, it has been argued that it also depends on temporal features (again, I use the term 'temporal' instead of 'tense' for a reason that will become obvious shortly). For instance, van Hout \& Roeper (1998) compare two types of agent nominalizations: lawn-mover and the mover of the lawn. Crucially, only the latter entail an event of moving the lawn. They claim that these nominalizations have several functional layers (VoiceP, AspP, TP) on top of the VP. According to them, the $\mathrm{T}$ head closes off the event variable of the verb, giving rise to the event entailment. In nominalizations like lawn-mover, on the other hand, no functional layers are present, thus, no event is entailed. In other words, a lawn-mover can be a person who has never mowed a lawn. It must be clarified that in their account, AspP is responsible for telicitity (i.e. it is a low aspect phrase). Regarding TP, they mention in a footnote that 'nominal tense' is different from 'sentential tense', but do not clarify this issue. These agent nominalizations have been discussed by Alexiadou \& Schäfer (2010) as well. They propose that the event variable is bound by a dispositional Asp head in the case of lawn-mover, and by 
an episodic Asp head in the case of mover of the lawn In the case of infinitives, too, it has been argued that [+tense] correlates with episodic interpretation (see Martin 2001 and the references therein): [-tense] infinitives cannot be used with episodic predicates, cf. John believed Peter to be rich/*to win the game (but see Wurmbrand 2014, who argues that episodic readings require perfective aspect). In sum, what is common between these accounts is that the temporal information of non-finite clauses is relevant for their episodic interpretation.

In §3.4, I discussed the temporal meaning of the two nominalizations, formed with the suffixes -(e)m and -(o)n. I argued that they do not relate to the utterance time, but to the assertion/topic time. The relevant examples are repeated below.

(27) elicited

$\begin{array}{llllllll}\text { Tolon Maša no Pet’a } & \text { [buskel'-zi-leś } & \text { kućapi } & \text { baśt-em-zi] } & \text { śariś } \\ \text { yesterday Masha and Petya } & \text { neighbor-3PL-ABL } & \text { puppy[ACC] buy-NMLZ-3PL about } \\ \text { veraśk-i-zi. } & & & & & & \\ \text { talk-PST-3PL } & & & & & \end{array}$

'Yesterday, Masha and Petya talked about how they had bought a puppy from their neighbor.'

(28) elicited

\begin{tabular}{|c|c|c|c|c|c|c|}
\hline Tolon & Maša & no & Peta & [buskel'-zi-leś & kućapi & baśt-on-zi] \\
\hline yesterday & Masha & and & Petya & neighbor-3PL-ABL & puppy[ACC] & buy-VN-3PL \\
\hline
\end{tabular}

talk-PST-3PL

'Yesterday, Masha and Petya talked about [their intention of] buying a puppy from their neighbor.'

These two examples make a statement about the event of Masha and Petya talking, which happened prior the utterance time. In (27), the event of buying a puppy precedes the event of talking, while in (28), it follows it. Thus, I argue that -(e)m-clauses encode a perfect/anterior event (preceding the assertion time), while -(on)-clauses express a prospective event (following the assertion time). In order to capture these facts, I propose that (at least) an AspP is projected in these clauses. In $\S 4.1 .2$, it was shown that some of the traditionally called 
converbs are actually postpositions. The proposal faced the following problem: these postpositions select for clauses that do not have any nominalizer. I explain this with the aspectual meaning of the two nominalizations: they are incompatible with a simultaneous reading (which is required in the case of 'when'-clauses, for example). Thus, in this case only the bare stem form can appear.

To further strengthen the claim that aspect is present in nominalizations, I present a minimal pair comparable to the English examples in (26). The -(o)n-nominalization in (29) can occur with the adverbial tolon 'yesterday' since it expresses relative future with respect to the matrix event. This is, however, impossible with the finite verb in future tense, which marks a future event with respect to utterance time (30).

(29) elicited

$\begin{array}{lllllll}\text { Maša no Pet’a [tolon } & \text { buskel-zi-leśs } & \text { kućapi } & \text { baśt-on-zi] } & \text { śariśs } \\ \text { Masha and } & \text { Petya yesterday } & \text { neighbor-3PL-ABL } & \text { puppy[ACC] buy-VN-3PL } & \text { about } \\ \text { vaźnal } & \text { veraśk-i-zí. } & & & & \\ \text { two.days.ago } & \text { talk-PST-3PL } & & & \end{array}$

'Masha and Petya talked two days ago about buying a puppy from their neighbor yesterday.'

(30) elicited

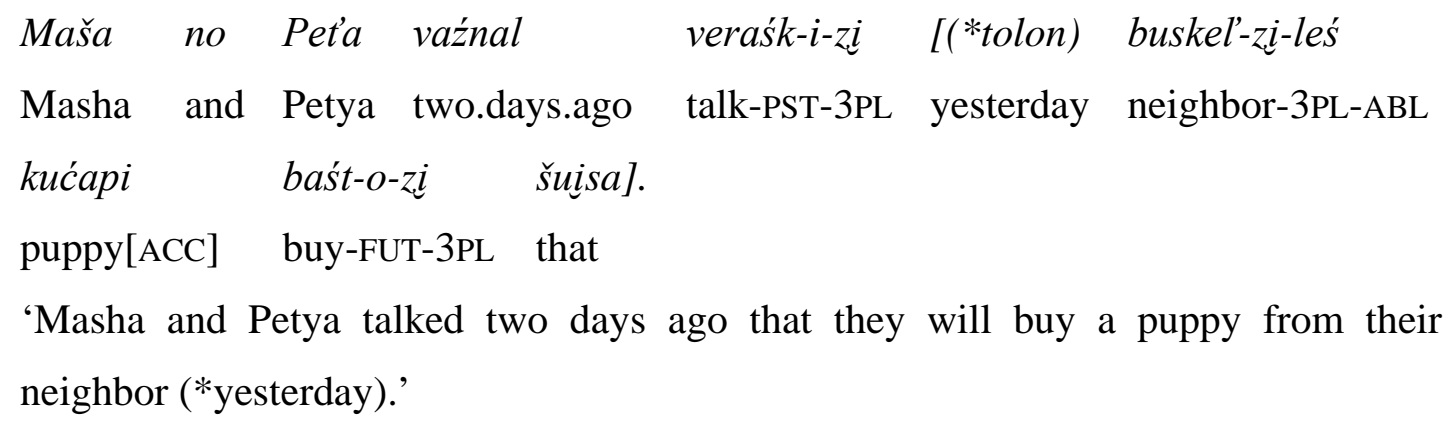

However, it seems that the position of the temporal adverbial in the matrix clause plays an important role in (29). Compare it with the minimally different (31), in which the temporal adverbial is placed sentence-initially, and the sentence is degraded. 
(31) elicited

$\begin{array}{llllll}\text { ?(?)Vaźnal } & \text { Maša no Peta } & \text { [tolon } & \text { buskel'zi-leś } & k \text { kúapi } \\ \text { two.days.ago } & \text { Masha } & \text { and Petya } & \text { yesterday } & \text { neighbor-3PL-ABL } & \text { puppy[ACC] } \\ \text { baśt-on-zi] } & \text { śariśs } & \text { veraśk-i-zi. } & & & \\ \text { buy-VN-3PL } & \text { about } & \text { talk-PST-3PL } & & & \end{array}$

'Two days ago, Masha and Petya talked about buying a puppy from their neighbor yesterday.'

The contrast between low and high two days ago in (29) and (31) can be explained in the following way: sentence-initial temporal adverbials have a scene-setting function, i.e. they specify the topic time/assertion time (cf. Frey 2003). In other words, example (31) is about two days ago. The low temporal adverbial in (29) has a different function: it simply specifies when the event of talking happened. Thus, it seems that the possibility of temporal adverbials in the non-finite clause depends not on the time of the matrix event, but on the topic time, i.e. on the time about which the utterance is made. Additionally, the immediately preverbal position of the temporal adverbial in (29) suggests that it is probably focused, thus the meaning of this sentence corresponds to 'As for their (intention) to buy a puppy tomorrow, it was yesterday that they talked about it.'

The topic time-marking function of sentence-initial adverbials is noted by Klein (1995: 162-165) as well. He argues that low adverbials do not mark the topic time explicitly, but the perfective nature of the English simple past tense nevertheless expresses that the topic time precedes the utterance time. Furthermore, he discusses the function of temporal adverbials in infinitives, e.g. yesterday in to have worked yesterday serves to mark the event time of working, but the infinitive lacks a topic time and is dependent on the topic time of the matrix clause.

A further example of the possible mismatch between the temporal adverbials in the matrix and the non-finite clause is given in (32). Again, the acceptability of such examples depends on word order: the sentence is degraded if the temporal adverbial in the matrix clause (tolon 'yesterday') is placed sentence-initially, but if it is immediately preverbal, the sentence is grammatical. 
(32) elicited

$\begin{array}{lllllll}<\text { ?(?)Tolon> } & \text { Maša } & \text { no Pet’a } & \text { [čukaźe } & \text { buskel'-zi-leś } & \text { kućapi } \\ \text { yesterday } & \text { Masha } & \text { and Petya tomorrow } & \text { neighbor-3PL-ABL } & \text { puppy[ACC] }\end{array}$

baśt-on-zi] śariśś <tolon> veraśk-i-zi.

buy-VN-3PL about yesterday talk-PST-3PL

'<?(?)Yesterday> Masha and Petya talked <yesterday> about buying a puppy from their neighbor tomorrow.'

Below I will apply this test to non-finite adverbial clauses, although a similar temporal mismatch is unlikely to be possible in temporal clauses. Note that it is ruled out even in finite temporal clauses: *When I was reading a book (yesterday), you will come home. Nontemporal adjuncts allow for such a mismatch, as shown below with a cause/reason clause.

(33) elicited, based on Turku-Izhevsk Corpus (Kenesh/D/5:783)

[Tolon kuaź zor-em-en] tunne busi-je odno=ik vetl-o-zi. yesterday weather rain-NMLZ-INS] today field-ILL definitely go-FUT-3PL 'Since it was raining yesterday (lit. with the weather raining/having rained yesterday), today they will definitely go to the field.'

Some postpositions can express either temporal or modal relations. For instance, the postposition bere 'after' can encode either a temporal or a causal relation between the events. Thus, it is similar to after and since in English. Originally, after and since expressed a temporal relation from which the causal relation/reading emerged through the conventionalizing of earlier conversational inferences (Traugott \& König 1991). Similarly, 'while'-clauses developed a concessive reading. Synchronically, causal and temporal 'since'clauses differ in many respects, for instance, ever can precede only temporal since (Haegeman 2012: 160); non-past tense in the adjunct signals a causal relation (Traugott \& König 1991: 194-195) (34a). Concessive while allows a distinct temporal adverb for many speakers (Traugott \& König 1991: 199-200) (34b).

(34) Traugott \& König (1991: 194, 200, ex. (3c), (13))

a. Since you are not coming with me, I will have to go alone.

b. ?While our business was extremely successful last year, this year does not look too promising. 
In light of this, it is not surprising that Udmurt non-finite clauses used as a complement of the postposition bere 'after' can have only a causal reading when modified by a temporal adverb indicating that the temporal reference of the non-finite clause is distinct from that of the matrix clause. ${ }^{18}$ This is demonstrated in (35).

\section{(35) elicited}

[Tolon peśanaj dor-i vetli-mte] bere čukaźe odno=ik vetl-o-m. yesterday grandmother at-ILL go-NMLZ.NEG after tomorrow definitely go-FUT-1PL 'Since/*after we didn’t visit grandma yesterday, we'll definitely visit her tomorrow.'

Next, I will discuss -sa-converbs is some more detail. Recall that they can be used as vague temporal adjuncts or as manner adverbs (§3.7.2.8). Firstly, I argue that the term 'manner adverbial' used in the traditional grammars is quite misleading since these converb clauses do not predicate of the event variable (cf. He ate quickly). Instead, they denote a state and predicate of an individual involved in the event (the subject of the matrix clause). Thus, these -sa-converbs are 'transparent adverbials' in Geuder’s (2004) terms. (In §5.4, I will show that transparent adverbials also differ from depictives in the interpretation of their subject.)

Temporal adjuncts and transparent adverbials differ with respect to the possibility of an overt subject: only temporal adjuncts can have an overt one. ${ }^{19}$ Their temporal interpretation is also different. Temporal -sa-adjuncts are said to be anterior or simultaneous to the matrix event (with a causal flavour). Generally, their temporal interpretation depends on the perfectivity of the verb: imperfective verbs are more naturally interpreted as simultaneous, while perfective verbs receive an anterior interpretation. The interpretation of the non-finite clause can also be influenced by pragmatic factors (as argued in the case of Hungarian and Kazakh, cf. Tóth 2000; Bartos 2009; Ótott-Kovács 2016). Transparent adverbials, on the other hand, denote a situation that is simultaneous with the one expressed in the matrix clause (and this straightforwardly follows from the idea that they predicate of the subject).

More importantly, temporal -sa-clauses and transparent adverbials also differ in the possibility of being derived from stative verbs. Stative transparent adverbials are acceptable

\footnotetext{
${ }^{18}$ It is also noteworthy that bere can also select for fully finite clauses, in which case it only has a causal or conditional meaning (GSUJa III 1974: 93).

${ }^{19}$ Aspectual converb constructions cannot have an independent subject either.
} 
(36), but temporal clauses with stative verbs are ruled out even though the causal relation between the events is (pragmatically) possible, cf. (37). ${ }^{20}$

(36) elicited

Kol’a Maša-jez [jarati-sa] kišno baśt-i-z.

Kolya Masha-ACC love-CVB wife take-PST-3SG

'Kolya married Masha for love (lit. loving).'

(37) elicited

*[Kol’a Maša-jez jaratí-sa] Pet’a voža.

Kolya Masha-ACC love-CVB Petya be.jealous[PRs.3sG]

Intended: 'Kolya loving Masha/since Kolya is in love with Masha, Petya is jealous.'

This means that temporal -sa-clauses are always episodic, whereas transparent adverbials might be non-episodic. As said above, temporal -sa-clauses can have either an anterior or a simultaneous reading, while transparent adverbials are always simultaneous with the event expressed by the matrix verb. Thirdly, overt subjects are licit only in temporal -saclauses. Based on these facts and in line with Tóth’s (2000) and Ótott-Kovács’ (2016) insights, I propose that transparent adverbials are smaller in size, i.e. VoicePs, while temporal -sa-clauses have an inflectional domain similarly to the rest of non-finite adverbial clauses.

One more clarification is in order regarding temporal -sa-clauses. Perevoshchikov (1959: 233) argues that -sa-clauses with independent subjects can have either an anterior or a simultaneous interpretation, but they always have a causal meaning (or at least, the two events are connected to each other). Even Same-Subject clauses often seem to imply a causal relation between the events. The idea that converbs express causality is very persistent in the literature (see Kazenin \& Testelets 2004 on Tsakhur, and Grashchenkov 2017 on -Ip-converbs used in several Turkic languages). Based on Kazenin \& Testelets’ (2004) description, Weisser (2015) proposes that the $\mathrm{T}$ head in Tsakhur converb clauses has a [ \pm cause] feature. However, I doubt whether the (alleged) causality between the events needs to be represented in the syntax. Recall that 'after'-clauses can only have a causal meaning if they contain a temporal adverbial

\footnotetext{
${ }^{20}$ The judgments for (37) were unanimous. However, it cannot be excluded that temporal -sa-clauses with stative verbs might be possible if the stative verb receives a coerced inchoative interpretation, e.g. to know $\rightarrow$ to get to know/find out.
} 
distinct from the one used in the matrix clause. If we apply this test to -sa-clauses, the result is ungrammatical, cf. (38) (the speakers correct it with the 'after'-clauses shown in (35)).

(38) elicited

*[Tolon peśanaj dor-ĩ vetlï-sa] čukaźe um vetle.

yesterday grandmother at-ILL go-CVB tomorrow NEG.FUT.1 go[PL]

Intended: 'Visiting grandma yesterday, we won't visit her tomorrow.'

My explanation of why (38) is ruled out is that -sa-adjuncts are not proper cause/reasonclauses: if they were, the temporal modifier would be licit. Thus, I assume that converb clauses have a temporal meaning (the causal interpretation might simply be an implicature).

To conclude, non-finite adverbial clauses have a deficient inflectional domain: they express temporal relations, but these are anchored to the topic time of the matrix clause. I maintain the view that non-finite adverbial clauses have a TP, keeping in mind that the temporal distinctions expressed in these clauses are essentially aspectual.

To complete the discussion of the inflectional domain, we should also consider negation. As mentioned in §2.3.2, sentence negation is expressed with a negative auxiliary that carries tense and person agreement markers, while the lexical verb is marked for number. This has been taken to suggest that NegP in Udmurt is below TP (Mitchell 2006). It has been observed that the negative auxiliary is never used in non-finite clauses (§3.2). One possible explanation would be that non-finite clauses lack NegP altogether. The problem is that negation can be expressed in certain non-finite clauses with the (unproductive) marker -t. I tentatively propose that this is to be explained with the selectional requirements of the negative verb, and not with the structure of the non-finite clauses in question. Negation in Udmurt has not been studied extensively from a theoretical point of view; the general assumption is that the lexical verb appears in a 'co-negative' or 'semifinite' form (Edygarova 2015). Thus, it might be the case that the negative verb selects for a special (non-finite) clause.

\subsubsection{CP}

In Chapter 3, I discussed the differences between finite and non-finite clauses, and pointed out that they differ along the following parameters: word order, wh-movement, and high adverbials. These differences are all related to the presence of a $\mathrm{C}$ layer. 
Let us begin with the position of the subject and object. Since objects can be accusativemarked or unmarked, one might ask what position they occupy in the clause. It has to be mentioned that objects need not be immediately preverbal, thus, it is plausible to assume that they are not in their base-generated position. As for accusative-marked objects, the question arises whether they are topicalized. I think that there is one empirical argument against the analysis of accusative-marked object as topics: OSV is degraded in non-finite adverbial clauses (§3.2).

The second problem is that it is not exactly clear what position topics occupy in Udmurt. Tánczos (2010) and Asztalos \& Tánczos (2016) propose that specific subjects and objects are topics located in Spec,TopP. Asztalos \& É. Kiss (2016) suggest that preverbal foci stay within the vP, and topics move to Spec,TP. This means that the focused object stays in its base-generated position, the subject moves to Spec,TP, where its default interpretation is topic, and the result is SOV word order. If the subject is focused, it stays in Spec,vP and the object moves to Spec,TP, giving rise to OSV word order. Under the latter approach, topicalization (of either the subject or the object) cannot be seen as evidence in favor of the presence of the CP layer.

The position of the subject is also uncertain. Recall that non-finite clauses display a fairly rigid SOV order (§3.2). However, we observed that subjects can be preceded by adjuncts without any problems (whereas OSV is degraded). In light of this, consider the following two examples.

(39) Udmurt Corpus (Удмурт дунне, 2009.11.18)

[apteka-os-in emjum-jos tirmi-mte-jen]

pharmacy-PL-INE medicine-PL be.enough-NMLZ.NEG-INS

'since there is shortage of medicines in the pharmacies (lit. since medicines are not enough)'

(40) Turku-Izhevsk Corpus (Invozho/A/12:66-67)

[vaće pumit vuilem inti-iss mi košk-em] bere

two.together against battle place-ELA we leave-NMLZ after

'after we left the place of the battle'

In (39), the adjunct precedes a non-specific subject. Thus, one might suppose that the subject stays in situ (in Spec,VoiceP or Spec,vP). In (40), however, the adjunct precedes a 
definite subject. The question arises whether it stays in situ (and if yes, why) or whether it moves. Our assumptions about the position of the subject have implications for the proposed height of attachment of the adverbial as well. If the subject is in situ in (39), the locative adverbial can be adjoined to the TP. With the definite subject in (40), the situation is even more complicated. The possibilities are: (i) subject in Spec,TP, adverbial adjoined to the TP, (ii) subject in Spec,TP, adverbial in CP (if it is a scene-setting adverbial), (iii) subject in situ (if it is in the immediately preverbal focus position), adverbial in Spec,TP.

What I would like to point out is that the word order possibilities in Udmurt non-finite adverbial clauses resemble (finite) adverbial clauses in English: argument fronting is ungrammatical, but adjunct fronting is allowed (41).

(41) Haegeman (2010: 629, 632, ex. (1), (9))

a. *While this paper I was revising last week, I thought of another analysis.

b. If on Monday we haven't found him, we'll call the RSPCA.

In earlier accounts (Haegeman 2003), it has been proposed that certain adverbial clauses are truncated and have only a FinP layer. The possibility of sentence-initial adjuncts, among other facts, casts doubt on this analysis. However, as pointed out above, it is unclear whether the locative adjuncts in the Udmurt examples are scene-setters, adjoined to the CP.

Given the uncertainties around the position of topics, I do not think that the examples above present strong evidence for the position that adjunct clauses have a TopP and a FocP. More likely, these layers are not projected, and the observed word order variations arise as a result of scrambling within the inflectional domain.

Turning to wh-movement, it was observed that wh-elements are possible in adjunct clauses, but they resemble echo questions (§3.2), as shown below.

(42) elicited

[Pijaš kịtči min-on] aźin buskel'-jos-iz kuno-je likkto?

boy where[ILL] go-VN before neighbor-PL-3SG visit-ILL come[PRS.3PL]

'His neightbors visit [him] before the boy goes where?'

In §3.2, it was also demonstrated that wh-elements are licit in non-finite argument clauses, and their interpretation is not comparable to echo questions. It must be said that these 
wh-elements probably stay in situ. Consider (43), in which the wh-elements are preceded by the temporal adverbial soku 'then' and by a locative phrase.

(43) Turku_Izhevsk_Corpus/Kenesh/F/3: 100-101

[Širobokov-len śemja-ja-zi soku kizíi=no mar lu-em] śariśs

Shirobokov-GEN family-INE/ILL-3PL then how=ADD what happen-NMLZ about

'I got to know [about what had happened then in Shirobokov's family] only four years ago.'

This contrast shows two things. Firstly, question formation cannot be directly related to finiteness but rather to clause type. Secondly, the possibility of wh-elements in non-finite argument clauses suggests that they have a CP. An interesting parallel is that wh-elements are licit in English infinitives (I didn't know who to invite), but not in clausal gerunds. Pires (2006) analyzes the latter as bare TPs, since wh-elements undergo long-distance movement to the matrix clause (What did everyone imagine Fred singing?). Udmurt non-finite adverbial clauses, on the other hand, do not really allow wh-elements, which can be seen as another piece of evidence against analyzing them as CPs.

A further test often used in the literature is the possibility of high adverbials, such as unfortunately, probably, evidently, frankly, etc. The applicability of this test is, however, limited in Udmurt. In §3.2, I discussed certain particles/clitics: kad' 'it seems/as if', vilem (expresses mirativity) and $u k$ 'after all/emphatic', which based on their meaning belong to the CP layer. They typically follow the main predicate, i.e. are sentence-final in a SOV word order. However, these do not occur after non-finite adverbial clauses formed. Udmurt also uses some speaker-oriented adverbials, e.g. žal'asa verano 'unfortunately'. For some speakers, this adverbial can be placed within the non-finite clause (44).

(44) elicited

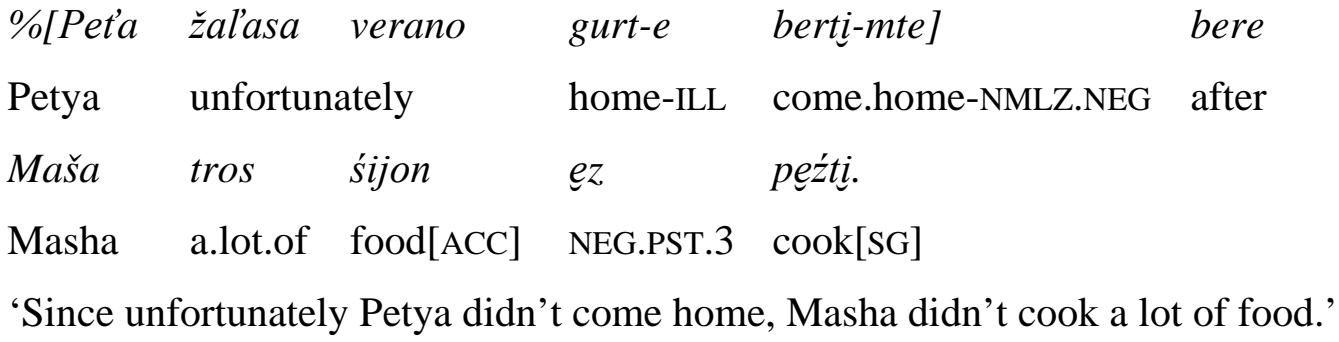


However, this adverbial is a (reduced) non-finite clause, it literary means 'if one has to say being sad'. It might be the case that adverbials of this kind are pronounced with a comma intonation (see also Haegeman 2010 on the same point about adverbials like by some misfortune/by sheer luck in comparison with unfortunately/luckily). Thus, it is not clear whether the placement of žal'asa verano 'unfortunately’ in (44) can be a reliable criterion.

Further tests demonstrating the presence of a CP are the possibility of overt complementizers (which is not an option in non-finite adverbial clauses, unless we consider the postpositions heading them to be (prepositional) complementizers) and the possibility of modal auxiliaries, evidential markers or imperatives (which are also ruled out).

In sum, I conclude that there is no compelling evidence for positing a CP in non-finite adverbial clauses. Thus, I consider them to be truncated at the TP level.

\subsection{Summary: the proposed structure}

Let us now take stock of the findings presented in the two subsections of this chapter. Firstly, I argue that the non-finite verb -sa is the only real converb in Udmurt. I propose that temporal -sa-clauses project up to TP, while -sa-converbs used as transparent adverbials are VoicePs.

The rest of non-finite adverbial clauses are postpositional phrases headed by either a morphologically bound P, i.e. a suffix, or by a postposition. As discussed in §2.3.1, postpositions do not form a unified class in Udmurt: there are relational nouns, inflecting and non-inflecting postpositions (Usacheva 2012; Simonenko \& Leontjev 2012). Recall also that Simonenko \& Leontjev (2012) treat locative cases (i.e. the ones that show Cx-Px order) on a par with relational nouns and inflecting postpositions. The structures of inflected postpositions and locative cases are repeated below.

a.Postpositions:

[PossP Poss [K LocP K Koc [NplaceP Nplace[PossP Poss [NumP Num [NP]]]]]

b. Cx-Px cases:

[PossP Poss [KLOCP KLOC [NumP Num [N]]]]

Based on this, I propose that non-finite adverbial clauses have similar structure. The PP analysis is obvious in the cases when postpositions like bere 'after' select for a nominalization. Now consider the cause/reason clauses formed with the nominalization -(e)m 
and the instrumental case (i.e. one of the Cx-Px case) (§3.7.2.2). In the case of (46), I assume the following structure (47). The only modification I make in comparison to Simonenko \& Leontjev's (2012) analysis is that I use FP instead of PossP for the functional projection hosting agreement.

(46) GSUJa II (1970: 118)

[ti kid'ok-e košk-em-eni-di]

2PL far-ILL go-NMLZ-INS-2PL

'because you went too far'

[FP F [KLOCP INS [TP T [AspP Asp [VoiceP Voice [VP]]]]]]

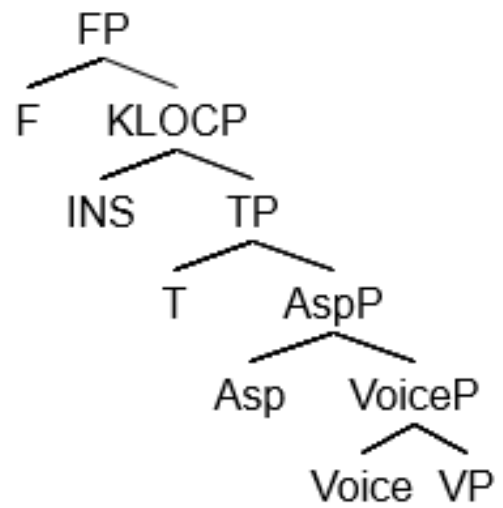

The structure depicted in (47) accounts for the nominalizations selected by the elative or adverbial case (I tentatively proposed that in temporal clauses with the adverbial case, we actually find the inessive/illative allomorph, but this is irrelevant with respect to the structure assumed).

In §4.1.2, I argued that -(o)nja-clauses contain the (reduced) postposition - $n$ - 'AT (place)', followed by the inessive/illative case (48). The structure of this example is shown in (49). Adjunct clauses formed with -toź- ('before’, 'until’, 'while’, rather', §3.7.2.7) also belong to this type: the terminative case is in KLOCP and is followed by the inessive/illative when agreement is marked. 
[baba-jeni-mi vịr-oń-ń-a-mi]].

grandmother-INS-1PL be.busy-VN-ń-INE/ILL-1PL

'while we/me and my grandmother were busy'

(49) [FP F [KLOCP INE/ILL [NplaceP -ń- [TP T [AspP Asp [VoiceP Voice [VP]]]]]]

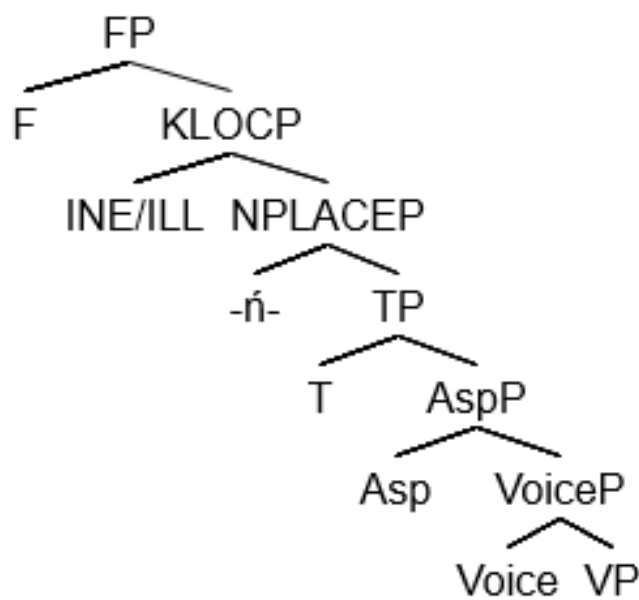

Thus, we find non-finite adverbial clauses headed by inflecting postpositions (49) or Cx-Px case markers (47). We also find non-inflecting Ps: in §4.1.2, I proposed that the traditionally called converb $-k u$ is a postposition meaning 'AT (time)'. Since -ku-clauses can show agreement (\$3.7.2.6), it seems that they have an FP (but no locative case is found). In the case of -tek 'without', we do not find any functional layers at all (but based on Munkácsi's 1887 example shown in (18), it seems that in the late $19^{\text {th }}$ century, -tek-clauses might have had the structure proposed for inflecting postpositions, cf. (49)).

A final remark is in order with respect to the agreement markers in FP. In Chapter 3, we saw that most non-finite adverbial clauses with independent subjects follow two morphosyntactic patterns: 'nominative subject and agreement' and 'nominative subject and no agreement’. In §4.2.2, we discussed at length how overt subjects of non-finite clauses are assigned case in the absence of agreement (and tense). If we take a look at the two patterns from the perspective of agreement, we might be tempted to say that agreement markers are optional (since non-finite adverbial clauses may show agreement, but often their predicates appear uninflected). This is what traditional grammars propose as well. This will be one of the topics discussed in the next chapter. 


\section{Subjects, agreement and adjunct control}

This chapter deals with several questions regarding subjects of non-finite adverbial clauses. More specifically, I discuss (subject) agreement (§5.1). Then, I turn to the variation between null and overt subjects (§5.2). Special attention is paid to the interpretive properties of null and overt subjects (§5.3). Null subjects are investigated in the light of adjunct control, which is itself a highly debated topic in recent generative studies. I review the main claims about adjunct control made in the literature about (§5.3). In §5.4, I take a closer look at adjunct control in Udmurt.

\subsection{Agreement}

As a preamble of the discussion of agreement in non-finite adverbial clauses, I provide a list of the different agreement markers used in Udmurt (here I use the term 'agreement' to cover both possessive suffixes and subject agreement suffixes used on verbs). They are summarized in Table 1. In Chapter 2, it was shown that nouns take different suffixes in order to express alienable and inalienable possession. Furthermore, we have seen that certain case suffixes precede the possessive suffixes, and in this case, a different set of possessive suffixes is used (the 'Cx-Px' set below). Subject agreement used on finite verbs is also given below.

\section{Table 1 Agreement markers in Udmurt}

\begin{tabular}{|l|c|c|c|c|}
\hline & $\begin{array}{c}\text { Alienable } \\
\text { possession }\end{array}$ & $\begin{array}{c}\text { Inalienable } \\
\text { possession }\end{array}$ & $\mathbf{C x - P x}$ & $\begin{array}{l}\text { Subject } \\
\text { agreement }\end{array}$ \\
\hline 1SG & $-(j) e$ & $-i$ & $-m$ & $\varnothing$ \\
\hline 2SG & $-(j) e d$ & $-i d$ & $-d$ & $-d$ \\
\hline 3SG & $-(j) e z$ & $-i z$ & $-z$ & $-z /-V$ \\
\hline 1PL & $-m i$ & $-m i$ & $-m i$ & $-m(i)$ \\
\hline 2PL & $-d i$ & $-d i$ & $-d i$ & $-d i$ \\
\hline 3PL & $-z i$ & $-z i$ & $-z i$ & $-z i /-V$ \\
\hline
\end{tabular}

Firstly, the four sets of agreement markers do not differ significantly from each other: in the plural they are (almost) identical. The main difference concerns the 1sG. Both the person agreement occurring on finite verbs and the possessive suffixes on nouns are assumed to be of the same origin, namely personal pronouns (Raun 1988). 
For the discussion of non-finite clauses, the Cx-Px type is the most important. Edygarova (2010) claims that this set of agreement markers constitute a separate paradigm, which differs from the general possessive paradigm used on nouns. Furthermore, she demonstrates that these suffixes are used not only on (possessed) nouns after certain case suffixes, but also on postpositions, pronouns and numerals. Below, I present a few illustrative examples. Edygarova (2010) claims that these suffixes express possession only when used on (non-derived) nouns (1a), but in all other cases, including when used on non-finite forms, they are agreement markers.

(1)
a. gurt-eni-m
gurt-a-m
gurt-oź-a-m
gurt-iśti-m
village-INS-1SG
village-INE/ILL-1SG
village-TERM-INE/ILL-1SG
village-ELA-1SG
'with my village'
'in(to) my village’
'(to) my village'
'from my village'
b. ber-a-m
back-INE/ILL-1SG
'behind me'
$a z ́-a-m$
dor- $a-m$
front-INE/ILL-1SG
next- INE/ILL-1SG
'in front of me'
'next to me'
c. kikn-a-mi
ogn- $a-m$
tWo-INE/ILL-1PL
one-INE/ILL-1SG
'the two of us'
'on my own/alone'

Given the fact that most non-finite adverbial clauses are headed by the Cx-Px type of case suffixes (e.g. the cause/reason clauses -(e)men and -(e)miś), it is not surprising that we find this agreement marker set used in non-finite clauses as well. Naturally, the -toź-clauses, being terminative-marked, take the same suffixes. Additionally, the -ku-clauses also take this set of suffixes. This set of agreement markers is also used on verbs in irrealis interrogative clauses expressing suggestion/demand/obligation (GSUJa I 1962). The verb form karom would be normally understood as a first 1PL future, i.e. 'we will do' (as opposed to the 1SG form karo 'I will do'). Nevertheless, example (2) is ambiguous: it can mean either 1SG or 1PL.

(2) fieldwork 2014, elicited

Mar kar-o-m?

what[ACC] do-FUT-1

'What shall/should I do?' or 'What shall/should we do?' 
In Chapter 3, we have seen three morphosyntactic patterns in non-finite adverbial clauses: (i) nominative subject and no agreement, (ii) nominative subject and agreement, (iii) genitive subject and agreement. The third pattern is attested only with the two nominalizations, while -ku and -toź - traditionally referred to as converbs - display only pattern (i) and (ii). Several questions arise with respect to these patterns.

Let us first discuss adverbial clauses formed with the two nominalizations. In Chapter 3, we have seen that these clauses show several morphosyntactic patterns. In the most common one, agreement is not indicated on the non-finite predicate and the subject bears nominative case, cf. (3). This is the 'unmarked' pattern. As argued in Chapter 4, in this case, the postposition selects for a TP.

(3) Georgieva \& Ótott-Kovács (2016: 58, ex. (15))

\begin{tabular}{|c|c|c|c|c|c|}
\hline [Tolkien & kul-em] & so-len & pi-jez & Christopher & ataj-ez-leś \\
\hline [Tolkien & die-NMLZ] after & 3SG-GEN & son-3sG & Christopher & father-3sG-ABL \\
\hline pottimte & kniga-os-se & pott-i- & & & \\
\hline
\end{tabular}

'After Tolkien's death (/ after Tolkien (had) died) his son Christopher published his father's unpublished books.'

The second pattern found in these clauses is the nominalized one: the subject is in genitive case and there is agreement on the non-finite predicate (4). This pattern is also expected since nominalizations used in argument position have genitive subjects. According to Dékány \& Tánczos (2017), these clauses have a DP layer on top of the verb phrase. Thus, it can be argued that the postposition in (4) selects for a DP.

(4) Georgieva \& Ótott-Kovács (2016: 60, ex. (18), (19))

\begin{tabular}{|c|c|c|c|c|c|}
\hline [Tolkien-*(len) & kul-em-ez] & bere & so-len & pi-jez & Christopher \\
\hline [Tolkien-GEN & die-NMLZ-3SG] & after & 3SG-GEN & son-3sG & Christopher \\
\hline ataj-ez-leś & pottimte & kniga-os- & & pott-i-z. & \\
\hline father-3sG-ABL & unpublished & book-PL- & SG.ACC & publish-PS & $-3 S G$ \\
\hline
\end{tabular}


Additionally, in Georgieva \& Ótott-Kovács (2016), we mention a third morphosyntactic pattern (labelled for convenience 'Nom+Agr'), namely when there is a possessive suffix on the non-finite predicate, but the subject is the nominative (5).

(5) Georgieva \& Ótott-Kovács (2016: 61, ex. (22))

$\begin{array}{llllllll}\text { \%[Kol'a } & \text { škola-je } & \text { min-em-ez] } & \text { bere } & \text { mon } & \text { kniga } & \text { lidž́̆i-ni } & k \text { kutsk-i. } \\ \text { [Kolya } & \text { school-ILL } & \text { go-NMLZ-3sG] } & \text { after } & \text { 1SG } & \text { book[ACC] } & \text { read-INF } & \text { start-PST[1sG] }\end{array}$
'After Kolya (had) left for school, I started reading a book.'

The different morphosyntactic patterns in adverbial clauses have not been recognized so far (most of the studies assume that the nominalized pattern is the most common one, cf. Dékány \& Tánczos 2017; Klumpp 2016: 562-566). As mentioned in Chapter 3, the 'unmarked' pattern is the most common in Different-Subject clauses, while the 'Gen+Agr' and 'Nom+Agr' patterns are not always possible.

In Georgieva \& Ótott-Kovács (2016: 59-61), we demonstrated that not all examples following the 'Gen+Agr' pattern are accepted by the native speakers or even if they are, speakers consider them less preferable than their minimal pairs following the 'unmarked' pattern. This is also supported by corpus data. I analyzed 578 'after'-clauses from the TurkuIzhevsk Corpus showing agreement on the non-finite predicate. ${ }^{1}$ Based on these data, one rarely finds examples with an overt subject in the presence of possessive suffixes on the nonfinite predicate: there are only 10 examples with nominative subjects and 8 examples of genitive-marked subjects. Hence, it seems that if agreement is indicated on the non-finite predicate, the subject is preferred to be null. If the subject is overt, then it is not clear what its case should be: genitive or nominative. Both patterns are attested, albeit rare in the corpus. The judgments of native speakers also vary with respect to these patterns (Georgieva \& ÓtottKovács 2016, In Prep.)

Several questions arise with respect to these patterns. Firstly, how to explain the 'Nom+Agr' pattern? Does the postpositions selects for a DP, and if yes, why do we find nominative instead of genitive case? The biggest issue with this pattern is that nominativemarked possessors are unattested with non-derived nouns used as possessors (cf. §2.3.1).

\footnotetext{
${ }^{1}$ This number also includes Same-Subject clauses.
} 
The abundance of patterns in Udmurt adverbial clauses is by no means exceptional cross-linguistically. Similar patterns have been discussed in the case of Meadow Mari and Komi-Zyryan (Serdobolskaya et al. 2012), as well as in Turkic languages (Kornfilt 2003; Ótott-Kovács 2016).

Serdobolskaya et al. (2012) claim that in Meadow Mari and Komi-Zyryan, subjects of non-finite clauses show variation between nominative and genitive case. They discuss mainly complement and only partly adjunct clauses. Serdobolskaya et al. (2012) argue that the nominative-genitive case variation can be attributed to semantic/pragmatic factors, such as animacy, thematic role and referentiality. Simplifying slightly their arguments, they claim that animate, agent and highly referential subjects are encoded with genitive case, whereas inanimate, patient and non-referential subjects prefer nominative case.

In Georgieva \& Ótott-Kovács (2016), we argued that these generalizations might be valid for Udmurt as well. Example (6) was accepted by four consultants, but rejected by five. Based on this example, one might argue that animacy plays a role in Udmurt, too.

(6) Georgieva \& Ótott-Kovács (2016: 61, ex. (21))

$\begin{array}{llllll}\text { \%[Šundi-len } & \text { pukś-em-ez] } & \text { bere agaj-e } & \text { azbar-e } & \text { pot-i-z. } \\ \text { sun-GEN } & \text { set-NMLZ-3SG } & \text { after } & \text { elder.brother-1SG } & \text { garden-ILL } & \text { go.out-PST-3SG }\end{array}$

'After the sun set, my elder brother went to the garden.'

The 'after'-clauses with overt subjects in the nominative/genitive case coming from the Turku-Izhevsk Corpus, however, do not obey the rules postulated for Komi-Zyryan and Meadow Mari non-finite clauses. In Udmurt 'after'-clauses, nominative case is attested with animate, agent and referential subjects, and genitive case can be used with inanimate, patient and non-referential subjects. As an illustration of this, consider example (7), in which the subject is inanimate, its thematic role is theme (the non-finite predicate is formed from an unaccusative verb), but it nevertheless bears genitive case.

(7) Turku-Izhevsk Corpus (Vordskem kyl/I/4.txt:110)
Šitaźe,
[sobrani-len
ortć-em-ez]
bere, kino
lu-o-z.
in.the.evening convention-GEN be.over-NMLZ-3SG after movie be-FUT-3SG
'In the evening, after the convention is over, there will be a movie.' 
The 'Nom+Agr' pattern has been discussed in a couple of generative studies dealing with Turkic languages. Kornfilt (2003) proposes that agreement in Modern Standard Turkish non-finite clauses headed by - $D X k$ (factive nominalization) are located in an independent syntactic head, AgrP. Moreover, she claims that $D X k$-nominalizations are categorically hybrid. This means that the Agr head must bear a referential index in order to be able to assign genitive case to the subject. The Agr head receives a 'primary' theta-role from the matrix predicate in argument clauses. Thus, if $-D X k$-clauses are in adjunct position, their subject will be in the default case (nominative), since the Agr head has not received a primary theta-role. The only exceptions from this rule are certain adjunct clauses ('according to'-, 'as much as'- and 'like'-clauses). Kornfilt (2003: 169-171) argues that these are free relative/comparative clauses, in which an operator assigns the primary theta-role.

This approach would explain why nominalization in argument position have genitivesubjects. It also fits the observations made about -(e)men-clauses (§3.7.2.2). These adverbial clauses express cause/reason, and in this case, they have nominative subjects (with or without agreement). But they also have another use: with the matrix verb gerž́aśkini 'to connect (intransitive)' the sentence means 'something is connected with/related to something' (8).

(8) Udmurt Corpus (Удмурт дунне, 2009.01.16)

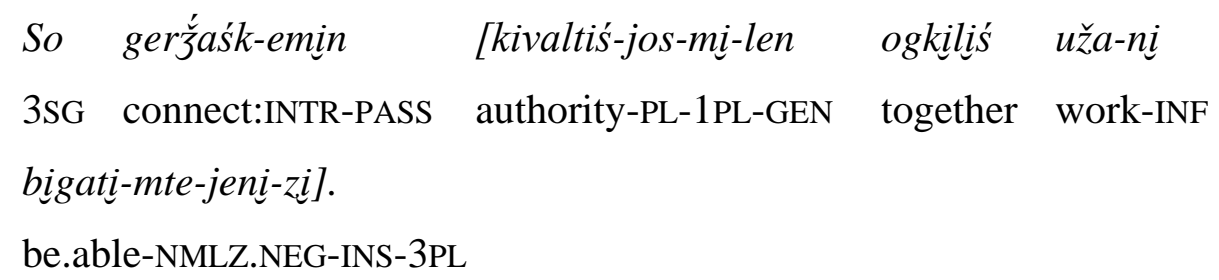

'This is related to the inability of our authorities to work together.'

In this case, it might be argued that this is a subcategorized adjunct, thus, the nominalized pattern is expected. However, the problems remain with 'after'-clauses like (7): they are clearly not subcategorized adjuncts, but nevertheless, the nominalized pattern is attested in them. More importantly, Kornfilt's approach predicts that agreement should be marked in adjunct clauses (as it is in Turkish), however, the most general pattern in Udmurt adverbial clauses with independent subjects is the 'unmarked' one.

Ótott-Kovács (2016) deals with a similar variation in Kazakh. The same three patterns are attested: 'unmarked', 'Nom+Agr' and 'Gen+Agr'. She proposes that the 'unmarked' pattern arises when a postposition/semantic case selects for an IP-sized non-finite clause. In 
her analysis, the I head of the non-finite clause assigns nominative case to the subject. For the 'Nom+Agr' and 'Gen+Agr', she argues that these are nominalized clauses: a DP layer is merged on top of the IP. In both cases, the subject is first assigned nominative case from the I head, and then the genitive case from the $\mathrm{D}$ head. The difference is that genitive case might be marked ('Gen+Agr') or 'unmarked', i.e. this is the 'Nom+Agr' pattern.

The existence of an 'unmarked genitive case' in Turkic languages is not an implausible idea, based on certain possessive constructions found in these languages. For instance, Pereltsvaig \& Lyutikova (2014) show that Tatar has two types of possessive constructions (with non-derived nouns): nominative and genitive ('ezafe-2' and 'ezafe-3', in their terms). The two possessor types differ from each other in several properties. Nominative possessors are non-referential and sit in a lower position, Spec,PossP. Genitive possessors introduce a referent and are found in Spec,DP. However, this analysis cannot be easily carried over to Tatar nominalized clauses: as Lyutikova \& Ibatullina (2015) point out, genitive and nominative subjects of nominalized clauses, unlike possessors, do not seem to appear in different structural positions (Spec,DP or Spec,PossP). Moreover, the subjects of nominalized clauses can be of any structural type and do not differ in terms of referential properties, but still exhibit case alternation.

The idea of subjects bearing unmarked genitive case seems unmotivated in the case of Udmurt since we never find unmarked possessors in the presence of agreement on the possessee (§2.3.1). One might tentatively propose that the 'Nom+Agr' pattern arises when the non-finite clauses do have a DP layer, but their subject does not move out of the verb phrase to Spec,DP, whereas genitive-marked subjects undergo further movement to Spec,DP. Such an analysis is also very speculative, and needs to be verified. More generally, it is unclear what determines the choice between the three patterns: dialectal variation, functional differences between them, competing grammars, etc., and at present, I cannot provide a definitive answer to these questions.

Turning to the non-finite verbs traditionally labelled as 'converbs', we find agreement in the -ku-clauses ('when') and -toź-clauses ('until', 'before', 'while', 'rather than'). I argued in Chapter 4 that this is not surprising if we view these clauses as headed by casemarkers/postpositions, similarly to the case suffixes that can be preceded by an agreement marker. Agreement markers in these clauses is generally not considered obligatory (Perevoshchikov 1959; Winkler 2001; Bartens 2000). 
Below, I provide statistics for the frequency of agreement in -ku- and -toź-clauses based on the Udmurt Corpus and the Udmurt Social Media Corpus. The results are presented in Table 2 ('+Agr' stands for non-finite clauses with agreement, '-Agr' for adjuncts without agreement). ${ }^{2}$

Table 2 Frequency of agreement in -ku- and -toź-clauses

\begin{tabular}{|l|l|r|l|r|}
\hline & \multicolumn{2}{|c|}{ Udmurt Corpus } & \multicolumn{2}{c|}{$\begin{array}{c}\text { Udmurt Social } \\
\text { Media Corpus }\end{array}$} \\
\hline -ku-clauses & + Agr & 8,596 & + Agr & 1,291 \\
\hline & - Agr & 4,692 & - Agr & 999 \\
\hline & Total & 13,288 & Total & 2,290 \\
\hline -toź-clauses & + Agr & 1,747 & + Agr & 169 \\
\hline & - Agr & 1,820 & - Agr & 518 \\
\hline & Total & 3,561 & Total & 687 \\
\hline
\end{tabular}

Several conclusions can be drawn from Table 2. They are connected to the frequency of the two adjunct clauses in general, and more specifically, between standard and spoken Udmurt (which the two corpora represent). The two adjunct clauses differ with respect to agreement as well: -ku-clauses occur more frequently with agreement, while -toź-clauses show the reversed pattern.

There are not many generalizations made about the factors determining when agreement appears on converbs in the literature. Bartens (2000: 245), for instance, claims that the person agreement is optional if the subject of the non-finite clause is coreferential with the subject of the main clause. On the other hand, if the subjects are not coreferential, the person agreement on the converbs seems obligatory. Thus, one might expect that agreement can be dropped in (9), but not in (10).

(9) GSUJa I (1962: 288)

$\begin{array}{lllll}\text { [Vuriśki-toź-ami] } & \text { pertem } & \text { kirž́an-jos-ti } & \text { kirž́a-śko-m } & \text { [...] } \\ \text { sew-CVB.LIM-1PL } & \text { different } & \text { song-PL-ACC } & \text { sing-PRS-1PL } & \end{array}$

'While we are sewing, we sing different songs [...]'

\footnotetext{
${ }^{2}$ Since the examples in the corpus have been annotated automatically, there might be some false positive hits. 
(10) elicited

$\begin{array}{lllll}\text { [Vuriśki-toź-ad] } & \text { (mi) } & \text { pertem } & \text { kirř́an-jos-tí } & \text { kĭř́a-śko-m. } \\ \text { sew-CVB.LIM-2SG } & \text { (1PL.EXCL) } & \text { different } & \text { song-PL-ACC } & \text { sing-PRS-1PL }\end{array}$

'While you are sewing, we sing different songs.'

This seems like a plausible generalization, but counterexamples are attested both ways: Same-Subject clauses can show agreement and Different-Subject clauses might not show agreement. I argue that presence/absence of agreement in these clauses is determined by several, possibly independent factors. This gives the (incorrect) impression that agreement is optional in these clauses. These factors include:

- Adjunct clauses with arbitrary subjects do not show agreement;

- Agreement with referential subjects is less frequent in generic/habitual sentences;

- The different uses of the -toź-non-finites ('until', 'while', etc.) do not behave uniformly with respect to agreement;

- Agreement is disallowed if the adjunct clause has an overt subject (Edygarova 2010).

Firstly, arbitrary null subjects are incompatible with subject agreement in the non-finite clause (Georgieva 2012). The minimal pair below shows that arbitrary reading is possible only in (11a) in which the subject is null and there is no agreement. On the other hand, the 3PL agreement in (11b) refers to a particular group of referents, established in the discourse, for instance the students in the class. (Arbitrary null subjects of adjunct clauses will be discussed in $\S 5.4 .2$.

(11) Georgieva (2012)
a. [Gožja-ku] predloženi-len
pum- $a-Z$
toćka
pukt-o. ${ }^{3}$
write-CVB.SIM sentence-GEN
end-INE/ILL-3SG
full stop[ACC]
put-PRS.3PL

'When writing one puts a full stop at the end of the sentence.'

b. [Gožja-ku-zi] predloženi-len pum-a-z toćka pukt-o. write-CVB.SIM-3PL sentence-GEN end-INE/ILL-3SG full stop[ACC] put-PRS.3PL

'When writing they put a full stop at the end of the sentence.' (referential only)

\footnotetext{
${ }^{3}$ Example (a) was adapted from GSUJa I (1962: 286).
} 
In Same-Subject clauses with referential subjects, agreement might be dropped if the matrix clause has a generic/habitual meaning, especially in present tense (Georgieva 2012). One illustrative example is given below (the speaker describes the customs of welcoming the guests on holidays). (However, agreement can be absent in episodic sentences as well, see the examples in §5.4.1.)

(12) fieldwork recording, 2014_07_21, VE, Alnash, Udmurtia

$\begin{array}{lllll}\text { [každij } & \text { kuno } & \text { pir-ti-ku] } & \text { niriśs=ik } & \text { pukte }<\mathrm{H}:> \\ \text { every } & \text { guest[ACC] } & \text { come.in-CAUS-CVB.SIM first=EMPH } & \text { put[PRS.3SG] } \\ \text { క̌ę } & v e z-i & \text { pukon-ez } & & \\ \text { table } & \text { next-ILL } & \text { chair-ACC [...] } & & \end{array}$

'When $\left[\mathrm{she}_{\mathrm{i}}\right]$ lets every/a guest come in, [the hosti $]$ first puts a chair next to the table [...]'

Based on my fieldwork, the -toź-non-finites behave in a different way with respect to agreement depending on their function. Recall that they can be used to encode 'until'-, 'before’-, ‘while’- and 'rather than’-clauses (§3.7.2.7). Consider the following minimal pair, which difference in the presence or absence of agreement.

(13) fieldwork 2013, elicited

$\begin{array}{llllll}\text { [Mon } & \text { škola-je } & \text { mini-toź] } & \text { Liza } & \text { gurt-e } & \text { bert-o-z. } \\ \text { 1SG } & \text { school-ILL } & \text { go-CVB.LIM } & \text { Liza } & \text { home-ILL } & \text { come.home-FUT-3SG }\end{array}$

'By the time I get to school, Liza will have come home.' or

'Before I go to school, Liza will come home.'

(14) fieldwork 2013, elicited

$\begin{array}{llllll}\text { [(Mon) } & \text { škola-je } & \text { mini-toź-am }] \quad \text { Liza } & \text { gurt-e } & \text { bert-o-z. } \\ \text { 1SG } & \text { school-ILL } & \text { go-CVB.LIM-1SG Liza } & \text { home-ILL } & \text { come.home-FUT-3sG } \\ \text { 'While I am on my way to school, Liza will come home.' }\end{array}$

Example (13) does not show agreement, and according to the judgments of many native speakers, the two events (going to school and coming home) are not simultaneous. In (14), on the other hand, agreement is marked, and the speakers suggest that the meaning of the adjunct clause is 'while'. These semantic differences can be supported by corpus data as well: it is 
much more frequent for 'while'-clauses, especially the ones expressing partial overlap between the events, to show agreement (the 'while'-clauses that can be paraphrased with ' $q$, as long as not-p' occur more often without agreement). It is questionable whether the difference is to be explained with agreement itself, but with the fact that the agreement marker is preceded by the inessive/illative $-a-$, and this gives the meaning of a temporal interval within which the event of the matrix clause takes place. In their 'before' use, such an interval is not present, thus agreement is not used. Furthermore, -toź-clauses typically do not show agreement when they express 'rather than'-clauses.

Edygarova (2010: 87) claims that the overt subject and person agreement are in complementary distribution in converb clauses. According to her, the sentence is grammatical only without the agreement marker.

(15) Edygarova (2010: 87)

$\begin{array}{lllll}\text { Ton }\left[\text { mon škola-je mini-ku- }\left({ }^{*}\right)\right] & \text { eš-te } & \text { pumita-d. } \\ \text { 2SG 1SG school-ILL go-CVB.SIM-1SG friend-2SG.ACC } & \text { meet-PST.2SG } \\ \text { 'When I was going to school, you met your friend.' }\end{array}$

This might lead us to think that the agreement markers used in these adjunct clauses are pronominal clitics or pronominal agreement markers (cf. Siewierska 1999, 2004; Fuß 2005). Several criteria have been proposed in the literature in order to distinguish between pronominal agreement and grammatical agreement markers. One of them is referentiality of these affixes: pronominal agreement markers, like free pronouns but unlike grammatical agreement, tend to be referential (Siewierska 1999). The most important test is the possibility of co-occurrence of the person agreement marker with an overt DP (i.e. subject-doubling). The hallmark of pronominal agreement markers is that they cannot co-occur with an overt DP subject. Additional tests focus on obligatoriness, morphological/phonological form, markedness, etc. It is cross-linguistically common for free pronouns to grammaticalize into pronominal agreement markers and later into grammatical agreement markers (see Siewierska 1999, 2004).

By referentiality I mean that these markers refer to a particular individual who the hearer can correctly identify based on the discourse context. This individual, i.e. the referent, must be part of the hearer's background knowledge, moreover, it must be contextually salient 
(see Chafe 1994: 93-107). We have already seen that the 3PL agreement markers in these adjunct clauses cannot refer to arbitrary subject, cf. (11b) above.

As for the subject-doubling criterion, Edygarova's (2010) can be taken to support the pronominal agreement analysis. However, one can easily find counterexamples from corpora, and even from the traditional grammars. Two examples are given below.

(16) GSUJa II (1970: 115)

$\begin{array}{lllll}{[\mathrm{Ti}} & \text { šutetski-toź-adi }] \quad \text { mi } & \text { turna-n-mes } & \text { bidest-i-m. } \\ \text { 2PL } & \text { rest-CVB.LIM-2PL } & \text { 1PL.EXCL } & \text { scythe-VN-1PL.ACC } & \text { finish-PST-1PL } \\ \text { 'While you were resting, we finished scything.' } & \end{array}$

(17) Karpova (2005: 408)

$\begin{array}{llllll}\text { wall'o, } & \text { [mon } & \text { biźż-ku-m], } & \text { Bud'onnoj } & \text { kolhoz nazvatsa } \\ \text { long.time.ago } & \text { 1SG } & \text { get.married-CVB.SIM-1SG } & \text { Budjonny } & \text { kolkhoz call } \\ \text { kari-śki-l-i-z. } & & & & \\ \text { do-INTR-FREQ-PST-3SG } & & & \end{array}$

'A long time ago, when I got married, the kolkhoz was (still) called Budjonny (a Soviet military commander).'

In Georgieva (2017a), I claim that there is variation among the speakers with respect to subject-doubling based on two questionnaires. The first one was conducted in 2012-2013 and the second was filled out in 2014. The first questionnaire was filled out online by ten native speakers of Udmurt in October-November 2012. During my fieldwork in July 2013, I worked on the same questionnaire with seventeen consultants, so altogether the questionnaire was filled out by twenty-seven native speakers of Udmurt. The speakers come from the following districts of the Republic of Udmurtia: Alnash, Balezino, Debes, Igra, Grakh, Jakshur-Bodya, Kez, Kiyasa, Mozhga, Pichi Purga and Sharkan.

Based on two questionnaires, I show that there are two varieties. In variety A, subjectdoubling yields ungrammaticality, while speakers of variety B do allow subject-doubling. Subject-doubling is more wide-spread among speakers of the Northern dialects (Kez, Balezino, Igra districts). My results demonstrate that there are some dialects in which agreement on the converbs is strictly pronominal (Mozhga and Sharkan districts), i.e. the Central dialects. Speakers of the Southern dialects (Alnash, Kiyasa and Grakh districts) 
display variation - some of them do accept examples with subject-doubling, while others do not. Hence, it seems that we are dealing with dialectal variation.

For my fieldwork in 2014, I compiled another questionnaire in which I tested subjectdoubling with different types of subjects. There is a great amount of cross-linguistic evidence that the possibility of subject-doubling depends on the type of subject: in some languages, subject doubling is allowed with pronouns but not with nouns, in others, the animacy or definiteness of the DP plays a role (Siewierska 1999, 2004; Fuß 2005). Hence, I included examples with both animate and inanimate subjects, as well as with non-referential subjects, such as indefinite, quantified subjects/bare quantifiers and wh-subjects. The results are summarized in Table 3.

Table 3 Subject-doubling with different subject types (Georgieva 2017a)

\begin{tabular}{|l|c|c|}
\hline & Variety A & Variety B \\
\hline 1sG pronoun & $X$ & $\checkmark$ \\
\hline 3sG pronoun & $X$ & $\checkmark$ \\
\hline Proper noun & $X$ & $\checkmark$ \\
\hline Indefinite DP & $X$ & $\checkmark$ \\
\hline Quantified DP & $X$ & $\checkmark$ \\
\hline Bare quantifier & $X$ & $? ?$ \\
\hline Inanimate DP & $X$ & $? ?$ \\
\hline Wh-subject & not applicable & not applicable \\
\hline
\end{tabular}

Subject-doubling with a wh-subject is not applicable since wh-elements are not licit in non-finite adjunct clauses (§3.2). As can be seen from the table, speakers from Variety A reject subject-doubling with all subject types. Speakers from variety B, on the other hand, generally allow it However, subject-doubling with a bare quantifier was degraded even for those speakers, cf. (18). The reason for this is probably not connected to the subject-doubling, but to the use of quantifier: we have seen that null subjects of adjunct clauses can have arbitrary interpretation (11a). Thus, the most natural way to express the intended meaning of (18) would be to use a null subject without any agreement. (Arbitrary subjects of adjunct clauses will be further discussed in §5.4.2.) 
(18) fieldwork 2014, elicited

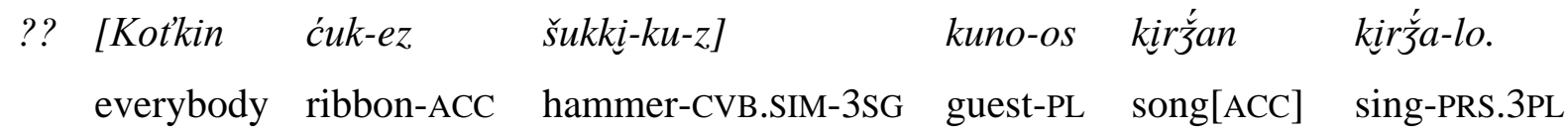
Intended: 'While everybody is hammering in the ribbon (into the beam), the guests are singing a song.'

As for subject-doubling with inanimate DPs, the results of the questionnaire show that it is fairly restricted. For instance, (19) was rejected by the respondents. However, I have found subject-doubling with an inanimate subject, cf. (20).

(19) fieldwork 2014, elicited

Tunne mon [šundi pukśí-toź-(*az)] uža-j.

Today 1SG sun set-CVB.LIM-3SG work-PST[1SG]

'Today I worked until sunset.'

(20) fieldwork 2014, spontaneous

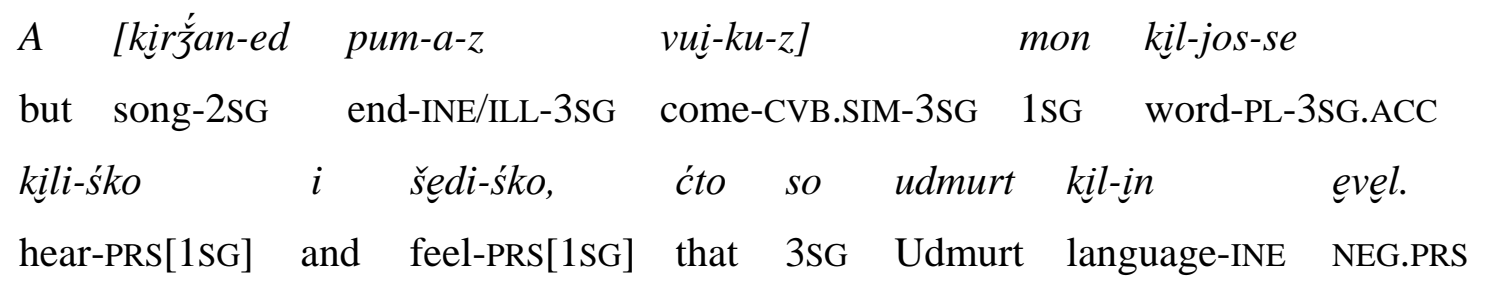

'But when your song comes to an end, I hear its words (lyrics) and realize that it is not in Udmurt.'

Example (20) was uttered in a context where the main topic of the conversation was the song. Given the fact that these agreement markers generally pick up referents that are established in the discourse, or more precisely, referents that are salient in the discourse, one needs to provide very strong context in order for inanimate subjects to be doubled (hence, it might be the case that the sentences used in the questionnaire, especially given with very little context, could not be interpreted as salient in the discourse).

Thus, it seems that the two patterns, i.e. nominative subject and agreement and nominative subject without agreement, are both judged grammatical by the speakers of Variety B. The question is what determines the choice between them (this is also related to the 
purported optionality of agreement in these adverbial clauses). Consider the next minimal pair from the questionnaire.

(21) fieldwork 2014, elicited
a. [Kol'a uśí-ku]
Liza anaj-ez-li
žingîrte
val.
Kolya fall-CVB.sim
Liza mother-3SG-DAT
call[PRS.3SG]
AUX.PST
b. \%[Kol'a uśíl-ku-z]
Liza anaj-ez-li
žingirte
val.
Kolya fall-CVB.SIM-3sg Liza mother-3SG-DAT call[PRS.3sG] AUX.PST
When Kolya fell down, Liza was calling her mom/was talking to her mom on the phone.'

For many of the native speakers who accept (21b), the two sentences do not have the same meaning. According to them, (21a) describes two independent events, and the meaning of the adjunct clause is to specify the time when Liza's calling her mom took place. In (21b), the Kolya's falling and Liza's calling her mom are viewed as two subevents of the same situation, moreover, the speakers suggest a causal construal between the subevents (e.g. Liza called her mom to tell her that Kolya is hurt).

Although the differences in meaning might seem very subtle, I believe they are indicative. For instance, consider (19), which was rejected by the speakers. The temporal clause 'until the sun set', as well as similar temporal clauses, e.g. 'when dawn broke', simply specify the time when the event of the main clause happens. They give an answer to the question 'when', and can be easily substituted with adverbs, e.g. at noon, last Monday, etc. On the other hand, in (20) clearly describes one single situation, in which the participants are shared (i.e. the song ends and I hear its words).

Similar contrasts are also found in adverbial clauses headed by nominalizations. The adverbial in (22a) simply gives the reason of the event described by the matrix clause, while in (22b) the subject of the adjunct clause is coreferential with the object of the matrix clause. Sentence (22b) exemplifies the problematic pattern of 'Nom+Agr' with nominalizations discussed above. 
(22) GSUJa II (1970: 118)

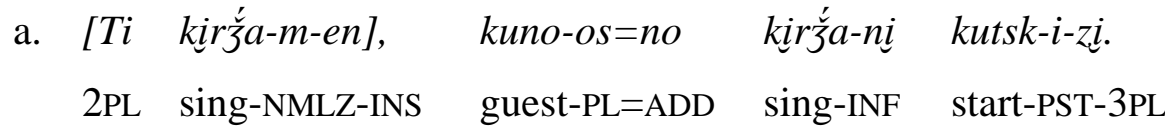

'Because you [started to] sing, the guests also started singing.'

b. [Ti kidd'ok-e košk-em-eni-di], mi kuara-des em kile.

2PL far-ILL go-NMLZ-INS-2PL 1PL.EXCL voice-2PL.ACC NEG.PST.1 hear[PL]

'Because you went too far, we couldn't hear your voice.'

Above I highlighted a couple of problematic issues with respect to agreement. It was shown that non-finite adjunct clauses formed with nominalizations display a pattern that is unattested with nominalizations in argument position and for which the available theoretical analyses cannot account in a satisfactory way. Additionally, I argued that the claims made in earlier studies about the optionality of agreement in the -ku- and -toź-clauses are related to several, possibly independent factors. I showed that there are dialectal differences with respect to subject-doubling and speculated about the (functional) differences between the morphosyntactic patterns. Thus, so far the main focus was on cases in which the subject was overt, with agreement being present or absent. Next, we will turn to another alternation, namely, the one between null and overt subjects.

\subsection{Null and overt subjects in Udmurt non-finite adverbial clauses}

In Chapter 3, it was demonstrated that most non-finite adverbial clauses in Udmurt display a variation between null and overt subjects. Consider the following minimal pair.

(23) Georgieva (2016b: 33, ex. (1), elicited)

[Gurt-e berti-sa] Kol'a Liza-li kńiga-ze śot-i-z.

home-ILL go.home-CVB Kolya Liza-DAT book-3SG.ACC give-PST-3sG

'_ $\mathrm{i}^{\mathrm{*} / *_{\mathrm{j}}}$ having gone home, Kolyai gave his book to Lizaj.'

(24) Georgieva (2016b: 33, ex. (2), elicited)

[So gurt-e berti-sa] Kol'a Liza-li kńiga-ze śot-i-z.

3SG home-ILL go.home-CVB Kolya Liza-DAT book-3SG.ACC give-PST-3SG

'Him*i/??j/k having gone home, Kolyai gave his book to Lizaj.' 
The null subject in (23) is interpreted as coreferential with the subject of the matrix clause, whereas the overt pronoun in (24) cannot be coreferential with it. This minimal pair raises several questions with respect to null subjects, e.g. (i) is it always the case that null subjects are coreferential with the matrix subject; (ii) can they be coreferential with any other constituent from the matrix clause; (iii) can they be interpreted as referring to a referent previously mentioned in the discourse. These questions are related to the category of the null subject, and the type of referential dependency between it and its antecedent. One of the approaches would be to assume a pro subject, whose reference is identified via coreference. According to the alternative analysis, we are dealing with a control structure. As we will see shortly, this is a highly debated question in the literature.

Let us first discuss the basic facts from English. In English, finite and non-finite adverbial clauses differ crucially with respect to the nature of their subjects, cf. (25).

a. After he i went home, Peteri watched some television.

b. After PROi going home, Peteri watched some television.

In (25a), the subject of the adverbial is a pronoun (he). This pronoun can be interpreted as coreferential with the subject of the matrix clause. Note that the cataphoric pronoun precedes its antecedent, thus, we are dealing with 'backward pronominalization'. Williams (1997) has argued that this type of referential dependency is possible only in subordinate clauses, but not in coordinate clauses (cf. *He went home and Peter $\mathrm{r}_{\mathrm{i}}$ watched some television). Hence, backward pronominalization can be used as diagnostics for distinguishing subordinate from coordinate clauses. In (25b), on the other hand, we find a different type of subject, a PRO. In Government and Binding Theory, PRO is defined as a covert DP that occurs in the subject position of non-finite clauses and bears the features [+anaphor, +pronominal] (Chomsky 1981) (for the analysis of PRO in more recent generative studies see below). The interpretation of PRO is determined by control.

The situation is more complicated in pro-drop languages like Udmurt. Unlike English, pro-drop languages utilize another type of null pronoun, pro. Thus, in pro-drop languages, the null subject of non-finite clauses can potentially be pro, and not only PRO, as opposed to English, where the situation is clear-cut. 
The existing studies on non-finite clauses in pro-drop languages differ radically regarding the nature of the empty subjects: some authors argue for a pro, others propose that it is a PRO. To put it simply, the debate is built around the following questions: (i) can the null subject alternate with an overt one, and (ii) can its reference be determined by discourse. The answer being 'yes' has been often taken as evidence of pro (Tóth 2000 for Hungarian; Erguvanl1-Taylan 1986 for Mondern Standard Turkish; Ótott-Kovács 2016 for Kazakh). Others have argued that (obligatorily controlled) PRO alternates with overt DP subjects in adjunct clauses (Sundaresan 2014).

Let us take a closer look at Modern Standard Turkish. In (26), I illustrate a non-finite adjunct clause ('while'). ${ }^{4}$ Observe that Modern Standard Turkish shows a similar variation: null subjects can alternate with an overt one in non-finite adjunct clauses.

(26) Modern Standard Turkish (Erguvanl1-Taylan 1986: 215, ex. (10b, d))

[_i çalış-ır-ken] Eroli müzik dinle-r.

work-AOR-while Erol music listen-AOR

'While hei works, Eroli listens to music.'

[O*ij çalış-ır-ken] Erol ${ }_{i}$ müzik dinle-r.

3SG work-AOR-while Erol music listen-AOR

'While he/she $*_{\text {}_{\mathrm{ij}}}$ works, Eroli listens to music.'

Erguvanl1-Taylan (1986) claims that the only way to express coreferentiality between the subject of the non-finite clause and subject of the matrix clause is by using a null subject ('zero anaphora' in her terms) (26a). If the subject is overt ('pronominal anaphora' in her terms), coreference is impossible (26b). Moreover, Erguvanl1-Taylan (1986: 223-224) discusses the importance of the discourse in such constructions. She claims that null subjects can find their antecedent beyond the boundaries of the sentence, as long as the antecedent is: "presupposed, predictable or recoverable from the immediate discourse” (Erguvanl1-Taylan 1986: 224).

Similar data have been presented about Kazakh as well. Ótott-Kovács (2016) argues that the null subject is a pro, and backward pronominalization in Kazakh works almost the same way as in English, with the small caveat: the subject must be null. Thus, the Kazakh counterparts of (26a) are said to have a pro subject, and pro-drop is obligatory in these clauses

\footnotetext{
${ }^{4}$ The glosses were slightly modified.
} 
since overt subjects are obviative. In a recent generative study on converb clauses (Weisser 2015), backward pronominalization is one of the decisive criteria for distinguishing subordination from coordination, but the fact languages often impose restrictions on the type of subject that can be co-indexed with the matrix subject is left unnoticed (it might be the case that only null subjects can be co-indexed or only anaphoric pronouns, etc.).

The competing approach is to analyze the null subject of non-finite clauses as (obligatorily controlled) PRO-s (Sundaresan 2014; Pires 2006 on non-inflected infinitives in Portuguese; Haddad 2007 on Telugu and Assamese). Based on data from Spanish, Italian, Romanian, Hungarian, Hindi and Japanese, Sundaresan (2014: 74-82) argues that only finite clauses can show pro-drop, non-finite clauses cannot. Even in the case of Modern Standard Turkish, there are studies which argue that the null subject of non-finite adverbial clauses is PRO. Kornfilt (2003: 155-156) states that the subject of 'while'-clauses is PRO, which cannot refer to a DP mentioned in the previous sentence. She proposes that PRO is licensed only in clauses without agreement. Furthermore, Oded (2011) discusses adjunct control in Modern Standard Turkish and, based on the diagnostics for distinguishing obligatory from non-obligatory control (see below in §5.3), concludes that we are dealing with obligatory control.

On the theoretical level, the variation between a PRO and an overt DP is problematic since they should be in complementary distribution according to Case Theory (Sundaresan \& McFadden 2009, as well as Landau 2013: 99-103). This has led several authors to assume that if a null subject can alternate with an overt one, then it must be pro (see Tóth 2000 in the case of Hungarian adverbial participles -vÁn). Sundaresan \& McFadden (2009), on the other hand, propose that the variation between PRO and overt DP subjects can be observed in adjunct clauses because they are not selected by the matrix predicate.

As will be shown in §5.3, a distinction is made between obligatory and non-obligatory control (OC and NOC henceforth) (see Williams 1980). ${ }^{5}$ In OC structures, the reference of the null subject is determined locally, within the same sentence. Under NOC, however, the reference is determined by the discourse, and it has been said to depend on logophoricity and topicality. Furthermore, it has been observed that adjunct clauses are particularly susceptible to non-obligatory control. In connection to this, the question arises of whether the null subject of a non-finite clause classified as pro because its reference is determined by discourse is not

\footnotetext{
${ }^{5}$ This dichotomy is rejected in the Two-Tiered Theory of Control (Landau 2015) who distinguishes between 'predicative' and 'logophoric' control.
} 
simply an instance of NOC PRO. This argument has been made within the Movement Theory of Control (Hornstein 2001, et seq.), according to which NOC PRO behaves like pro, as well as by McFadden \& Sundaresan (2016: 7) who state that NOC is equivalent to pro-drop (at least with non-arbitrary readings).

It is important to emphasize that the possibility of discourse interpretation of the null subject does not cut across the distinction of pro and PRO: for instance, the Hungarian adverbial participles -vÁn have a pro subject that can be logophorically controlled (Tóth 2000), while the -va-participles have a PRO subject, but logophoric control is also an option (Bartos 2009; Tóth 2000).

Furthermore, it has been observed that certain finite subordinate clauses, e.g. subjunctive clauses, have a pro subject that is obligatorily controlled (Landau 2004). Another observation made in the literature is that the obligatorily controlled pronoun might be overt, as in Korean, for example (Madigan 2008). Based on these considerations, the existence of a single pronoun ('minimal pronoun') has been proposed (Landau 2015; McFadden \& Sundaresan 2016)

Returning to Udmurt, one way to approach the minimal pair presented in (23) and (24) is to say that (23) contains a pro, and its references is determined via backward pronominalization. Under this analysis, it remains to be explained why the overt pronoun in (24) cannot be co-indexed with the matrix subject.

The coreference between the overt subjects is ruled out irrespective of the order of the matrix and non-finite clauses: in (27), the converb clause follows the matrix clause, but the coreference between the subjects is still impossible (however, observe that the coreference between the indirect object of the matrix clause and the embedded subject is now allowed, in contrast to (24)).

(27) Georgieva (2016b: 38, ex. (16), elicited)

$\begin{array}{lllllll}\text { Kol'a } & \text { Liza-li } & \text { kńiga-ze } & \text { śot-i-z } & \text { [so gurt-e } & \text { berti-sa]. } \\ \text { Kolya } & \text { Liza-DAT } & \text { book-3sG.ACC } & \text { give-PST-3SG } & \text { 3SG home-ILL } & \text { go.home-CVB }\end{array}$

'Kolyai gave his book to Lizaj, him*ij/k having gone home.'

In $3^{\text {rd }}$ person, the use of overt subjects leads to disjoint reference, as shown in (24) and (27), while in $1^{\text {st }}$ and $2^{\text {nd }}$ person, the result is ungrammatical (28). 
(28) Georgieva (2016b: 36, ex. (8), elicited)

\begin{tabular}{|c|c|c|c|c|c|}
\hline *[Mon & uśi-ku] & mon & kuara-me=no & $e j$ & potti. \\
\hline 1SG & fall-CVB.SIM & $1 \mathrm{SG}$ & voice-1SG.ACC=ADD & NEG.PST & let.out[SG] \\
\hline
\end{tabular}

The contrast between null and overt subjects can be observed not only with respect to matrix subject, but also with respect to the certain dative- and genitive-marked DPs (they will be touched upon in §5.4.2) (Georgieva 2016b). In (29), we find a deontic construction in which the highest argument of the non-finite predicate is assigned dative case. ${ }^{6}$ The dativemarked DP is understood as the controller of the null subject in the adjunct clause. The overt pronoun is disjoint in reference (30).

(29) elicited

Kol'a-li [škola-je vuí-sa] direktor-en veraśk-on-o lu-i-z.

Kolya-DAT school-ILL arrive-CVB head.teacher-INS talk-VN-ATTR be-PST-3sG 'As_i got to school, Kolyai had to talk to the head teacher.'

(30) elicited

Kol'a-li [so škola-je vui-sa] direktor-en veraśk-on-o lu-i-z. Kolya-DAT 3SG school-ILL arrive-CVB head.teacher-INS talk-VN-ATTR be-PST-3SG 'As_*i/j got to school, Kolyai had to talk to the head teacher.'

The only overt pronouns that allow coreference in Udmurt are the reflexive pronouns. The reflexive pronouns are morphologically segmentable into a pronominal stem and a possessive suffix, and can additionally be marked for case. The Udmurt reflexive pronouns can be used as intensifiers (this has been briefly discussed in Volkova 2014 based on the Beserman dialect). ${ }^{7}$ According to König et al. (2013), intensifiers are: “[..] adjoined to either NPs or VPs, are invariably focused and thus are prosodically prominent. The main function of intensifiers can be seen in the evoking of alternatives to the referent of the NP they relate to”. König et al. (2013) distinguish two kinds of intensifiers: nominal and adverbial, as illustrated below.

\footnotetext{
${ }^{6}$ Here I do not wish to claim that the dative-marked DP is a quirky subject, hence I use the term 'highest argument'.

${ }^{7}$ These are called 'emphatic personal pronouns’ in GSUJa I (1962: 182-183). 
(31) König et al. (2013)
a. The director himself opened the letter.
adnominal intensifier
b. The director opened the letter himself.
adverbial intensifier

The two types of intensifiers are found in Udmurt, too. In (32a), we find an adnominal intensifier, whereas (32b) contains an adverbial intensifier. ${ }^{8}$ In both examples, the pronoun is nominative.

(32) elicited
a. Pet'a aćiz
gožtet-ez gožt-i-z.
Petya REFL.3SG letter-ACC write-PAST-3SG

'Petya himself wrote the letter.'

$\begin{array}{llll}\text { b. Pet’a } & \text { gožtet-ez } & \text { aćiz } & \text { gožt-i-z. } \\ \text { Petya } & \text { letter-ACC } & \text { REFL.3SG } & \text { write-PAST-3SG }\end{array}$

'Petya wrote the letter himself.'

The matrix clause of (24) and (27) was slightly modified in order to ensure the contrast needed for the intensifier. The context of (33) is that someone had to go home to help mother, and since Kolya went home, it was not necessary for Liza to go home, too, and Kolya asked her to stay. However, this example has another reading as well: someone else, e.g. their father went home, and Kolya asked Liza to stay.

\section{(33) elicited}
[Aćiz
gurt-e
berti-sa]
Kol'a
Liza-jez
kilili-ni
kos-i-z.
REFL.3SG home-ILL
go.home-CVB
Kolya Liza-ACC
stay-INF order-PST-3SG
'Himself $\mathrm{i}_{\mathrm{j} j}$ having gone home, Kolyai, ordered Liza to stay.'

\footnotetext{
${ }^{8}$ Volkova (2014: 121) provides examples of both types. She claims that adnominal intensifiers are typically preposed to the DP they modify. As for the adverbial intensifiers, she does not make any statements with respect to their position, but in her example, the adverbial intensifier is placed after the subject, but not immediately preceding the verb. Hence her example of adverbial intensifier looks like (32a) that illustrates the adnominal intensifier use according to my informants. Since her data come from the Beserman dialect, it might be the case that there are significant differences between the Udmurt dialects with respect to the placement of intensifiers.
} 
Thus, reflexive subjects can be coreferential with the matrix subject, but it can also refer to a previously mentioned referent. Null subjects, on the other hand, differ from reflexives. ${ }^{9}$ First, let us see whether discourse can directly influence the interpretation of the null subject. (34a) serves as discourse context that is conducive to the non-coreferential reading of the null subject presented in (34b). As can be seen from the translation line, the non-coreferential reading is impossible despite the context.

$$
\text { Georgieva (2012) }
$$
a. Kat'a-len eš-ez
Kol'a
biblioteka-je
$\min -i-z$.
Katya-GEN friend-3SG Kolya library-ILL
go-PST-3SG

'Katya’s friend Kolya went to the library.'

$\begin{array}{lllllll}\text { b. } & \text { [Otin uli-toź], } & \text { Kat’a } & \text { bazar-iśs } & \text { vill } & \text { derem } & \text { baśt-i-z. } \\ \text { there } & \text { be-CVB.LIM } & \text { Katya } & \text { market-ELA new } & \text { dress[ACC] buy-PST-3SG }\end{array}$

Intended: *'While he (= Kolya) was there, Katya bought a new dress at the market.'

Grammatical, but contextually infelicitous reading: 'While she (= Katya) was there,

Katya bought a new dress at the market.'

Similar evidence has been presented by Sundaresan (2014) in the case of Tamil. She argues that the coreference between the subjects cannot be eliminated by pragmatic factors, such as discourse salience. Sundaresan (2014) takes this as evidence in favor of an OC PRO analysis rather than pro being accidentally coreferential with the subject of the main clause.

What I would like to emphasize is that the reference of the null subject in non-finite adjunct clauses is by no means unrestricted. Providing a discourse context is not enough to obtain coreferentiality with a non-subject referent (34). This serves as evidence that we are dealing with a control structure. This is also supported by the interpretive properties of overt subjects.

However, it will be shown that there are cases when the null subject does not refer to the matrix subject. An example is given in (35). In this sentence, the matrix subject is tibir 'back', but the null subject is interpreted as 1SG, i.e. 'when/while I sit' or has an arbitrary reading, i.e. 'when/while one sits'

\footnotetext{
${ }^{9}$ A question arises whether the reflexive pronouns can be analysed as pronounced PROs. Similar suggestions have been made for Korean by Madigan (2008), but Lee (2009) provides counterarguments. Based on the examples above, it seems that reflexive pronouns can, but need not be controlled by the matrix subject, and there might be other differences between them and null subjects. I will leave this question for future research.
} 
(35) fieldwork, spontaneous

[Puki-sa] tibigir žad'e.

sit-CVB back be.tired[PRS.3sG]

'Sitting, [my/one’s] back gets tired.'

Based on this, I argue that some Udmurt non-finite adjunct clauses are OC structures (this will be demonstrated by using several diagnostics discussed in the literature, see below), but others, like the one presented in (35), show NOC. It will be discussed which factors facilitate NOC. In the next section, I will summarize the main properties of control with special reference to adjunct control before examining the Udmurt data.

\subsection{Control: theoretical preliminaries}

There are different tests in the literature to tell apart OC and NOC constructions. These are the following: possibility of arbitrary control and long-distance control, c-command relation between the antecedent and the PRO, strict/sloppy reading under ellipsis, control by an only+NP argument, possibility of split antecedents, de se/de re reading, and possibility of partial control (cf. Hornstein 2001; Williams 1980, a.o.). Below, I illustrate the differences between OC and NOC with respect to these tests in complement infinitives.

In OC structures, arbitrary control is ruled out (36a), moreover, the antecedent must be local and it must c-command the PRO, cf. (36b, c), respectively. Additionally, (36d) confirms that OC structures allow only for sloppy reading under ellipsis. Example (36e) indicates that split antecedents are impossible, and (36f) shows that OC structures allow for de se reading only, i.e. the unfortunate believes of himself that he will receive a medal. (36g) means that only Churchill could have this memory for Churchill alone gave the speech.

(36) Hornstein (2001: 31, ex. (21))

a. *It was expected PRO to shave himself.

b. ${ }^{*} J_{o h n}$ thinks that it was expected $P R O_{i}$ to shave himself.

c. *John'si campaign expects PROi to shave himself.

d. Johni expects PROi to win and Bill does too.

Strict reading: $\boldsymbol{X}$ ‘... Bill expects John to win.'

Sloppy reading: $\checkmark$ '...Bill expects Bill to win.' 
e. ${ }^{*} J_{o h n}$, told Maryj, $P R O_{i+j}$ to leave together.

f. The unfortunate $e_{i}$ expects $P R O_{i}$ to get a medal.

g. Only Churchill remembers PRO giving the BST speech.

Contrary to OC complement infinitives, NOC structures allow for all criteria discussed so far. Example (37a) shows that antecedent is not necessary in NOC structures, moreover, if present, it need not be local or c-commanding the PRO (37b, c). Example (37d) shows that strict reading is possible in NOC, (37f) might have either a de se or a de re interpretation, and (37g) is consistent with many people other than Churchill recalling that the BST speech was a big deal.

(37) Hornstein (2001: 32, ex. (23))

a. It was believed that PRO shaving was important.

b. John $n_{i}$ thinks that it is believed that $P R O_{i}$ shaving himself is important.

c. Clinton'si campaign believes that $P R O_{i}$ keeping his sex life under control is necessary for electoral success.

d. John thinks that PRO getting his resume in order is crucial and Bill does too.

e. John $n_{i}$ told Maryj that PROi+j washing each other would be fun.

f. The unfortunate believes that PRO getting a medal would be boring.

g. Only Churchill remembers that PRO giving the BST speech was momentous.

Because of the interpretive restrictions, OC in examples such as (36), PRO is often said to enter into a syntactic dependency with a locally c-commanding antecedent (Chomsky 1981; Hornstein 2001; Landau 2000). This means that the referent of PRO is determined syntactically. The tests given above show that OC PRO behaves as a bound variable. In NOC, on the other hand, the referent of PRO is not determined by the sentence itself, but based on the context of the utterance. Thus, its interpretation resembles a pronoun (Chomsky 1981; Hornstein 2001). Based on this, it seems that in OC structures PRO is bound locally, whereas NOC involves cases when PRO's interpretation is not locally bound. Most theories of control assume that OC and NOC are in complementary distribution. A common idea is that NOC occurs only when OC is blocked (Hornstein 2001; McFadden \& Sundaresan 2016). However, it has been also argued that control is a semantic/pragmatic phenomenon rather than a syntactic one (see Duffley 2014). 
So far we have been discussing complement control. It must be said that adjunct control has attracted much less attention in the literature on control (the relevant studies dealing with adjunct control in English are Williams 1992; Kawasaki 1993; Landau 2013: Ch. 6, 2017; Pires 2006; Adler 2006; Hornstein 2001; Janke \& Bailey 2017; Green 2018, a.o). Additionally, the cross-linguistic analysis on adjunct control is more limited: cf. Haddad (2007) on Telugu and Assamese; Kissock (2014) on Telugu; Sundaresan (2014) on Telugu, Tamil, Spanish, Italian and Hungarian; Oded (2011) on Turkish, Nunes (2014) on Portuguese and Lyngfelt (2009) on Swedish. The generalizations made in them differ dramatically from author to author, as does the theoretical apparatus.

Although it is often assumed that adjunct control is strictly OC (Hornstein 2001; Pires 2006; Sundaresan 2014), NOC is also attested (Williams 1992; Kawasaki 1993; Landau 2013, 2017; Green 2018). Furthermore, it seems that adjunct control is more susceptible to pragmatic or contextual influence than complement control. Landau (2013) proposes that there are two groups of adjuncts, namely OC and NOC adjuncts (these two groups roughly correspond to Williams’ 1992 Predicative and Logophoric adjuncts). The potential candidates to be labelled as OC adjuncts are listed in (38). According to Landau (2013), these clauses pass the diagnostics for OC.

(38) English OC adjuncts (Landau 2013: 221-222, ex. (432))

a. Temporal gerund (including without-clause)

Billi called us [before/after/while/without $P R O_{i}$ visiting his aunt].

b. Result clause

Maryi grew up [PROi to be a famous actress].

c. Outcome/telic clause

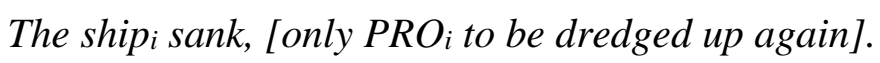

d. Goal clause

Maxi works hard [PROi to stay out of jail].

e. Stimulus clause

Maryi smiled [PROi to think what a fool she had been].

f. Object purpose clause

We bought Maryi the dog [PROi to play with].

g. Subject purpose clause

She called a detective [PRO $_{i}$ to investigate the affair]. 
Examples of NOC adjuncts are given in (39). One of the defining features of NOC PRO is that it is [+human] (Landau 2013 and the references therein).

(39) Kawasaki (1993: 173, 177, ex. (24), (31b))

a. [After PRO pitching the tents], darkness fell quickly.

b. Many women were harassed by John. [After PRO talking to the manager], complaints were filed.

There are several properties that determine the choice between OC and NOC in adjunct clauses. Some of them are structural: the attachment site of the adjunct, certain structural properties of the matrix and adjunct clause. Others are semantic/pragmatic. These include logophoricity, topicality, the OC reading resulting in 'semantic anomaly', and the [initiator] status of the subjects. It must be emphasized that none of these properties is without exception (for an overview see Green 2018).

Williams (1992) and Kawasaki (1993) note that the position of the adjunct clause plays a very important role with respect to the control status of the clause. The main generalization is that sentence-initial adjuncts prefer NOC while sentence-final ones display OC. This can be explained by the attachment site of the adjunct: sentence-final adjuncts are adjoined to VP, while sentence-initial ones are assumed to be adjoined to the main TP. However, exceptions are well-documented in both directions: sentence-final adjuncts may show NOC (especially if set off by a pause), as shown in (40), and initial adjuncts may fall under OC (41).

(40) Landau (2013: 232, ex. (451f))

There will be no progress [without PRO investing economic and human resources].

(41) Kawasaki (1993: 31, ex. (23c))

[After PROi causing a lot of trouble], the dishwasheri finally broke down.

Additionally, NOC is more likely to be available when the matrix clause is either passive or has an expletive subject (cf. Lyngfelt 2009). In this case, it has often been argued that an implicit argument in the matrix clause controls the PRO (42). Unaccusative verbs are also more likely to allow NOC than unergative ones (Green 2018). This is probably connected to the type of subject: non-human subjects in the matrix clause often fail to control. 
(42) Landau (2017: 98, ex. (19a))

The bank was robbed [while PRO masquerading as security guards].

Furthermore, it has also been proposed that the structure of the adjunct itself plays a role. Landau (2017) suggests that only OC by the matrix subject is allowed when the adjunct clause is passive (43).

(43) Landau (2017: 99, ex. (19c))

*The bank was robbed [while PRO being caught on camera].

It has been observed that control into adjuncts can be influenced by several nonstructural properties. NOC arises when subject control would make the sentence denote an odd or impossible situation (Williams 1992; Lyngfelt 2009). In (44), the subject, fears fails to control since fears, being inanimate, cannot listen to anything. This also can explain the NOC reading of (42): banks cannot masquerade. Landau (2017) calls this 'semantic anomaly': although a [-human] PRO is favored pragmatically, the [+human] nature of NOC PRO prevails, resulting in an odd sentence: \#[After PRO being spoiled in a refrigerator], there is nothing even a good cook can do.

(44) Williams (1992: 307, ex. (29a))

Johni's fearsj always go out of control, [when PROi/\#j listening to Larouche].

In a recent talk, Landau (2018) suggested that NOC is only available if PRO and its potential OC controller mismatch in [init] features (45a). An argument is [+init] if it is the 'initiator' who intentionally brings about a situation/event (see Farkas 1988). Furthermore, Landau (2018) claims that objects do not qualify as NOC controllers, even when logophoric, because they are [-init], cf. (45b) (OC by the matrix subject is ruled out since it is inanimate, thus unsuitable controller).

(45) Landau (2018)

a. The ship [-INIT] was sunk [PRO $[+I N I T]$ to collect the insurance].

b. *The grade disappointed $\mathrm{John}_{i}$ [after $\mathrm{PRO}$ i preparing himself for an A]. 
Kawasaki (1993) explains NOC with topicality. Consider (39b) in which many women is the topic established in the discourse, hence, it qualifies as controller of the null subject. She also observes that agents in passive sentences can serve as controllers only if the agent is [+human] and the derived subject is [-human] (46a) (the agent might be either explicit or implicit). Moreover, Kawasaki (1993: 165-166) argues that the correct interpretation of this sentence is (46b) and not (46c). Her explanation is that the missing subject must refer to an individual whose existence has been established in the discourse.

(46) Kawasaki (1993: 165, ex. (11))
a. After PRO getting some money, a bank account was opened.
b. S/he opened a bank account after s/hei got some money.
c. \#Someone ${ }_{i}$ opened a bank account after s/he $e_{i}$ got some money.

Williams (1992) proposes that the antecedent is the logophoric center of the sentence, i.e. the person whose views of the world the sentence is reporting. Landau (2013) suggests that experiencers are particularly prominent as logophoric controllers since their mental perspective is necessarily invoked. In fact, the antecedent need not be grammatically represented, if it is presupposed. This is illustrated by the three examples below.

(47) Williams (1992: 297, 299, 300, ex. (3), (5a), (8))
a. On arriving in town, John's fears were exacerbated.
b. Having just arrived in town, the main hotel seemed to Bill to be the best place to stay.
c. Having just arrived in town, the new hotel seemed like a good place for a stop.

The logophoricity of NOC is supported by the following facts. The perspective holder is often the speaker (this holds for (47c) which is uttered from the perspective of the speaker). In non-first-person contexts, NOC is more difficult to obtain (48a), but if the perspective holder is given in the preceding context, as in (48b), NOC is possible (Green 2018).

(48) Green (2018: 52, ex. (67))

a. ??That oasis was a vision [after PRO dragging himself through the desert all day].

b. Sam ${ }_{i}$ thinks [that oasis will be a vision [after $\mathrm{PRO}_{i}$ dragging himself through the desert all day]]. 
Furthermore, Green (2018) demonstrates that the PP for me is optional when NOC PRO refers to the speaker. But in non-first-person contexts, the PP is no longer optional, since it is necessary to establish the referent as a logophoric center (unless the preceding discourse establishes it as a perspective holder like in (48b)).

(49) Green (2018: 52, ex. (68))

a. It was hard (for mei) to eat any kind of meat for a while [after PROi finishing this book].

b. It was hard *(for $\left.\mathrm{Jim}_{j}\right)$ to eat any kind of meat for a while [after $\mathrm{PRO}_{j}$ finishing this book].

The logophoric approach faces some difficulties with examples like (50). The problem is that my car cannot be a logophoric center of the sentence since Williams (1992) argues that only animates can serve as logophoric centers.

(50) Williams (1992: 309, ex. (35a))

Having run smoothly for years, it was finally time for my car to be serviced.

Having overviewed the main characteristics of adjunct control, let us turn to Udmurt.

\subsection{Adjunct control in Udmurt}

We have already seen that the matrix subject can control the null subject of -sa-converbs (23). Temporal and causal/modal adverbial clauses, i.e. the ones that show null/overt DP subject variation, also show subject control in the vast majority of cases. Three representative examples are given below illustrating different types of adjunct clauses. In this dissertation, I do not discuss control into purpose/rationale clauses.

(51) GSUJa I (1962: 288)

$\begin{array}{rllll}\text { [...] [otin uli-toź], } & \text { śed } & \text { tel'-in } & \text { ul-o. } \\ \text { there live-CVB.LIM } & \text { dark } & \text { forest-INE } & \text { live-FUT[1sG] }\end{array}$

'[...] I I would rather live in a dark forest than_i live there.' 
(52) elicited

[Gurt-e berti-tek] Kol'a mezme val.

home-ILL come.home-CVB.NEG Kolya be.sad[PRES.3SG] AUX.PST

'Without_i coming home/not having come home, Kolyai was sad.'

(53) elicited

[škola-iśs bert-em] bere Liza kńiga lỉdži-ni kutsk-i-z.

school-ELA come.home-NMLZ after Liza book[ACC] read-INF start-PST-3sG

'After_i coming home from school, Lizai started reading a book.'

Control by the matrix object is also an option (at least in some languages, e.g. Portuguese and Modern Standard Turkish, see Nunes 2014 and Oded 2011, respectively). In Udmurt, there is only one case in which objects can control the null subject of the predicative adjunct, namely, in causative constructions. (One potential complication will be discussed in $\S 5.4 .2$.

Recall that the causee is accusative-marked in Udmurt causative constructions (§2.3.2). Tánczos (2016) presents evidence that causative construction can be modified by -saconverbs in their manner reading. In this case, the causee can control the null subject of the converb in both factive and periphrastic causative constructions. An example of factive causatives is given in (54) (which differs minimally from Tánczos’ original example).

(54) elicited, based on Tánczos (2016: 128, ex. (60b))

Saša Maša-jez [divan villin killlì-sa] kirz̆a-t-i-z.

Sasha Masha-ACC sofa on lie-CVB sing-CAUS-PST-3sG

'Sashai made Mashaj sing_i/j lying on the sofa.'

This possibility of either subject or object control can be explained in the following way: as Tánczos (2016) argues, Udmurt causatives are monoclausal, but bi-eventive. The modification by a non-finite clause is meant to demonstrate exactly their bi-eventivity. Recall also that in Tánczos' analysis of factive causatives, there are two VoicePs, hence, there are two potential adjunction sites for the adjunct. Moreover, she analyzes the causative 
constructions as ECM constructions, thus the causee is not an object, but an agent. This analysis is supported by the fact that genuine objects cannot serve as controllers (55). ${ }^{10}$

(55) elicited

Saša Maša-jez [divan viling killlì-sa] /[minja-sa] tuspukt-i-z.

Sasha Masha-ACC sofa on lie-CVB smile-CVB photograph-PST-3SG

'Sashai photographed Mashaj_i/*j sitting on the sofa/smiling.'

In connection to (55), it is worth mentioning that Hungarian adverbial participles - $v a$ show different behavior. Similarly to the Udmurt -sa-converb, they can be used as adverbials traditionally referred to as manner adverbials or as vague temporal clauses (Tóth 2000; Bartos 2009). Bartos (2009) shows that the manner reading corresponds to either transparent adverbials or depictives, in Geuder's (2004) terms. He also shows that these -va-clauses may display subject control, but in some cases, object control is also a possibility, cf. (56).

(56) Bartos (2009: 94, ex. (32a))

[Hungarian]

Laci $_{\mathrm{i}}$ [PRO $\mathrm{P} / \mathrm{j}$ mosolyogva] fotózta le Marit.

Laci smile:vA photograph:PST.3sG down Mari:ACC

'Laci photographed Mary smiling.'

Bartos (2009: 94-95) makes the following observation regarding the choice of controller: with object control, the participle functions as a pure depictive (i.e. Mary's smiling is not related to the photographing event), whereas the subject control, the transparent adverbial reading is more salient or even preferred (i.e. there is a sense of motivation between the smiling of the photographer and the event of taking pictures of Mary). As Geuder (2004: 156) argues, transparent adverbials differ from depictives since the former can only be predicated of the agent, not of the object. Based on (55), I argue that -sa-converbs are indeed transparent adverbials, and not pure depictives.

So far we have seen that subject control is the most common case. Additionally, I demonstrated that object control is generally ruled out. Before applying the standard

\footnotetext{
${ }^{10}$ In order to obtain the intended object control reading, my consultants paraphrased with a 'when'-clause: 'When Masha was lying on the sofa/smiling, Sasha took a picture of her.'
} 
diagnostics for distinguishing OC from NOC, it is necessary to discuss some of the structural requirements for OC that were summarized in $\S 5.3$.

Firstly, Udmurt does not have expletives, thus, such examples cannot be tested. As for passive, Udmurt uses a non-finite construction, the so-called "resultative participle" -(e)min (briefly mentioned in §3.4). It can be segmented into the -(e)m-non-finite and an inessive case markers. This passive construction cannot be used in adverbial clauses (since it already contains a case-marker, it cannot be selected by a postposition, for example). Hence, it is impossible to test the predictions about control into passive adjuncts.

As noted in $\S 5.3$, the attachment site of the adjunct clause plays an important role with respect to control. In English, sentence-initial adjuncts are much more susceptible to nonsubject control, while sentence-final ones show strong preference for subject control. It has been suggested that they are attached to the matrix TP or VP, respectively. Thus, it is important to clarify what the attachment site of non-finite adjunct clauses in Udmurt is.

To begin with, non-finite adjunct clauses are less often sentence-final in Udmurt, given that Udmurt is an OV language. ${ }^{11}$ Furthermore, non-finite clauses, especially temporal/causal ones, can be placed rather freely with respect to the matrix clause. This also interacts with topicalization/focusing of other constituents. Below, I will discuss two cases, -sa-converbs in their manner reading and temporal/causal adjuncts (including temporal -sa-converbs).

The -sa-converbs in their manner reading are typically immediately preverbal (57). They might not be immediately preverbal, but still in a low position in the matrix clauses (58).

(57) Perevoshchikov (1959: 199)

\begin{tabular}{|c|c|c|c|c|}
\hline Ćeberlud & sel'sovet-iśs & Lenin $\quad$ nim-o & kolhoz-len & predsedatel'-ez $=$ no \\
\hline Cheberlud & municipality-ELA & Lenin name-ATTR & kolkhoz-GEN & chairman-3sG=ADD \\
\hline [šumpotisa] & $v u-i-z$ & 亏̆ardon-e. & & \\
\hline rejoice-CVB & arrive-PST-3SG & Dzhardon-ILL & & \\
\hline
\end{tabular}

'The chairman of the Lenin kolkhoz of the Cheberlud municipality also arrived at the “Dzhardon”, rejoicing.’

\footnotetext{
${ }^{11}$ As mentioned in §2.3.2, recent studies argue that there an ongoing change from OV to VO. Nevertheless, nonfinite adjunct clauses generally tend to precede the matrix verb. 
(58) elicited

Kol’a Maša-jez [jarati-sa] kišno baśt-i-z.

Kolya Masha-ACC love-CVB wife take-PST-3sG

'Kolya married Masha for love (lit. loving),'

It has been proposed for Hungarian and Kazakh non-finite manner clauses that the nonfinite clause is left-adjoined to the matrix VoiceP (Tóth 2000; Ótott-Kovács 2016). Based on this, it can be argued that the non-finite clause is adjoined to VoiceP in (58). Given that the immediately preverbal position is associated with focus in Udmurt, it seems that the converb in (57) is focused (similar facts have been observed in Hungarian, see Tóth’s 2000: 246).

Additionally, transparent adverbials sometimes appear sentence-finally, as in (59), but in this case, I argue that this is the result of focusing pereśmitoz' 'to old age' and the movement of the matrix verb, while the transparent adverbial is left in its base-generated position.

(59) GSUJa I (1962: 272).

Pereśmi-toź ul-i-z Erkemej Pedor [jormi-sa].

become.old-CVB.LIM live-PST-3SG Erkemey Pedor want.for-CVB

'Erkemey Pedor lived in poverty to old age.'

Crucially, manner converbs cannot occur in sentence-initial position. Example (60) is acceptable only if the subject is focused, but not with neutral order.

(60) elicited

*[Puk-ti-sa] biger-jos vato.

sit-CAUS-CVB Tatar-PL bury[PRS.3PL]

Intended: 'Tatars bury [the corpse] seated

(lit. Tatars bury [the corpse] by making it sit).'

Turning to temporal/causal adjuncts, they show rather free word order with respect to the matrix clause. Sentence-initial adjunct clauses are very common (61), but sentence-final adjuncts are also attested (62). Another option is center-embedding, i.e. when the adjunct 
clause appears within the matrix clause (63). These three options are available in the case of all temporal/causal adjuncts, including the temporal -sa-converbs.

(61) fieldwork 2014, elicited

[Kol'a kirž́an-ze kirž́a-ku] mon so šori ućk-i.

Kolya song-3SG.ACC sing-CVB.SIM 1SG 3SG at look-PST[1sG]

'When Kolya was singing his song, I looked at him.'

(62) Udmurt Corpus (Удмурт дунне, 2008.07.16)

Oźi uža-z, [vojna birigl-toź=ik].

this.way work-PST.3SG war end-CVB.LIM=EMPH

'[The girl] worked like this until the war ended.'

(63) elicited

Pet'a-len [pispu-iśs tetći-sa] pid-iz vesś lu-i-z.

Petya-GEN tree-ABL jump-CVB foot-3SG sore become-PST-3sG

'When Petya jumped from the tree, he hurt his foot (lit. Petya's, jumping from the tree, foot got hurt).'

In the case of Hungarian and Kazakh, temporal non-finite adjuncts are attached higher than manner adjuncts. Bartos (2009: 97) does not explicitly state which projection they are adjoined to, but assumes that they attach below TP. Ótott-Kovács (2016) claim that temporal converb clauses modify the matrix IP (in her account, the IP covers both AspP and TP). Demirdache \& Uribe-Etxebarria (2004) argue that (finite) temporal clauses are adjoined to AspP since they modify the Assertion Time.

A different proposal is put forward by Weisser (2015: 78) who argues that converb clauses are adjoined to Spec,vP since they semantically modify the event of the matrix clause. However, that his analysis does not exclude adjunction to lower or higher projections (Weisser 2015: 78, fn. 39). Furthermore, Weisser (2015: 79-80) assumes that converb clauses may be moved to the left periphery of the matrix clause or be extraposed to the right. In this way, one can derive sentence-initial and sentence-final converb clauses, respectively. In case of center-embedding, he proposes that they stay in their base-generated position. 
The question is what the underlying position of temporal/causal non-finite clauses is in Udmurt, and how to derive the different surface word order possibilities. For instance, in sentence-initial adjuncts like (61), the matrix subject is also a topic. So, the question arises whether the adjunct clause is adjoined to the matrix CP since it precedes the topic. The answer depends on our assumptions on topicalization in Udmurt. In §4.2.3, it was already noted that that it is not exactly clear what position topics occupy in Udmurt: Spec,TopP or Spec,TP (cf. Tánczos 2010; Asztalos \& Tánczos 2016, and Asztalos \& É. Kiss 2016, respectively). Hence, if we take the approach suggested by Tánczos (2010) and Asztalos \& Tánczos (2016), the adjunct clause must be in the CP. On the other hand, if topics are in Spec,TP, as suggested by Asztalos \& É. Kiss (2016), the adjunct clause might still be adjoined to TP, but above the topicalized subject.

Similar issues arise with the center-embedded word order. In this case, the adjunct clause is preceded by a topic, as in (63) above, in which the non-finite clause is preceded by an (external) possessor. Center-embedding is also possible when the adjunct clause follows the matrix subject (64). This example also contains a high adverbial, žal'asa verano 'unfortunately', which can be placed sentence-initially or after the topicalized subject. Additionally, some speakers allow the high adverbial to be placed after the temporal nonfinite clause. However, in $\S 4.2 .3$, it was noted that this adverbial is probably not a reliable test.

(64) elicited

\begin{tabular}{|c|c|c|c|c|}
\hline$<$ žal'asa verano> & Maša & $<$ žal'asa verano $>$ & Pet'a & bert-em \\
\hline unfortunately & Masha & unfortunately & [Petya & come.home-NMLZ] \\
\hline$\%<z ̌$ zal'asa verano $>$ & viśílni & $u s^{\prime}-i-z$. & & \\
\hline unfortunately & be.sick-IN & fall-PST-3SG & & \\
\hline
\end{tabular}

In this dissertation, I do not aim at clarifying the exact position of topics and high adverbials in Udmurt in general, but I make the following claims with respect to the placement of adjunct clauses and their control properties. Firstly, in VO languages like English, OC adjuncts are generally sentence-final. Recall from §3.7.1 that the typological studies on adverbial clauses have proposed that the functional equivalents of sentence-final adjuncts in OV languages are the center-embedded clauses (Thompson et al. 2007). This 
might lead us to think that NOC will be found with sentence-initial adjuncts, whereas centerembedded adjuncts will always show OC. This generalization is incorrect, however. Sentence (65) exemplifies center-embedding with NOC. Observe that the 'when'-clause is preceded by the wh-element mali 'why', which is moved to the $\mathrm{CP}^{12}$, and the subject Volod'a is topicalized across the converb clause.

(65) Turku-Izhevsk Corpus (Vordskem kyl/C/7:32)

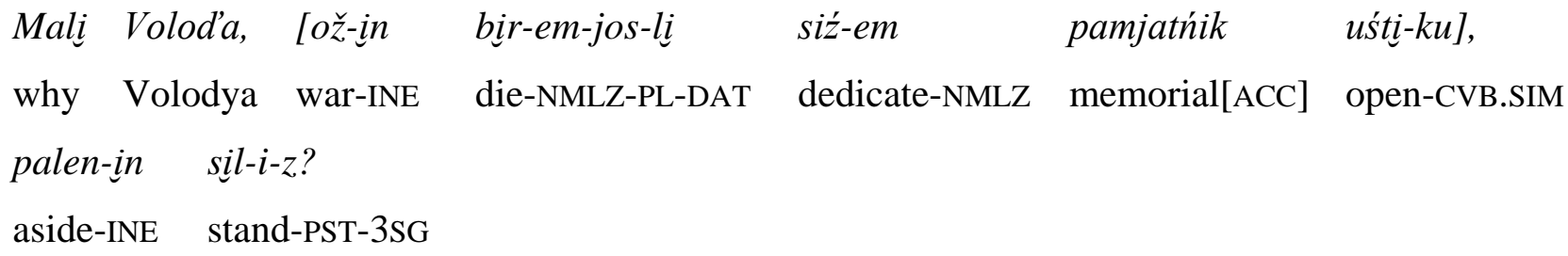

'Why did Volodyai stand aside during the inauguration ceremony of the memorial dedicated to those who died in the war (lit. when _j opening the memorial)?’

In the next section, I will apply some of the diagnostics proposed for distinguishing OC from NOC. Most of the examples will be with sentence-initial adjuncts. As we will shortly see, they display OC properties. Thus, it can be proposed that they originate from a lower position.

\subsubsection{Applying the OC/NOC tests}

In this subsection, I will discuss several tests: the locality of the antecedent, the ccommanding relation between the antecedent and the null subject, and the de se/de re readings and ellipsis. Furthermore, I will discuss some additional diagnostics relevant for the OC/NOC distinction.

To begin with, the null subject of the non-finite clause must have a local antecedent in Udmurt. Example (66) superficially suggests that either the lower (Liza) or the higher subject (Petya) can be coreferential with the subject, cf. Reading 1 and Reading 2, respectively.

\footnotetext{
${ }^{12}$ Generally, wh-movement is considered not to be obligatory in Udmurt (Winkler 2011: 146), but the word order of the above-given example suggests that we are dealing with overt wh-movement.
} 
(66) elicited

$\begin{array}{lllllll}\text { Pet’a } & \text { vera-z } & \text { [škola-iśs } & \text { bert-em] } & \text { bere Liza kńiga } \\ \text { Petya } & \text { said-PST.3SG } & \text { school-ELA } & \text { come.home-NMLZ after Liza book[ACC] } \\ \text { lidǰ̌́i-ni } & \text { kutsk-i-z } & \text { šuisa. } & & & & \\ \text { read-INF } & \text { start-PST-3SG } & \text { that } & & & & \end{array}$

Reading 1: 'Petyai said that [[after _ ${ }^{*}{ }_{i j}$ coming home from school] Liza ${ }_{j}$ started reading a book].'

Reading 2: '[Petya said [after _ ${ }^{\mathrm{i} /{ }^{*} \mathrm{j}}$ coming home from school]] that Lizaj started reading a book.'

My consultants suggested that Reading 1 is possible when the pause sets off the higher finite clause and the non-finite clause, i.e. the adjunct is sentence-initial, adjoined to the embedded finite clause. On the other hand, Reading 2 is possible if the higher clause and the non-finite clause are pronounced without a pause, and the pause comes right after the nonfinite clause. This indicates that we are dealing with a sentence-final adjunct. Crucially, in both cases the null subject of the non-finite clauses finds its antecedent locally. Observe that in both cases, the null subject can be coreferential with only one DP, but not with both.

Secondly, it seems that the antecedent must c-command the null subject. As example (67a) indicates, the null subject of the non-finite clause cannot be coreferential with the possessor in Spec,DP since it is not c-commanded by it (but see the discussion on control by possessors in the §5.4.2). This holds for sentence-initial adjuncts, as well (67b).

(67) elicited
a. Liza-len anaj-ez
[rinok-iśs
berti-sa]
śijon
péźt-i-z.
Liza-GEN mother-3SG
market-ELA come.home-CVB
food[ACC]
cook-PST-3SG
b. [Rinok-iś berti-sa]
Liza-len anaj-ez
śijon
peźt-i-z.
market-ELA come.home-CVB
Liza-GEN mother-3sG food[ACC]
cook-PST-3SG
'_* ${ }^{*}$ j j having come home from the market, Lizai's mom ${ }_{j}$ prepared a meal.'

Furthermore, consider (68) which was judged odd in the context that the subject was not aware that he is the person who is sick (the context has been taken from Sundaresan 2014). This suggests that the null subject receives de se interpretation. 
elicited

(Context: All doctors in the hospital undergo compulsory testing for the flu before flu season. The tests are anonymized, are then analyzed by random doctors in the hospital. Kolya, unknowingly, ends up analyzing his own sample, which turns out positive. So Kolya knew someone was sick at his workplace, but he didn’t know it was him.)

$\begin{array}{llllllll}\text { \#[Viśi-ni } & \text { uśi-sa/ } & \text { uś-em } & \text { bere] } & \text { Kol’a } & \text { asliz } & \text { ukol } & \text { pukti-ni } \\ \text { be.sick-INF } & \text { fall-CVB } & \text { fall-NMLZ } & \text { after } & \text { Kolya } & \text { himself.DAT } & \text { shot[ACC] give-INF } \\ \text { malpa-z. } & & & & & & & \end{array}$

decide-PST.3SG

'Having fallen ill/after falling ill, Kolya decided to give himself a shot.'

Now let us turn to ellipsis. The prediction is that in OC structures, only sloppy readings will be possible. ${ }^{13}$ The very first problem is how to construct these examples. When I first tested ellipsis, I tried using the clitic =no 'also, even' (used also in coordination). My first results showed that both strict and sloppy readings are possible, as shown in (69).

(69) fieldwork 2016, elicited

\begin{tabular}{|c|c|c|c|c|c|}
\hline [škola-įś & bert-em] & bere & Liza & kńiga & lidiš́ci-ni \\
\hline school-ELA & come.home-NMLZ & after & Liza & book[ACC] & read-INF \\
\hline kutsk-i-z, & Pet'a $=$ no. & & & & \\
\hline art-PST-3sG & Petya $=A D D$ & & & & \\
\hline
\end{tabular}

Strict reading: $\checkmark$ 'After _ i coming home from school, Lizai started reading a book, and (after _i coming home from school), Petya j did, too.'

Sloppy reading: $\checkmark$ 'After_i coming home from school, Lizai started reading a book, and (after _j coming home from school), Petyaj did, too.’

I would like to discuss ellipsis in more detail because I believe that its application is slightly more problematic. The biggest issue with ellipsis in adjuncts is that the adjunct might not even be present in the elided clause (as opposed to complements which are always elided). If the adjunct clause is not elided, the interpretation is compatible with a strict reading. This is, however, a "pseudo strict" reading since there is no null subject to be controlled, and the

\footnotetext{
${ }^{13}$ It should be noted that OC gives only sloppy reading not only with VP-ellipsis, but also with stripping (Landau 2013: 30 and the references therein). However, most of the studies use VP-ellipsis.
} 
strict reading is inferred from the first part of the sentence which states that Liza came home from school. Taking into account these facts, I changed my methodology, and tested ellipsis by asking my consultants 'What happened to Petya?'. It turned out that (69) can simply mean that Petya started reading a book, i.e. the adjunct clause is not present at all, and the "pseudo strict” reading arises.

This problem is acknowledged in the literature, and most authors simply state that one must ensure that the adjunct is elided too (cf. Pires 2006: 34, fn. 31), but to my knowledge, only Sundaresan (2014) makes a more concrete proposal how to control for this. What she proposes is that only part of the adjunct clause should be elided. She provides an example from Spanish whose English translation is given in (70). In this example, the adjunct clause is elided only partially, its temporal adverbial this year still being present, and this ensures that the adjunct clause is present in the elided vP. According to her results, in this case only a sloppy reading is possible.

(70) Sundaresan (2014: 77)

EC $\{i, * j\}$ showing the first symptoms of the flu last year, Carlosi then got vaccinated. And [CP EC $\{j, * i\}$ showing the first symptoms of the flu this year], María $j$ (then) did too.

However, I consider this test slightly problematic. Observe that if we disregard the stroke-through material, the sentence looks like: 'This year, Maria did too.', i.e. this year can be interpreted as a temporal adverbial in the matrix clause. I applied this test to Udmurt with an adjunct that cannot be interpreted as part of the matrix sentence. The result is ungrammatical, which suggests that it is impossible to elide only part of the non-finite clause.

(71) elicited

*[Gripp-en viši-ni uśi-sa] Kol'a asliz ukol pukt-i-z, flu-INS be.sick-INF fall-CVB Kolya himself.DAT shot give-PST-3sG noš gepatit-en $\quad$ Maša $=$ no.

but hepatitis-INS Masha=ADD

Intended: 'Having got the flu, Kolya gave himself a shot, and [becoming sick] with hepatitis, Masha did too.' 
I also tried testing ellipsis with negation, and in this case the adjunct clause does get elided with the rest of the verb phrase. According to my consultants, example (72) can mean only that Petya came home from school, but did not read a book. This proves that if the adjunct clause is properly elided with the matrix clause, the null subject has a sloppy reading.

(72) elicited

$\begin{array}{llllll}\text { [škola-iś } & \text { bert-em] } & \text { bere Liza kńiga lidš́i-ni } \\ \text { school-ELA } & \text { come.home-NMLZ } & \text { after Liza book[ACC] read-INF } \\ \text { kutsk-i-z, } & \text { Pet’a es } & & & & \\ \text { start-PST-3SG } & \text { Petya NEG.PST.3 } & & & & \end{array}$

Strict reading: $\boldsymbol{X}$ 'After _i coming home from school, Lizai started reading a book (but) after _i coming home from school, Petyaj, didn’t read.'

Sloppy reading: $\checkmark$ 'After_i coming home from school, Lizai started reading a book (but) after _j coming home from school, Petyaj, didn’t read.'

One way to explain why the ellipsis test works only with negation but not with the additive clitic is that VP-ellipsis requires an (auxiliary) verb like in English (cf. Goldberg 2005). Since no previous studies on ellipsis in Udmurt exist, I cannot provide an account of this. A possible explanation of why the adjunct clause is elided together with the matrix clause under negation might be the operator nature of negation: it can/must have the adjunct clause in its scope. ${ }^{14}$

It is also worth considering the position of the adjunct clause. We have seen that sentence-initial adjuncts can have only sloppy reading under ellipsis (with a negative verb) (72). Some authors test ellipsis with center-embedded adjuncts (cf. Grashchenkov 2017; Haddad 2007; Oded 2011). According to my results, there is no difference between sentenceinitial and center-embedded adjuncts with respect to ellipsis.

The only+NP test also gives the desired results: the null subjects behaves like a bound variable, as shown in (73).

\footnotetext{
${ }^{14}$ I thank Krisztina Szécsényi for this suggestion.
} 
(73) elicited

Kol'a gine [gurt-iśs gorod-e koškị-sa] mevzme.

Kolya only village-ELA city-ILL leave-CVB be.sad[PRS.3sG]

'Having moved to the city, only Kolya is sad.'

$\mathbf{X}$ But Masha and Petya, Kolya having moved to the city, are not sad.

$\checkmark$ But Masha and Petya, having moved to the city, are happy.

Furthermore, recall that according to Landau (2000 et seq.), NOC PRO is always [+human]. On the other hand, OC PRO can be [-human]. I would also like to emphasize that in Udmurt null subjects can be controlled by a [-human] matrix subject (74). If we accept that NOC PRO is always [+human], examples like (74) serve as evidence that certain non-finite adjunct clauses in Udmurt show obligatory control.

(74) GSUJa I (1962: 275)

$\begin{array}{lllll}\text { Odig } & \text { ti-je } & \text { snarjad } & u s ́-i-z=n o & \text { pušt-i-z, } \\ \text { one } & \text { lake-ILL } & \text { shell } & \text { fall-PST-3sG=ADD } & \text { explode-PST-3sG } \\ \text { [vu-ez } & \text { villań } & \text { džuti-sa]. } & & \\ \text { water-ACC } & \text { upwards } & \text { lift-CVB } & & \end{array}$

'A shell fell and exploded in one lake, splashing the water.'

In (75), the non-finite predicate is the verb tijaśkini 'to break:INTR' which is normally not used with human referents. In out of the blue context, (75) is odd, while (76) is perfect since it can be understood as [+human] even without context.

(75) elicited

\#[Tijaśki-sa] tros katastrofa-os lui-l-o.

break:INTR-CVB many accident-PL be-FREQ-3PL

Intended: 'A lot of accidents happen, when cars break.' 
(76) elicited

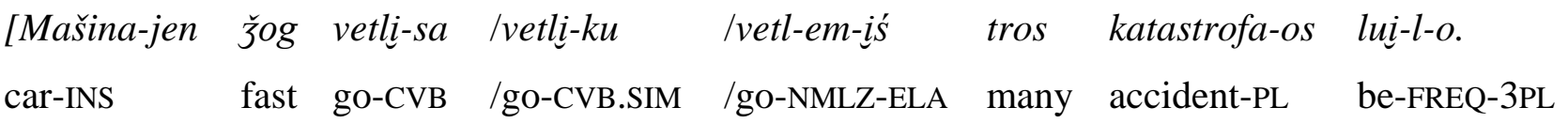
'A lot of accidents happen, driving fast/when driving fast/because of driving fast.'

In sum, null subjects in Udmurt adjunct clauses pass the OC tests (despite the slight complications with ellipsis). However, in the next section I will show that certain non-finite adjunct clauses display NOC.

\subsubsection{NOC adjuncts}

Logophoric/topical control in adjunct clauses is attested in a number of cases. Below I will take a closer look at them.

The first major type of NOC adjuncts are the 'speech act' adverbial clauses. They modify or qualify the speech act which the speaker is performing in uttering the main clause (Thompson et al. 2007: 267). Thompson et al. (2007) give examples of finite 'speech act' adverbial clauses (e.g. As I'm sure you're aware, bananas have doubled in price since last year, If you're interested, the Lakers just won), but non-finite ones are also very frequent, e.g. Roughly/strictly/figuratively/generally/relatively speaking, To tell you the truth/To be honest, etc. In Kortmann's (1991) study on free adjuncts and absolute constructions, speech act adverbials are one of the most frequent case when the null subject does not refer to the matrix subject. As noted by Green (2018: 174-175) and Lyngfelt (2009), speech act adverbials show only NOC, which can be explained with the fact that they express speaker-oriented modality. This type is also attested in Udmurt, often with the converb form of the verb vera- 'say'. A couple of examples are mentioned in GSUJa I (1962: 277-278) as 'introductory words/phrases': vakćijak verasa 'shortly speaking', muket śamen verasa 'in other words (lit. saying in a different way)' and ogja verasa 'generally speaking'. Below I illustrate one of the most frequent ones, zemze verasa 'to tell you the truth' (77). Probably žal'asa verano 'unfortunately (lit. if one has to say being sad)' also belongs to this type.

(77) Udmurt Corpus (Удмурт дунне, 2011.02.11)

$\begin{array}{lllllll}\text { [Zem-ze } & \text { vera-sa], } & \text { Mavrodi nomir } & \text { vil'-ze } & \text { ez } & \text { čekti. } \\ \text { true-3sG.ACC } & \text { say-CVB } & \text { Mavrodi } & \text { nothing } & \text { new-3sG.ACC } & \text { NEG.PST.3 } & \text { suggest[SG] }\end{array}$

'To tell you the truth (lit. saying the truth), Mavrodi didn’t suggest anything new.' 
The other type of NOC involves arbitrary subjects. In (78), the reference of the null subject of the matrix clause can roughly be paraphrased with 'everybody' or 'people in general'. As Cinque (1988) argues this is the so-called 'quasi-universal' reading of arbitrary subjects, found in sentences with generic time reference (but not with specific time reference).

(78) Georgieva (2012)

[Centr-e vetli-ku] tros kalik-ez lue pumita-ni. center-ILL go-CVB.SIM many people-ACC can[PRS.3SG] meet-INF 'One ${ }_{i}$ can meet a lot of people when _ ${ }^{i}$ going to the city center/to the administrative center of the district.'

The interpretation of (78) suggest that the null subject of the non-finite adjunct clause refers to the null subject of the matrix clause, i.e. the goer is the meeter. Thus, one might be tempted to reduce this to OC by the null subject of the matrix clause. A question arises of whether the null arbitrary subject of the adjunct clause can have independent reference from the null arbitrary subject of the main clause. Consider the example in (79).

(79) Ackema \& Schoorlemmer (1995: 182, ex. (24b))

Potatoes are tastier [after PRO boiling them].

As noted by Landau (2013: 232, fn. 4), this sentence does not imply that the tasters are the boilers, thus cannot be easily reduced to an instance of control by an implicit argument. Ackema \& Schoorlemmer (1995: 182) argue that the implicit experiencer in the matrix clause serves as controller, cf. Most physics books are difficult even after reading them several times, but acknowledge that this effect is weaker in (79), which according to them supports the pragmatic, non-syntactic nature of control in these examples. Green (2018: 53) claims that in case the tasters are not the boilers, this example can be used only if the situation is described from the perspective of the boilers. According to him, this also speaks in favor the logophoric nature of NOC.

Similar examples are attested in Udmurt, as well. The null subject of the main clause in (80) is arbitrary, roughly corresponding to the arbitrary they in English. The null subject of the temporal adjunct is also null, but most importantly, it has independent reference from the matrix subject. Note that the interpretation of the sentence is probably influenced by 
pragmatic factors: normally the one who puts a stamp in the passport is not the one that crosses the border.

(80) fieldwork, spontaneous

[Granica-jez ortći-ku] pasport-e pećat' ug pukto.

border-ACC cross-CVB.SIM passport-ILL stamp[ACC] NEG put[PRS.3PL]

'(When)_ j crossing the border, theyi don't put a stamp in the passport.'

This is quite productive pattern, consider the examples below. I argue that the NOC reading is facilitated by two factors: the generic reading of the matrix clause and semantic/pragmatic oddity if OC obtained: in both cases, we are dealing with an event involving two persons (a person who says hello and a person who greets back in (81) and a person who calls and a person who picks up the phone in (82), respectively). Observe also that NOC is possible with center-embedded adjunct (82).

(81) Perevoshchikov, G. K. 1993, “Tulkymly pumit”, p. $42^{15}$

\begin{tabular}{|c|c|c|c|c|}
\hline Kitijaz & [క̌́ećjaśki-ku] =no & ved' & $u g$ & vaźili $[\ldots]$ \\
\hline sometimes & greet-CVB.SIM=ADD & EMPH & NEG.PRS.3 & answer[SG] \\
\hline
\end{tabular}

(82) fieldwork, elicited

Ol’a kenak [žingirti-ku] telefon-ze ug baśti.

Olya aunt call-CVB.SIM phone-3sG.ACC NEG.PRS.3 pick.up[sG]

'Aunt Olyai doesn’t pick up her phone when_j calling [her].'

According to my consultants, in examples (78) and (80)-(82), the null subject can be interpreted as [+speaker]. This suggests that NOC is influenced by logophoricty in Udmurt. Furthermore, it seems that these examples express the perspective of the null subject in the adjunct clause: (80), for instance, is meant to reassure the travelers that their passports will not be checked from the perspective of the traveler(s) who have already crossed a border; (81) and (82) are uttered from the perspective of the greeters and callers, respectively.

\footnotetext{
15 This novel is available online at: http://elibrary.unatlib.ru/handle/123456789/4599. (Retrieved: 2018-07-01.) 
Non-human interpretation is ruled out, cf. (83) which differs minimally from (80). This is a possible situation, for instance when goods are being imported, or pets travel abroad, but it was nevertheless rejected by the native speakers. They noted that even if this reading were possible, it would imply a human referent importing the goods or carrying the pet abroad. In order to obtain the [-human] reading, an overt subject should be used in the adjunct clause (when dogs/goods cross the border).

(83) elicited

[Granica-jez ortći-ku] document-jos-iz ros-pros ućko.

border-ACC cross-CVB.SIM document-PL-ACC thoroughly watch[PRS.3PL]

'(When)_[+human]j ${ }^{*} \_[- \text {human]j crossing the border, theyi check the documents thoroughly.' }$

NOC arbitrary readings seem to be more frequent in generic contexts, but they are also attested in the case of matrix clauses with episodic interpretations. In this case, the null subject of the adjunct clause is interpreted as 'someone', i.e. quasi-existential reading according to Cinque (1988). An illustrative example is given in (84).

(84) Turku-Izhevsk Corpus (Vordskem kyl/C/7:32)

Mali Volod'a, [ož-inn bir-em-jos-lị siź-em pamjatńik uśti-ku],

why Volodya war-INE die-NMLZ-PL-DAT dedicate-NMLZ memorial[ACC] open-CVB.SIM

palen-in sill-i-z?

aside-INE stand-PST-3SG

'Why did Volodyai stand aside during the inauguration ceremony of the memorial dedicated to those who died in the war (lit. when _j opening the memorial)?'

There is one curious case of NOC in which the matrix object controls the null subject of the adjunct clause. Two examples are given below with first person objects. The object need not be overt, cf. (86). 
(85) fieldwork recording, 130729_002, ES, Izhevsk

$\begin{array}{lllll}\text { [Dišsetski-ki] } & \text { mil'emiz } & \text { dišet-i-zi } & \text { Baškiri-in } & \text { udmurt } \\ \text { study-CVB.SIM } & \text { 1PL.EXCL.ACC } & \text { teach-PST-3PL } & \text { Bashkiria-INE } & \text { Udmurt } \\ \text { marịm } & \text { kill-ja [...] } & & & \\ \text { thingy } & \text { language-ADV } & & & \end{array}$

'At school we were taught Udmurt in Bashkiria.' (lit. 'Studying they taught us Udmurt.')

(86) Udmurt Corpus (Удмурт дунне 2010.04.06)

(Context: In our childhood, we used to spend summer working.)

[Sižil škola-je minini-sa=no], arńanunal-jos-ị kartoškabusi-je

autumn school-ILL go-CVB=ADD weekend-PL-ILL potato.field-ILL

isto val.

send[PRS.3PL] AUX.PST

'Even _i having gone to school in the autumn, they used to send [usi] to the potato field.'

These examples are also problematic since objects are unsuitable controllers in NOC structures (Landau 2018). Moreover, in §5.4., I argued that object control is ruled out (except for causees in causative constructions, for which it seems plausible to assume that they are underlyingly agents). The objects in examples (85) and (86) are clearly logophoric: for instance, native speakers, when given example (86) in out of the blue context, interpret it as referring to the speaker. Similar examples with non-first person object control are considered odd in general, and speakers often correct them with causatives, e.g. they ordered him go to the potato field, in which control by causee is allowed. Note also that the subject of the matrix clause is a non-referential they, and this also facilitates the NOC reading. It can be tentatively proposed that the matrix clause (functionally) corresponds to a passive, i.e. we were taught/sent, in which case the control pattern is expected (see also GSUJa II 1970, F. Gulyás \& Speshilova 2014 who discuss impersonal constructions with 3PL null subjects).

Thirdly, I would like to discuss experiencers. In the previous subsection, I argued that the null subject of the non-finite clause cannot be controlled by the possessor of the matrix subject. However, there are some exceptions to this, especially with those possessors who are experiencers. We have already seen one example (63), in which the possessor is the controller. In most cases, the possessee is inanimate, cf. (87), and often the possessive relation is inalienable. 
(87) Turku-Izhevsk Corpus (Kenesh/A/7:71)

[Kuraď̆-em-de malpa-sa], šokan-e=ik pitsaśke.

suffer-NMLZ-2sG.ACC think-CVB breath:N-1SG=EMPH close:INTR[PRS.3sG]

'When I think about how much you suffer, I can barely breathe.

(lit. thinking of your suffering, my breath stops.)'

The control by a possessor is not restricted to first person, as demonstrated by (88) and (89). Observe that in the latter example the matrix subject is [+human], but fails to control.

(88) elicited

Bakća-in uža-sa, triceps-ed bude=no bude.

garden-INE work-CVB triceps-2SG grow[PRS.3SG]=ADD grow[PRS.3SG]

'Working in the garden, your triceps keeps growing.'

(89) elicited

[Vaškala kỉř̆an-jos-inz kỉlzị-sa] Maša-len tod-a-z lỉkt-i-z

old song-PL-ACC listen-CVB Masha-GEN mind-INE/ILL-3sG come-PST-3sG

Pet'a.

Petya

'Listening to the old songs, Masha thought of Petya (lit. to Masha's mind came Petya).'

Since the subjects of the matrix clause is [-human], OC would result in an odd situation, as in Williams' (1992) example Johni's fearsj always go out of control, [when PROi/\#j listening to Larouche], discussed in §5.3. In other words, breaths cannot think, triceps cannot work in the garden, hence (88) and (89) show NOC, and not OC by the matrix subject. Another important factor is that the possessors in (87)-(89) are experiencers (recall that experiencers are favored as controllers, cf. §5.3).

The possibility of possessors to serve as controllers has been noted by Kawasaki (1993), as well, who argues that the possessors are the topics of the sentence. Landau (2000: 109111) observed that this is also attested with infinitives: It is crucial for Bill'si success [PROi to teach himself Japanese]. He terms this 'logophoric extension' and claims that the logophoric extension of Bill is non-distinct from Bill. 
Dative-experiencers also serve as controllers, as shown in (90). Compare this with (91), in which the dative goal cannot control the subject of the embedded clause, although this reading is pragmatically possible (Kolya was sent call-up papers before joining the army). The only possible, albeit slightly odd interpretation of (91) is that Kolya was sent a letter before someone/people in general/the speaker(s) went to the army.

(90) elicited

$\begin{array}{lllllll}\text { [Armij-e mino-n] } & \text { aźin } & \text { Kol'a-li } & \text { ulon kapći } & \text { pote } & \text { val. } \\ \text { army-ILL go-VN before } & \text { Kolya-DAT life easy } & \text { seem[PRS.3sG] AUX.PST } \\ \text { 'Before _i joining the army, life seemed easy to Kolya.' }\end{array}$

(91) elicited

$\begin{array}{llllll}\text { [Armi-je } & \text { mino-n] } & \text { aźin } & \text { Kol’a-li } & \text { gožtet } & \text { likkt-i-z. } \\ \text { army-ILL } & \text { go-VN } & \text { before } & \text { Kolya-DAT } & \text { letter } & \text { come-PST-3sG }\end{array}$

'Before _*j joining the army, Kolyai was sent a letter.'

In sum, NOC is also possible in Udmurt adjunct clauses. Generally, the types of NOC we have seen support the generalizations made in the literature on adjunct control. Based on the presented examples, it seems that NOC is determined by logophoricity, which explain the general preference for NOC controllers to be interpreted as referring to the speaker, but there are additional factors that play a role. For instance, the controller must be an experiencer, or the OC reading would result in odd situations. In most cases we have seen at least two of these criteria should be met for NOC to be obtained (with the exception of speech act modifiers that allow only NOC). This proves that the interpretation of null subjects is by no means unrestricted.

\subsection{Summary}

This chapter focused on several topics connected to subjects of non-finite adverbial clauses. One of them was subject agreement. It was shown that non-finite adverbial clauses formed with nominalizations selected by postpositions show several morphosyntactic patterns one of which is unattested with nominalizations used in argument position and possessive constructions; I argued that the existing analyses fail to propose a satisfactory account of this pattern. I suggested that the presence/absence of agreement is to be explained by several 
independent factors (pace the existing grammars according to which agreement is optional). Moreover, I showed that there is dialectal variation with respect to subject-doubling (pace Edygarova 2010) and suggested a possible functional motivation in order to explain the choice of a morphosyntactic pattern.

Furthermore, I discussed the alternation between null and overt subjects and its theoretical implications: (i) what is the nature of the null subject, pro or PRO; (ii) what are the interpretive properties of overt subjects. Then I turned to null subjects whose interpretive properties were analyzed in light of adjunct control. Adjunct control has been a highly debated topic in generative syntax. According to one of the approaches, adjunct and complement control is accounted for in the same vein. Although this analysis is elegant from a theoretical point of view, it is probably too restrictive to capture the pragmatic nature of adjunct control. The alternative analysis, on the other hand, emphasizes the pragmatic factors influencing the interpretation of null subjects, but it misses the generalization: the interpretation of null subject is not completely free. What I showed is that the interpretation of null subjects in non-finite adjunct clauses is not simply coreference with any referent mentioned in the discourse (as the 'small pro analyses' argue). I applied the standard diagnostics for distinguishing between obligatory and non-obligatory control and proved that certain adjunct clauses are indeed obligatory control structures. Furthermore, I discussed nonobligatory control into adjunct clauses. I pointed out several factors that lead to nonobligatory control: lack of (suitable) controller, logophoricity, experiencer thematic role and world knowledge. I argued that at least two of these factors should be present in order for non-obligatory control to obtain. 


\section{Conclusion}

The syntax of Udmurt has been an understudied area of research. This thesis can be considered a step forward towards the syntactic description of Udmurt. My main aim was to provide a description of non-finite adverbial clauses in Udmurt and raise several theoretical questions in connection to their structure. Below I first summarize the main findings of this dissertation. Then I will outline a couple of topics for further research.

In Chapter 3, I discussed the theoretical issues connected to finiteness. In unison with recent theoretical studies on finiteness, I proposed that finiteness is a clausal property. It was shown that Udmurt non-finite and finite clauses differ in a number of morphosyntactic and syntactic properties. The differences concern mostly the inflectional and complementizer domains of these clauses. I discussed the two nominalizations, formed with the suffixes $-(e) m$ and $-(o) n$, and refined several claims made in previous studies regarding their temporal meaning, argument structure, and syntactic distribution. For instance, I claimed that both nominalizers can be used to form 'event' and 'non-event' nominalizations, and only the latter can be pluralized. I also showed that -(e)m-nominalizations have a perfect/anterior meaning, while -(o)n-nominalizations have a prospective meaning, thus, the temporal differences between them are aspectual. Both nominalizations can be used in relative, argument and adverbial clauses, and this has led many researches to distinguish between homonymous 'participles', ‘deverbal nouns’ and 'converbs'. I argued against this approach and proposed that the morphosyntactic and syntactic differences are to be explained with the structure of the three different clause types. Furthermore, I presented a general overview of non-finite relative, argument and adverbial clauses. The discussion of relative and argument clauses was less detailed since this dissertation mainly focuses on adverbial clauses, but I highlighted certain differences between the three clause types with respect to their morphosyntactic properties: the case-marking of subjects and agreement on them. The discussion of non-finite adverbial clauses encompassed several clause types, the functions of which were classified according to Kortmann's (1996) typological study. Again, special attention was given to the case-marking of the subject and presence/absence of agreement in these clauses. It was shown that the most common pattern in non-finite adverbial clauses with independent subjects is when the subject bears nominative case and there is no agreement. However, other patterns are also attested: 'nominative subject and agreement' or 'genitive subject and agreement'. Furthermore, I showed that the -(e)men-clauses used as subcategorized adverbials preferred 
the nominalized pattern (i.e. their subject is genitive), whereas that the -(e)men-clauses used as cause/reason adjuncts have nominative subjects. I discussed one curious and previously undescribed case: -(o)nja-clauses. I showed that these temporal clauses imply that the event described by the adjunct clause not only happens simultaneously with the event denoted by the matrix clauses, but also that the two events happen at the same place, thus, a spatial mismatch is excluded. This observation was made for the -(o)nja-clauses in the Middle Cheptsa dialect, and similar facts have been presented for the Beserman Udmurt -(o)ńńigaclauses (Usachova \& Serdobolskaya 2015). The discussion of -(o)nja-clauses also touched upon the status of the so-called 'adverbial case', for which I argued that there is compelling evidence to analyze it as (an allomorph of) the inessive/illative marker (at least when used in certain non-finite clauses).

Chapter 4 dealt with the internal structure of non-finite adverbial clauses. I addressed two main questions. Firstly, the notion of 'converb' came under closer inspection. I demonstrated that most adverbial clauses are syntactically postpositional phrases, i.e. nonfinite clauses selected by a semantic case or postposition. Thus, the number of converbs was reduced to only one, -sa. I proposed that the non-finite adverbial clauses headed by postpositions differ with respect to presence of a case layer and agreement layer on top of them (this analysis is in line with the recent studies on postpositional phrases in Udmurt). I applied several tests in order to determine the internal structure of non-finite adverbial clauses. The main question was whether we find evidence for a full-blown CP in these clauses, and if not, at which clause level does truncation takes place. I demonstrated that we find solid evidence for the VP domain (based on arguments, various adverbials, causative constructions, low aspect morphology in these clauses). Turning to the inflectional domain, one of the most interesting question was whether the presence of nominative subject suggest that its case is licensed by a $\mathrm{T}$ head. This is a very debated question in the generative literature, with two main proposals on the market: (i) nominative case is licensed structurally or (ii) nominative as a default/unmarked case. Several case studies of individual languages were reviewed. I argued that even if we do not adopt the structural approach to nominative case, an inflectional domain must be present. This is motivated with the temporal properties of non-finite adverbial clauses (which express relative tense, i.e. aspect) and the possibility of an episodic interpretation. In the case of the proper converb -sa, I argued that it heads a VoiceP when used as a manner adverbial (following Geuder 2004, I call this use 'transparent adverbial'), while temporal -sa-clauses have an inflectional domain. I argued that we do not 
find convincing evidence for a CP layer in the Udmurt non-finite adverbial clauses, thus, I proposed that they are truncated at the TP level.

Chapter 5 focused on several questions with respect to subjects of non-finite clauses. I touched upon some problematic issues with respect to the agreement used in non-finite adverbial clauses. These included the abundance of morphosyntactic patterns in non-finite adverbial clauses formed with nominalizations, for which the existing theoretical approaches do not provide a satisfactory account, and the optionality of agreement in non-finite adverbial formed with non-finite forms traditionally called converbs. Furthermore, I discussed the variation between null and overt subjects. I drew parallels with other languages in which similar variation is found. The existing studies make very different proposals with respect to the nature of the null subjects in non-finite adverbial clauses and their interpretive properties. I argued that there is compelling evidence for analyzing the referential dependency between the null subject and its antecedent as a control structure and not as (accidental) coreference. The main syntactic and semantic/pragmatic properties of adjunct control were reviewed based on recent generative studies. Then, I applied the well-established tests for distinguishing obligatory from non-obligatory control, and demonstrated that null subjects of (certain) nonfinite clauses show obligatory control. However, non-obligatory control is also found. Nonobligatory control into adjuncts is triggered by several factors, such as lack of (suitable) controller, logophoricity, experiencer thematic role and world knowledge. I argued that at least two of these factors should be present in order for non-obligatory control to obtain. Thus, the interpretation of the null subject is by no means free. At the same time, the Udmurt data prove that a very restrictive analysis of adjunct control cannot be on the right track either since logophoric/topical control into adjuncts is attested in a number of cases.

There are several topics for future research based on the questions discussed in this dissertation. Some of them are more tightly related to the previous chapters, some of them are more like an outlook. Into the first group belong the problematic issues with agreement that have not been solved in a fully satisfactory way. Furthermore, the discussion of the internal structure of adverbial clauses can be further elaborated. In this dissertation I took the rather unusual approach of investigating adjunct control in a language about which no previous study on complement control exists. Hence, I think that a study on complement control in Udmurt will gives us a general picture on control in this language. As for adjunct control, the investigation of the syntacticians' favourites, rationale clauses, will make a thrilling task for future research. There are some more general questions with respect to the syntax of Udmurt that are worth taking a closer look at. To begin with, our understanding of the structure of 
main clauses is still very limited, especially from a theoretical point of view. Since the topic of this dissertation was non-finite adverbial clauses, two further topics immediately come to mind: finite adverbial clauses and adverbs/adverbials. Hopefully, this dissertation will serve as a starting point for future research, and these questions will be given a more detailed analysis.

Overall, this dissertation provides a descriptive analysis that can be used as a reference book on the various types of non-finite adverbial clauses in Udmurt. The description of adverbial clauses was supported by an impressive amount of language data as well as by statistics regarding frequency of the individual adverbial clause types/morphosyntactic patterns based on corpus data. The thesis also aimed to lay out the foundations of the theoretical analysis of non-finite adverbial clauses in Udmurt, based on which more detailed accounts can be provided in the future. The findings of the thesis contribute to the description of the Udmurt language, and more generally, to the field of Finno-Ugristics. Furthermore, some of the questions discussed in this dissertation are of theoretical importance, such as the notion of finiteness, the structure of converb clauses and adjunct control. 


\section{Appendix 1 Transliteration used in this dissertation}

\begin{tabular}{|c|c|}
\hline Standard Udmurt orthography & Latin transliteration \\
\hline $\mathrm{a}$ & $\mathrm{a}$ \\
\hline 6 & $\mathrm{~b}$ \\
\hline B & $\mathrm{v}$ \\
\hline$\Gamma$ & $g$ \\
\hline д & $\mathrm{d}$ \\
\hline $\mathrm{e}$ & $\mathrm{e}$ \\
\hline$\ddot{\mathrm{e}}$ & jo \\
\hline ж & $\check{\mathrm{Z}}$ \\
\hline$\ddot{\varkappa}$ & $\check{3}$ \\
\hline 3 & $\mathrm{z}, \mathrm{z}$ \\
\hline$\ddot{3}$ & $\frac{\dot{6}}{3}$ \\
\hline и & $\mathrm{i}$ \\
\hline$\ddot{\mathrm{u}}$ & $\mathrm{i}$ \\
\hline й & $\mathrm{j}$ \\
\hline к & $\mathrm{k}$ \\
\hline л & 1 \\
\hline $\mathrm{M}$ & $\mathrm{m}$ \\
\hline $\mathrm{H}$ & $\mathrm{n}$ \\
\hline o & 0 \\
\hline$\ddot{0}$ & $\underline{\mathrm{e}}$ \\
\hline$\Pi$ & $\mathrm{p}$ \\
\hline $\mathrm{p}$ & $\mathrm{r}$ \\
\hline $\mathrm{c}$ & $\mathrm{s}, \dot{s}$ \\
\hline $\mathrm{T}$ & $\mathrm{t}$ \\
\hline $\mathrm{y}$ & $\mathrm{u}$ \\
\hline$\phi$ & $\mathrm{f}$ \\
\hline $\mathrm{x}$ & $\mathrm{h}$ \\
\hline$ц$ & $\mathrm{C}$ \\
\hline $\mathrm{Y}$ & ć \\
\hline$\ddot{\mathbf{u}}$ & $\check{c}$ \\
\hline ш & $\breve{s}$ \\
\hline щ & ŚŚ \\
\hline $\mathbf{b}$ & - \\
\hline Ы & $\mathrm{i}$ \\
\hline $\mathrm{b}$ & - \\
\hline э & $\mathrm{e}$ \\
\hline Ю & (j)u \\
\hline Я & (j)a \\
\hline
\end{tabular}




\section{References}

A. Kövesi, Magda. 1965. A permi nyelvek ösi képzöi. Budapest: Akadémiai Kiadó.

Aarts, Bas. 1992. Small clauses in English: the nonverbal types. Berlin \& Boston: Mouton de Gruyter.

Abels, Klaus. 2005. Expletive negation in Russian: A conspiracy theory. Journal of Slavic Linguistics 13: 5-74.

Abney, Steven. 1987. The English noun phrase in its sentential aspect. MIT: PhD Thesis.

Abondolo, Daniel (ed.) 1998. The Uralic Languages. London \& New York: Routledge.

Ackema, Peter \& Maaike Schoorlemmer. 1995. Middles and Nonmovement. Linguistic Inquiry 26: 173-197.

Adger, David. 2007. Three domains of finiteness: a minimalist perspective. In: Irina Nikolaeva (ed.), Finiteness: theoretical and empirical foundations, 23-58. Oxford \& New York: OUP.

Adler, Allison N. 2006. Syntax and Discourse in the Acquisition of Adjunct Control. MIT: PhD Thesis.

Alexiadou, Artemis 2001. Functional Structure in Nominals: Nominalization and Ergativity. Amsterdam \& Philadelphia: John Benjamins.

Alexiadou, Artemis \& Florian Schäfer. 2010. On the syntax of episodic vs. dispositional -er nominals. In: Artemis Alexiadou \& Monika Rathert (eds.), The syntax of nominalizations across languages and frameworks, 9-38. Berlin \& Boston: Mouton de Gruyter.

Arkhangelskiy, Timofey A. 2014. Clitics in the Beserman dialect Of Udmurt. Higher School of Economics Research Paper No. WP BRP 10.

Assmann, Anke, Svetlana Edygarova, Doreen Georgi, Timo Klein \& Philipp Weisser. 2014. Case stacking below the surface: On the possessor case alternation in Udmurt. The Linguistic Review 31: 447-485.

Asztalos, Erika. 2010. Transitive and Intransitive Passivization in Udmurt. In: Sándor Csúcs et al. (eds.), Congressus XI. Internationalis Fenno-Ugristarum, 53-61. Piliscsaba: Reguly Társaság. Asztalos, Erika \& Katalin É. Kiss. 2016. Discourse-Motivated Word Order Variation in Udmurt. Talk given at Olomouc Linguistics Colloquium, Olomouc.

Asztalos, Erika \& Orsolya Tánczos. 2016. Aboutness Topic in Udmurt. Talk given at Information structure and discourse in the minority languages of the Russian Federation workshop at Language Documentation and Linguistic Theory 5, London. 
Asztalos, Erika \& Orsolya Tánczos. 2014. Competing Grammars in Nowadays Udmurt. Talk given at 7th Budapest Uralic Workshop, Budapest

Asztalos, Erika, Katalin Gugán \& Nikolett Mus. 2017. Uráli VX szórend: nyenyec, hanti és udmurt mondatszerkezeti változatok. In: Katalin É. Kiss, Attila Hegedüs \& Lilla Pintér (eds.), Nyelvelmélet és diakrónia 3, 30-62. Budapest-Piliscsaba: PPKE BTK.

Baker, Mark. 2015. Case: Its Principles and Its Parameters. Cambridge: CUP.

Bartens, Raija. 2000. Permiläisten kielten rakenne ja kehitys. Helsinki: SUS 238.

Bartos, Huba. 2009. The syntax of Hungarian -vA adverbial participles: A single affix with variable merge-in locations. In: Katalin É. Kiss (ed.), Adverbs and adverbial adjuncts at the interfaces, 75-101. Berlin \& Boston: Mouton de Gruyter.

Basilico, David. 2003. The Topic of Small Clauses. Linguistic Inquiry 34: 1-35.

Bereczki, Gábor. 1983. A Volga-Káma-vidék nyelveinek areális kapcsolatai. In: János Balázs (ed.), Areális nyelvészeti tanulmányok, 207-236. Budapest: Tankönyvkiadó.

Bianchi, Valentina. 2003. On finiteness as logophoric anchoring. In: Jacqueline Guéron \& Liliane Tasmovski (eds.), Temps et Point de Vue/Tense and Point of View, 213-246. Paris: Université Paris X Nanterre.

Bíró, Bernadett. 2014. Cselekvésneves szerkezetek a manysiban. Szegedi Tudományegyetem: PhD Thesis.

Borsley, Robert D. \& Jaklin Kornfilt. 2000. Mixed extended projections. In: Robert D. Borsley (ed.), The Nature and Function of Syntactic Categories, 101-131. Brill.

Brykina \& Aralova 2012 = Брыкина, Мария М. \& Н. В. Аралова 2012. Системы причастий в марийском и пермских языках. In: Кузнецова, Ариадна И. (отв. ред.), Финно-угорские языки: Фрагменты грамматического описания. Формальный и функциональный nodxodbl, 476-521. Москва: Рукописные памятники Древней Руси.

Census $1989=$ USSR Census of 1989. Available at: http://www.demoscope.ru/weekly/ssp/sng_nac_lan_89_1_1.php. Retrieved: 05.10.2017

Census $2002=$ The Russian Census of 2002. Available at: http://www.perepis2002.ru/index.html?id=17. Retrieved: 05.10.2017.

Census 2010 = The Russian Census of 2010. Chapter 4: Nationality, language proficiency, citizenship. http://www.gks.ru/free_doc/new_site/perepis2010/croc/perepis_itogi1612.htm Retrieved: 05.10.2017.

Chafe, Wallace. 1994. Discourse, consciousness, and time: The flow and displacement of conscious experience in speaking and writing. Chicago: The University of Chicago Press.

Chomsky, Noam. 1995. The Minimalist Program. Cambridge, Mass.: The MIT Press. 
Chomsky, Noam. 1981. Lectures on Government and Binding. Dordrecht: Foris.

Cinque, Guglielmo. 1999. Adverbs and functional heads: A cross-linguistic perspective. Oxford: OUP.

Cinque, Guglielmo. 1988. On si constructions and the theory of arb. Linguistic Inquiry 19: 521581.

Comrie, Bernard. 1981. Language Universals and Linguistic Typology: Syntax and Morphology. Oxford: Blackwell.

Comrie, Bernard \& Sandra A. Thompson. 2007. Lexical nominalizations. In: Timothy Shopen (ed.), Language typology and syntactic description, Vol. 3: Grammatical categories and the lexicon, 2nd edn., 334-381. Cambridge: CUP.

Cristofaro, Sonia. 2003. Subordination. Oxford: OUP.

Csepregi, Márta. 2012. Participiális jelzős szerkezetek két hanti nyelvjárásban. Nyelvtudományi Közlemények 108: 61-94.

Csúcs, Sándor. 2005. Die Rekonstruktion der permischen Grundsprache. Budapest: Akadémiai Kiadó.

Cysouw, Michael. 2013. Inclusive/Exclusive Distinction in Independent Pronouns. In: Matthew S. Dryer \& Martin Haspelmath (eds.), The World Atlas of Language Structures Online. Leipzig: Max Planck Institute for Evolutionary Anthropology. (Available online at http://wals.info/chapter/39, Accessed on 2017-12-08.)

Dékány, Éva \& Orsolya Tánczos. 2017. The structure of the Udmurt past participle. Talk given at Budapest Linguistics Conference 2, Budapest.

Dékány, Éva \& Orsolya Tánczos. 2015. Udmurt relative clauses with and without a left periphery. Talk given at Budapest Linguistics Conference, Budapest.

Dékány, Éva, Orsolya Tánczos \& Katalin Gugán. 2017. From prenominal to postnominal relative clauses in Udmurt and Khanty. Mutatvány "Az uráli nyelvek mondattanának változása aszimmetrikus kontaktushelyzetben" OTKA-projektum eredményeiböl, Budapest.

Demirdache, Hamida \& Myriam Uribe-Etxebarria. 2004. The syntax of time adverbs. In: Jacqueline Guéron \& Jacqueline Lecarme (eds.), The syntax of time, 143-180. Cambridge, Mass.: MIT Press.

Duffley, Patrick J. 2014. Reclaiming Control as a Semantic and Pragmatic Phenomenon. Amsterdam \& Philadelphia: John Benjamins.

É. Kiss, Katalin \& Orsolya Tánczos. Forthcoming. From possessor agreement to object marking: the functional evolution of the Udmurt -jez suffix. Language. 
Edygarova, Svetlana. 2015. Negation in Udmurt. In: Matti Miestamo, Anne Tamm \& Beáta Wagner-Nagy (eds.), Negation in Uralic Languages, 265-292. Amsterdam \& Philadelphia: Benjamins.

Edygarova, Svetlana. 2014. The varieties of the modern Udmurt language. Finnish-Ugrische Forschungen 62: 376-398.

Edygarova 2010 = Едыгарова, Светлана. 2010. Категория посессивности в удмуртском языке.

University of Tartu: PhD Thesis.

Emelyanov 1927 = Емельянов, Аркадий И. 1927. Грамматика вотяцкого языка. Ленинград:

Издание Ленинградского восточного института им. А. С. Енукидзе.

Erguvanl1-Taylan, Eser. 1986. Pronominal versus Zero Representation of Anaphora in Turkish. In:

Dan I. Slobin \& Karl Zimmer (eds.), Studies in Turkish linguistics, 209-232. Amsterdam \& Philadelphia: Benjamins.

F. Gulyás, Nikolett. 2017. Személytelen szerkezetek finnugor nyelvekben. Funkcionális és tipológiai megközelítés. ELTE: PhD Thesis.

F. Gulyás, Nikolett \& Yulia Speshilova. 2014. Impersonals and passives in contemporary Udmurt. Finnisch-Ugrische Mitteilungen 38: 59-91.

Farkas, Donca F. 1988. On obligatory control. Linguistics and Philosophy 11: 27-58.

Fejes, László. 2005. Összetett szavak finnugor nyelvekben. ELTE: PhD Thesis.

Fokos-Fuchs, Dávid Rafael. 1958. Die Verbaladverbien der permischen Sprachen. Acta Linguistica Hungarica 8: 273-342.

Fraurud, Kari. 2001. Possessive with extensive use: A source of definite articles? In: Irène Baron, Michael Herslund \& Finn Sørensen (eds.), Dimensions of Possession, 243-267. Amsterdam \& Philadelphia: John Benjamins.

Frey, Werner. 2003. Syntactic conditions on adjunct classes. In: Ewald Lang, Claudia Maienborn \& Cathrine Fabricius-Hansen (eds.), Modifying Adjuncts, 163-210. Berlin \& Boston: Mouton de Gruyter.

Fuß, Eric. 2005. The Rise of Agreement. A formal approach to the syntax and grammaticalization of verbal inflection. Amsterdam \& Philadelphia: John Benjamins.

Gelderen, Elly van. 2013. Clause structure. Cambridge: CUP.

Georgieva, Ekaterina. 2017a. Person agreement on converbs in Udmurt. In: Ferenc Kiefer, James Blevins, \& Huba Bartos (eds.), Perspectives on Morphological Organization: Data and Analyses, 86-122. Leiden: Brill.

Georgieva, Ekaterina. 2017b. Az 'ahelyett, hogy’-mellékmondatok az udmurt nyelvben. FUD 24: $15-38$. 
Georgieva, Ekaterina. 2017c. Converbs in Udmurt - a unified class? Talk given at Budapest Linguistics Conference 2, Budapest.

Georgieva, Ekaterina. 2016a. The case-marking of subjects in Udmurt, Komi-Zyryan and Meadow Mari non-finite clauses. Nyelvtudományi Közlemények 112: 77-107.

Georgieva, Ekaterina. 2016b. Kitett alanyok az udmurt nem-finit mellékmondatokban. In: Zsuzsanna Gécseg (ed.), LingDok Kötet 15, 31-50. Szeged: JATEPress.

Georgieva, Ekaterina. 2012. Igeneves szerkezetek az udmurt nyelvben. Szegedi Tudományegyetem: MA Thesis.

Georgieva, Ekaterina \& Eszter Ótott-Kovács (In Prep.) Syntactic similarities between non-finite clauses in Udmurt and Tatar?

Georgieva, Ekaterina \& Eszter Ótott-Kovács. 2016. Nem-finit alárendelői mellékmondatok a Volga-vidéki nyelvi areában. In: Zsuzsanna Gécseg (ed.), LingDok Kötet 15, 51-67.

Gerland, Doris. 2014. Definitely not possessed? Possessives with non-possessive function. In: Thomas Gamerschlag, Doris Gerland, Rainer Osswald \& Wiebke Petersen (eds.), Frames and Concept Types. Applications in Language and Philosophy, 269-292. Dordrecht: Springer.

Geuder, Wilhelm. 2004. Depictives and transparent adverbs. In: John R. Austin, Stefan Engelberg, \& Gisa Rauh (eds.), Adverbials - The Interplay between Meaning, Context, and Syntactic Structure, 131-166. Amsterdam \& Philadelphia: John Benjamins.

Giannakidou, Anastasia. 1998. Polarity sensitivity as (non) veridical dependency. Amsterdam \& Philadelphia: John Benjamins.

Givón, Talmy. 2001. Syntax: An Introduction, Vol. 2. Amsterdam \& Philadelphia: John Benjamins. Goldberg, Lotus Madelyn. 2005. Verb-stranding VP ellipsis: A cross-linguistic study. McGill University: PhD Thesis.

Grashchenkov 2017. = Гращенков, Павел В. 2017. Композициональность в лексической и синтаксической деривации разноструктурных языков. MGU dissertation.

Green, Jeffrey Jack. 2018. Adjunct control: syntax and processing. University of Maryland: PhD Thesis.

Grimshaw, Jane. 1990. Argument Structure. Cambridge, Mass.: MIT Press.

GSUJa I 1962 = Перевощиков, П. Н. (отв. ред.). 1962. Грамматика современного удмуртского языка. Фонетика и морфология. Ижевск: Удмуртское книжное издательство.

GSUJa II 1970 = Алатырев, В. И. (отв. ред.). 1970. Грамматика современного удмуртского языка. Синтаксис простого предложения. Ижевск: Удмуртия.

GSUJa III 1974 = Вахрушев, В. М. (отв. ред.). 1974. Грамматика современного удмуртского языка. Синтаксис сложного предложения. Ижевск: Удмуртия. 
Haddad, Youssef. 2007. Adjunct control in Telugu and Assamese. University of Florida: PhD Thesis.

Haegeman, Liliane. 2012. Adverbial Clauses, Main Clause Phenomena, and Composition of the Left Periphery. Oxford: OUP.

Haegeman, Liliane. 2010. The internal syntax of adverbial clauses. Lingua 120: 628-648.

Haegeman, Liliane. 2003. Notes on long adverbial fronting in English and the left periphery. Linguistic Inquiry 34: 640-649.

Hamari, Arja. 2011. The abessive in the Permic languages. Suomalais-Ugrilaisen Seuran Aikakauskirja 93: 37-84.

Haspelmath, Martin. 1998. The semantic development of old presents: New futures and subjunctives without grammaticalization. Diachronica 15: 29-62.

Haspelmath, Martin. 1996. Word-class-changing inflection and morphological theory. In: Gert Booij, \& Jaap van Marle (eds.), Yearbook of Morphology 1995. Dordrecht: Springer.

Haspelmath, Martin. 1995. The Converb as a Cross-linguistically Valid Category. In M. Haspelmath \& E. König (eds.), Converbs in cross-linguistic perspective, 1-55. Berlin \& Boston: Mouton de Gruyter.

Haumann, Dagmar. 2007. Adverb Licensing and Clause Structure in English. Amsterdam \& Philadelphia: John Benjamins.

Hetterle, Katja. 2015. Adverbial Clauses in Cross-Linguistic Perspective. Berlin \& Boston: Mouton de Gruyter.

Hewitt, George. 1995. Georgian. A structural reference grammar. Amsterdam \& Philadelphia: John Benjamins.

Honti, László. 2004. Hiedelmek és hipotézisek az uralisztikában. MNy 100: 1-15.

Hooper, Joan B. \& Sandra A. Thompson. 1973. On the applicability of root transformations. Linguistic Inquiry 4: 465-497.

Hornstein, Norbert. 2001. Move! A Minimalist Theory of Construal. Oxford: Blackwell Publishing. Horváth, Laura. 2011. Páros igék és szerepük az aspektualitásban. Aspektus és akcióminőség az udmurt nyelvben. In: Zsuzsanna Gécseg (ed.), LingDok 10, 61-85. Szeged: JATEPress.

Hout, Angeliek van \& Thomas Roeper. 1998. Events and aspectual structure in derivational morphology. MIT Working papers in linguistics 32: 175-220.

Jääts, Indrek. 2015. Fallen Ill in Political Draughts. In: Heiko F. Marten, Michael Rießler, Janne Saarikivi \& Reetta Toivanen (eds.), Cultural and Linguistic Minorities in the Russian Federation and the European Union, 107-126. Dordrecht: Springer. 
Jakovlev 1931 = Яковлев, Иван В. 1931. Удмурт кылрадъян: Элементарная грамматика удмуртского языка. Ижевск: Удкнига.

Janke, Vikki \& Laura R. Bailey 2017. Effects of discourse on control. Journal of Linguistics 53: 533-566.

Kalinina 2001 = Калинина, Людмила И. 2001. Причастия и причастные конструкции в удмуртском языке. Ижевск: Издательский дом Удмуртский универстит.

Karpova 2005 = Карпова, Людмила Л. 2005. Среднечепецкий диалект удмуртского языка. Ижевск: Рос. акад. наук, Урал. отд-ние, Удмурт. ин-т истории, яз. и лит. УрО РАН.

Karttunen, Lauri. 1974. Until. CLS 10: 284-297.

Kawasaki, Noriko. 1993. Control and Arbitrary Interpretation in English. UMASS: PhD Thesis.

Kazenin, Konstantin I. \& Yakov G. Testelets. 2004. Where coordination meets subordination: Converb constructions in Tsakhur (Daghestanian). In: Martin Haspelmath (ed.), Coordinating Constructions, 227-241. Berlin \& Boston: Mouton de Gruyter.

Keenan, Edward L. \& Bernard Comrie. 1977. Noun phrase accessibility and Universal Grammar. Linguistic Inquiry 8: 63-99.

Kelmakov 2015 = Кельмаков, Валентин К. 2015. Образиы удмуртской речи: Южные говоры. Ижевск: Удмуртия.

Kelmakov 2003 = Кельмаков, Валентин К. 2003. Диалектная и историческая фонетика удмуртского языка. Часть I. Ижевск: Издательский дом "Удмуртский университет".

Kelmakov 1998 = Кельмаков, Валентин К. 1998. Краткий курс удмуртской диалектологий. Ижевск: Издательство Удмуртского университета.

Kelmakov 1990 = Кельмаков, Валентин К. 1990. Образиы удмуртской речи 2: Срединные говоры, Ижевск: Удмуртский институт истории, языка и литературы УО АН СССР.

Kelmakov 1981 = Кельмаков, Валентин К. 1981. Образиы удмуртской речи: северное наречие и срединные говоры. Ижевск: Удмуртия.

Kelmakov 1975 = Кельмаков, В. К. 1975. Спаренные глаголы в удмуртском языке. Bonpocbl удмуртского языкознания 3. Ижевск. 90-105.

Kelmakov, Valentin \& Sara Hannikainen. 1999. Udmurtin kielioppia ja harjoituksia. Helsinki: Suomalais-Ugrilainen Seura.

Kirillova 2008 = Кириллова, Лариса Е. (отв. ред.) 2008. Удмурт-ӥуч кыллюкам = Удмуртскорусский словарь. Ижевск: РАН. УрО. Удм. ин-т ИЯЛ.

Kissock, Madelyn J. 2014. Evidence for 'finiteness' in Telugu. Natural Language and Linguistic Theory 32: 29-58.

Klein, Wolfgang. 1994. Time in language. London: Routledge. 
Klumpp, Gerson. 2016. Semantic functions of complementizers in Permic languages. In: Kasper Boye \& Petar Kehayov (eds.), Complementizer Semantics in European Languages, 529-586. Berlin \& Boston: Mouton de Gruyter.

Kondratyeva $2011=$ Кондратьева, Наталья В. 2011. Категория падежа имени существительного в удмуртском языке. Ижевск: Удмуртский университет.

Kondratyeva 2000 = Кондратьева, Наталья В. 2000. Особенности выражения прямого объекта в удмуртском языке в зависимости от характера глагола объекта. Пермистика 6: 100102.

König, Ekkehard \& Peter Siemund (with Stephan Töpper). 2013. Intensifiers and Reflexive Pronouns. In: Matthew S. Dryer \& Martin Haspelmath (eds.), The World Atlas of Language Structures Online. Leipzig: Max Planck Institute for Evolutionary Anthropology. (Available online at http://wals.info/chapter/47, Accessed on 2018-03-03.)

Koptjevskaja-Tamm, Maria. 1993. Nominalizations. London: Routledge.

Kornfilt, Jaklin. 2015. Turkish relative clauses: how exceptional are they from a Central Asian Turkic perspective? In Öner Özçelik \& Amber Kennedy Kent (eds.), Proceedings of the 1st Conference on Central Asian Languages and Linguistics (ConCALL -1) Vol. 1, 3-24. Indiana University: CeLCAR.

Kornfilt, Jaklin. 2005. Agreement and its placement in Turkic Nonsubject Relative clauses. In: Guglielmo Cinque \& Richard S. Kayne (eds.), The Oxford Handbook of Comparative Syntax. 513-541. Oxford: OUP.

Kornfilt, Jaklin. 2003. Subject case in Turkish nominalized clauses. In: Uwe Junghanns \& Luka Szucsich (eds.), Syntactic structures and morphological information, 129-216. Berlin \& Boston: Mouton de Gruyter.

Kornfilt, Jaklin. 1997. Turkish. London: Routledge.

Kornfilt, Jaklin \& Omer Preminger. 2015. Nominative as no case at all: an argument from raisingto-accusative in Sakha. In: Andrew Joseph \& Esra Predolac (eds.), Proceedings of the 9th Workshop on Altaic Formal Linguistics (WAFL9), 109-120. Cambridge, MA: MIT Working Papers in Linguistics.

Kornfilt, Jaklin \& John Whitman. 2011. Introduction: Nominalizations in syntactic theory. Lingua 121: 1160-1163.

Kortmann, Bernd. 1996. Adverbial Subordination: A Typology and History of Adverbial Subordinators Based on European Languages. Berlin \& Boston: Mouton de Gruyter.

Kortmann, Bernd. 1991. Free Adjuncts and Absolutes in English: Problems of Control and Interpretation. London \& New York: Routledge. 
Kozmács, István. 2008. Az -śk- képzö az udmurt (votják) igeképzésrendszerében. Nyitra: Konstrantin Filozófus Egyetem.

Kozmács, István. 2001. Az udmurt (votják) nyelv alapjai. Budapest: ELTE Finnugor Tanszék.

Kozmács, István. 1998. Inkluzív személyes névmás a finnugor nyelvekben? Votják мu - acмеoc. Néprajz és Nyelvtudomány 39: 137-143.

Kratzer, Angelika. 1998. More structural analogies between pronouns and tenses. In: Devon Strolovitch \& Aaron Lawson (eds.), Proceedings of SALT VIII, 92-110. Ithaca, NY: Cornell University.

Kratzer, Angelika. 1996. Severing the external argument from its verb. In Johan Rooryck \& Laurie A. Zaring (eds.), Phrase Structure and the Lexicon. 109-137. Dordrecht: Kluwer.

Landau, Idan. 2018. From predication to control and back again: Lessons and puzzles. Talk given at GLOW 41, Budapest.

Landau, Idan. 2017. Adjunct Control Depends on Voice. In: Claire Halpert, Hadas Kotek \& Coppe van Urk (eds.), A Pesky Set: Papers for David Pesetsky, Cambridge, 93-102. MA: MITWPL.

Landau, Idan. 2015. A Two-Tiered Theory of Control. Cambridge, MA: MIT Press.

Landau, Idan. 2013. Control in generative grammar: a research companion. Cambridge: CUP.

Landau, Idan. 2004. The scale of finiteness and the calculus of control. Natural Language and Linguistic Theory 22: 811-877.

Landau, Idan. 2000. Elements of Control: Structure and Meaning in Infinitival Constructions. Dordrecht: Kluwer Academic Publishers.

Lyngfelt, Benjamin. 2009. Towards a comprehensive construction grammar account of control: A case study of Swedish infinitives. Constructions and Frames 1: 153-189.

Lytkin 1952 = Лыткин, Василий И. 1952. Древнепермский язык. Москва: Издательство Академии наук СССР.

Lyutikova, Ekaterina, \& Dilya Ibatullina. 2015. Case theory and case variation in Tatar. In: E. A. Лютикова, А. В. Циммерлинг, М. Б. Коношенко (ред.), Типология морфосинтаксических параметров 2015, 226-242. Москва: МГПУ.

Madigan, Sean. 2008. Control constructions in Korean. University of Delaware: PhD Thesis.

Marantz, Alec. 1991. Case and licensing. In: Germán F. Westphal, Benjamin Ao \& Hee-Rahk Chae (eds.), ESCOL 91: Proceedings of the Eighth Eastern States Conference on Linguistics, 234253. Ohio State University.

Martin, Roger. 2001. Null Case and the Distribution of PRO. Linguistic Inquiry 32: 141-166.

McCawley, James D. 1983. What's with with? Language 59: 271-287. 
McFadden, Thomas \& Sandhya Sundaresan. 2016. Failure to control is not a failure: it's pro. In: Christopher Hammerly \& Brandon Prickett (eds.), Proceedings of NELS 46, Vol. 3: 1-10. Amherst, MA: GLSA.

Mitchell, Erika. 2006. The mopho-syntax of negation and the position of NegP in Finno-ugric languages. Lingua 116: 228-244.

Munkácsi, Bernát 1952. Volksbräuche und Volksdichtung der Wotjaken. Aus dem Nachlasse von Bernhard Munkácsi. Herausgegeben von D. R. Fuchs. Suomalais-Ugrilaisen Seuran Toimituksia 102. Helsinki: Suomalais-Ugrilaisen Seura.

Munkácsi, Bernát. 1887. Votják népköltészeti hagyományok. Budapest: Magyar Tudományos Akadémia.

Munkácsi, Bernát. 1881. Votják nyelvmutatványok. Nyelvtudományi Közlemények 17: 247-302.

Nasibullin 1982 = Насибуллин, Риф Ш. (отв. ред.). 1982. Образцы речи удмуртского языка. Ижевск: Науч.-исслед. ин-т при Совете Министров Удмурт. АССР.

Nikolaeva, Irina. 2007. Introduction. In: Irina Nikolaeva (ed.), Finiteness. Theoretical and Empirical Foundations, 1-19. Oxford \& New York: OUP.

Nikolaeva, Irina. 2003. Possessive affixes in the pragmatic structuring of the utterance: evidence from Uralic. In: Pirkko Suihkonen \& Bernard Comrie (eds.), International symposium on deictic systems and quantification in languages spoken in Europe and North and Central Asia. Collection of papers, 130-145. Izhevsk and Leipzig: Udmurt State University and Max Planck Institute for Evolutionary Anthropology.

Nikolaeva, Irina. 1999. Ostyak. München \& Newcastle: Lincon Europa.

Noonan, Michael. 2007. Complementation. In: Timothy Shopen (ed.), Language typology and syntactic description, Vol. 2: Complex constructions, 2nd edn., 52-150. Cambridge: CUP.

Nunes, Jairo. 2014. Adjunct Control and edge features. In: Peter Kosta, Steven L. Franks, Teodora Radeva-Bork \& Lilia Schürcks (eds.), Minimalism and beyond: Radicalizing the interfaces, 79108. Amsterdam \& Philadelphia: John Benjamins.

Oded, Ilknur. 2011. Recalculating adjunct control. University of Maryland: PhD Thesis.

Oltra-Massuet, Isabel. 2013. Deverbal Adjectives at the Interface. A Crosslinguistic Investigation into the Morphology, Syntax and Semantics of -ble. Berlin \& Boston: Mouton de Gruyter.

Ótott-Kovács, Eszter. 2016. The Syntax of Non-Finite Clauses in Kazakh. Szegedi Tudományegyetem: PhD Thesis.

Pereltsvaig, Asya, \& Ekaterina Lyutikova. 2014. Possessives within and beyond NP. In: Anna Bondaruk, Gréte Dalmi \& Alexander Grosu (eds.), Advances in the Syntax of DPs: Structure, agreement, and case, 193-219. Amsterdam \& Philadelphia: John Benjamins. 
Perevoshchikov 1959 = Перевощиков, Петр Н. 1959. Деепричастия и деепричастные конструкиии в удмуртском языке. Ижевск: Удмуртское книжное издательство.

Pesetsky, David \& Esther Torrego. 2004. Tense, case, and the nature of syntactic categories. In: Jacqueline Guéron \& Jacqueline Lecarme (eds.), The syntax of time, 495-537. Cambridge, Mass.: MIT Press.

Pimenov 1993 = Пименов, Владимир В. 1993. Удмурты: историко-этнографические очерки. Ижевск: УдмИИЯЛ.

Pires, Acrisio. 2006. The Minimalist Syntax of Defective Domains: Gerunds and Infinitives. Amsterdam \& Philadelphia: John Benjamins.

Posti, Lauri \& Terho Itkonen (eds.). 1973. FU-transkription yksinkertaistaminen: Az FU-átírás egyszerüsítése. Zur Vereinfachung der FU-Transkription. On Simplifying of the FUtranscription (Castrenianumin toimitteita 7). Helsinki: Helsingin Yliopisto.

Pylkkänen, Liina. 2008. Introducing Arguments. Cambridge, MA: MIT Press.

Raposo, Eduardo. 1987. Case Theory and Infl-to-Comp: The Inflected Infinitive in European Portuguese. Linguistic Inquiry 18: 85-109.

Raun, Alo. 1988. Proto-Uralic comparative historical morphosyntax. In: Denis Sinor (ed.), The Uralic languages: description, history and foreign influences, 555-571. Leiden \& New York: Brill.

Rédei, Károly. 1988. Geschichte der permischen Sprachen. In: Denis Sinor (ed.), The Uralic languages: description, history and foreign influences, 351-394. Leiden \& New York: Brill.

Riessler, Michael. 2016. Adjective attribution. Berlin: Language Science Press.

Rizzi, Luigi. 1997. The fine structure of the left periphery. In: Liliane Haegeman (ed.), Elements of Grammar, 281-337. Dordrecht: Kluwer.

Salánki. Zsuzsanna. 2007. Az udmurt nyelv mai helyzete. ELTE: PhD Thesis.

Schütze, Carson T. 2001. On the Nature of Default Case. Syntax 4: 205-238.

Serdobolskaya, Natalia. 2016. Semantics of complementation in Adyghe. In: Kasper Boye \& Petar Kehayov (eds.), Complementizer Semantics in European Languages, 691-744. Berlin \& Boston: Mouton de Gruyter.

Serdobolskaya \& Toldova 2012 = Сердобольская, Наталья В. \& Толдова, Светлана Ю. 2012. Дифференцированное маркирование прямого дополнения в финно-угорских языках. In: Кузнецова, Ариадна И. (отв. ред.), Финно-угорские языки: Фрагменты грамматического описания. Формальныцй и функциональный подходыl, 59-141. Москва: Рукописные памятники Древней Руси. 
Serdobolskaja et al. 2012 = Сердобольская, Н. В., Ильевская, А. А., Минор, С. А., Митева, П. С., Файнвейц, А. В., Матвеева, Н. С. 2012. Конструкции с сентенциальными актантами в финно-угорских языках. In: Кузнецова, Ариадна И. (отв. ред.), Финно-угорские языки: Фрагменты грамматического описания. Формальный и функциональный подходы, 382 476. Москва: Рукописные памятники Древней Руси.

Serebrennikov 1964 = Серебренников, Борис А. 1964. Основные линии развития падежной и глаголной систем в уральских языках. Москва: Наука.

Setälä, Eemil Nestor. 1901. Über transskription der Finnisch-ugrischen Sprachen. FinnischUgrische Forschungen 1: 15-52.

Shirobokova, Larisa. 2011. Az udmurt-orosz kétnyelvüség (Udmurt Köztársaság, Sarkan járás, Muvyr község). ELTE: PhD Thesis.

Shutov 1999 = Шутов, Александр Ф. 1999. Гипотаксис в удмуртском языке: пособие для студентов по синтаксису. Ижевск: Издательство "Удмуртский университет".

Siegl, Florian. 2004. The 2nd past in the Permic languages - form, function, and a comparative analysis from a typological perspective. University of Tartu: MA thesis.

Siewierska, Anna. 1999. From anaphoric pronoun to grammatical agreement marker: Why objects don't make it. Folia Linguistica 33: 225-252.

Siewierska, Anna. 2004. Person. Cambridge: CUP.

Simonenko \& Leontyev 2012 = Симоненко, А. П. \& А. П. Леонтьев 2012. Морфосинтаксис именного комплекса в финно-пермских языках: анализ в рамках программы минимализма. In: Кузнецова, Ариадна И. (отв. ред.), Финно-угорские языки: Фрагменты грамматического описания. Формальный и функичиональный подходы, 262-339. Москва: Рукописные памятники Древней Руси.

Simons, Gary F. \& Charles D. Fennig (eds.). 2017. Ethnologue: Languages of the World, Twentieth edition. Dallas, Texas: SIL International. Online version: http://www.ethnologue.com.

Sinor, Denis (ed.). 1988. The Uralic Languages: Description, History and Foreign Influences.

Stassen, Leon. 1985. Comparison and Universal Grammar. Oxford: Basil Blackwell.

Suihkonen, Pirkko (ed.) 1995. Udmurt-English-Finnish Dictionary with a Basic Grammar of Udmurt. Helsinki: Suomalais-Ugrilainen Seura.

Sundaresan, Sandhya \& Thomas McFadden. 2009. Subject distribution in Tamil and other languages: Selection vs. Case. Journal of South Asian Linguistics 2: 5-34.

Sundaresan, Sandhya. 2014. Making sense of silence: Finiteness and the (OC) PRO vs. pro distinction. Natural Language and Linguistic Theory 32: 59-85. 
Tamm, Anne. 2014. The Partitive Concept versus Linguistic Partitives: From Abstract Concepts to Evidentiality in the Uralic Languages. In: Silvia Luraghi \& Tuomas Huumo (eds.), Partitive Cases and Related Categories, 89-152. Berlin \& Boston: Mouton de Gruyter.

Tánczos, Orsolya. 2010. Szórendi variációk és lehetséges okaik az udmurtban. Nyelvtudományi Közlemények 107: 218-228.

Tánczos, Orsolya. 2013. Hogy ... hogy - Kettős kötőszók az udmurt mondatban. In Katalin É. Kiss \& Attila Hegedűs (eds.), Nyelvelmélet és kontaktológia 2, 279-293. Piliscsaba: PPKE.

Tánczos, Orsolya. 2016. Causative construction and their syntactic analysis in the Udmurt language. PPKE: PhD Thesis.

Teiermayer, Andrea. 2002. Cselekvésnevek az udmurtban. Szegedi Tudományegytem: MA Thesis. Teplyashina 1965 = Тепляшина, Тамара И. 1965. Памятники удмуртской письменности ХVII века. Москва: Академия наук СССР, Ин-т языкознания.

Teplyashina 1970 = Тепляшина, Тамара И. 1970. Язык бесермян. Москва: Наука.

Thompson, Sandra A. 1972. Instead of and Rather Than Clauses in English. Journal of Linguistics 8: $237-249$.

Thompson, Sandra A., Robert E. Longacre \& Shin Ja J. Hwang. 2007. Adverbial clauses. In: Timothy Shopen (ed.), Language typology and syntactic description, Vol. 2: Complex constructions, 2nd edn., 237-300. Cambridge: CUP.

Timerkhanova 2011 = Тимерханова, Надежда Н. (отв. ред.). 2011. Удмурт кыллэн кыкабтодосэз (морфологиез): тодослькк-дылиетскон издание. Ижевск: Издательство „Удмуртский университет“.

Tóth, Ildikó. 2000. -vA and -vÁn participles in Hungarian. In: Gábor Alberti \& István Kenesei (eds.), Approaches to Hungarian 7, 239-256. Szeged: JATEPress.

Traugott, Elizabeth C. \& Ekkerhard König 1991. The semantics-pragmatics of grammaticalization revisited. In: Elizabeth C. Traugott \& Bernd Heine (eds.), Approaches to grammaticalization I, 189-218. Amsterdam \& Philadelphia: John Benjamins.

Ürögdi, Barbara. 2012. Operator Movements in Embedded Clauses. ELTE: PhD Thesis.

Usacheva 2012 = Усачева, Мария Н. 2012. Локативные падежи в составе групп с пространственным значением в пермских языках In: Кузнецова, Ариадна И. (отв. ред.), Финно-угорские языки: Фрагменты грамматического описания. Формальный и функииональный подходыl, 141-217. Москва: Рукописные памятники Древней Руси.

Usacheva \& Serdobolskaya 2015 = Усачева, Мария Н. \& Наталья В. Сердобольская. 2015. Грамматикализация новой деепричастной формы на -оннига- в бесермянском 
удмуртском. In: Е. А. Лютикова, А. В. Циммерлинг, М. Б. Коношенко (ред.) Типология морфосинтаксических параметров 2015, 366-392. Москва: МГПУ.

Usacheva, Maria \& Timofey Arkhangelskiy. 2017. Grammaticalization of new cases in Beserman Udmurt. Linguistica Uralica LIII: 27-48.

Vilkuna, Maria. 1998. Word order in European Uralic. In: Anna Siewierska (ed.), Constituent order in the languages of Europe, 173-235. Berlin \& Boston: Mouton de Gruyter.

Vladykin \& Khristolyubova 1997 = Владыкин, Владимир Е. \& Людмила С. Христолюбова. 1997. Этнография удмуртов. 2-е издание. Ижевск: Удмуртия.

Volkova, Anna. 2014. Licensing Reflexivity: Unity and variation among selected Uralic languages. Utrecht: LOT dissertation series.

Weisser, Philipp. 2015. Derived Coordination. A Minimalist Perspective on Clause Chains, Converbs and Asymmetric Coordination. Berlin \& Boston: Mouton de Gruyter.

Wichmann, Yrjö. 1901. Wotjakische sprachproben II. Sprichwörter, Rätsel, Märchen, Sagen und Erzählungen. Journal de la Société Finno-Ougrienne XIX: 1-200.

Williams, Edwin. 1997. Blocking and Anaphora. Linguistic Inquiry 28: 577-628.

Williams, Edwin. 1992. Adjunct Control. In: Richard Larson, Sabine Iatridou, Utpal Lahiri \& James Higginbotham (eds.), Control and Grammar, 297-322. Dordrecht: Kluwer Academic Publishers.

Williams, Edwin. 1980. Predication. Linguistic Inquiry 11: 203-238.

Winkler, Eberhard. 2011. Udmurtische Grammatik. Wiesbaden: Harrassowitz.

Winkler, Eberhard. 2001. Udmurt. München \& Newcastle: Lincom Europa.

Wintschalek, Walter. 1993. Die Areallinguistik am Beispiel syntaktischer Übereinstimmungen im Wolga-Kama-Areal. Wiesbaden: Harrassowitz.

Wurmbrand, Susi. 2014. Tense and aspect in English infinitives. Linguistic Inquiry 45: 403-447.

Wurmbrand, Susi. 2001. Infinitives: Restructuring and clause structure. Berlin \& Boston: Mouton de Gruyter

Ylikoski, Jussi. 2003. Defining non-finites: action nominals, converbs and infinitives. SKY Journal of Linguistics 16: 185-237.

Zamyatin, Konstantin. 2015. The Evolution of Language Ideology in Post-Soviet Russia. In: Heiko F. Marten, Michael Rießler, Janne Saarikivi \& Reetta Toivanen (eds.), Cultural and Linguistic Minorities in the Russian Federation and the European Union, 280-313. Dordrecht: Springer. 